



\title{
SYNTHESES AND \\ ELECTRON DENSITY DETERMINATION OF NOVEL PolyIMIDO SULfUR YLIDES
}

\author{
Dissertation zur Erlangung des \\ mathematisch-naturwissenschaftlichen Doktorgrades \\ der Georg-August-Universität Göttingen
}

\author{
vorgelegt von \\ Stephan Michael Deuerlein \\ aus Gunzenhausen
}

Göttingen 2007 

Eingereicht am:

19.09.2007

Referent:

Prof. Dr. D. Stalke

Co-Referent:

Prof. Dr. H. W. Roesky

Datum der mündlichen Prüfung: $\quad 31.10 .2007$

Prüfer Anorganische Chemie: $\quad$ Prof. Dr. D. Stalke

Prüfer Technische Chemie: $\quad$ Prof. Dr. M. Buback

Prüfer Kristallographie: $\quad$ Prof. Dr. W. Kuhs

Erweiterte Prüfungskommision: Prof. Dr. U. Diederichsen

Prof. Dr. J. Magull 

„Ausdauer wird früher oder später belohnt - meistens aber später.“

Wilhelm Busch 



\section{DANKSAGUNG}

Die vorliegende Arbeit wurde in der Zeit von Januar 2004 bis September 2007 im Arbeitskreis von Prof. Dr. D. Stalke an den Instituten für Anorganische Chemie der Universitäten Würzburg und Göttingen angefertigt. An dieser Stelle soll all jenen Dank ausgesprochen werden, die zum Gelingen dieser Arbeit beigetragen haben.

Zu allererst möchte ich mich bei Herrn Prof. Dr. D. Stalke bedanken. Sowohl die gewährten wissenschaftlichen Freiheiten, als auch die stete Diskussionsbereitschaft, das angenehme Arbeitsklima und den festen Glauben, dass mein Ylid sich doch noch als Schatz erweist, habe ich sehr geschätzt.

Dem gesamten Arbeitskreis, inklusive des zugehörigen Umfeldes, danke ich für die gute Stimmung und die Hilfestellungen bei meinen vielfältigen Problemen, v. a. in der Anfangszeit.

Herr Dr. Dirk Leusser hat mich in die Kristallographie und die Elektronendichteuntersuchungen eingeführt, wofür ich ihm sehr dankbar bin. Auch die Motivation und Geduld, immer wieder einen Versuch mit meinem Ylid durchzustehen, war vorbildlich. Gleiches gilt für die viele Arbeit, welche die Hilfe bei der Datenauswertung mit sich brachte. Noch mehr weiß ich aber die Freundschaft zwischen mir Konservativem und einem Linken zu schätzen.

Herrn Dipl. Chem. Holger Ott danke ich für die tollen Ergebnisse aus einem großartigen F-Praktikum. Viel mehr genieße ich aber die Freundschaft, die sicher sehr schnell zwischen uns entwickelt hat.

Frau Ulrike Flierler danke ich zusammen mit Herrn Dr. Thomas Stey für das gute "team-work" und die sehr angenehm zusammen verbrachte Zeit. Ohne diese Freundschaften hätte ich die Durststrecken dieser Arbeit sich nicht so gut überstanden.

Dem Rest der Würzburger-Connection, den Herren Dipl. Chem. Gerald Schwab und Thomas Schulz, danke ich wie Holger, Ulli und Dirk dafür, dass ich nicht ganz allein ins Feindesland musste.

Meinem Admin-Vorgänger Herrn Dr. Alex Murso, sowie meinem Nachfolger in spe Herrn Daniel Kratzert, danke ich für die Entlastung bei den täglichen Sorgen mit dem Rechnersystem, sowie für die angenehme gemeinsame Zeit im Labor. 
Den mehr oder minder festen Mitarbeitern des Arbeitskreises, den Damen Veronika Duchnik, Heike Tappe und Michaela Thomas, sowie den Herren Martin Schlote, Hans-Georg Schmidt und Dr. Michael Witt gilt mein dank für die Zusammenarbeit und den freundlichen Umgang.

Meinen unzähligen F-Praktikanten möchte ich für die angenehme Zusammenarbeit und das ab und an auch vernünftige Ergebnis danken.

Allen Mitarbeitern der Werkstätten, besonders seien hier die Herren Berthold Fertig und Hans-Joachim Heymel genannt, bin ich zu großem Dank verpflichtet, da ohne sie so mancher Umbau/Neubau von Gerätschaften nicht möglich gewesen wäre und sie auch in der Zeit des Umzugs eine elementare Hilfe waren.

Der gleiche Dank gilt auch den Damen und Herren aus den Analytik-Abteilungen, sowie den Hausmeistern und Sekretärinnen.

Meinen gnädigen Korrektoren Ulli, Holger und Dirk, sowie Guschdl, der mit dem Rotstift schneller ist als sein Schatten, sei für die Verbesserung meines Englisch und die fachlichen Anmerkungen gedankt.

Frau Kathrin Rösch danke ich für die seit Schulzeiten anhaltende Freundschaft und die vielen herrlichen, tanzend verbrachten Stunden.

Sir Robert Stephenson Smyth Baden-Powell, $1^{\text {st }}$ Lord of Gilwell, den Pfadfindern der DPSG und v. a. den Mitgliedern des Gunzenhäuser Stammes danke ich dafür, dass sie einen maßgeblichen Beitrag dazu geleistet haben, aus mir den Menschen zu machen, der ich bin.

Meiner Freundin Frau Susanne Kohlmajer danke ich, dass sie sich doch noch hat finden lassen und es entgegen aller Unterschiede mit mir aushält. Trotz manchen Schocks (Werneck lässt grüßen) bringt sie stetig Freude in mein Leben. Die gemeinsame Zeit der Erstellung meiner Doktor- und ihrer Diplomarbeit kann ich nur mit "geteiltes Leid ist halbes Leid" dankbar zusammenfassen.

Meinen Eltern und meiner Schwester danke ich für die anhaltende Unterstützung in allen Lebensfragen. Ein besseres Heim und eine bessere Heimat könnte ich mir nicht wünschen. 


\section{CONTENTS}

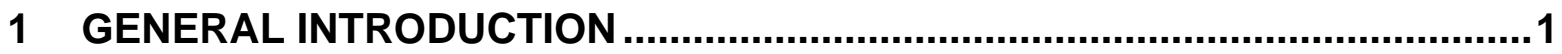

2 CHARGE DENSITY STUDY ON A LITHIUM SULFUR YLIDE ........................

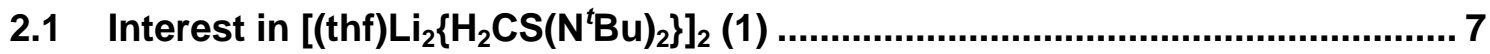

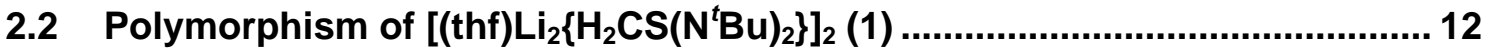

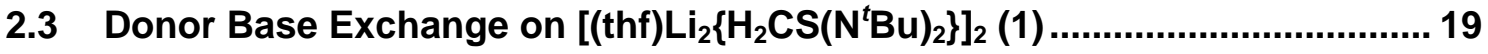

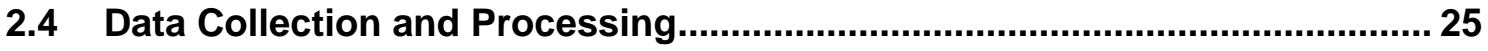

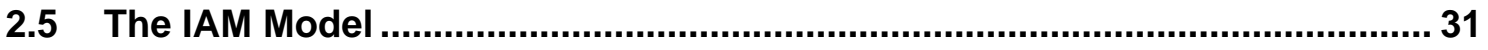

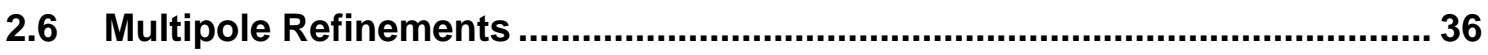

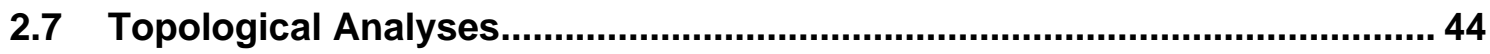

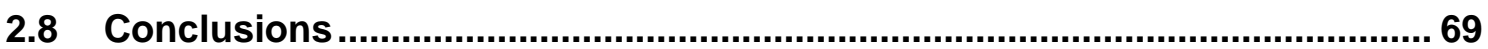

3 METAL COMPLEXES OF DIIMIDO SULFUR YLIDES ..................................71

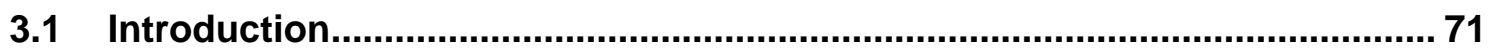

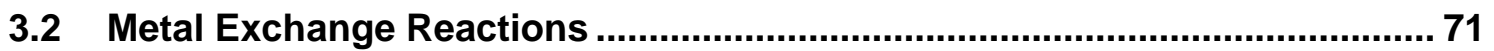

3.3 Reactions Employing Grignard Reagents.................................................. 74

3.4 Reactions with Dialkyl Metal Compounds .................................................... 81

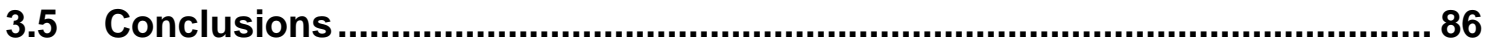

4 POLYDENTATE POLYIMIDO SULFUR-CARBON-PHOSPHORUS LIGANDS..87

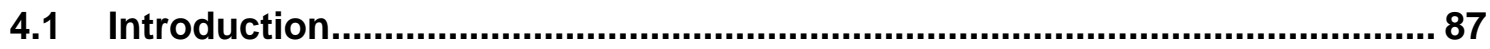

4.2 Reactions of Lithium Sulfur Ylides with Chlorophosphanes ................................ 89

4.3 Addition of $\mathrm{R}_{2} \mathrm{PCH}_{2} \mathrm{Li}$ to a Sulfur Diimide ..................................................... 91

4.4 Crystal Structure of Trimethyl Arsane Oxide (16) ........................................ 93

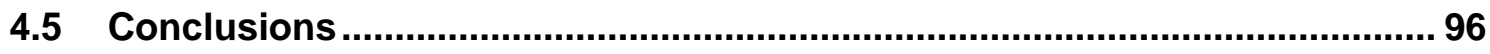

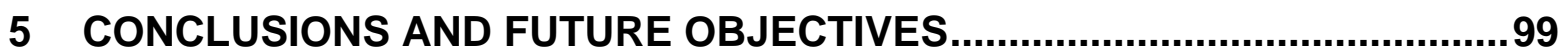




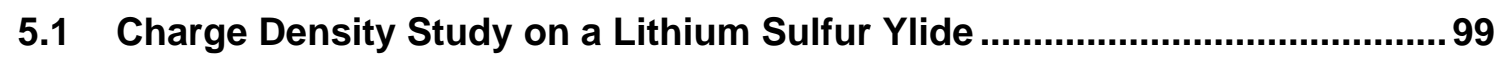

5.2 Metal Complexes of Diimido Sulfur Ylides ............................................. 101

5.3 Polydentate Polyimido Sulfur-Carbon-Phosphorus Ligands ...................... 102

6 ZUSAMMENFASSUNG UND ZUKÜNFTIGE ZIELE ................................ 105

6.1 Elektronendichteuntersuchung eines Lithium-Schwefel-Ylids ...................... 105

6.2 Metallkomplexe der Diimidoschwefelylide ............................................. 107

6.3 Polydentate Polyimido-Schwefel-Kohlenstoff-Phosphor-Liganden................ 108

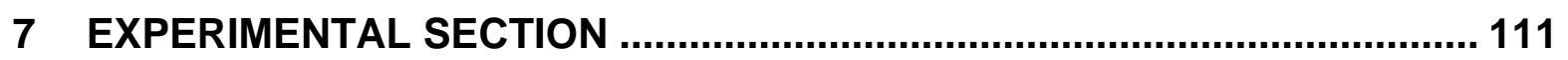

7.1 General ............................................................................................. 111

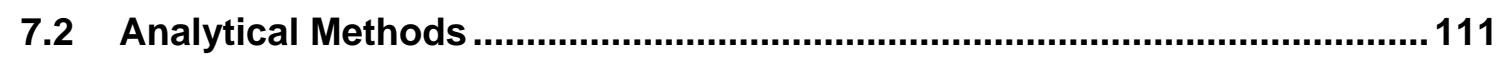

7.3 Syntheses and Characterizations .......................................................... 113

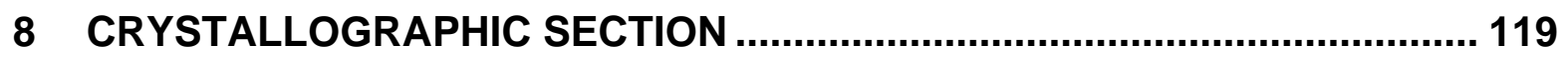

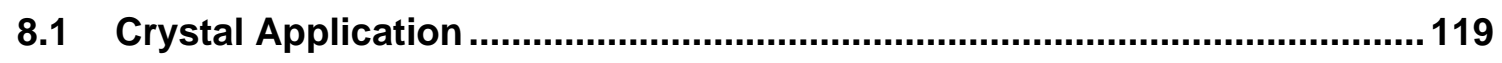

8.2 Data Collection and Processing ............................................................. 119

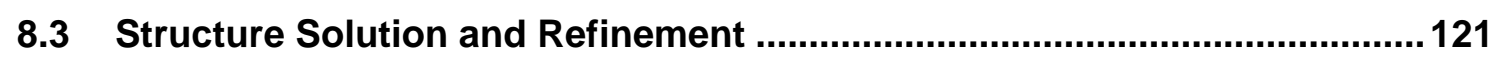

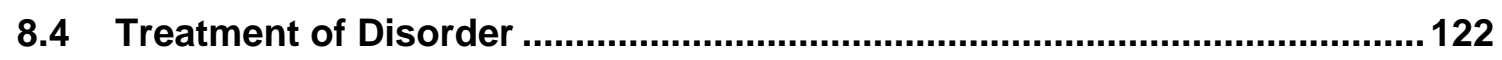

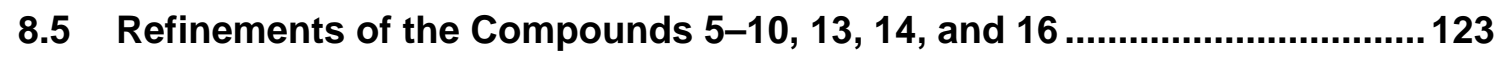

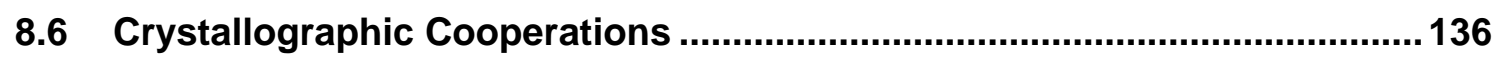

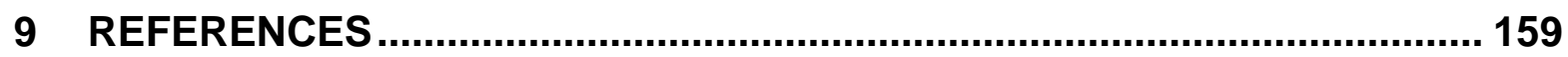




\section{ABBREVIATIONS}

\begin{tabular}{|c|c|c|c|}
\hline$\AA$ & Ångstrom & DTA & differential thermo analysis \\
\hline$A D$ & anno domini & e & electron \\
\hline ADP & anisotropic displacement parameters & e.g. & for example \\
\hline AP & atom position & ED & electron density \\
\hline av. & average & Eq. & equation \\
\hline BASF & batch scaling factor & esd & experimental standard deviation \\
\hline $\mathrm{BC}$ & before christ & ESP & electrostatic potential \\
\hline $\mathrm{BCC}$ & bonding charge concentration & Et & ethyl \\
\hline $\mathrm{BCP}$ & bond critical point & $\mathrm{FT}$ & Fourier transform / \\
\hline $\mathrm{Bu}$ & butyl & & Fourier transformation \\
\hline $\mathrm{Bz}$ & benzyl & GoF & goodness of fit \\
\hline$c$ & cyclo & $\mathrm{h}$ & hour(s) \\
\hline calc. & calculated. & Hal & halogen atom \\
\hline $\mathrm{CC}$ & charge concentration & Hex & hexanyl \\
\hline CCD & charge coupled device & $\mathrm{HF}$ & Hartree-Fock \\
\hline $\mathrm{CCP}$ & cage critical point & $i$ & iso \\
\hline$C D$ & electronic charge density & i.e. & that is \\
\hline cf. & confer & IAM & independent atom model \\
\hline $\mathrm{CP}$ & critical point & LP & lone-pair \\
\hline CSD & cambridge structural database & M & metal atom \\
\hline$d$ & day(s) & M & molar \\
\hline DABCO & diaza bicyclo[2,2,2]octane & $\mathrm{Me}$ & methyl \\
\hline decomp. & decomposition & $\min$ & minute(s) \\
\hline dem & diethoxy methane & $\mathrm{MM}$ & multipole model \\
\hline \multirow[t]{2}{*}{ DEPT } & distortionless enhancement by & MO & molecular orbital \\
\hline & polarization transfer & MS & mass spectrometry \\
\hline DFG & $\begin{array}{l}\text { Deutsche Forschungs Gemeinschaft } \\
\text { (german research association) }\end{array}$ & MSDA & $\begin{array}{l}\text { mean square displacement } \\
\text { amplitude }\end{array}$ \\
\hline DFT & density functional theory & NBCC & non-bonding charge concentration \\
\hline dme & dimethoxy ethane & $\mathrm{N}_{2} \mathrm{SCP}$ & diimido methyl sulfinato \\
\hline \multirow[t]{2}{*}{ DMSDA } & difference of mean square & & phosphanide fragment \\
\hline & displacement amplitudes & NMR & nuclear magnetic resonance \\
\hline DSC & differential scanning calorimetry & $\mathrm{Ph}$ & phenyl \\
\hline
\end{tabular}




$\begin{array}{ll}\text { parm. } & \text { parameter(s) } \\ \text { ppm } & \text { parts per million } \\ \text { Pr } & \text { propyl } \\ \text { QTAIM } & \text { quantum theory of atoms in molecules } \\ \text { R } & \text { hydrogen atom or alkyl or aryl group } \\ \text { RCP } & \text { ring critical point } \\ \text { rt } & \text { room temperature } \\ \text { s, sec. } & \text { secondary } \\ \text { SF } & \text { scaling factor } \\ \text { SOF } & \text { site occupation factor } \\ \text { SPP } & \text { Schwerpunkt Programm (priority } \\ & \text { program) } \\ t, \text { tert. } & \text { tertiary } \\ \text { thf } & \text { tetrahydro furane } \\ \text { tmeda } & \text { tetramethyl ethylene diamine } \\ \text { vs. } & \text { versus } \\ \text { VSCC } & \text { valence shell charge concentration } \\ \text { VSEPR } & \text { valence shell electron pair repulsion }\end{array}$




\section{LIST OF COMPOUNDS}

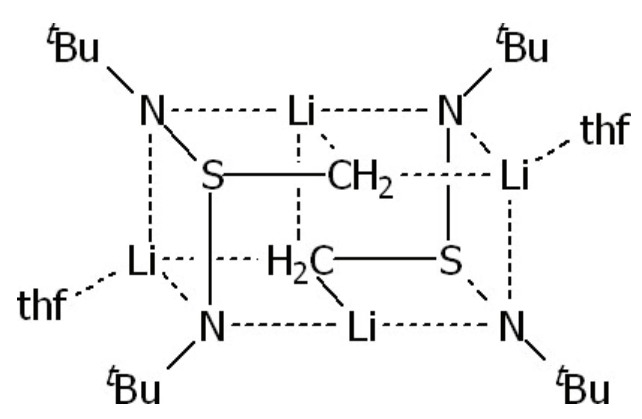

$\left[(\text { thf }) \mathrm{Li}_{2}\left\{\mathrm{H}_{2} \mathrm{CS}\left(\mathrm{N}^{t} \mathrm{Bu}\right)_{2}\right\}\right]_{2}(\mathbf{1 - 4}) /$ Monsun

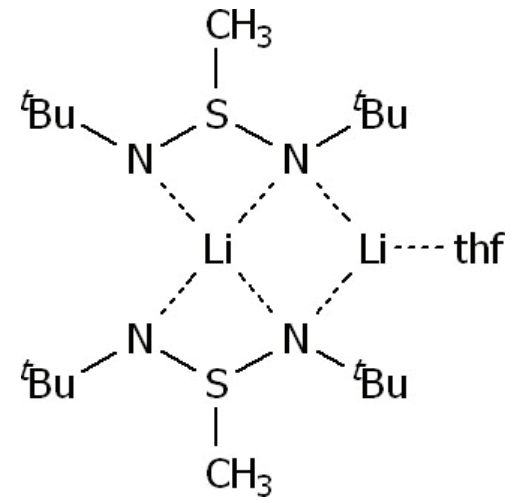

[(dem) $\left.\mathrm{Li}_{2}\left\{\mathrm{MeS}\left(\mathrm{N}^{t} \mathrm{Bu}\right)_{2}\right\}_{2}\right]$ (5) / Demlich

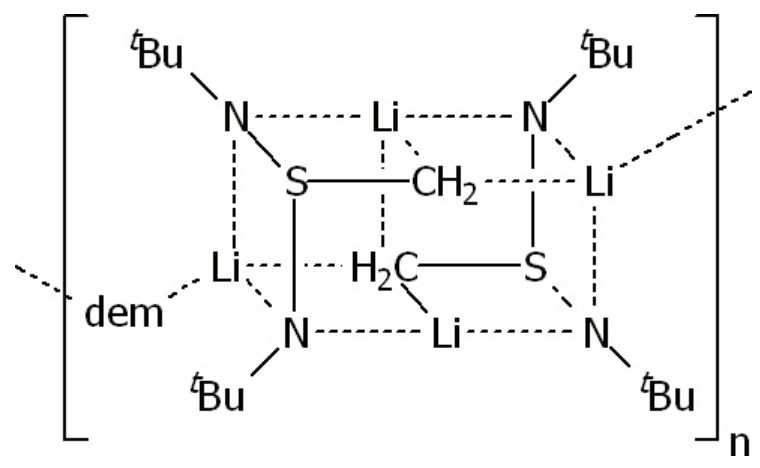

$\left[(\mathrm{dem}) \mathrm{Li}_{4}\left\{\mathrm{H}_{2} \mathrm{CS}\left(\mathrm{N}^{t} \mathrm{Bu}\right)_{2}\right\}_{2}\right](\mathbf{6}) /$ Neulich

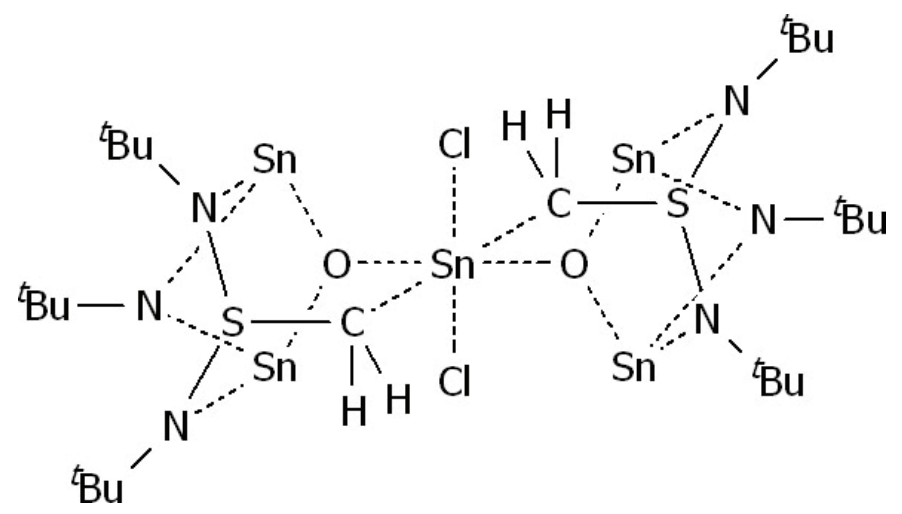

$\left[\mathrm{Cl}_{2} \mathrm{SnO}_{2}\left\{\mathrm{Sn}_{2}\left(\mathrm{HN}^{t} \mathrm{Bu}\right)\right\}\left\{\mathrm{H}_{2} \mathrm{CS}\left(\mathrm{N}^{t} \mathrm{Bu}\right)_{2}\right\}_{2}\right](7) /$ Hexe 


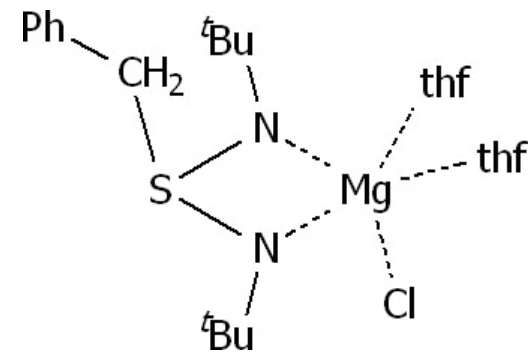

$\left[(\text { thf })_{2} \mathrm{MgCl}\left\{\mathrm{BzS}\left(\mathrm{N}^{t} \mathrm{Bu}\right)_{2}\right\}\right](8) / \mathrm{HoMg}$

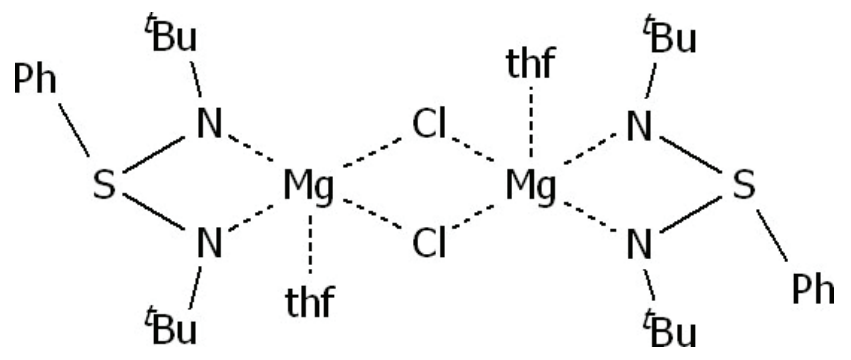

$\left[(\text { thf }) \mathrm{Mg}(\mathrm{Cl})\left\{\mathrm{PhS}\left(\mathrm{N}^{t} \mathrm{Bu}\right)_{2}\right\}\right]_{2}(\mathbf{9}) /$ Schorsch

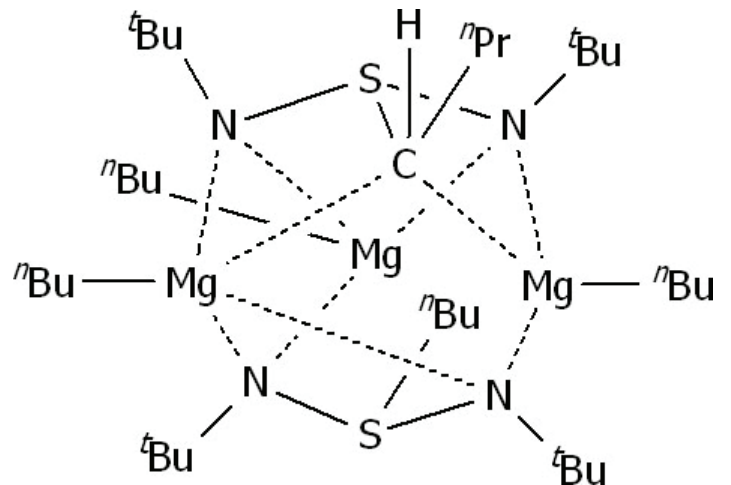

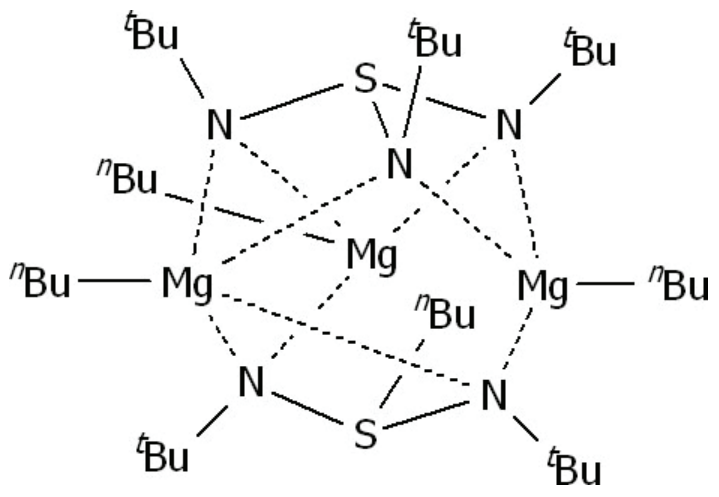

$\left.\left[\left({ }^{n} \mathrm{BuMg}\right)_{9}{ }^{n} \mathrm{BuS}\left(\mathrm{N}^{t} \mathrm{Bu}\right)_{2}\right\}_{3}\left\{\left(\mathrm{C}_{4} \mathrm{H}_{8}\right) \mathrm{S}\left(\mathrm{N}^{t} \mathrm{Bu}\right)_{2}\right\}_{2}\left\{\mathrm{~S}\left(\mathrm{~N}^{t} \mathrm{Bu}\right)_{3}\right\}\right](10-12) /$ DoppelBu

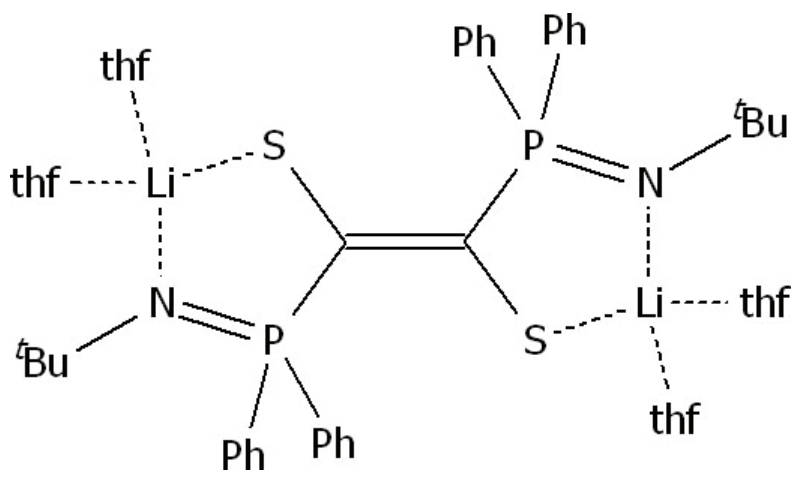

$\left[(\text { thf })_{4} \mathrm{Li}_{2}\left\{\left({ }^{t} \mathrm{BuN}\right) \mathrm{Ph}_{2} \mathrm{P}(\mathrm{S}) \mathrm{CC}(\mathrm{S}) \mathrm{PPh}_{2}\left(\mathrm{~N}^{t} \mathrm{Bu}\right)\right\}\right]$ (13) / Trouble

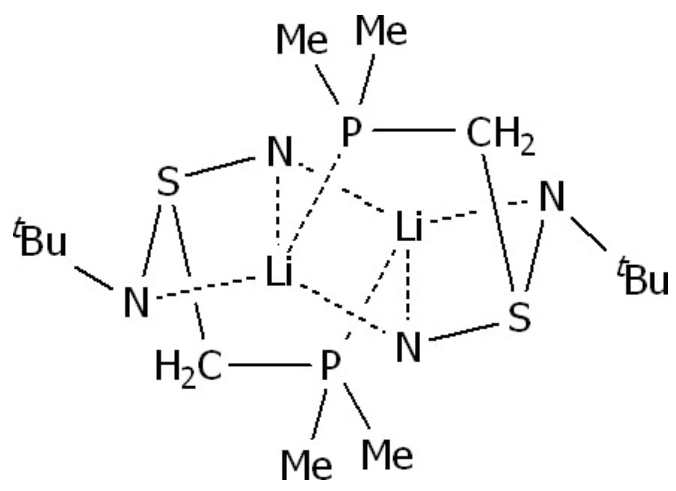

$\left[\mathrm{Li}\left\{\mathrm{Me}_{2} \mathrm{PCH}_{2} \mathrm{~S}\left(\mathrm{~N}^{t} \mathrm{Bu}\right)_{2}\right\}\right]_{2}(\mathbf{1 4}) /$ Schnecke

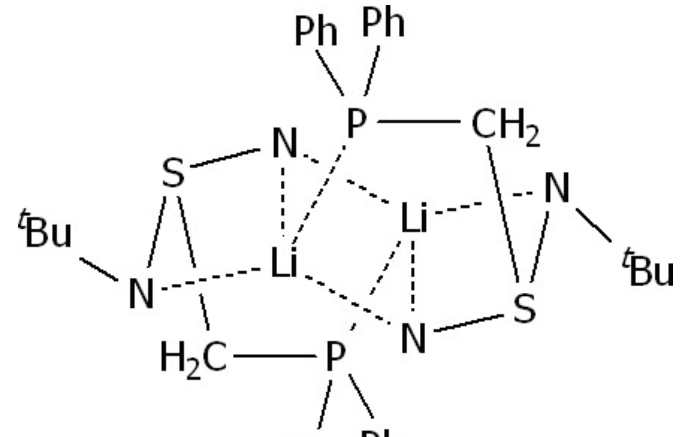

$\mathrm{Ph} \mathrm{Ph}$<smiles>C[Sb](C)(C)=O</smiles>

$\left[\mathrm{Li}\left\{\mathrm{Ph}_{2} \mathrm{PCH}_{2} \mathrm{~S}\left(\mathrm{~N}^{t} \mathrm{Bu}\right)_{2}\right\}\right]_{2}(15) /-$ 


\section{GeNERAL INTRODUCTION}

The existence of sulfur is known to mankind since the beginning of human civilization. It is one of the few naturally occurring elements. With a natural abundance of $0.048 \%$ on earth, it is on the $15^{\text {th }}$ position of all elements. ${ }^{[1]}$ It can be found overground near hot springs and in volcanic regions. Enormous deposits are concentrated in salt domes underground. Although sulfur was at first dreaded for its noxious fumes when burning, mankind soon learned to use this feature to its benefits. The use of sulfur as fumigating agent is historically documented by the famous lines in Homer's Odyssey (750-650 BC): ${ }^{[2,3]}$

"Bring sulfur straight, and fire (the monarch cries), she hears, and at the word obedient flies.

With fire and sulfur, cure of noxious fumes, he purged the walls, and blood-polluted rooms."

The word sulfur is derived from the Arabic sufra, meaning yellow, and was transformed to the Latin sulfur. Thus, it is not derived from classical Greek and should therefore not be spelled sulphur. ${ }^{[4]}$ Instead, the Greek term $\theta \varepsilon \tilde{i}$ v (theion) for sulfur is the genesis of the prefix thio for sulfur containing compounds, e.g. thioester. The exploration of the chemical behavior of sulfur and its compounds started as early as $300 \mathrm{BC}$ when the Chinese employed it as medicine. However, Chinese gun powder, containing $10 \%$ sulfur, was mentioned in historical documents as late as 1044 AD. European alchemists appreciated sulfur for its reactivity and used it due to its high affinity to metals.

Despite this long history, the chemistry of this element and sulfur containing compounds has neither been fully understood nor entirely explored so far. Even new allotropes of sulfur have been recently discovered. ${ }^{[5]}$ The comprehension is not only missing for curious reactions, but also for fundamental processes as the vulcanization of rubber with elemental sulfur. ${ }^{[6,7]}$ Both, the bonding situation and the resulting reactivity of sulfur compounds, are widely discussed. ${ }^{[8]}$

Based on this, it is easy to understand, why the exploration of sulfur compounds first focused on the acids of sulfur, their salts, and the sulfoxides. The production of sulfuric acid is such a basic and important industrial process, that economic growth can be scaled to it. ${ }^{[9]}$ The annual amount of sulfuric acid production is on the increase and reached $165 \cdot 10^{6} \mathrm{t}$ in 2001 . All other sulfur chemistry did not evolve evenly fast 
until the second half of the $20^{\text {th }}$ century (cf. Figure 1-1), when substituted sulfur compounds were found to be versatile ligands. The upraise was further promoted in 1979 by the discovery that polymeric $(\mathrm{SN})_{\mathrm{x}}$ is superconductive at low temperatures $(<0.33 \mathrm{~K}) \cdot{ }^{[10]}$ The interest in this physical phenomenon and the electron distribution in $(\mathrm{SN})_{\mathrm{x}}$ led to the first studies on the nature of sulfur nitrogen bonding, although $(\mathrm{SN})_{\mathrm{x}}$ had already been synthesized in 1910 by Burt. ${ }^{[11]}$ Moreover, a great variety of binary sulfur nitrogen compounds was explored.

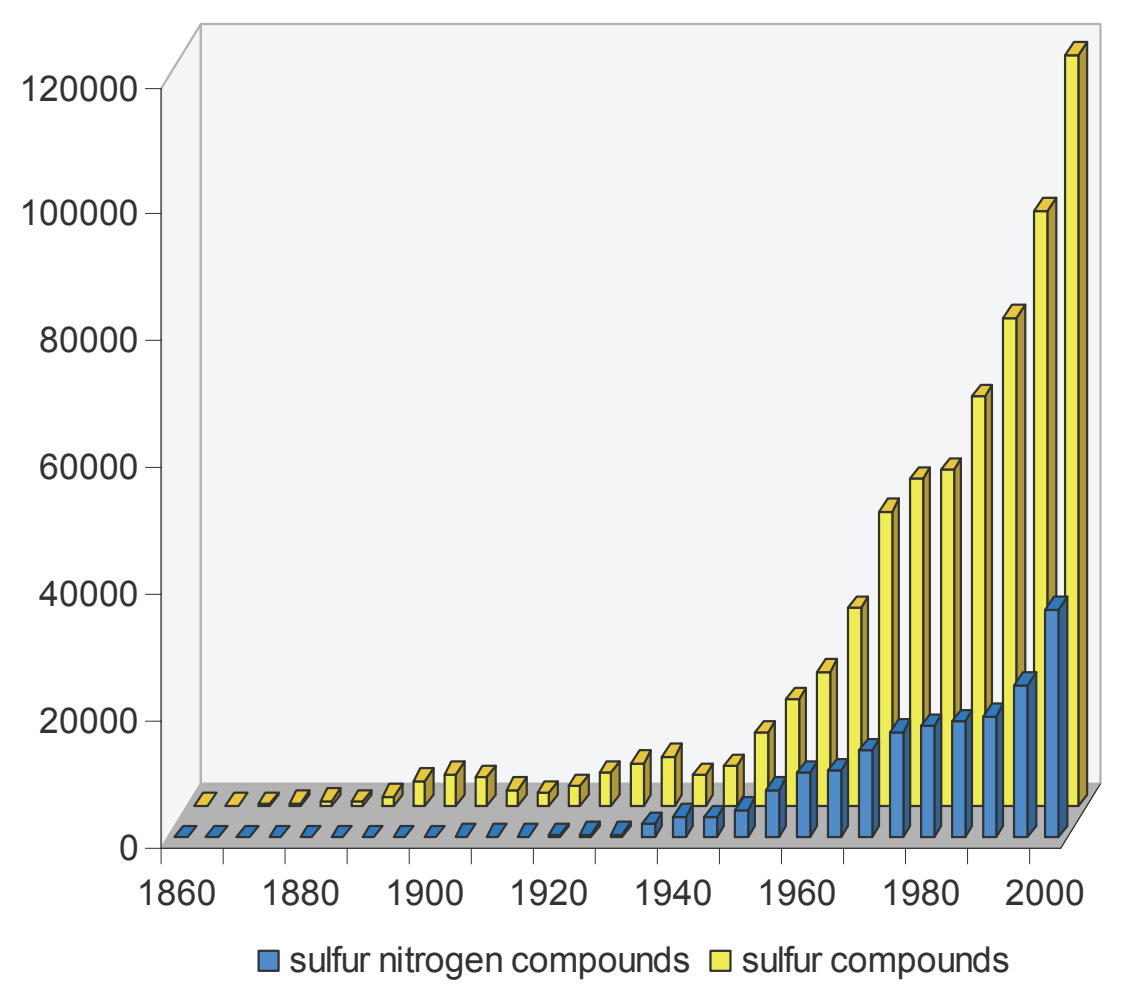

Figure 1-1: No. of publications on sulfur (yellow) and sulfur nitrogen compounds (blue) in 5-year-ranges.

Although the synthesis of the first amino sulfur compound $\mathrm{SO}_{2}\left(\mathrm{NH}_{2}\right)_{2}$ was reported as early as 1892 by Traube, ${ }^{[12]}$ this branch of chemistry did not prosper until the Second World War. The synthesis of the first aliphatic sulfur diimide $S\left(N^{n} B u\right)_{2}$ by Goehring and Weis $^{[13]}$ in 1956 gave the so far idle chemical field the necessary impetus for a quick development (cf. Figure 1-1). In the following years, several other sulfur diimides were reported. ${ }^{[14-16]}$ The synthesis of symmetrical sulfur diimides is commonly achieved in high yields by reaction of amines with sulfur dichloride, ${ }^{[17-21]}$ sulfur tetrahalogenide ${ }^{[13,22-24]}$ or hydrogen sulfide. ${ }^{[25,26]}$ An additional pathway is the reaction of thionyl chloride with a metal amide (cf. Scheme 1-1). ${ }^{[27-31]}$ 


$$
2 \mathrm{SCl}_{2}+6 \mathrm{H}_{2} \mathrm{NR} \quad \longrightarrow \quad \mathrm{S}\left(\mathrm{NR}_{2}+4 \mathrm{RNH}_{3} \mathrm{Cl}+1 / 8 \mathrm{~S}_{8}\right.
$$

(a)

$\mathrm{SX}_{4}+6 \mathrm{H}_{2} \mathrm{NR}$

$\longrightarrow \mathrm{S}(\mathrm{NR})_{2}+4 \mathrm{RNH}_{3} \mathrm{X}$

(b)

$\mathrm{H}_{2} \mathrm{~S}+3 \mathrm{BrNHR}+2 \mathrm{H}_{2} \mathrm{NR} \longrightarrow \mathrm{S}(\mathrm{NR})_{2}+3 \mathrm{RNH}_{3} \mathrm{Br}$

(c)

$$
\mathrm{SOCl}_{2}+2\left[\mathrm{MNR}\left(\mathrm{SiMe}_{3}\right)\right] \longrightarrow \mathrm{S}\left(\mathrm{NR}_{2}+\mathrm{O}\left(\mathrm{SiMe}_{3}\right)_{2}+2 \mathrm{MCl}\right.
$$

(d)

Scheme 1-1: Common synthetic routes to sulfur diimides.

Due to the hazardous syntheses, sulfur triimides have been investigated far less than the diimides. Up to 1997 , these compounds had to be prepared using $\mathrm{NSF}_{3}{ }^{[32,33]}$ or $\mathrm{OSF}_{4}{ }^{[34]}$ Then Fleischer reported in two publications on a safe route to sulfur triimides. Starting from the corresponding sulfur diimide the dianion $\mathrm{S}(\mathrm{NR})_{3}{ }^{2-}$ is prepared by addition of a lithium amide [LiNHR]. ${ }^{[35]}$ The resulting sulfite analogue can be oxidized utilizing a halogen to prepare the desired sulfur triimide in high yields (cf. Scheme 1-2). ${ }^{[36]}$

$$
\begin{array}{ll}
2 \mathrm{~S}(\mathrm{NR})_{2}+4[\mathrm{LiNHR}] & \longrightarrow\left[\mathrm{Li}_{2}\left\{\mathrm{~S}(\mathrm{NR})_{3}\right\}\right]_{2}+2 \mathrm{H}_{2} \mathrm{NR} \\
{\left[\mathrm{Li}_{2}\left\{\mathrm{~S}(\mathrm{NR})_{3}\right\}\right]_{2}+2 \mathrm{X}_{2}} & \longrightarrow 2 \mathrm{~S}(\mathrm{NR})_{3}+4 \mathrm{LiX}
\end{array}
$$

Scheme 1-2: Preparation of sulfur triimides.

The isoelectronic principle by Langmuir ${ }^{[37,38]}$ allows to envisage the sulfur diimides and triimides as analogues of sulfur oxo compounds (cf. Table 1-1). ${ }^{[39-43]}$ The isoelectronic replacement of an oxygen atom by an imido group NR relates the one to the other. According to Langmuir, this leads to compounds, which resemble the original ones in many properties (spatial arrangement of the atoms, reactivity, coordination chemistry, etc.). Nevertheless, the organic substituents of the imido groups modify these features. Thus, the polyimido compounds are soluble in non-polar, organic solvents and show different redox chemistry compared to the sulfur oxo species. Moreover, the choice of the substituent allows the tuning of the reactivity of the polyimido sulfur compounds. This leads to a broad variety of 
reactivities and reactions as presented in various reviews for the sulfur diimides and triimides. $^{[41,42,44,45]}$

Table 1-1: Examples of compound classes isoelectronic to $\mathrm{SO}_{\mathrm{x}}$.

\begin{tabular}{l|lll}
\hline $\mathrm{SO}_{2}$ & $\mathrm{~S}(\mathrm{NR})_{2}$ & $\left(\mathrm{R}_{2} \mathrm{C}\right) \mathrm{S}(\mathrm{NR})$ & $\mathrm{S}\left(\mathrm{CR}_{2}\right)_{2}$ \\
$\mathrm{SO}_{3}$ & $\mathrm{~S}(\mathrm{NR})_{3}$ & $\left(\mathrm{R}_{2} \mathrm{C}\right) \mathrm{S}(\mathrm{NR})_{2}$ & $\left(\mathrm{R}_{2} \mathrm{C}\right)_{2} \mathrm{~S}(\mathrm{NR})$ \\
$\mathrm{SO}_{3}{ }^{2-}$ & $\mathrm{S}(\mathrm{NR})_{3}{ }^{2-}$ & $\left(\mathrm{R}_{2} \mathrm{C}\right) \mathrm{S}(\mathrm{NR})_{2}{ }^{2-}$ & $\left(\mathrm{R}_{2} \mathrm{C}\right)_{2} \mathrm{~S}(\mathrm{NR})^{2-}$ \\
$\mathrm{SO}_{4}$ & $\mathrm{~S}(\mathrm{NR})_{4}$ & $\left(\mathrm{R}_{2} \mathrm{C}\right) \mathrm{S}(\mathrm{NR})_{3}$ & $\left(\mathrm{R}_{2} \mathrm{C}\right)_{2} \mathrm{~S}(\mathrm{NR})_{2}$ \\
$\mathrm{SO}_{4}{ }^{2-}$ & $\mathrm{S}(\mathrm{NR})_{4}{ }^{2-}$ & $\left(\mathrm{R}_{2} \mathrm{C}\right) \mathrm{S}(\mathrm{NR})_{3}{ }^{2-}$ & $\left(\mathrm{R}_{2} \mathrm{C}\right)_{2} \mathrm{~S}(\mathrm{NR})_{2}{ }^{2-}$ \\
\hline
\end{tabular}

The polyimido sulfur compounds are commonly considered to be heterocumulenes. Accordingly, they have been used in cycloadditions ${ }^{[46]}$ and en-reactions. ${ }^{[47,48]}$ Apart from this, they play an important role in asymmetric aminations, ${ }^{[47,49,50]}$ substitution reactions, ${ }^{[46]}$ and as synthetic intermediates. ${ }^{[51]}$ Moreover, they are versatile ligands in coordination chemistry. ${ }^{[24,40,41]}$

Addition of an alkyl or aryl group to the formal $\mathrm{S}=\mathrm{N}$ double bonds leads to the organic diimido sulfinates ${ }^{[52-55]}$ and organo triimido sulfonates ${ }^{[56]}$ (cf. Scheme 1-3). These classes of compounds were first explored by Kuyper and Vrieze in 1976. ${ }^{[57]}$ Soon afterwards, they became a flourishing field of main group and transition metal chemistry. ${ }^{[27,57-60]}$ These anions show the same steric demand as cyclopentadienyl ligands and are soluble in non-polar organic solvents. ${ }^{[5]}$

$2 \mathrm{~S}(\mathrm{NR})_{2} \stackrel{2 \mathrm{LiCR}_{2} \mathrm{H}}{\longrightarrow}\left[\mathrm{Li}_{2}\left\{\mathrm{HR}_{2} \mathrm{CS}(\mathrm{NR})_{2}\right\}_{2}\right] \stackrel{2 \mathrm{RLi}}{-2 \mathrm{RH}}\left[\left[\mathrm{Li}_{4}\left\{\mathrm{R}_{2} \mathrm{CS}(\mathrm{NR})_{2}\right\}_{2}\right]\right.$

Scheme 1-3: Reactions of sulfur diimides with organo lithium reagents.

The organo polyimido sulfur chemistry can be extended further if the alkyl substituent is deprotonated in a-position to the sulfur atom (cf. Scheme 1-3). The resulting $\mathrm{CR}_{2}$ group is, like the NR group, isoelectronic to an oxygen atom (cf. Table 1-1). Thus, the former organo diimido sulfinates and organo triimido sulfonates become analogues of the sulfite and sulfate dianions, respectively (cf. Table 1-1). Ten complexes of this kind have been synthesized and crystallized so far. ${ }^{[61-65]}$ The additional carbanionic site takes part in the coordination of the metal ion. While the sulfur(IV) species prefer to form dimers for an enhanced coordination of the lithium cations, the only known sulfur(VI) species remains monomeric. This might be caused 
by the additional nitrogen donor site present, but could also be due to the tmeda donor.

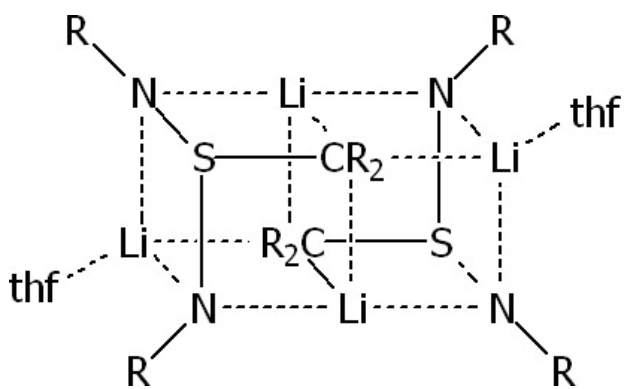

(a)

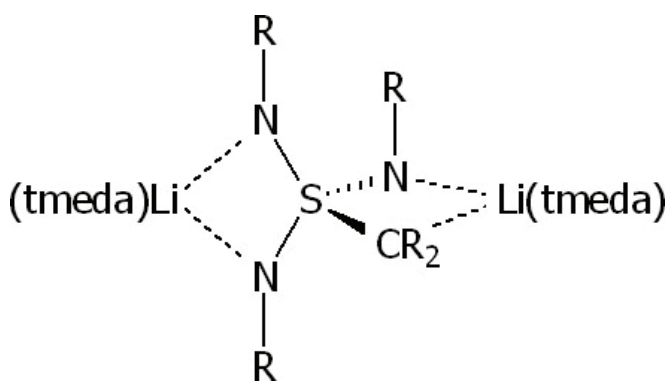

(b)

Scheme 1-4: Metal coordination in (a) diimido sulfur ylides and (b) triimido sulfur ylides.

Although these dianions seem to be ideal ligands because of their three or four donating sites, no complexes with other metals than lithium have been reported prior to this study. This is due to the prominent redox chemistry of these compounds, which inhibits metal exchange by standard methods. ${ }^{[64,66]}$ In addition to their coordination chemistry, polyimido sulfur ylides are especially interesting, as they can be regarded as Corey ylides. ${ }^{[62,67,68]}$ The advantage of using polyimido sulfur ylides instead of classical Corey ylides is the capability to transfer the carbon or alternatively the imido substituents, depending on the reaction conditions. ${ }^{[69,70]}$ This will be discussed further in chapter 2.1.

The transimidation reactions of polyimido sulfur compounds are not fully understood yet. $^{[71]}$ It is hard to understand, why the strong $S=N$ double bond depicted in classical Lewis formulae can be cleaved so easily. Similar questions arise for the formal $\mathrm{S}=\mathrm{C}$ double bond. This one seems to be even weaker, as hydrolysis of [(tmeda) $\left.\mathrm{Li}_{2}\left\{\mathrm{H}_{2} \mathrm{CS}\left(\mathrm{N}^{t} \mathrm{Bu}\right)_{3}\right\}\right]$ leads to cleavage of the $\mathrm{S}=\mathrm{C}$ rather than the $\mathrm{S}=\mathrm{N}$ bond. ${ }^{[65]}$ This can only be explained by single bond character and charge separation. The chemistry of Corey and Wittig ylides also favors the ylidic $\mathrm{S}^{+}-^{-} \mathrm{C}$ formulation. On the other hand, the Lewis rule for avoiding charge separation suggests the ylenic $\mathrm{S}=\mathrm{C}$ form. This is in accordance with the short S-C distances. Hence, it has not been finally decided, despite the importance of these compounds in organic chemistry $^{[14,72-74]}$ and numerous studies on their character. ${ }^{[8,75-79]}$

Taking all the above-mentioned into account, a lot of problems and questions remain open throughout polyimido sulfur chemistry. This is astonishing as it has been explored extensively over the last decades. In order to deal with the open questions, specific tasks have been established for this thesis. 


\section{Scope of this Thesis:}

In order to elucidate the bonding situation in Corey and polyimido sulfur ylides, an experimental electron density study on $\left[(\text { thf }) \mathrm{Li}_{2}\left\{\mathrm{H}_{2} \mathrm{CS}\left(\mathrm{N}^{t} \mathrm{Bu}\right)_{2}\right\}\right]_{2}(\mathbf{1})$ was to be performed. Electron density studies have proved to be the instrument of choice to shed light on such issues. ${ }^{[80-82]} 1$ seems to be an ideal choice for these kinds of studies, because two additional questions can be addressed. The presence of formal $\mathrm{S}=\mathrm{N}$ double bonds implies a hypervalent sulfur atom. An investigation of the bonding situation between the sulfur and nitrogen atoms by an electron density study allows a better description and helps to decide whether the sulfur atom is hypervalent or not. The coordination motif of a carbanion capping an $\mathrm{Li}_{3}$ triangle in 1 is ubiquitous throughout organo lithium chemistry, ${ }^{[83]}$ but the driving forces for its formation are sparsely understood. Hence, the bonding situation of the $\mathrm{Li}_{3} \mathrm{C}$ motif was to be investigated.

The literature-known crystalline form of $\left[(\text { thf }) \mathrm{Li}_{2}\left\{\mathrm{H}_{2} \mathrm{CS}\left(\mathrm{N}^{t} \mathrm{Bu}\right)_{2}\right\}\right]_{2}(\mathbf{1})$ is not suitable for an experimental electron density determination via multipole refinement on high-order X-ray diffraction data and subsequent topological analyses, due to the present disorder. Thus, the polymorphism of $\mathbf{1}$ had to be investigated to find a modification with high metric symmetry but free of disorder.

The second task of this thesis was to investigate the coordination chemistry of alkylene diimido sulfite dianions. Two strategies should be attempted to obtain a polyimido sulfur ylide coordinated to metals other than lithium. I) Transmetalation of $\left[(\text { thf }) \mathrm{Li}_{2}\left\{\mathrm{H}_{2} \mathrm{CS}\left(\mathrm{N}^{t} \mathrm{Bu}\right)_{2}\right\}\right]_{2}$ (1) and II) reactions of tert.-butyl sulfur diimide with dialkyl magnesium, copper, and zinc reagents along with other Grignard compounds to introduce the non-lithium metal at the beginning of the synthetic route.

Last but not least, the functionalization of organo diimido sulfinates was to be expanded by the introduction of an additional donor site in the backbone of the carbon substituent at the central sulfur atom. Ideally, this donor should be soft in terms of the HSAB concept by Pearson. ${ }^{[84-86]}$ By these means, simultaneous coordination of hard and soft metals would be possible, promoting the catalytic versatility of the complexes. 


\section{Charge Density Study on a Lithium Sulfur YLIDE}

\subsection{Interest in $\left[(\text { thf }) L i_{2}\left\{\mathrm{H}_{2} \mathrm{CS}\left(\mathrm{N}^{t} \mathrm{Bu}\right)_{2}\right\}\right]_{2}(1)$}

The first ylide was discovered by Stevens in 1928 in the search for a protective group for secondary amines. ${ }^{[87]}$ However, the term ylide was invented only in 1944 by Wittig, combining the -yl ending of a homo-polar valence and the -id ending of a heteropolar bond of a carbon atom to a heteroatom. ${ }^{[88]}$ In other terms, ylides are defined as organic molecules that have a contributing Lewis structure with opposite charges on adjacent heteroatoms, each of which has an octet of electrons. The first sulfur ylide was discovered by Wittig and Fritz in 1952. ${ }^{[89]}$

Corey's sulfur ylides $\left(\mathrm{R}_{2}(\mathrm{O}) \mathrm{S}^{+}-{ }^{-} \mathrm{CR}_{2}\right)$ play an important role in organic syntheses. ${ }^{[14,72-74]}$ They are mainly used in $\mathrm{CR}_{2}$-transfer reactions (e.g. in stereoselective epoxidations). Sulfur ylides can be used as one-step epoxidating agents, ${ }^{[90,91]}$ whereas classical Wittig reagents $\left(\mathrm{R}_{3} \mathrm{P}^{+}-{ }^{-} \mathrm{CR}_{2}\right)$ would require a two-step synthesis (cf. Scheme 2-1). In the latter case the carbonyl compound would have to be transformed into an alkene first, with control of the relative configuration, and then asymmetrically oxidized, with control over the absolute configuration. Interestingly, the oxygen atom is removed in the first step and another oxygen atom is reattached in the second.

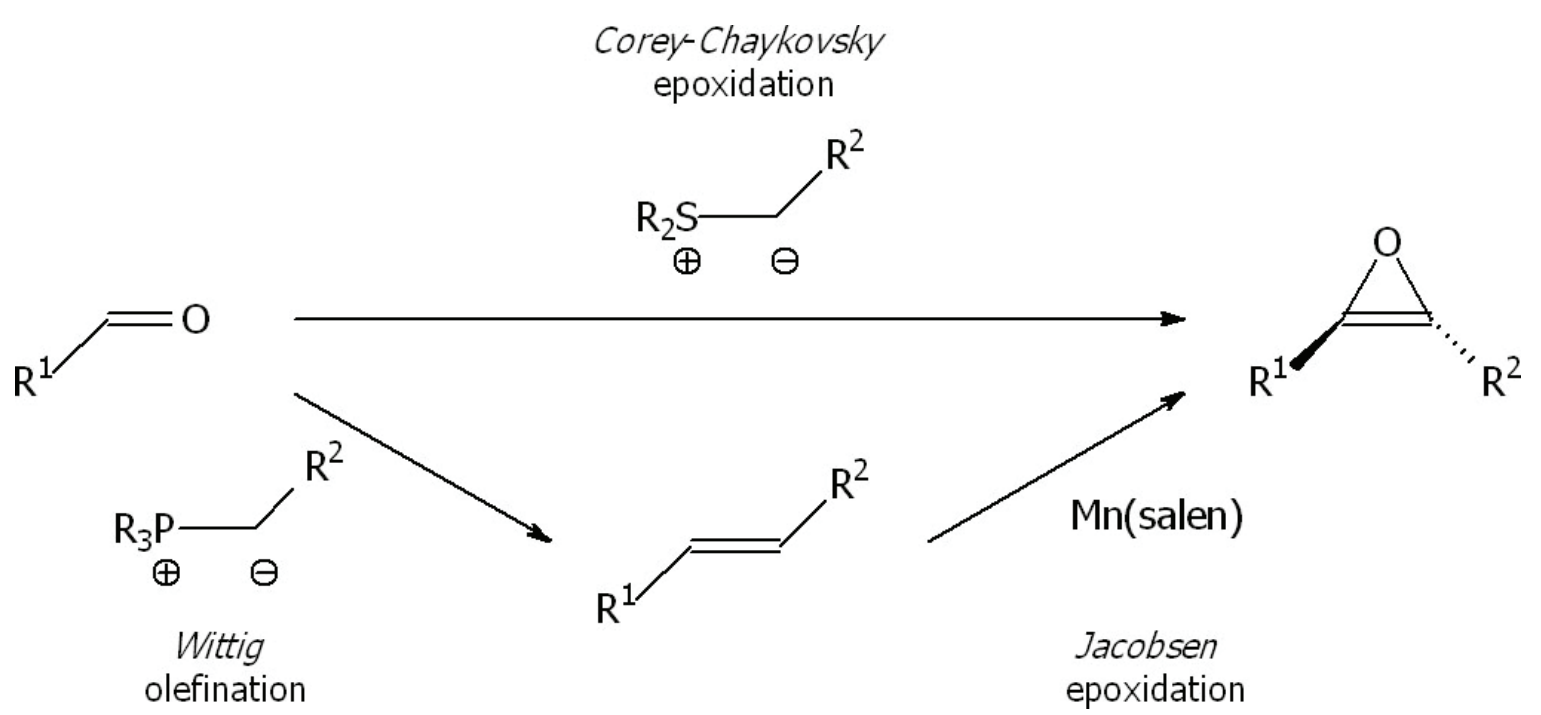

Scheme 2-1: Schematic epoxidation reactions utilizing Corey and Wittig ylides $\left(R, R^{1}, R^{2}=\right.$ alkyl). 
Additionally, activated sulfur ylide complexes react stereospecifically with alkenes to form cyclopropanes. ${ }^{[67,92-97]}$ Use of imines instead of alkenes leads to aziridines. ${ }^{[68,98,99]}$

If imido sulfur ylides $\left((\mathrm{RN})_{n} \mathrm{~S}^{+}-{ }^{-} \mathrm{CR}_{2}, \mathrm{n}=2,3\right)$ are utilized, transimidation reactions are feasible by choice of the experimental conditions (particularly the temperature) as well. The reaction conditions also decide if a Wittig-like olefination (thermodynamic conditions) or a Cannizzaro-like reaction takes place in the case of $\mathrm{C}=\mathrm{C}$ bond formation. ${ }^{[69,70]}$ Furthermore, sulfur ylides are often applied as intermediates in ring expansion reactions. ${ }^{[100]}$ Thus, with just one reagent five important organic reaction types are feasible (cf. Scheme 2-2).

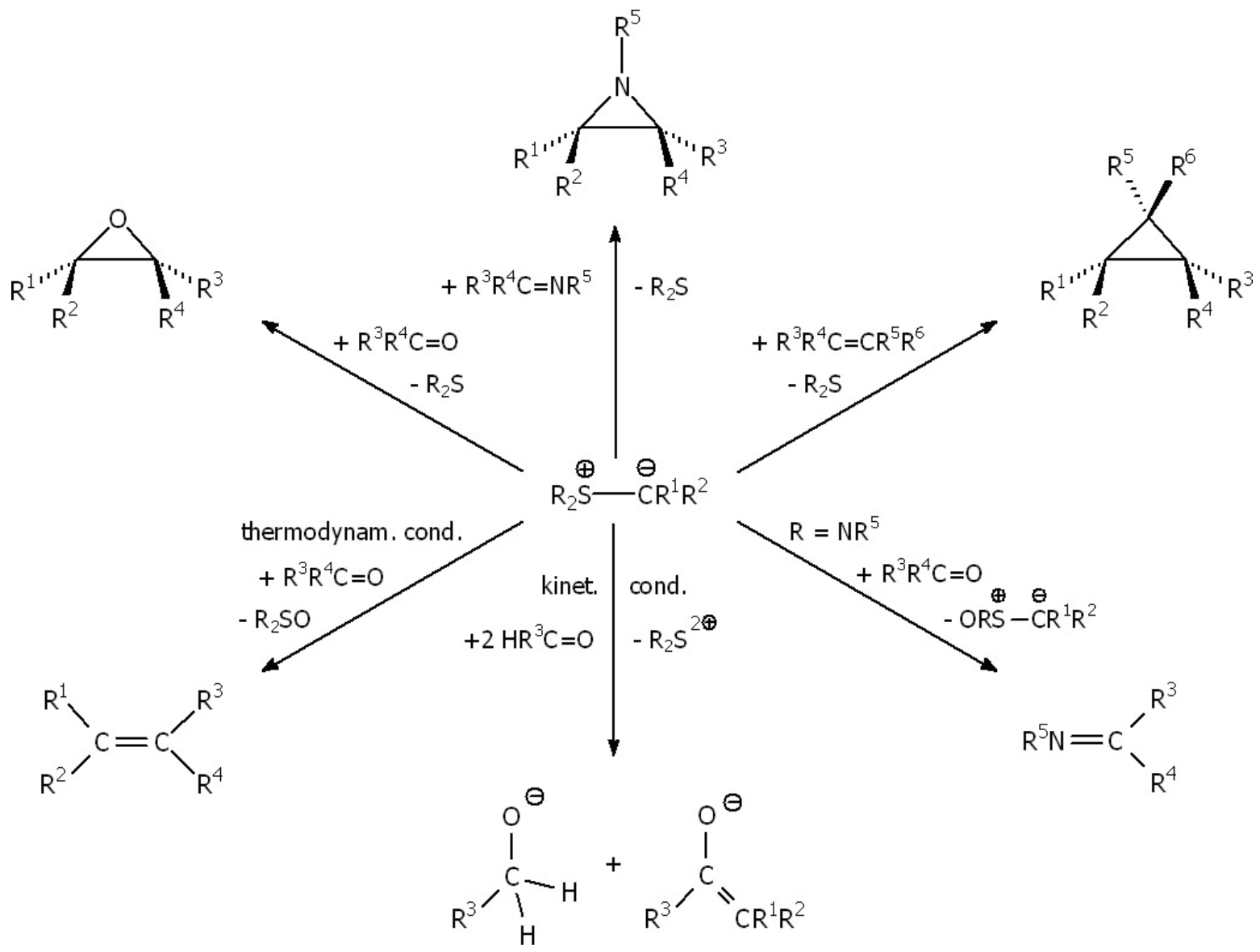

Scheme 2-2: Possible reaction pathways of sulfur ylides $\left(R=\right.$ alkyl, aryl, imido; $R^{1}-R^{6}=$ alkyl, aryl).

All of this emphasizes the synthetic versatility of sulfur ylides and illustrates, why their bonding properties are still under debate. The $\mathrm{S}-\mathrm{C}$ as well as the $\mathrm{S}-\mathrm{N}$ bond cleavages ${ }^{[101]}$ clearly contradict the classical Lewis notation of an $S=C$ or $S=N$ double bond (hypervalent ylenic form, (cf. Scheme 2-3a). ${ }^{[65]}$ Thus, an ylidic resonance form seems much more correct (cf. Scheme 2-3b-d). ${ }^{[62]}$ This fuels the dispute to which extent sulfur ylides are dominated by ylidic or ylenic bonding. 


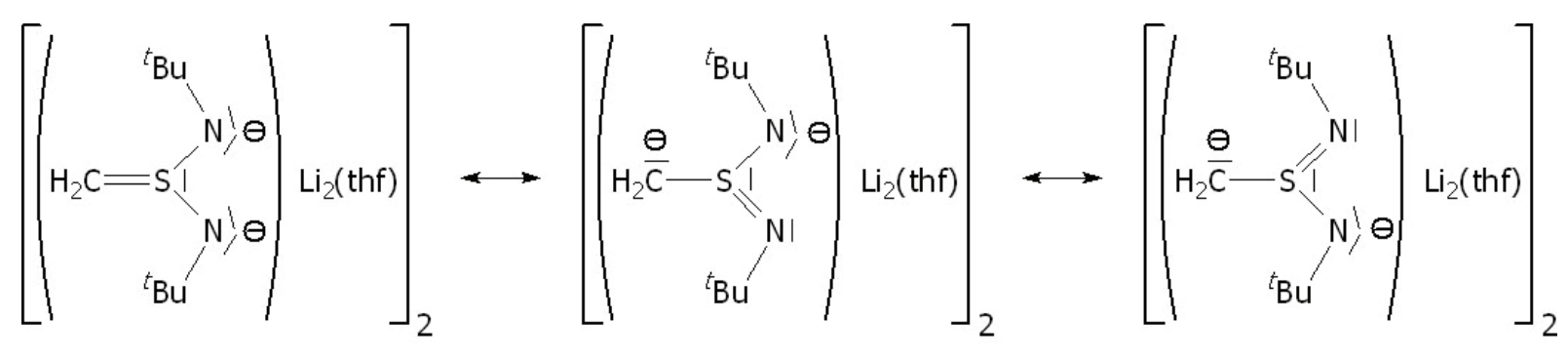

(a)

(b)

(c)

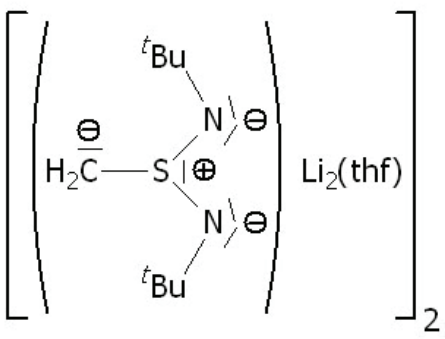

(d)

Scheme 2-3: Possible Lewis formulae for $\left[(\operatorname{thf}) \mathrm{Li}_{2}\left\{\mathrm{H}_{2} \mathrm{CS}\left(\mathrm{N}^{t} \mathrm{Bu}\right)_{2}\right\}\right]_{2}$ (1).

Cleavages of formal $\mathrm{S}=\mathrm{N}$ double bonds are found frequently in the literature. ${ }^{[56,71,101,102]}$ Some reactions are induced by redox chemistry involving a metal chloride, but most reactions occur at room temperature without a redox starter (cf. Scheme 2-4).

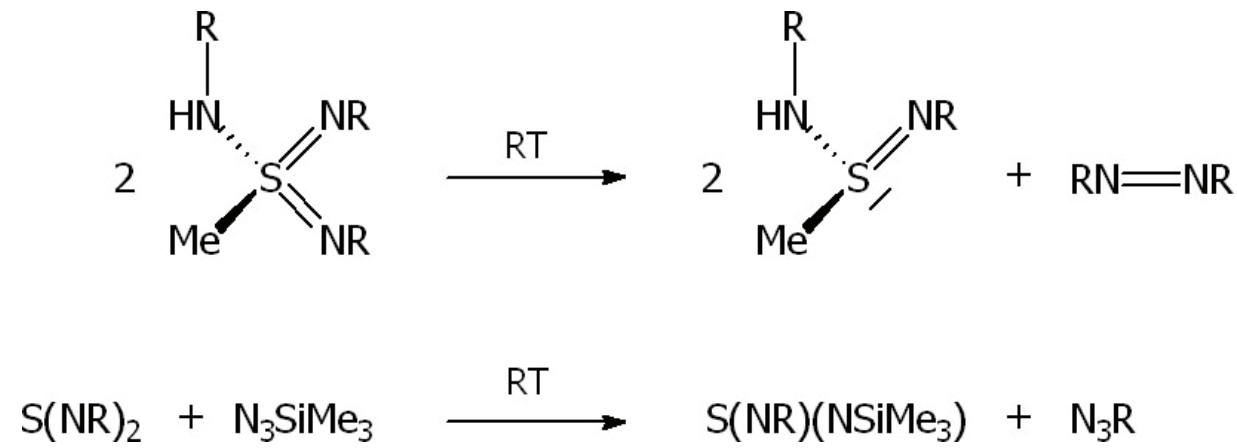

Scheme 2-4: Examples of formal $S=N$ double bond cleavages. ${ }^{[56,71]}$

Experimental charge density studies are clearly the appropriate tool to decide on bonding and reactivity questions. The studies on the sulfurtriimide $\mathrm{S}\left(\mathrm{N}^{t} \mathrm{Bu}\right)_{3}$ explained the stunning reactivity of this molecule. ${ }^{[81]}$ Although $S\left(N^{t} B u\right)_{3}$ is planar, nucleophilic attack at the sulfur atom is only possible for reagents containing small or planar nucleophiles. This is not straightforward from the chemical and sterical point of view, but can easily be understood if the reactive surface of the molecule is investigated. The electron density is distributed in a way that only an attack along the 
$\mathrm{N}-\mathrm{S}-\mathrm{N}$ bisection is possible (cf. Figure 2-1). Due to the orientation and steric demand of the tert.-butyl groups this is only possible for small or planar nucleophiles.

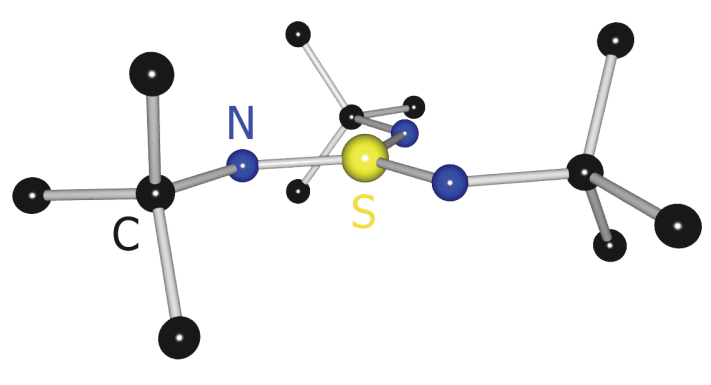

(a)

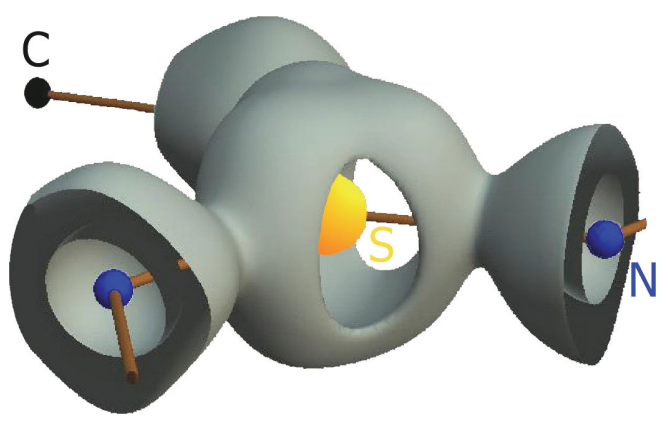

(b)

Figure 2-1: (a) Molecular structure and (b) reactive surface of $\mathrm{S}\left(\mathrm{N}^{t} \mathrm{Bu}\right)_{3}{ }^{[81]}$

Other questions concerning bonding features have also been answered by recent experimental charge density studies. ${ }^{[103-106]}$ Especially interesting are the studies within our group on $\mathrm{S}=\mathrm{N} / \mathrm{S}^{+}-\mathrm{N}$ bond characteristics. ${ }^{[80-82,107]}$ These will be used as benchmark systems and reference points for this thesis.

It seems astonishing, that, although a lot of experimental electron density studies have been presented throughout the last decade, no such study has been performed on a sulfur ylide. Only theoretical studies on the kind of bonding involved have been made ${ }^{[75,76,78,108]}$ Their results are highly contradictory. Thus, theoretical tools are not appropriate to elucidate the bonding situation. Additionally, most experimental evidences are based on geometrical features rather than real electronic properties. ${ }^{[8]}$ In order to decide on the above-mentioned questions, [(thf) $\left.\mathrm{Li}_{2}\left\{\mathrm{H}_{2} \mathrm{CS}\left(\mathrm{N}^{t} \mathrm{Bu}\right)_{2}\right\}\right]_{2}$ (1) has been chosen as an appropriate candidate for investigation of a sulfur ylide and has the prospect of functionalized tailor-made $\mathrm{CR}_{2} / \mathrm{NR}$-transfer reagents and is therefore of major structural as well as synthetical interest. The $\left[\mathrm{H}_{2} \mathrm{CS}\left(\mathrm{N}^{t} \mathrm{Bu}\right)_{2}\right]^{2-}$ dianion is an analogue of $\mathrm{SO}_{3}{ }^{2-}$, in which two oxygen atoms are isoelectronically replaced by a $\mathrm{N}^{t} \mathrm{Bu}$ imido group and the third one is substituted by a $\mathrm{CH}_{2}$ methylene group. The sulfur bonded atoms form a potential tridentate ligand.

The coordination of a carbanion to an $\mathrm{Li}_{3}$-triangle, a structural motif well-known in organo lithium chemistry, is present in $\mathbf{1}$, too. ${ }^{[3,109]}$ This provides the opportunity to study the interactions within this motif for the first time on the basis of an experimental charge density determination. Up to now the bonding mode and the forces that keep the lithium cations together were not fully understood. The $\mathrm{Li}-\mathrm{C}$ bonding situation is also subject to debates on its character. ${ }^{[110]}$ Numerous 
theoretical ${ }^{[110-133]}$ as well as experimental ${ }^{[134-145]}$ approaches were not able to finally decide on the degree of ionic and covalent contribution to the bonding. The knowledge gained from the presented experiment should enable chemists to tailor target organo lithium compounds. Additionally, a better understanding of the reaction behavior, especially of stereochemically active organo lithium reagents, can be envisaged. This is essential as reactions employing organo lithium compounds are fundamental to most synthetic routes in modern organic ${ }^{[72,73,146-148]}$ and inorganic chemistry. ${ }^{[149,150]}$

To put it in a nut-shell, four questions can be formulated concerning the bonding situations in $\left[(\text { thf }) \mathrm{Li}_{2}\left\{\mathrm{H}_{2} \mathrm{CS}\left(\mathrm{N}^{t} \mathrm{Bu}\right)_{2}\right\}\right]_{2}$ (1): I) What kind of $\mathrm{S}-\mathrm{N}$ bonding is present $(\mathrm{S}=\mathrm{N}$ vs. $\left.S^{+}-\mathrm{N}\right)$ ? II) Is the $S-C$ bond ylenic $(S=C)$ or ylidic $\left(S^{+}-C\right)$ ? III) Is, thus, the sulfur atom hypervalent? IV) What kind of interaction between the carbanion and the lithium atoms is present?

In order to perform an experimental charge density study and clarify the points of interest, the following steps have to be taken: I) A high quality X-ray diffraction experiment with collection of high-order reflections. II) Determination of the standard structure, the so-called IAM (independent atom model) or promolecule. III) Modeling of the ED (electron density) with Slater-type radial functions. IV) Analyses of the topology of the obtained electron density. Because of the interest in subtle differences of the electron density distribution within the bonds, the experiment has to be performed on top level.

The literature-known modification ${ }^{[62]}$ of $\left[(t h f) \mathrm{Li}_{2}\left\{\mathrm{H}_{2} \mathrm{CS}\left(\mathrm{N}^{t} \mathrm{Bu}\right)_{2}\right\}\right]_{2}(\mathbf{1})$ will be called $\mathbf{2}$ in order to distinguish it from other polymorphs. Whenever the mere chemical substance or all modifications are meant, $\mathbf{1}$ will be used instead.

Although, the crystals of 2 show sufficiently high symmetry (space group $P 2{ }_{1} / c$ ), this polymorph phase is not suitable for experimental electron density studies due to its thf disorder. Disorder prevents a sufficient deconvolution of bond densities, atomic positions, thermal motion parameters and the site occupancy factors. Therefore, a non-disordered polymorph of $\left[(\text { thf }) \mathrm{Li}_{2}\left\{\mathrm{H}_{2} \mathrm{CS}\left(\mathrm{N}^{t} \mathrm{Bu}\right)_{2}\right\}\right]_{2}$ (1) was searched for extensively in the course of the diploma thesis prior to this doctoral thesis. ${ }^{[6]}$ The resulting three polymorph phases were reinvestigated throughout this work in order to obtain suitable crystals for an experimental electron density study and gain a deeper insight into the polymorph transitions. Additionally, a systematic replacement of the donor molecule was undertaken to find a non-disordered substitute for thf. 


\subsection{Polymorphism of $\left[(\text { thf }) \mathrm{Li}_{2}\left\{\mathrm{H}_{2} \mathrm{CS}\left(\mathrm{N}^{t} \mathrm{Bu}\right)_{2}\right\}\right]_{2}(1)$}

\subsubsection{Basics of Polymorphism}

The term polymorphism refers to the phenomenon that one chemical substance may adopt several different crystal structures at different temperature, pressure or crystallization conditions. This was first described by Mitscherlich for sulfur and potassium carbonate in $1822 .{ }^{[151]}$ The phase diagram of sulfur is shown in Figure 2-2. Other prominent examples of elements and compounds adopting different modifications are carbon (graphite, diamond, fullerenes), barium titanate (cubic or tetragonal) and ice (13 crystalline and 5 amorphous modifications).

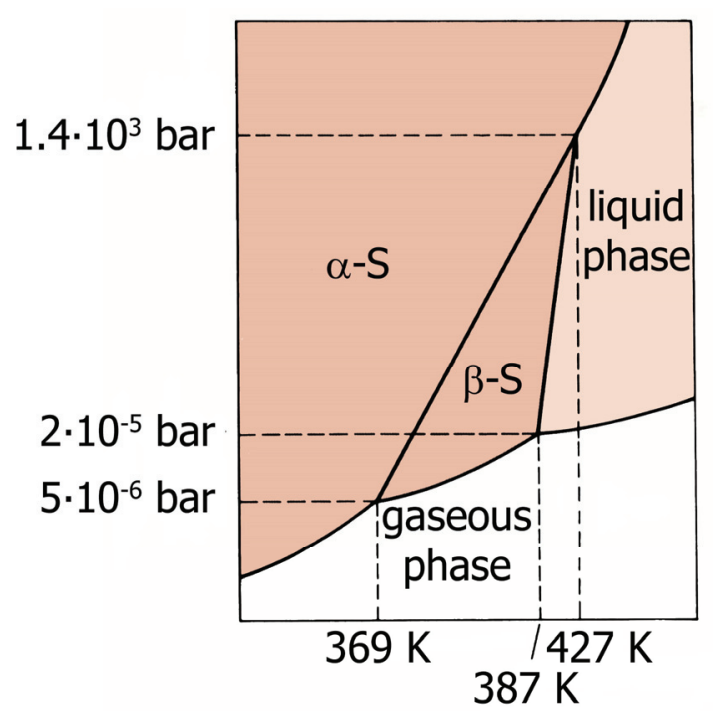

Figure 2-2: Phase diagram of sulfur.

These days the target-oriented synthesis of polymorphs is an important field of pharmacy and biomedicine. The modifications are tailored in a way, that the drugs are optimally absorbed and distributed in the human body. ${ }^{[152]}$ In order to do so, studies have been performed to understand the mechanisms of crystallization. [153] This knowledge can be used to predict the structure of undiscovered modifications to a certain degree. ${ }^{[154]}$ Additionally, the exploration of polymorph phases is important for the synthesis of functional polymers ${ }^{[155]}$ and reactive organometallic species. ${ }^{[156]}$ The existence of different solid phases is due to multiple local minima of the free energy of the crystal. The equilibrium structure adopts the form suitable for the local minimum at the respective conditions. In principle, this leads to a sudden change of the microscopic structure and the macroscopic properties triggered by an infinitesimal change of the thermodynamic parameters at the phase border. However, polymorphs 
are often found outside their equilibrium regions in a metastable state. This is caused by the transformation energy involved with phase transitions and the low mobility of atoms in solid phases. This leads, in certain cases, to infinitely slow transitions. The most prominent example for such a case is diamond. This carbon modification is stable at standard conditions, although graphite is thermodynamically more stable and diamond is formed only at pressures above $6 \cdot 10^{5}$ bar along with temperatures above $1500 \mathrm{~K}$.

The transformation energy responsible for all this is based on the change of direct thermodynamic functions during the phase transition. The modification of entropy $S$, volume $\mathrm{V}$, etc. is connected to a latent heat of transformation by the ClausiusClapeyron equation (Eq. 2-1). Polymorph transitions with such a behavior are called first-order transitions. These are destructive, because the crystal structure changes suddenly.

Eq. 2-1: $\quad \frac{d T}{d p}=\frac{T(\Delta T)}{Q}$

In contrast, for second-order transitions the derivatives of the above-mentioned thermodynamic functions, i.e. the heat capacity $C$, the compressibility $k$, etc., change. This continuous transition allows the crystals to stay intact.

All phase transitions are associated with a change in crystal symmetry. For first-order transitions this change is random. For second-order transitions the space group symmetry of one modification has to be a subgroup of the other. In most cases the symmetry increases with decreasing temperature, but this is not obligatory.

A second way to discriminate phase transitions is by the structural reorganization that occurs. Three types are commonly established, the reconstruction phase transitions, the displacement ones and those of the order-disorder type.

For the first kind of phase transition the crystal structures of the initial and the resulting modification differ essentially. In most cases, the coordination numbers of the atoms change.

If the changes in atomic positions are moderate, a displacement transition is present. In many cases these subtle changes lead to differences in the dipole moment and the ferroelectric properties.

The order-disorder phase transition changes a random arrangement of atoms or molecules into an ordered one. This occurs especially if weak bonds are formed (e.g. hydrogen bonds). 


\subsubsection{Polymorphs of $\left[(\text { thf }) \mathrm{Li}_{2}\left\{\mathrm{H}_{2} \mathrm{CS}\left(\mathrm{N}^{t} \mathrm{Bu}\right)_{2}\right\}\right]_{2}(1)$}

The attempt to obtain crystals suitable for a charge density study of $\left[(\text { thf }) \mathrm{Li}_{2}\left\{\mathrm{H}_{2} \mathrm{CS}\left(\mathrm{N}^{t} \mathrm{Bu}\right)_{2}\right\}\right]_{2}$ (1) resulted in the discovery of three different polymorph phases. Whereas the first polymorph of the literature-known modification ${ }^{[62]}$ was determined by routine X-ray structure analysis, the second was searched for extensively in order to get a non-disordered low-temperature crystalline phase.

The literature-known polymorph 2 can be crystallized from a 2:5 thf $/ n$-hexane mixture at $268 \mathrm{~K}$ over night. The crystals of this monoclinic phase (space group $\mathrm{P} 2{ }_{1} / \mathrm{c}$ ) are of block-like shape and stable to a temperature of $146 \mathrm{~K}$. The unit cell parameters are listed in Table 2-1. One of the thf molecules present in the dimer shows weak signs of a disorder, which was not taken into account during the standard-resolution refinement. Nevertheless, this slight disorder was regarded to be problematic for charge density studies. In order to derive a meaningful charge density, the bond densities need to be deconvoluted from thermal motion. Therefore, the site occupation factors need to be determined very precisely. The analytic tools for charge density determination lack the feature to determine and refine them. Hence, the values determined during the standard refinement with an IAM have to be used. Those values highly correlate with all parameters of the multipole model, which could therefore be seriously affected by errors.

Another modification, which will be referred to as 3 , can be obtained from a $1: 2$ mixture of thf and $n$-hexane at $257 \mathrm{~K}$ after 7 days. The rhombohedral plates are stable between 293 and $128 \mathrm{~K}$ and adopt the triclinic space group $\mathrm{P} \overline{1}$.
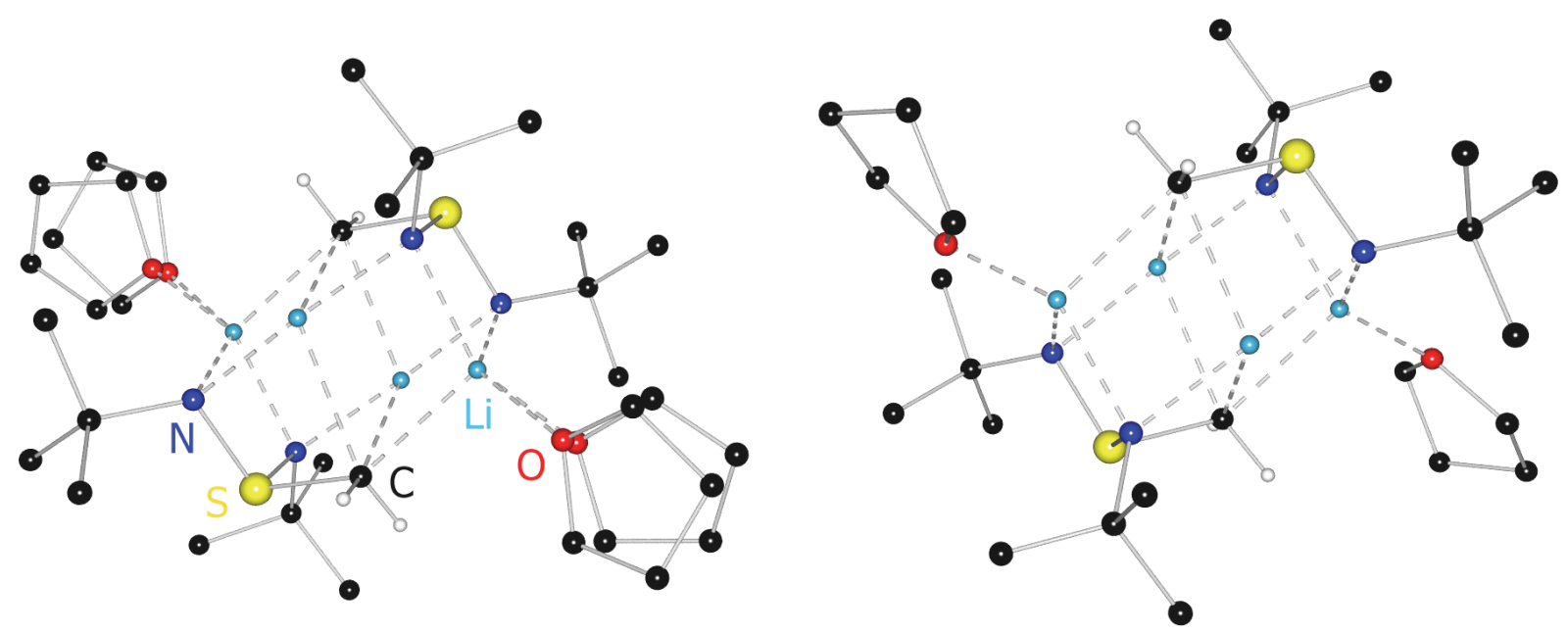

Figure 2-3: Molecular structure, relative orientation and disorder of the molecules in 3. 
The asymmetric unit of $\mathbf{3}$ contains two independent halves of the dimer, one of which shows no disorder while in the second the thf donor molecule is disordered over two sites (cf. Figure 2-3). The site occupation factors refine to 0.54 and 0.46 . For the same reasons already stated for $\mathbf{2}$, this polymorph is not suitable for charge density studies.

Crystallization below $245 \mathrm{~K}$ from a very dilute $4: 1 \mathrm{thf} / n$-hexane mixture leads to needles of the third polymorph 4 . In order to gain high-quality crystals of block shape for charge density studies, the fine needles need to be partially dissolved and batchcrystallized several times (approx. 2 month of crystallization in total). The crystals need to be handled with special care since a phase transition $\mathbf{4} \rightarrow \mathbf{3}$ takes place immediately if the temperature is raised above $245 \mathrm{~K}$. Below a temperature of $120 \mathrm{~K}$ the crystal quality of $\mathbf{4}$ decreases. No signs of disorder were found during standard refinement of this polymorph. The cell constants of the low-temperature polymorph 4 in the orthorhombic space group Pbca are listed in Table 2-1, together with those for the other polymorphs.

Table 2-1: Crystallization parameters and crystal data for the three polymorphs of $\left[\left(t_{h}\right) L_{2}\left\{\mathrm{H}_{2} \mathrm{CS}\left(\mathrm{N}^{t} \mathrm{Bu}\right)_{2}\right\}\right]_{2}(\mathbf{1})$.

\begin{tabular}{l|c|c|c}
\hline polymorph & $\mathbf{2}$ & $\mathbf{3}$ & $\mathbf{4}$ \\
\hline stable temp. range & $173-387 \mathrm{~K}$ & $161-298 \mathrm{~K}$ & $120-245 \mathrm{~K}$ \\
crystallization/ & $268 \mathrm{~K}$ & $257 \mathrm{~K}$ & $245 \mathrm{~K}$ \\
data coll. temp. & $146 \mathrm{~K}$ & $128 \mathrm{~K}$ & $120 \mathrm{~K}$ \\
space group & $\mathrm{P} 2_{1} / \mathrm{c}$ & $\mathrm{P} \overline{1}$ & $\mathrm{Pbca}$ \\
lattice consts. & $9.609(1) / 18.840(4) /$ & $10.509(6) / 11.620(7) /$ & $17.582(1) / 17.531(1) /$ \\
a/b/c $[\AA]$ & $10.080(2)$ & $15.336(9)$ & $22.009(1)$ \\
cell angles $\alpha / \beta / \gamma\left[{ }^{\circ}\right]$ & $90 / 111.06(3) / 90$ & $110.7(1) / 92.4(1) / 91.1(1)$ & $90 / 90 / 90$ \\
cell volume $\left[\AA^{3}\right]$ & $1702.9(6)$ & $1749.6(9)$ & $6783.7(8)$ \\
suitable for charge & no & no & yes \\
density studies & $($ slight $(<10 \%)$ & $(0.54 / 0.46$ thf disorder $)$ & \\
& thf disorder) & & \\
\hline
\end{tabular}

Since the lattice constants $a$ and $b$ are almost equal, it was examined with XPREP ${ }^{[157]}$ if the tetragonal space group $\mathrm{P}_{2}{ }_{2}{ }_{1} 2$ suits the tentative present higher symmetry. However, all quality criteria and the lattice exceptions rule out the tetragonal space group (cf. Scheme 2-2) and the molecule was therefore treated in Pbca. 
Table 2-2: Quality criteria for orthorhombic vs. tetragonal space group assignment of 4.

\begin{tabular}{c|rrrl}
\hline space group & $\mathrm{R}_{\text {sym }}$ & CFOM & $\mathrm{R}_{\text {int }}$ & $\mathrm{R}_{\Sigma}$ \\
\hline Pbca & 0.025 & 1.35 & 0.0308 & 0.0185 \\
$\mathrm{P}_{2}{ }_{2} 2$ & 0.660 & 48.06 & 0.6547 & 0.0927 \\
\hline
\end{tabular}

The observation that the crystals of the polymorph $\mathbf{4}$ suffer at temperatures below $120 \mathrm{~K}$ lead to the assumption that at least one other low-temperature modification is present. Although a wide range of different solvent mixtures (apolar: hexane, pentane, cyclopentane; polar: $\left.\mathrm{THF}, \mathrm{Et}_{2} \mathrm{O}, \mathrm{DABCO}, \mathrm{NEt}_{3}, \mathrm{DEM}, \mathrm{DME}\right)$ and crystallization temperatures $(245 \mathrm{~K}-188 \mathrm{~K})$ were investigated, no other modification could be isolated yet.

\subsubsection{Crystal Structure of $\left[(\text { thf }) \mathrm{Li}_{2}\left\{\mathrm{H}_{2} \mathrm{CS}\left(\mathrm{N}^{t} \mathrm{Bu}\right)_{2}\right\}\right]_{2}(1)$}

In all polymorphs, [(thf) $\left.\mathrm{Li}_{2}\left\{\mathrm{H}_{2} \mathrm{CS}\left(\mathrm{N}^{t} \mathrm{Bu}\right)_{2}\right\}\right]_{2}$ (1) adopts a dimeric structure by formation of an $\mathrm{S}_{2} \mathrm{~N}_{4} \mathrm{C}_{2} \mathrm{Li}_{4}$ double-cube (cf. Figure 2-4). The two cubes are fused by a common $\mathrm{Li}_{2} \mathrm{C}_{2}$-face. The four ${ }^{t} \mathrm{Bu}$ groups and the two thf donor molecules are bonded to the edges of the double-cube.

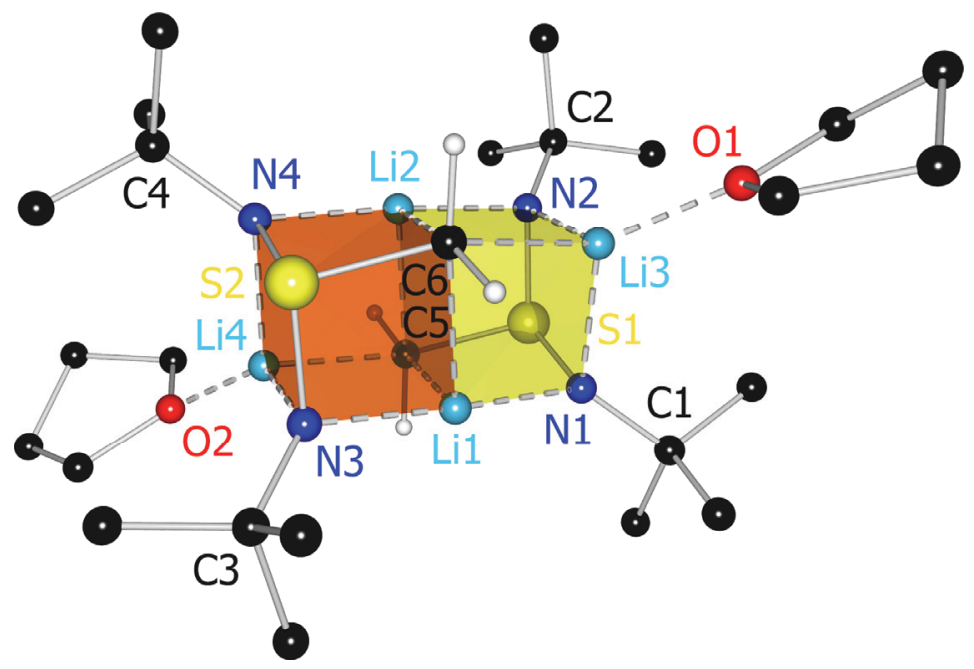

Figure 2-4: Molecular structure and double-cube motif of $\left[(\operatorname{thf}) \mathrm{Li}_{2}\left[\mathrm{H}_{2} \mathrm{CS}\left(\mathrm{N}^{t} \mathrm{Bu}\right)_{2}\right\}\right]_{2}(4)$.

The structures of aza and carba sulfites are mainly determined by the preferred environment of the heteroatoms. ${ }^{[62]}$ Thus, the nitrogen atoms in 1 are coordinated tetrahedrally by one trivalent sulfur(IV) atom, one tertiary carbon atom, and two lithium atoms. The ylidic carbon atoms, in contrast, adopt an octahedral coordination 
polyhedron, made up of three lithium atoms, one sulfur and two hydrogen atoms. This leads to the formation of the double-cube. In addition, this is the only way to establish a structural motif well-known throughout organolithium chemistry, the carbanion-capped $\mathrm{Li}_{3}$-triangle (cf. Figure 2-5). ${ }^{[83,109]}$ Any other dimerization (e.g. the formation of an $\mathrm{Li}_{4}$-tetrahedron as in $(\mathrm{MeLi})_{4}$ ) would result in two $\mathrm{Li}_{3}$-faces which lack coordination by a carbanion, as the two carbanions present can only coordinate one of the four $\mathrm{Li}_{3}$-faces each. All lithium atoms in $\left[(\text { thf }) \mathrm{Li}_{2}\left\{\mathrm{H}_{2} \mathrm{CS}\left(\mathrm{N}^{t} \mathrm{Bu}\right)_{2}\right\}\right]_{2}(1)$ have a fourfold coordination sphere. The faint lines between the lithium atoms in all figures do not correspond to any kind of bonding but are used to highlight the $\mathrm{Li}_{3} \mathrm{C}$ motif (cf. Figure 2-5b). The two lithium atoms of the common $\mathrm{Li}_{2} \mathrm{C}_{2}$-face are coordinated by the two anionic carbon atoms and by one nitrogen atom of each $\mathrm{SN}_{2}$-unit. The other two lithium atoms reside in diagonal opposite corners of the double-cube. Therefore, based on the geometrical data, they only form three bonds within the cube (to two nitrogen atoms of one $\mathrm{SN}_{2}$-unit and the carbanionic carbon atom of the other half of the dimer). The apical coordination site is occupied by an oxygen atom of a thf donor molecule.

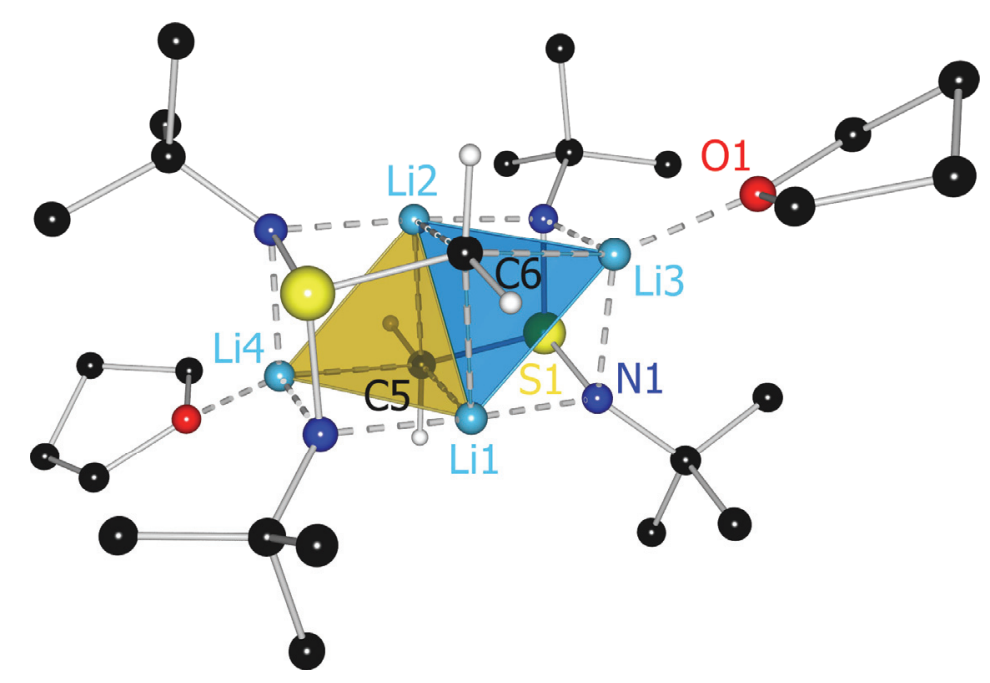

(a)

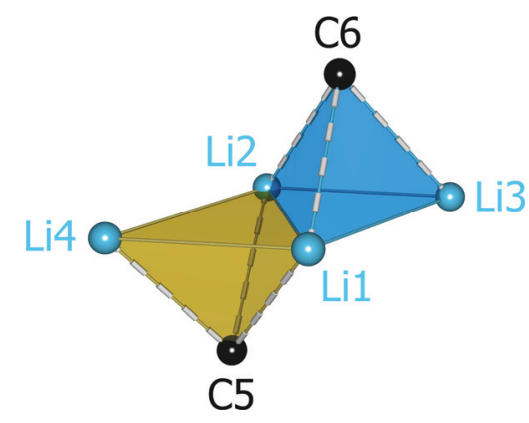

(b)

Figure 2-5: (a) $\mathrm{Li}_{3} \mathrm{C}$-motifs in $\left[(\text { thf }) \mathrm{Li}_{2}\left\{\mathrm{H}_{2} \mathrm{CS}\left(\mathrm{N}^{t} \mathrm{Bu}\right)_{2}\right\}\right]_{2}(4)$, (b) extracted $\mathrm{Li}_{3} \mathrm{C}$ fragments.

The structure of the dimer is very similar in all polymorphs of $\left[(\text { thf }) \mathrm{Li}_{2}\left\{\mathrm{H}_{2} \mathrm{CS}\left(\mathrm{N}^{t} \mathrm{Bu}\right)_{2}\right\}\right]_{2}$ (1) as can be seen from a superpositional plot of the molecules (cf. Figure 2-6). The central part of the double-cube is very rigid and even the ${ }^{t} \mathrm{Bu}$-groups do not rotate significantly since they adopt a sterically ideal staggered arrangement with respect to the three in-cube bonds of the pivotal nitrogen atom 
(one S-N, two Li-N bonds). The only structural degree of freedom therefore is the torsion of the thf molecules. Because of this similarity, only the structural features of the low-temperature modification 4 will be discussed. Additionally, both cubes of the dimer are almost equal in 2, 3, and $\mathbf{4}$ and only the thf carbon atoms do not fit the non-crystallographic center of inversion in the middle of the double-cube. For this reason, the discussion will be limited to one half of the dimer.

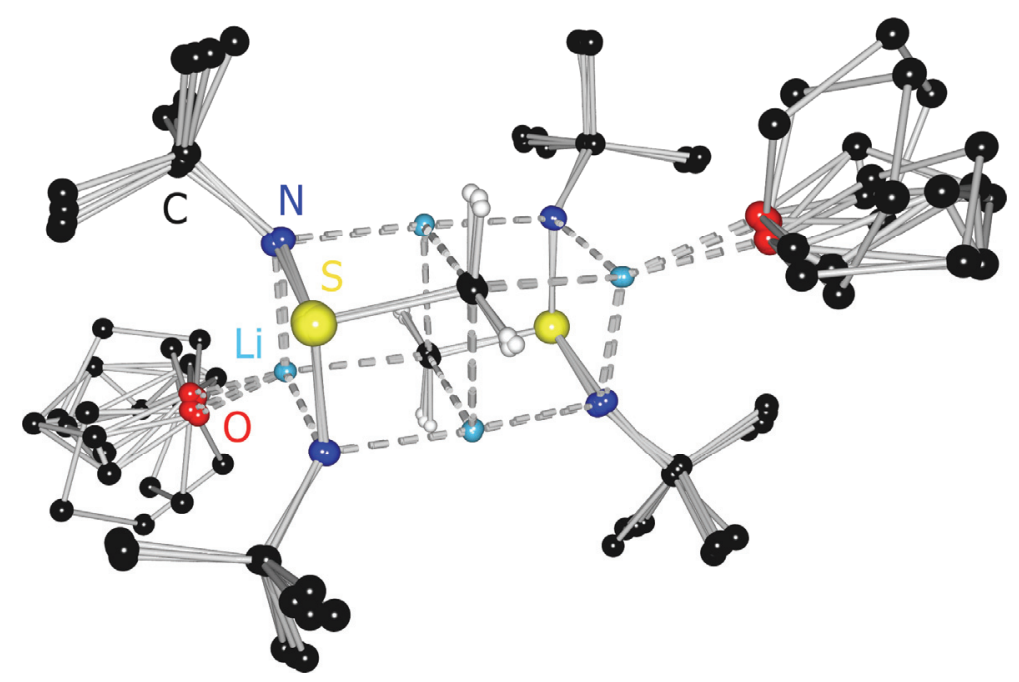

Figure 2-6: Superposition of all [(thf) $\left.\mathrm{Li}_{2}\left\{\mathrm{H}_{2} \mathrm{CS}(\mathrm{NtBu})_{2}\right\}\right]_{2}$ dimers in the polymorphs $\mathbf{2}, \mathbf{3}$, and $\mathbf{4}$ including all positions of the disordered thf molecules.

The S-N bond lengths in $\left[(\text { thf }) \mathrm{Li}_{2}\left\{\mathrm{H}_{2} \mathrm{CS}\left(\mathrm{N}^{t} \mathrm{Bu}\right)_{2}\right\}\right]_{2}(2-4)$ are almost equal (1.6487(4) and 1.6561(4) $\AA$, cf. Table 2-3) and in the range reported for similar compounds, like $\mathrm{S}(\mathrm{NR})_{3}{ }^{2-}$ and $\mathrm{RS}(\mathrm{NR})_{2}{ }^{-[52-55,62,158,159]}$ It is worthy to note that the $\mathrm{N}-\mathrm{Li}$ bond lengths differ significantly. While N1 forms contacts of $1.9822(8)$ and 2.1047(9) $\AA$ to Li1 and Li3, respectively, the N2-Li bonds are 2.0085(9) (Li2) and 2.0589(9) $\AA$ (Li3) in length. Nevertheless, the contact to the lithium atom in the corner of the cube ( $\mathrm{Li3}$ ) is longer to both nitrogen atoms. The S-C bonds are 1.7803(4) $\AA$ long and therefore only slightly below the range typically quoted for alkyl diimido sulfinates ${ }^{[52-55,158,159]}$ and alkyl triimido sulfonates ${ }^{[56,92]}(1.79-1.81 \AA)$.

Table 2-3: Selected bond lengths $[\AA]$ and angles $\left[^{\circ}\right]$ in $\left[(\text { thf }) \mathrm{Li}_{2}\left\{\mathrm{H}_{2} \mathrm{CS}\left(\mathrm{N}^{t} \mathrm{Bu}\right)_{2}\right\}\right]_{2}(4)$.

\begin{tabular}{ll}
\hline S1-N1 & $1.6487(4)$ \\
S1-N2 & $1.6561(4)$ \\
S1-C5 & $1.7803(4)$ \\
Li1-C5 & $2.4013(9)$ \\
Li2-C5 & $2.3829(9)$ \\
Li4-C5 & $2.2753(8)$ \\
\hline
\end{tabular}

\begin{tabular}{ll}
\hline Li1-N1 & $1.9822(8)$ \\
Li3-N1 & $2.1047(9)$ \\
Li2-N2 & $2.0085(9)$ \\
Li3-N2 & $2.0589(9)$ \\
Li3-O1 & $1.9472(9)$ \\
\hline
\end{tabular}

\begin{tabular}{lr}
\hline N1-S1-N2 & $103.97(2)$ \\
N1-S1-C5 & $99.30(2)$ \\
N1-Li3-N2 & $77.40(3)$ \\
N1-Li1-C5 & $72.52(3)$ \\
Li1-C5-Li2 & $69.19(3)$ \\
C5-Li1-C6 & $109.95(3)$ \\
\hline
\end{tabular}


$\mathrm{Li} 1, \mathrm{Li} 2$, and $\mathrm{Li} 4$ form an isosceles triangle. The $\mathrm{Li} 1 \cdots \mathrm{Li} 2$ distance in the common face of the double-cube is considerably longer $(2.7162(11) \AA)$ than the $\mathrm{Li} \cdots \mathrm{Li}$ distances including Li4 (2.6315(11) and 2.6496(11) $\AA$ ). Although the carbanion $\mu_{3}$ caps the $\mathrm{Li}_{3}$ triangle, not all $\mathrm{Li}-\mathrm{C}$ bond distances are equal. $\mathrm{C} 5-\mathrm{Li} 4$ is about $0.11 \AA$ shorter than the other two Li-C contacts (2.3829(9) and 2.40131(9) $\AA$ ). Thus, the carbanion is shifted away from the hypotenuses closer to the tip of the isosceles $\mathrm{Li}_{3}$ triangle, which makes the bond to Li4 the preferred coordination. This effect was also observed in the hexameric structure of $\left.\left[{ }^{t} \mathrm{BuLi}\right)_{6}\right]{ }^{[109]}$

\subsubsection{Determination of the Type of the Polymorph Transitions}

Attemptring to characterize the polymorph transitions, a displacement transition type (compared to reconstruction or order-disorder transition types) can be assigned due to the fact that most atomic positions stay constant (only the thf carbon atoms shift as already mentioned, cf. Figure 2-6). ${ }^{[160]}$

The transitions presented here are of first order; $\mathrm{P} 2{ }_{1} / \mathrm{C}$ is not a subgroup of $\mathrm{Pbca}$ and all transitions are destructive. During these phase transitions superheating/cooling takes place.

The transformation energies of the transitions were determined by DSC (differential scanning calorimetry) to be exothermic from 2 to $3(-280.1 \mathrm{~J} / \mathrm{mol})$ and also from 3 to $4(-185.1 \mathrm{~J} / \mathrm{mol})$. The figures given should be handled with caution because a low-temperature standard (below $173 \mathrm{~K}$ ) was not available. Nevertheless, the exothermic behavior is doubtless. Due to the energies involved in the phase transitions and the low mobility of atoms in crystals, the phases are metastable at temperatures other than their crystallization (cf. stable temperature ranges stated in Table 2-1).

\subsection{Donor Base Exchange on $\left[(\text { thf }) \mathrm{Li}_{2}\left\{\mathrm{H}_{2} \mathrm{CS}\left(\mathrm{N}^{t} \mathrm{Bu}\right)_{2}\right\}\right]_{2}(1)$}

In addition to attempts to grow crystals of $\left[(\text { thf }) \mathrm{Li}_{2}\left\{\mathrm{H}_{2} \mathrm{CS}\left(\mathrm{N}^{t} \mathrm{Bu}\right)_{2}\right\}\right]_{2}(\mathbf{1})$ of suitable size and quality, another strategy was employed to enable an experimental electron density study on a polyimido sulfur ylide. It was examined if other donors than thf would coordinate the lithium atoms without disorder. As mentioned above, the ${ }^{t} \mathrm{Bu}$ groups of the double-cube in 1 adopt a staggered arrangement in relation to the 
bonds to their pivotal nitrogen atom within the cube (cf. Figure 2-7), which fixes the positions of all ${ }^{t} \mathrm{Bu}$ groups in all polymorphs.

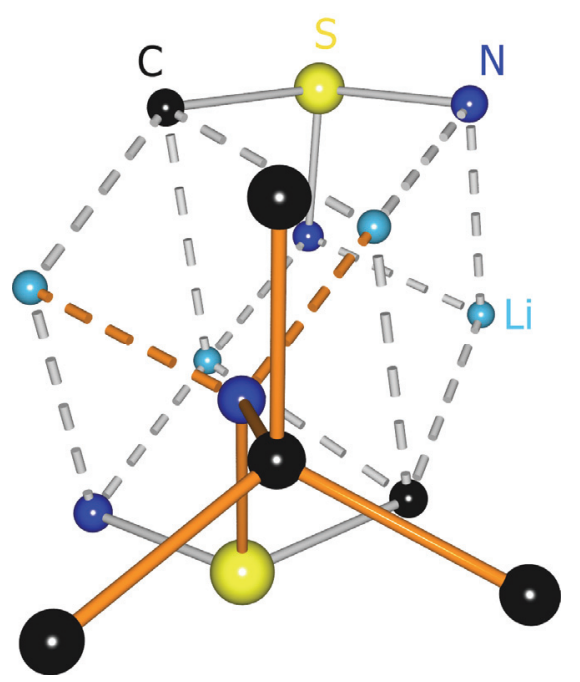

Figure 2-7: Staggered arrangement of the ${ }^{t} \mathrm{Bu}$ groups in respect to the corners of the double-cube.

In order to mimic this situation for the donor molecules and avoid disorder, donors with local threefold symmetry were employed. Attempts with triethylamine, 1,4-diazabicyclo[2.2.2]octane, and N,N',N"-trialkyl-1,4,7-triazacyclononane were dissatisfactory as no exchange of thf even at high nitrogen donor concentrations occurred. This is probably due to the superior donor capacity of thf, which will be explained later. In order to avoid thf, the syntheses of the compounds were performed directly in the donor solvents with threefold symmetry. No reaction occurred for all of the mentioned solvents. Even the addition of methyl lithium to the sulfur diimide $\mathrm{S}\left(\mathrm{N}^{t} \mathrm{Bu}\right)_{2}$ was not possible in these solvents.

This is obviously due to the low donor capacity of the nitrogen atoms involved, as the reaction has also been conducted successfully in diethyl ether. ${ }^{[61]}$ Although the diethyl ether molecule in $\left[\left(\mathrm{Et}_{2} \mathrm{O}\right) \mathrm{Li}_{2}\left\{\mathrm{H}_{2} \mathrm{CS}\left(\mathrm{N}^{t} \mathrm{Bu}\right)_{2}\right\}\right]_{2}$ is disordered, several other oxygen donors were employed to obtain non-disordered compounds. Diethoxy methane seemed to be an promising candidate, as $\left[(\mathrm{dem}) \mathrm{Li}_{4}\left\{\mathrm{H}_{2} \mathrm{CS}\left(\mathrm{N}^{t} \mathrm{Bu}\right)\left(\mathrm{NSiMe}_{3}\right)\right\}_{2}\right]_{n}$ shows no disorder of the dem donor connecting the double-cubes to chains of a coordination polymer. ${ }^{[64]}$ This complex, however, is not suitable for experimental electron density determinations as the ${ }^{t} \mathrm{Bu}$ and $\mathrm{SiMe}_{3}$ groups are disordered over their mutual positions.

A simple exchange of the thf donor against any other oxygen donor was similarly unsuccessful as for the nitrogen donors. Thus, di-tert.-butyl sulfur diimide $S\left(N^{t} B u\right)_{2}$ was reacted directly with two equivalents of methyl lithium in dem (cf. Scheme 2-5). 


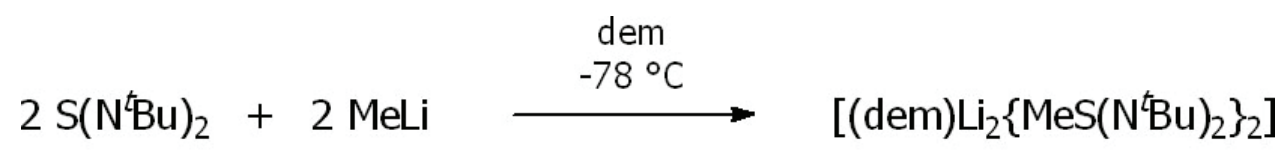

5

Scheme 2-5: Synthesis of $\left[(\mathrm{dem}) \mathrm{Li}_{2}\left\{\mathrm{MeS}\left(\mathrm{N}^{t} \mathrm{Bu}\right)_{2}\right\}_{2}\right](5)$.

Astonishingly, this does not lead to the formation of the ylide, like for $\left[(\text { thf }) \mathrm{Li}_{2}\left\{\mathrm{H}_{2} \mathrm{CS}\left(\mathrm{N}^{t} \mathrm{Bu}\right)_{2}\right\}\right]_{2}(1)$ and $\left[(\mathrm{dem}) \mathrm{Li}_{4}\left\{\mathrm{H}_{2} \mathrm{CS}\left(\mathrm{N}^{t} \mathrm{Bu}\right)\left(\mathrm{NSiMe}_{3}\right)\right\}_{2}\right]_{\mathrm{n}}$. Instead, methyl lithium is only added to the diimide, no deprotonation occurs and the alkyl diimido sulfinate $\left[(\mathrm{dem}) \mathrm{Li}_{2}\left\{\mathrm{MeS}\left(\mathrm{N}^{t} \mathrm{Bu}\right)_{2}\right\}_{2}\right](5)$ can be isolated and crystallized. [(dem)Li $\left.\mathrm{i}_{2}\left\{\mathrm{MeS}\left(\mathrm{N}^{t} \mathrm{Bu}\right)_{2}\right\}_{2}\right](5)$ adopts one of the eight known structural motifs for alkyl diimido sulfinates (cf. Scheme 2-6f).

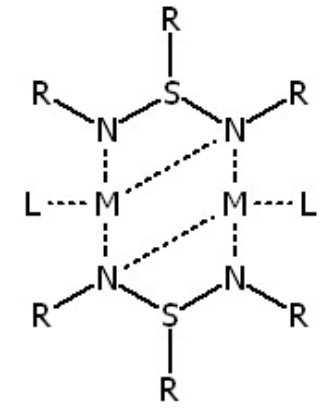

(a)

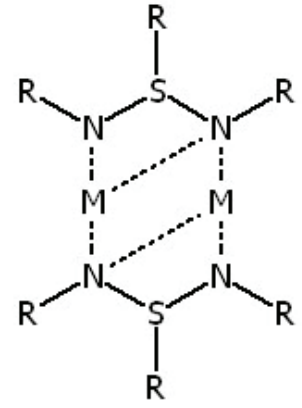

(b)<smiles>[R][R]1N([R])N([R])[Y1]([R])N([R])[Si]([R])N1[R]</smiles>

(c)

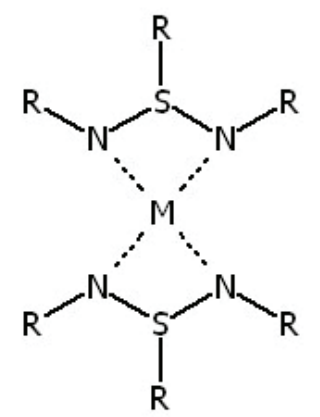

(d)

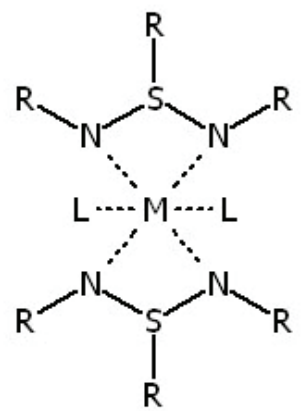

(e)

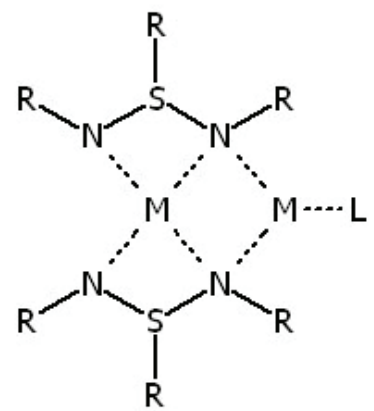

(f)<smiles>[R]N1[Si]([R])N([Y])[Y]1([Z])[H]</smiles>

(g)<smiles>[R]N1[SH]([R])N([R])[N+]1(I)[Y](I)(I)O[Si]1([R])N([R])N1[R]</smiles>

(h)

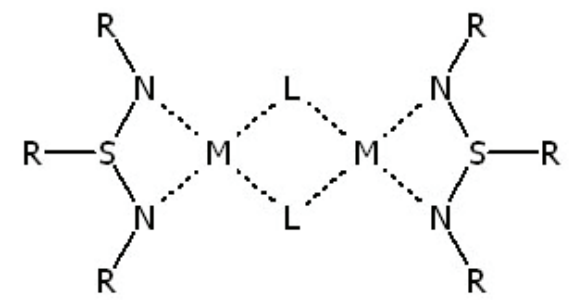

(i)

Scheme 2-6: Structural motifs known for alkyl diimido sulfinates. 
One lithium atom of the dimer is coordinated by all nitrogen atoms, while the other one is only coordinated by one nitrogen atom of each anion. The latter lithium atom is additionally coordinated by one oxygen atom of the dem donor molecule. Interestingly, the second oxygen atom is not involved in any coordination (cf. Figure 2-8). None of the known crystal structures containing $\mathrm{Li}-\mathrm{O}_{\text {dem }}$ contacts show this behavior, the second lithium atom is always involved in a metal coordination. No bridging of two dimer units and no formation of a coordination polymer occurs. A similar separation of the dimer unit can be observed for $\left[(\mathrm{dme}) \mathrm{Li}_{2}\left\{\mathrm{PhS}\left(\mathrm{NSiMe}_{3}\right)_{2}\right\}_{2}\right],{ }^{[55]}$ although dme acts as a chelating ligand in this molecule.

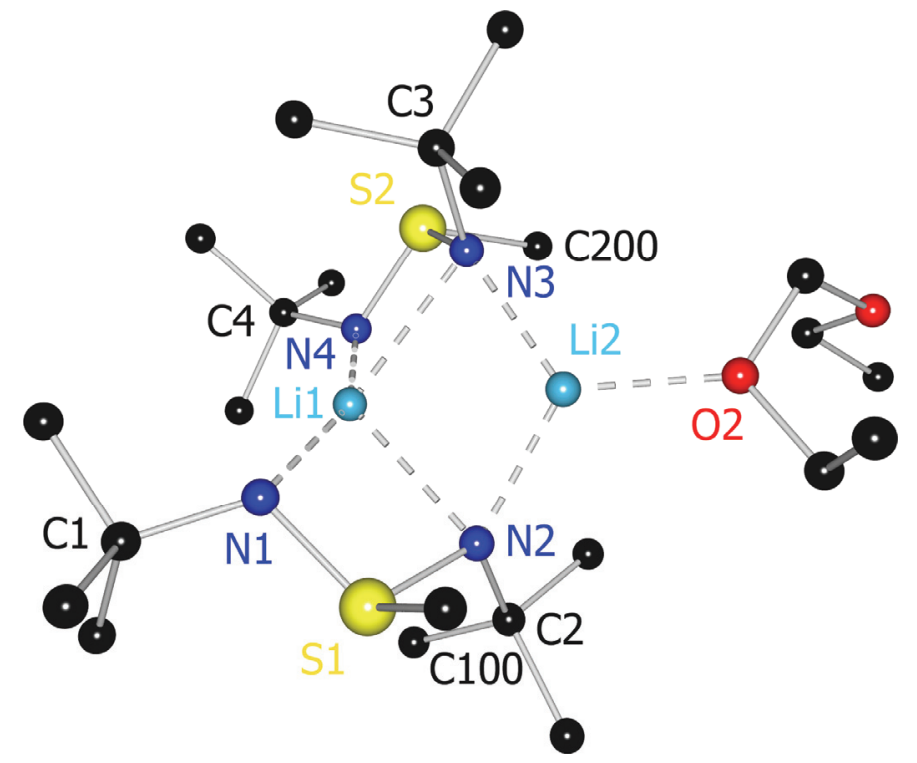

Figure 2-8: Molecular structure of $\left[(\mathrm{dem}) \mathrm{Li}_{2}\left\{\mathrm{MeS}\left(\mathrm{N}^{t} \mathrm{Bu}\right)_{2}\right\}_{2}\right](\mathbf{5})$.

All bond lengths and angles are quite similar to those of the literature-known compounds of the formula $\left[(\mathrm{do}) \mathrm{Li}_{2}\left\{\mathrm{PhS}\left(\mathrm{NSiMe}_{3}\right)(\mathrm{NR})\right\}_{2}\right.$ (do $=\mathrm{Et}_{2} \mathrm{O}, \mathrm{dme} ; \mathrm{R}=\mathrm{SiMe}_{3}$, $\left.{ }^{t} \mathrm{Bu},{ }^{c} \mathrm{Hex}\right) \cdot{ }^{[54,55]}$ The $\mathrm{Li}-\mathrm{O}$ bond distance $(1.946(2) \AA)$ is closer to the range reported for $\mathrm{Li}-\mathrm{O}_{\mathrm{Et}} \mathrm{O}(1.897-1.941 \AA)$, than to that for $\mathrm{Li}-\mathrm{O}_{\mathrm{dme}}(2.369-2.417 \AA)$. The bond lengths and angles in $\mathbf{5}$ nearly show mirror symmetry relative to Li1-Li2-O2. This symmetry is clearly broken by the dem donor and the orientation of the alkyl groups. Thus, different from the other representatives of the structural motif $f$ in Scheme 2-6, 5 does not adopt mirror-symmetry.

The two $\mathrm{SN}_{2}$ units are tilted by $78.7^{\circ}$ with respect to each other and the methyl groups reside on opposite sites of the $\mathrm{SN}_{2}$ planes. Thus, the steric strain between the tert.-butyl groups is minimized. Apart from the tilting, the two units of the dimer are equal in all bond distances and angles (cf. Table 2-4). 
The coordination of the lithium atoms is asymmetric. Li1 has four coordinative contacts, Li2 only three. The low coordination number of Li2 is in part responsible for the short Li-O contact (1.946(2) $\AA$ ). The bonds Li1-N1 and Li1-N4 (1.983(2) and $1.974(2) \AA$ ) are slightly shorter than the nitrogen contacts of Li2 (Li2-N2 2.000(2) and Li2-N3 1.991(2) $\AA$ ). This is due to the different coordinative situation at the nitrogen atoms. While N1 and N4 coordinate only one lithium atom (Li1), N3 and N2 show contacts to both lithium atoms. The contacts of N3 and N2 to Li1 are on av. $0.255 \AA$ longer than to Li2, thus the nitrogen atoms favor the lithium atom with the lower coordination number.

Table 2-4: Selected bond lengths $[\AA]$ and angles $\left[^{\circ}\right]$ in $\left[(\operatorname{dem}) \mathrm{Li}_{2}\left\{\mathrm{MeS}\left(\mathrm{N}^{t} \mathrm{Bu}\right)_{2}\right\}_{2}\right](\mathbf{5})$.

\begin{tabular}{|c|c|c|c|c|c|}
\hline S1-N1 & $1.6157(9)$ & Li1-N1 & $1.983(2)$ & $\mathrm{N} 1-\mathrm{S} 1-\mathrm{N} 2$ & $103.30(5)$ \\
\hline S1-N2 & $1.6362(9)$ & Li1-N2 & $2.239(2)$ & N3-S2-N4 & $103.43(5)$ \\
\hline S2-N3 & $1.6149(9)$ & Li1-N3 & $2.262(2)$ & N1-S1-C100 & $105.81(6)$ \\
\hline S2-N4 & $1.6361(10)$ & Li1-N4 & $1.974(2)$ & N2-S1-C100 & $100.39(6)$ \\
\hline S1-C100 & $1.8092(13)$ & Li2-N2 & $2.000(2)$ & N1-Li1-N2 & $74.04(7)$ \\
\hline \multirow[t]{3}{*}{ S2-C200 } & $1.8062(13)$ & Li2-N3 & $1.991(2)$ & N3-Li1-N4 & $73.73(7)$ \\
\hline & & Li2-O2 & $1.946(2)$ & N2-Li1-N3 & $97.33(9)$ \\
\hline & & & & N2-Li2-N3 & $115.78(11)$ \\
\hline
\end{tabular}

Although, direct reaction of $S\left(N^{t} B u\right)_{2}$ with two equivalents methyl lithium in dem does not yield the diimido sulfur ylide, $\mathbf{5}$ can be deprotonated with methyl lithium in dem to obtain $\left[(\mathrm{dem}) \mathrm{Li}_{4}\left\{\mathrm{H}_{2} \mathrm{CS}\left(\mathrm{N}^{t} \mathrm{Bu}\right)_{2}\right\}_{2}\right]_{\mathrm{n}}(\mathbf{6})$ (cf. Scheme 2-5). Crystals of 6 can be obtained from a thf $/ n$-hexane mixture at $-24^{\circ} \mathrm{C}$.

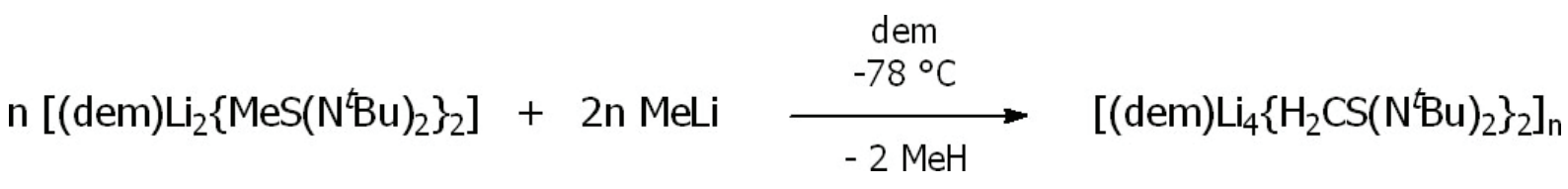

Scheme 2-7: Synthesis of $\left[(\mathrm{dem}) \mathrm{Li}_{4}\left\{\mathrm{H}_{2} \mathrm{CS}\left(\mathrm{N}^{t} \mathrm{Bu}\right)_{2}\right\}_{2}\right]_{\mathrm{n}}(\mathbf{6})$.

The sulfur ylide 6 forms a double-cube dimer in the crystal similar to all literatureknown diimido sulfur ylides. ${ }^{[61-64]}$ In contrast to those, but similar to $\left[(\mathrm{dem}) \mathrm{Li}_{4}\left\{\mathrm{H}_{2} \mathrm{CS}\left(\mathrm{N}^{t} \mathrm{Bu}\right)\left(\mathrm{NSiMe}_{3}\right)\right\}_{2}\right]$, the double-cubes in the new compound are bridged by the dem donor and thus form a coordination polymer (cf. Figure 2-9). 


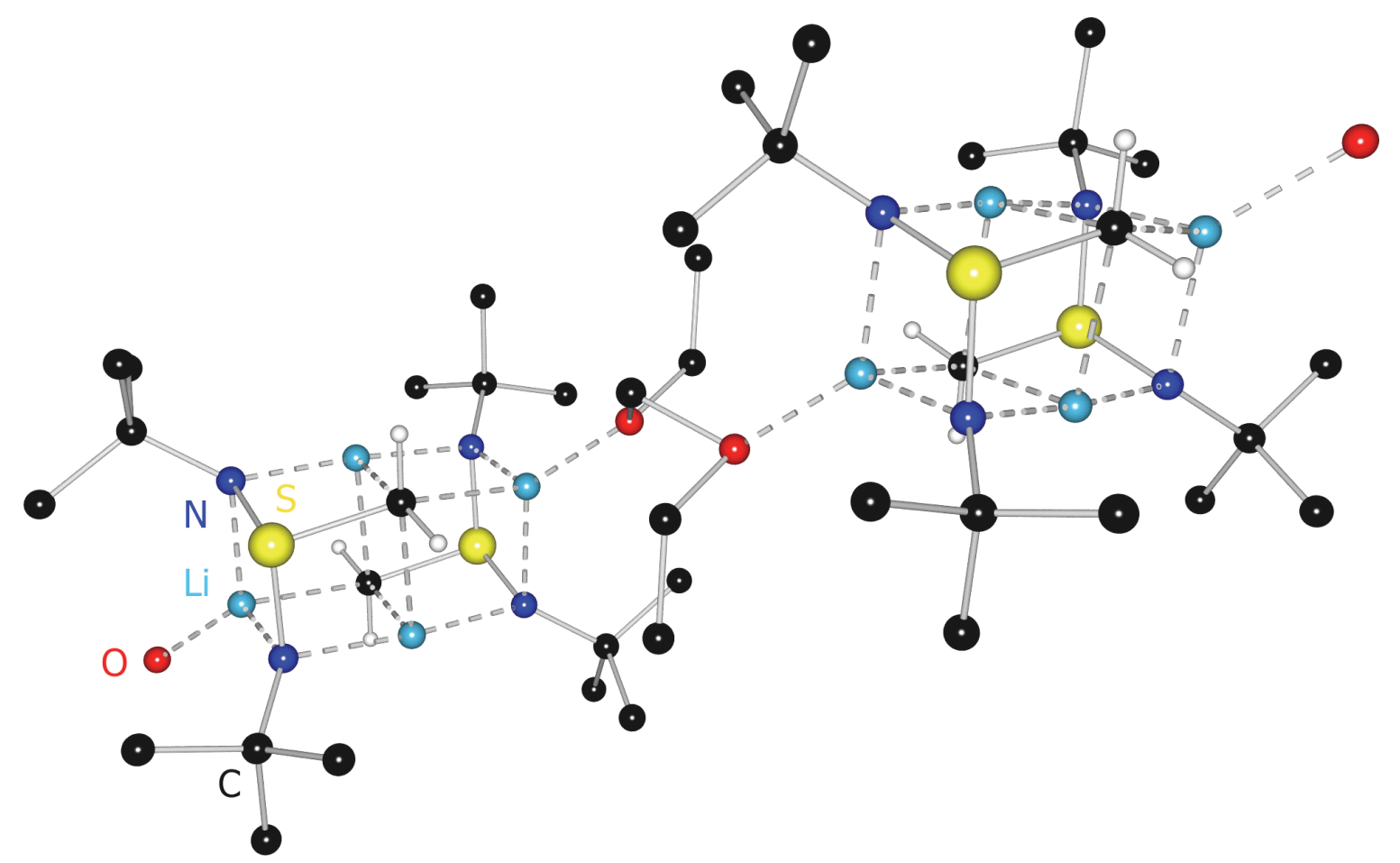

Figure 2-9: Polymeric strain of $\left[(\mathrm{dem}) \mathrm{Li}_{4}\left\{\mathrm{H}_{2} \mathrm{CS}\left(\mathrm{N}^{t} \mathrm{Bu}\right)_{2}\right\}_{2}\right]_{\mathrm{n}}(6)$.

[(dem) $\left.L i_{4}\left\{\mathrm{H}_{2} \mathrm{CS}\left(\mathrm{N}^{t} \mathrm{Bu}\right)_{2}\right\}_{2}\right]_{n}$ (6) shows similar bond lengths and angles compared to known diimido sulfur ylides, especially $\left[(\text { thf }) L_{2}\left\{\mathrm{H}_{2} \mathrm{CS}\left(\mathrm{N}^{t} \mathrm{Bu}\right)_{2}\right\}\right]_{2}(1)$ and $\left[(\text { thf }) \mathrm{Li}_{2}\left\{\mathrm{H}_{2} \mathrm{CS}\left(\mathrm{N}^{t} \mathrm{Bu}\right)\left(\mathrm{NSiMe}_{3}\right)\right\}\right]_{2}$. Only the $\mathrm{Li}-\mathrm{C}$ bond lengths in the central $\mathrm{Li}_{2} \mathrm{C}_{2}$ face show a broader diversity. The Li2-C1 contact $(2.322(3) \AA)$ is shorter than the comparable ones in the reference compounds (2.330-2.385 $\AA$ ), while the situation is contrary for Li2-C1A (2.444(3) $\AA$ vs. 2.373-2.441 $\AA$ ). Thus the favored coordination of one lithium atom by each carbon atom is more prominent in 6 .

Table 2-5: Selected bond lengths $[\AA]$ and angles $\left[{ }^{\circ}\right]$ in $\left[(\operatorname{dem}) \mathrm{Li}_{4}\left\{\mathrm{H}_{2} \mathrm{CS}\left(\mathrm{N}^{t} \mathrm{Bu}\right)_{2}\right\}_{2}\right]_{\mathrm{n}}(6)$.

\begin{tabular}{|c|c|c|c|c|c|}
\hline $\mathrm{S} 1-\mathrm{N} 1$ & $1.6543(10)$ & Li1-N1 & $2.118(3)$ & $\mathrm{N} 1-\mathrm{S} 1-\mathrm{N} 2$ & $104.48(5)$ \\
\hline S1-N2 & $1.6606(10)$ & Li1-N2 & $2.045(2)$ & $\mathrm{N} 1-\mathrm{S} 1-\mathrm{C} 1$ & $99.06(5)$ \\
\hline $\mathrm{S} 1-\mathrm{C} 1$ & $1.7848(12)$ & Li2-N1 & $1.989(2)$ & N1-Li1-N2 & 77.99(9) \\
\hline Li1A-C1 & $2.271(3)$ & Li2A-N2 & $2.030(2)$ & N1-Li2-C1 & $74.34(8)$ \\
\hline Li2-C1 & $2.322(3)$ & Li1-O1 & $2.007(2)$ & Li2-C1-Li2A & $70.64(9)$ \\
\hline Li2A-C1 & $2.444(3)$ & & & C1-Li2-C1A & 109.37(9) \\
\hline
\end{tabular}

Although, the dem molecules are fixed by coordination of the two oxygen atoms to one lithium atom each, the carbon atoms are still disordered over two positions (cf. Figure 2-10). 


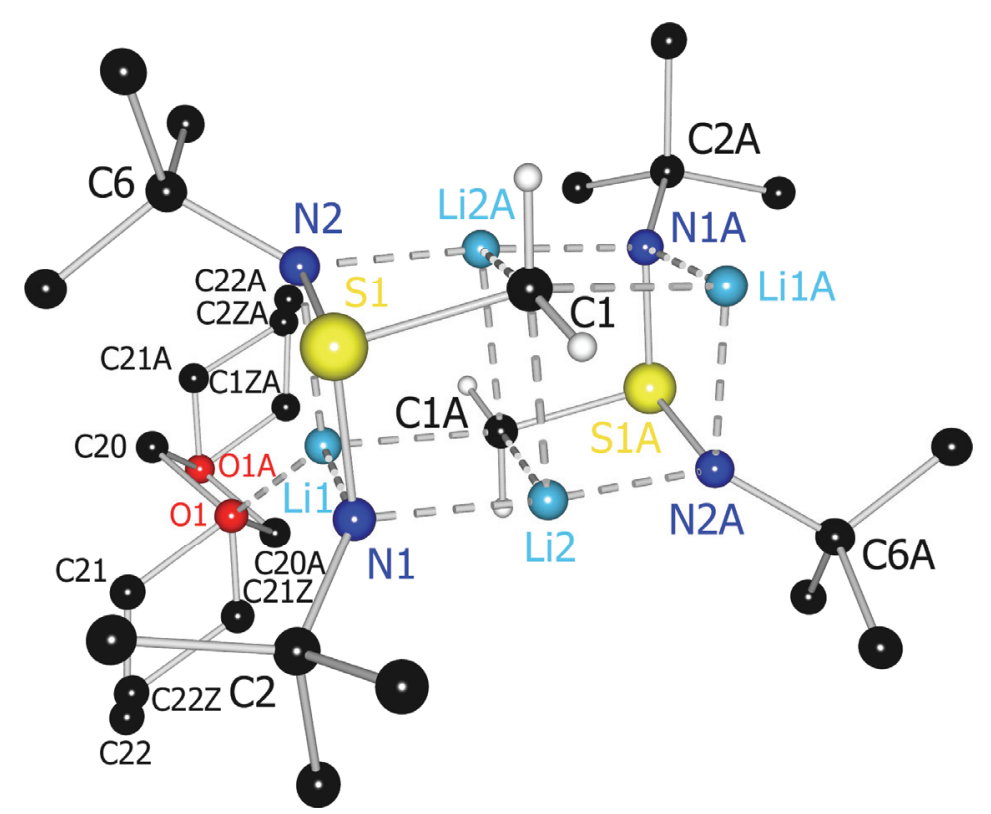

Figure 2-10: Disorder and labeling scheme in $\left[(\operatorname{dem}) \mathrm{Li}_{4}\left\{\mathrm{H}_{2} \mathrm{CS}\left(\mathrm{N}^{t} \mathrm{Bu}\right)_{2}\right\}_{2}\right]_{n}(6)$.

Again, the disorder renders 6 as unsuitable for an experimental electron density study. Thus, the crystals of the low-temperature polymorph of $\left[(\text { thf }) \mathrm{Li}_{2}\left\{\mathrm{H}_{2} \mathrm{CS}\left(\mathrm{N}^{t} \mathrm{Bu}\right)_{2}\right\}\right]_{2}$ (4) needed to be employed in the high-order X-ray diffraction experiment.

\subsection{Data Collection and Processing}

\subsubsection{Preliminary Studies at a Synchrotron (HASYLAB at the DESY)}

The low-temperature polymorph $\left[(\text { thf }) \mathrm{Li}_{2}\left\{\mathrm{H}_{2} \mathrm{CS}\left(\mathrm{N}^{t} \mathrm{Bu}\right)_{2}\right\}\right]_{2}$ (4) seemed to be a suitable candidate for a high angle diffraction experiment and subsequent multipole refinement, as mentioned above.

However, the small size of the crystals and the needle-like shape made a measurement on a standard sealed tube diffractometer impossible. Our tests with MoK $(\alpha)$ radiation $(\lambda=0.71073 \AA)$ from a Siemens sealed tube on a Bruker D8 three-circle goniometer equipped with an APEXI detector were unsatisfactory. Reflections could only be recorded up to the modest resolution of $(\sin \theta / \lambda)_{\max }=0.652 \AA^{-1}$, due to the strong decrease of reflection intensity with the diffraction angle. ${ }^{[161]}$ This is only slightly above the requirement for a standard structure determination $\left((\sin \theta / \lambda)_{\max }=0.63 \AA^{-1}\right)$.

High-order data of at least $(\sin \theta / \lambda)_{\max }=1.00 \AA^{-1}$ is needed for a multipole refinement. ${ }^{[162]}$ The reflections at high diffraction angles $\left(\sin \theta / \lambda \geq 0.80 \AA^{-1}\right)$ are less 
influenced by the diffuse bond densities and give rise to bias-free atomic positions. ${ }^{[163]}$ Furthermore, the additional reflections are vital to get a satisfactory data-to-parameter ratio for the multipole refinement (vide infra).

As a consequence, we tried to gain access to more intense $X$-ray sources. The beamline D3 at the HASYLAB of the DESY in Hamburg was our first choice. Two problems were to be solved prior to the experiments: I) The crystals need to be kept at below $-30{ }^{\circ} \mathrm{C}$ during transport due to the polymorph transition at $-28{ }^{\circ} \mathrm{C}$ and II) a mounting facility with inert gas supply was missing at D3. The first problem was countered by transporting the crystals in mother liquor in Schlenk flasks put on dry ice. The second one was solved by construction of a small portable mounting facility, where a Schlenk line with vacuum pump and inert gas supply, together with a polarization microscope and an X-TEMP2 (low-temperature table-top nitrogen gas stream cooling device) ${ }^{[164]}$ were fitted on a $0.7 \times 0.5 \mathrm{~m}$ table as base (cf. Figure 2-11 and Figure 2-12). Thus, mounting was possible in close proximity in the hatch of the five-circle Huber goniometer and low temperatures were assured from crystallization over mounting up to the measurement.
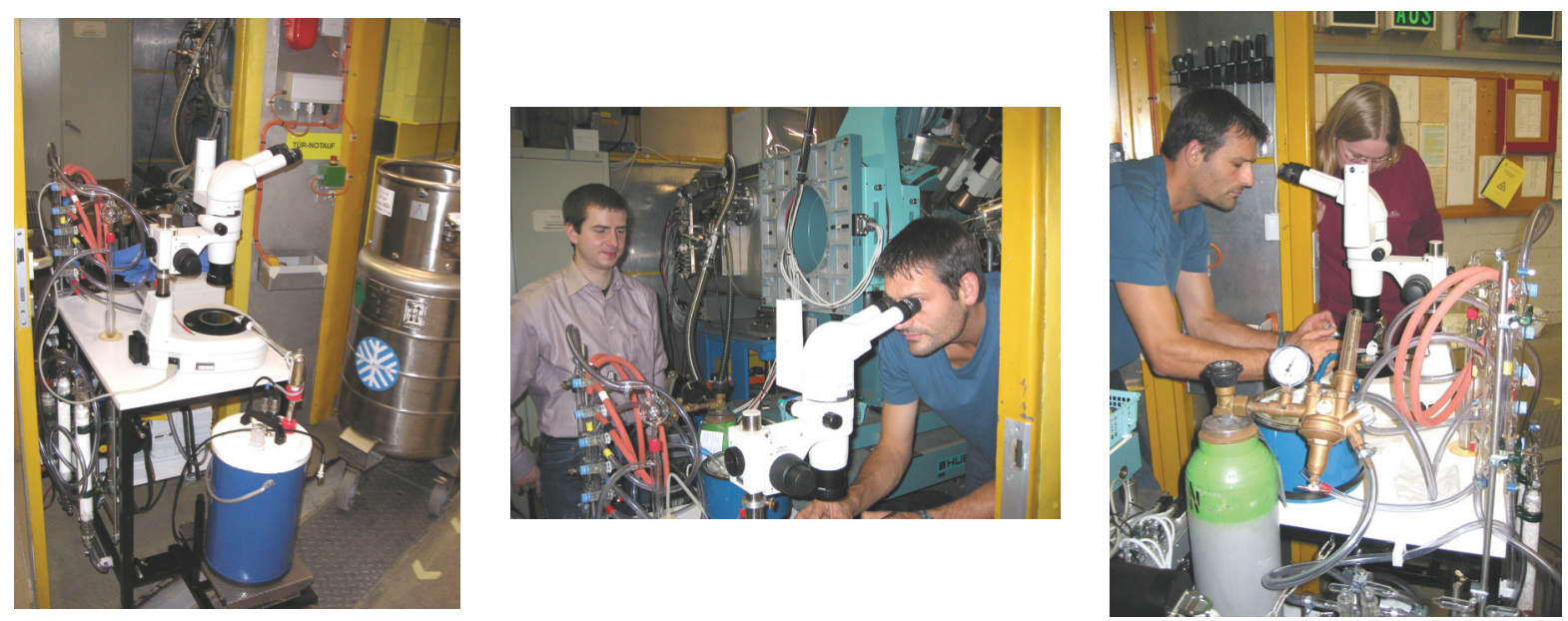

Figure 2-11: Mounting facility for crystal application at the beamline D3 of the HASYLAB/DESY.

Despite of these efforts, the crystals suffered from the shaking movement during transportation and the dry ice temperature, which is below crystallization temperature. Thus, only split or twinned samples could be found. Cutting the crystals left non-twinned samples of a maximum size of $0.1 \mathrm{~mm}$ diameter. The diffraction power of those was too little for the planned experiments. 


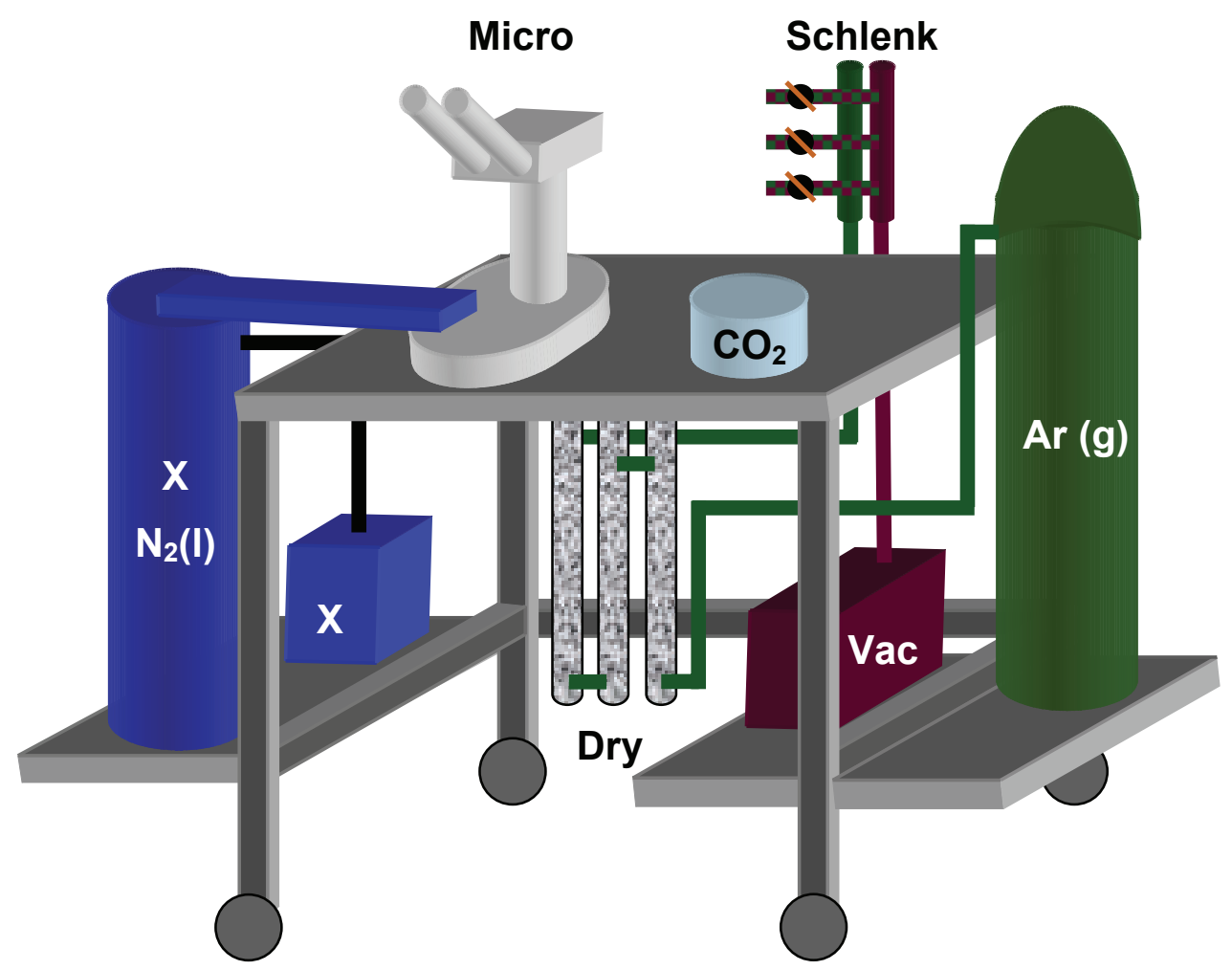

Figure 2-12: Front view of the mounting facility for crystals $\left(X N_{2}(I)\right.$ : liquid nitrogen dewar for $X-T E M P$, $\mathrm{X}$ : X-TEMP control, Micro: microscope, Dry: drying unit for gas supply, $\mathrm{CO}_{2}$ : cooling bath, Schlenk: Schlenk line, Vac: vacuum pump, $\operatorname{Ar}(\mathrm{g})$ : gas supply).

Additionally, the experimental setup did not provide as much improvement over in-house facilities as expected. This was mainly due to the fact that an outdated CCD detector (SMART1k) was installed.

Later, another attempt was made because the installation of an up-to-date MAR CCD detector improved the instrumentation. For the crystal transportation a different technique was applied. Suitable crystals of the right size were prepared in Göttingen and mounted on the glass fibre of a magnetic pin in perfluorinated polyether oil. This was capped and dipped into liquid nitrogen. The magnetic pin could later be mounted on a diffractometer head with a magnetic base. This technique is well established for protein crystals. The crystals of $\left[(\text { thf }) \mathrm{Li}_{2}\left\{\mathrm{H}_{2} \mathrm{CS}\left(\mathrm{N}^{t} \mathrm{Bu}\right)_{2}\right\}\right]_{2}(4)$ suffered from the low temperature to some extent, but were still suitable for high order diffraction experiments.

Nevertheless, all efforts were not successful. The MAR detector did improve the experimental situation considerably and high resolution data could be recorded. However, no integration software for the MAR images suitable for charge density purposes is available. The MAR software has been designed for standard structures and XDS by Kabsch ${ }^{[165,166]}$ has been designed for protein crystallography. The 
five-circle setup equipped with an open-flow nitrogen cooling device was very limited in all rotation angles, thus no high redundancy of the data as needed for sensible scaling and absorption correction could be obtained. Furthermore, not all important experimental specifications are known for D3. For example, some vital parameters for an oblique angle correction (spot shape and spread near the detector edges) are missing. Due to these facts the collected data proved to be worthless.

For all these reasons no further attempts were made to collect a high-order data set of $\left[(\text { thf }) \mathrm{Li}_{2}\left\{\mathrm{H}_{2} \mathrm{CS}\left(\mathrm{N}^{t} \mathrm{Bu}\right)_{2}\right\}\right]_{2}(4)$ at the HASYLAB.

\subsubsection{X-ray Experiment on a Rotating Anode Diffractometer}

The successful grant application to the DFG priority program 1178 "Experimental Charge Density as the Key to Understand Chemical Interactions" and the support thereof provided our group with a strong in-house X-ray source. The Bruker TXS Mo rotating anode is equipped with an APEX II CCD detector, mounted on a threecircle D8 goniometer, and INCOATEC Helios mirrors as monochromator optics (cf. Figure 2-13). This setup is unique throughout the world and supplies very intense and brilliant $\operatorname{MoK}(\alpha)$ radiation $(\lambda=0.71073 \AA)$, and made it possible to investigate a single crystal of 4 up to a resolution of $(\sin \theta / \lambda)_{\max }=1.14 \AA^{-1}$. The recorded data are satisfactory for an experimental charge density study.

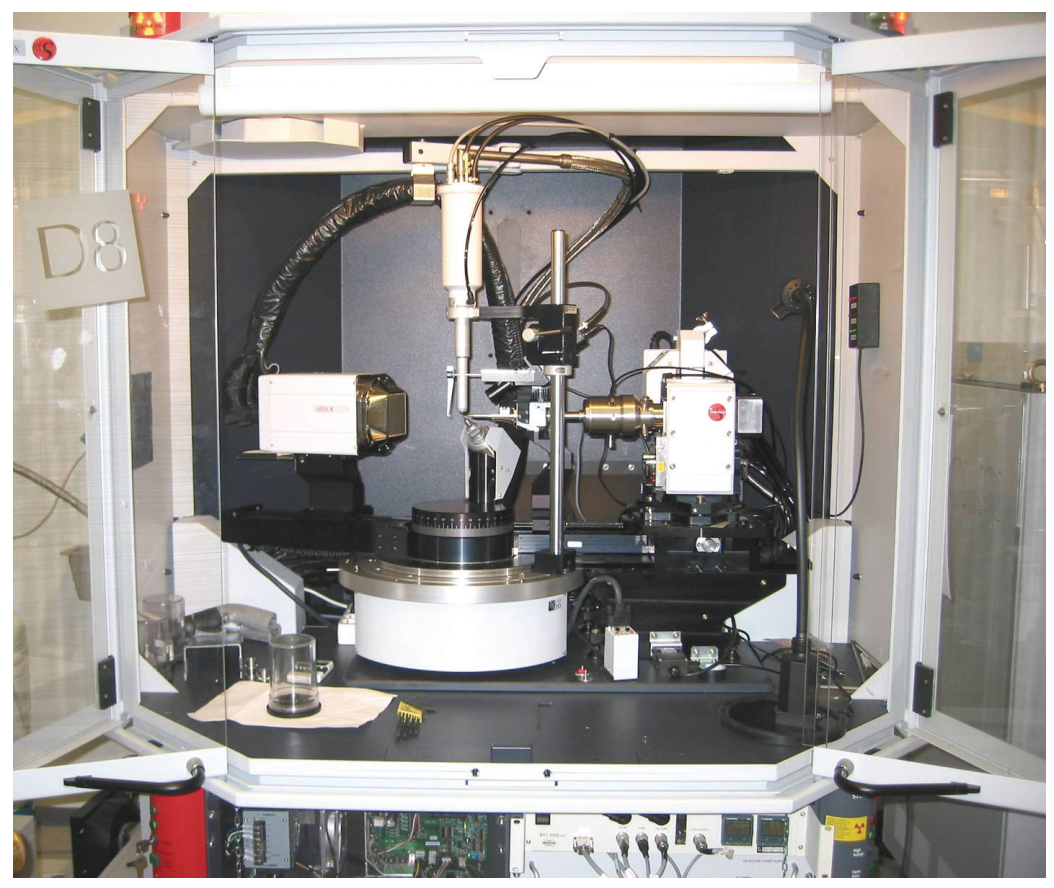

Figure 2-13: Bruker TXS Mo rotating anode equipped with an APEX II CCD detector and INCOATEC Helios mirror optics as monochromator. 
A $0.3 \times 0.25 \times 0.2 \mathrm{~mm}^{3}$ sized crystal of 4 was picked under a polarization microscope with help of the X-TEMP2 cooling device, ${ }^{[164]}$ coated with perfluorinated polyether oil and mounted on a glass fibre glued to the magnetic pin of the goniometer head. ${ }^{[167,168]}$ Oil and crystal were shock-cooled in the cold gas stream of the Kryoflex open flow nitrogen cooling device attached to the diffractometer. The amorphous frozen oil served as glue and protected the sensitive chemical compound along with the nitrogen gas stream from moisture and oxygen.

The size of the APEX II detector limits the recorded resolution range of a single image. At a detector position of $2 \theta=-31^{\circ}$ at $5.0 \mathrm{~cm}$ detector-to-sample distance a range of $\sin \theta / \lambda$ from 0 to $0.70 \AA^{-1}$ is covered. Hence, the reflections had to be recorded with two different detector positions in order to gain the desired high- and low-order data. The second detector position was chosen to ensure maximum overlap of the reflections and thus sensible scaling of the data was possible.

The data collection was controlled with the APEX2 package. ${ }^{[169]}$ All scans were performed in an omega-scan mode with a step-width of $-0.3^{\circ}$ at fixed $\varphi$-angles at $120 \mathrm{~K}$. One high-order batch (6 runs with 600 frames each) was recorded at $4 \mathrm{~cm}$ detector-to-sample distance with an exposure time of $90 \mathrm{~s}$. This supplies Bragg reflections in the range of $0.48 \AA^{-1} \leq \sin \theta / \lambda \geq 1.14 \AA^{-1}$ for the determination of the contracted charge densities. Two low-angle batches were recorded at $5.0 \mathrm{~cm}$ detector-to-sample distance with exposure times of $10 \mathrm{~s}$ and $20 \mathrm{~s}$ (6 runs with 600 frames each) up to $(\sin \theta / \lambda)_{\max }=0.70 \AA^{-1}$. The quality of these reflections is of special importance because diffuse bond densities need to be modeled during the multipole refinement. The diffuse densities contribute comparatively high to the reflections at low Bragg angles.

This procedure led to high-resolution data $\left((\sin \theta / \lambda)_{\max }=1.14 \AA^{-1}\right)$ and a completeness of $100 \%$ up to $\sin \theta / \lambda=1.09 \AA^{-1}$ and of overall $99.8 \%$. The redundancy of 18 for the overall data and even 11 for the high-order reflections facilitated a sensible data scaling and absorption correction.

The determination of the unit cell and orientation matrix was performed with the tool supplied in the APEX2 package. ${ }^{[169]}$ The collected frames were integrated with SAINT ${ }^{[170]}$ using the $3 d$ profiling method described by Kabsch. ${ }^{[165]}$ The refined final matrices were then used as input for a second improved SAINT run. The unit cell parameters were finally determined to $a=17.5816(11) \AA, b=17.5311(11) \AA$, $c=22.0092(13) \AA$, and $\alpha=\beta=y=90^{\circ}$ (cf. Table 2-6). 
Absorption correction, scaling, and merging of the three integrated data sets was performed with SADABS 2006/4 ${ }^{[171]}\left(T_{\min }=0.8785, T_{\max }=0.9285\right)$. SADABS 2006/4 is a version of SADABS modified for charge density purposes in a way, that all batches can be corrected for absorption at one time correctly and that an optimal scaling and merging result is obtained. Additionally, the hkl-file output is compatible with XD2006. ${ }^{[172]}$ XPREP $^{[157]}$ was used to determine the space group prior to the SADABS data procession, being crucial for a correct treatment. Merging of the collected 796739 reflections with respect to the point group 222 lead to 43652 unique reflections. The quality criteria show the low values characteristical for a good data set $\left(R_{\text {int }}=0.0364\right.$ and $R_{\Sigma}=0.0154$, cf. Table 2-6).

Table 2-6: Crystallographic data for the low- and high-order data collection of $\left[(\text { thf }) \mathrm{Li}_{2}\left\{\mathrm{H}_{2} \mathrm{CS}\left(\mathrm{N}^{t} \mathrm{Bu}\right)_{2}\right\}\right]_{2}(4)$.

\begin{tabular}{ll|ll}
\hline \multicolumn{3}{l}{ identification code: Monsun } & \\
\hline $\mathrm{a}[\AA]$ & $17.5816(11)$ & crystal dimension $\left[\mathrm{mm}^{3}\right]$ & $0.30 \times 0.25 \times 0.20$ \\
$\mathrm{~b}[\AA]$ & $17.5311(11)$ & crystal system & orthorhombic \\
$\mathrm{c}[\AA]]$ & $22.0092(13)$ & space group & Pbca \\
formula hill & $\mathrm{C}_{26} \mathrm{H}_{56} \mathrm{Li}_{4} \mathrm{~N}_{4} \mathrm{O}_{2} \mathrm{~S}_{2}$ & $\vee\left[\AA^{3}\right]$ & $6783.8(7)$ \\
molecular weight $[\mathrm{g} / \mathrm{mol}]$ & 548.63 & & \\
\hline
\end{tabular}

\begin{tabular}{|c|c|c|c|}
\hline \multicolumn{2}{|c|}{ low order batch 1 and 2} & \multicolumn{2}{|c|}{ high order batch } \\
\hline distance $_{\text {detector-to-sample }}[\mathrm{cm}]$ & 5.0 & distance $_{\text {detector-to-sample }}[\mathrm{cm}]$ & 4.0 \\
\hline$\varphi$-positions $\left[{ }^{\circ}\right]$ & $\begin{array}{l}0,45,90,135,180 \\
270\end{array}$ & $\varphi$-positions $\left[{ }^{\circ}\right]$ & $\begin{array}{l}0,45,90,135,180 \\
270\end{array}$ \\
\hline frames per run & 600 & frames per run & 600 \\
\hline$\Delta \omega\left[^{\circ}\right]$ & 0.3 & $\Delta \omega\left[^{\circ}\right]$ & 0.3 \\
\hline exposure time [s] & $10 / 20$ & exposure time [s] & 90 \\
\hline reflections collected & 153209 / 153173 & reflections collected & 490357 \\
\hline $\sin \theta / \lambda\left[\AA^{-1}\right]$ & $0.05-0.70$ & $\sin \theta / \lambda\left[\AA^{-1}\right]$ & $0.48-1.14$ \\
\hline \multicolumn{4}{|l|}{ overall } \\
\hline data coll. temperature $[\mathrm{K}]$ & $120(2)$ & $F(000)$ & 2400 \\
\hline$\mu\left[\mathrm{mm}^{-1}\right]$ & 0.185 & $\mathrm{~T}_{\min } / \mathrm{T}_{\max }$ & 0.8785 / 0.9285 \\
\hline reflections collected & 796739 & reflections unique & 43652 \\
\hline $\mathrm{R}_{\text {int }} / \mathrm{R}_{\Sigma}$ & 0.0364 / 0.0154 & redundancy & 18 \\
\hline
\end{tabular}




\subsection{The IAM Model}

\subsubsection{Basics of X-ray Scattering and IAM Modeling}

Due to the proportions of atoms, X-ray beams instead of visible light have to be used to gain a picture of the contents of crystals. This is quite problematic because no lens-systems appropriate for the construction of an X-ray microscope are available. Thus, a direct view at atoms and electron distributions is impossible. Nevertheless, the diffraction patterns discovered 1912 by Friedrich, Knipping, and Laue ${ }^{[173]}$ permit another way to gain an insight into electron distributions in crystals. The positions and intensities of the reflections from elastic scattering of the X-rays are connected to the electron density (atomic positions and their interactions) by Fourier transformation. The kinematic theory of scattering by Born ${ }^{[174]}$ provides a connection between the X-ray intensities I and the scattering amplitudes $F(H)$ (Eq. 2-2).

\section{Eq. 2-2:}

$$
\text { I } \sim|F(\mathbf{H})|^{2}
$$

Although the kinematic theory is strictly valid only for crystals thinner than $1 \mu \mathrm{m}$, the scattering of typical crystals $(d \geq 0.1 \mathrm{~mm}$ ) is still well described due to their mosaicity. Thus, application of the dynamic theory, ${ }^{[175,176]}$ which takes all energy exchanges into account, is not needed.

The scattering amplitudes are the Fourier transforms of the static electron density in the crystal (Eq. 2-3).

\section{Eq. 2-3:}

$$
F(\mathbf{H})=\int_{V} \rho(\mathbf{r}) \exp (2 \pi i \mathbf{H r}) d \mathbf{r}
$$

The expression of the structure factor $F(\mathbf{H})$ can be approximated by describing the electron density of the crystal as a summation over the nuclei-centered atomic densities (Eq. 2-4).

Eq. 2-4:

$$
\rho(\mathbf{r})=V^{-1} \sum_{\mathbf{H}} F(\mathbf{H}) \exp (-2 \pi i \mathbf{H r})
$$

This implicates that the ED (electron density) or CD (electronic charge density) $\rho(\mathbf{r})$ can be derived directly from the experiment. In a real experiment, this is subject to some restrictions. The observed structure factors are affected by experimental errors. Only a finite number of reflections can be collected, thus Fourier truncation errors occur. Last but not least, the phase information is lost in the course of the experiment due to the measurement of intensities, i.e. squared structure factors. These limitations make it necessary to model the ED. The calculated structure factors $F_{\text {calc }}$ 
of the parameterized models are compared to the experimental ones $F_{\mathrm{obs}}$ and refined by least-squares and gradient-descent methods.

Eq. 2-5 gives an expression for the structure factor, where $f_{\mathrm{q}}(\mathbf{H})$ is the scattering factor and $t_{\mathrm{q}}(\mathbf{H})$ the temperature factor.

\section{Eq. 2-5:}

$$
F(\mathbf{H})=\sum_{q} f_{q}(\mathbf{H}) t_{q}(\mathbf{H}) \exp \left(2 \pi \mathbf{H r}_{q}\right)
$$

The duration of the diffraction experiment largely exceeds the period of thermal vibrations of atoms. Therefore, the electron density $\rho(\mathbf{r})$ is the time-average of the atomic electron densities, which can be described as pure vibrational states ${ }^{[177]}$ within the convolution approximation. ${ }^{[178]}$ In most cases a harmonic approximation with nuclear displacement vectors $\mathbf{u}$ and the MSDA (mean square displacement amplitude) $\mathbf{U}$ is sufficient (Eq. 2-6).

Eq. 2-6:

$$
P_{0}(\mathbf{u})=(2 \pi)^{-3 / 2}(\operatorname{det} \mathbf{U})^{-1 / 2} \exp \left(-\frac{1}{2} \mathbf{u}^{\prime} \mathbf{U}^{-1} \mathbf{u}\right)
$$

Sometimes anharmonic effects are not negligible. In those cases the Gram-Charlierexpansion can be used to model small anharmonicities. ${ }^{[179]}$

Within the IAM (independent atom model) approach the crystal electron density is described as superposition of spherical atomic densities. This is commonly referred to as promolecule density $\rho_{\text {pro }}$ (r) (Eq. 2-7) and leads to a spherical scattering factor (Eq. 2-8).

Eq. 2-7:

$$
\rho_{\text {pro }}(\mathbf{r})=\sum_{q} \rho_{q}^{\text {at }}\left(r^{\prime}\right)
$$

Eq. 2-8:

$$
f_{q}(\mathbf{H})=\int_{V_{q}} \rho_{q}^{\text {at }}\left(r^{\prime}\right) \exp \left(2 \pi i H r^{\prime}\right) d V_{q}
$$

The IAM parameters for modeling the crystal electron density are the three fractional coordinates $(x, y, z)$ and the six anisotropic displacement parameters $U_{i j}$ for non-hydrogen atoms or one isotropic displacement parameter $U_{\text {iso }}$ for hydrogen atoms, respectively.

The IAM approach neglects all density deformations, either from atomic interactions or from lone-pair densities. For heavy atoms with predominant core electron scattering this approximation is valid. For lighter atoms, however, the determined parameters, especially the temperature factors, are biased. ${ }^{[180]}$ This is particularly true for hydrogen atoms. Their whole electron density is shifted towards the bonded atom and hence the interatomic distances are determined too small. This has to be compensated by shifting the hydrogen atoms to distances derived from neutron diffraction experiments. ${ }^{[181]}$ 


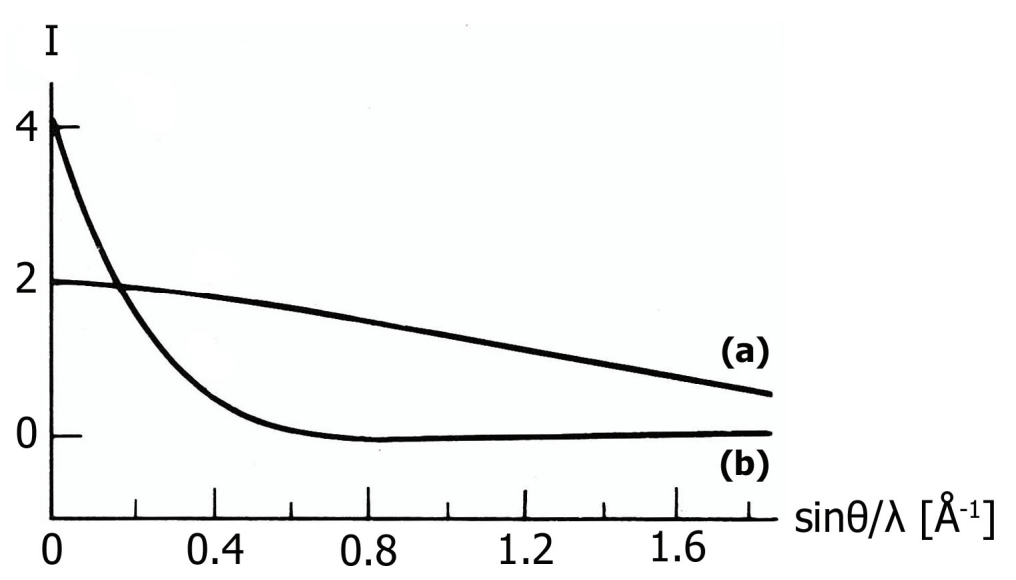

Figure 2-14: Resolution dependence of X-ray scattering amplitudes by (a) K-and (b) L-shell of carbon.

The bias introduced for all other elements can be reduced significantly if only high-order data are used. At high Bragg angles the influence of polarization effects from bonding is minimized, because predominantly contracted densities (core densities) contribute to these reflections. The decrease of scattering power at high resolution affects valence densities more than core densities (cf. Figure 2-14).

The application of a high-order refinement with $\sin \theta / \lambda \geq 1.00 \AA$ results in reliable structural parameters for all non-hydrogen atoms. The results obtained are in good agreement with those from other methods, e.g. neutron diffraction. ${ }^{[163,182-184]}$

The nucleus-centered finite multipole formalism by Hansen and Coppens, ${ }^{[185]}$ applied later on during this charge density study, is, as the name suggests, based on an atomic description of the crystal as starting model. The independent atoms of this description, the so-called promolecule, do not and should not account for the bond densities, which will be treated by the multipole model. Thus, bias-free results of the independent atom modeling are of great importance.

In all refinements the function $M\left(p_{i}, k\right)$ (Eq. 2-9) is minimized using statistical weights $w_{H}$ (Eq. 2-10).

Eq. 2-9:

$$
M\left(p_{i}, k\right)=\sum_{\mathbf{H}} w_{\mathbf{H}}\left[k\left|F_{\text {obs }}(\mathbf{H})\right|^{2}-\left|F_{\text {calc }}(\mathbf{H})\right|^{2}\right]^{2}=\min
$$

Eq. 2-10:

$$
w_{\mathrm{H}}=1 / \sigma_{\mathrm{H}}^{2}
$$

The weighting scheme is not refined but kept fixed at statistical weights, because the program for multipole modeling comes with no feature for adjustment of the weighting scheme during refinement. Hence, the weights from IAM, which are optimized for the spherical atom refinement, would introduce bias into the multipolar modeling. 
The results of the refinements can be verified by comparison of the calculated to the observed structure factors. Commonly used criteria are the residuals $R 1$ (Eq. 2-11) and $w R 2$ (Eq. 2-12). If the model is refined against $F^{2}$, the $w R 2$ is more significant.

Eq. 2-11: $\quad R 1=\frac{\sum_{H} w_{H}\left(\left|F_{\text {obs }}\right|-\left|F_{\text {calc }}\right|\right)}{\sum_{H} w_{H}\left|F_{\text {obs }}\right|} \quad$ Eq. 2-12: $\quad w R 2=\frac{\sum_{H} w_{H}\left(\left|F_{\text {obs }}\right|^{2}-\left|F_{\text {calc }}\right|^{2}\right)^{2}}{\sum_{H} w_{H}\left|F_{\text {obs }}\right|^{4}}$ Additionally, the GoF (goodness of fit), a figure of merit showing the relation between deviation of $F_{\text {calc }}$ from $F_{\text {obs }}$ and the over-determination of refined parameters, is calculated (Eq. 2-13).

Eq. 2-13:

$$
\mathrm{GoF}=\sqrt{\frac{\sum_{H} w_{H}\left(\left|F_{\text {obs }}\right|-\left|F_{\text {calc }}\right|\right)^{2}}{N-n}}
$$

\subsubsection{IAM Refinement}

The structure was solved with direct methods using SHELXS. ${ }^{[186]}$ All IAM refinements were performed on $F^{2}$ with SHELXL. ${ }^{[187]}$

In order to introduce as little bias as possible in the IAM from bond densities, the positional and anisotropic displacement parameters of all non-hydrogen atoms were refined with high-order data $\left(\sin \theta / \lambda \geq 1.00 \AA^{-1}\right)$, exclusively. After this step all parameters of the non-hydrogen atoms were kept fixed by means of the AFIX 1 instruction in SHELXL. ${ }^{[187]}$

The hydrogen atoms were localized in a second step via difference Fourier syntheses from low-order data $\left(\sin \theta / \lambda \leq 0.50 \AA^{-1}\right)$. Refinement of the hydrogen atom parameters was achieved with the same cut-off without distance restraints. An isotropic riding model was applied for the thermal motion parameters, with $U_{\text {iso }}$ constrained to $1.5 U_{\text {eq }}$ of the pivot atom for the methyl groups and $1.2 U_{\text {eq }}$ of the pivot atom for all others. After converged refinement the hydrogen atoms were shifted along their bonding vectors to neutron diffraction distances of $1.085 \AA .{ }^{[181]}$

Figure 2-15 shows the IAM model obtained after convergent refinement. 


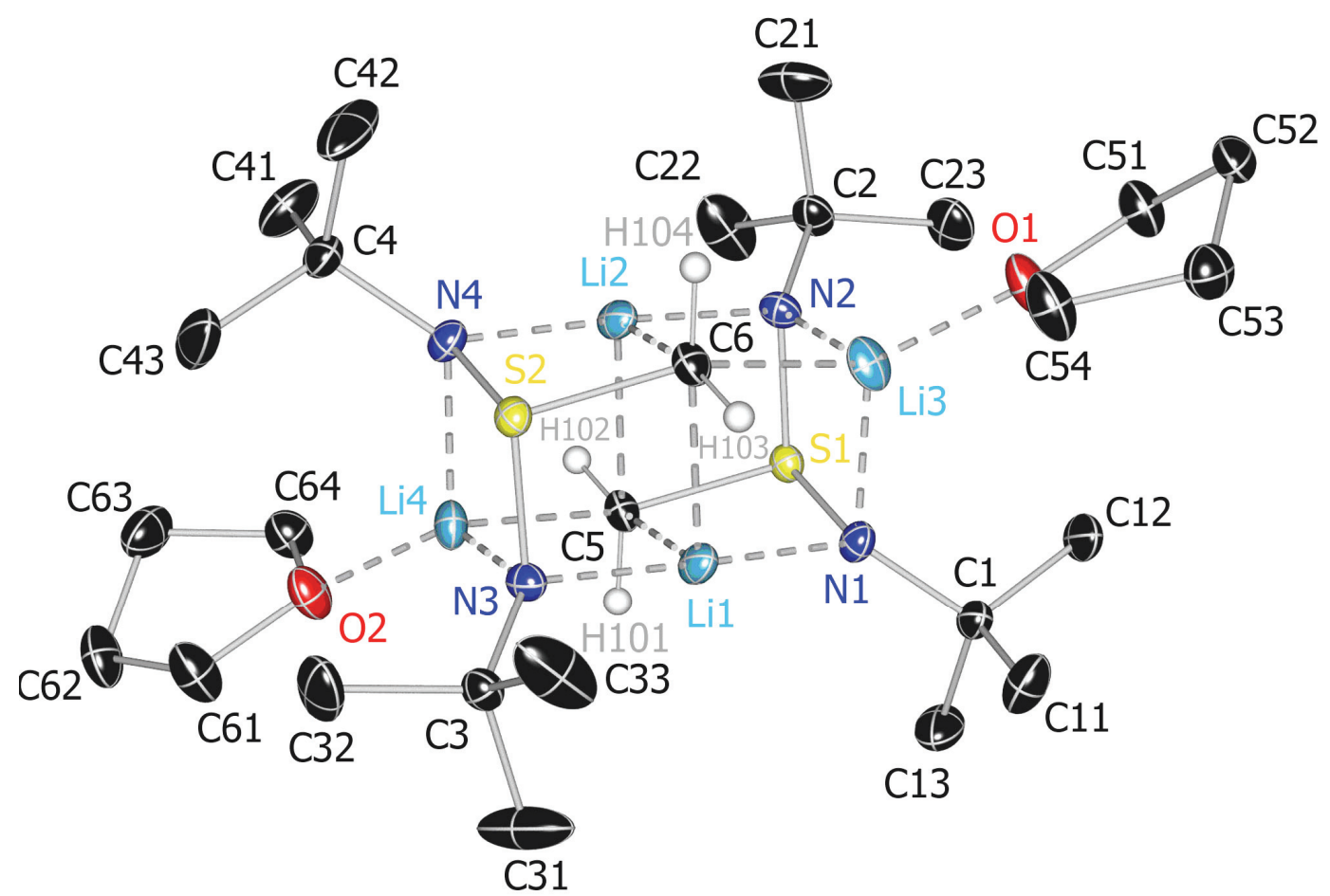

Figure 2-15: ADP representation of the asymmetric unit of $\left[(\text { thf }) \mathrm{Li}_{2}\left\{\mathrm{H}_{2} \mathrm{CS}\left(\mathrm{N}^{t} \mathrm{Bu}\right)_{2}\right\}\right]_{2}$ (4); all except the methylene hydrogen atoms are omitted for clarity, ADP's are depicted at the $50 \%$ probability level.

Only statistical weights $w_{H}$ were used to avoid the introduction of bias into the multipole refinement. This should be kept in mind when comparing the quality criteria shown in Table 2-7 to those of standard X-ray structures.

Table 2-7: Quality criteria after the IAM refinement of $\left[(\text { thf }) \mathrm{Li}_{2}\left[\mathrm{H}_{2} \mathrm{CS}\left(\mathrm{N}^{t} \mathrm{Bu}\right)_{2}\right\}\right]_{2}(4)$ with high-order data only.

\begin{tabular}{lc|ll}
\hline no. of reflections & 41445 & $R 1(I>4 \sigma(I))$ & 0.0784 \\
$\begin{array}{l}\text { no. of reflections } \\
(I>4 \sigma(I))\end{array}$ & 28200 & $w R 2$ (all data) & 0.1177 \\
no. of parameters & 511 & GoF & 7.638 \\
\hline
\end{tabular}

The high GoF value is due to a systematic underestimation of the uncertainties of the reflections at higher Bragg angles. Hence, the model quality seems to be too bad compared to the data quality and the GoF is far from its optimal value of 1 . Therefore, for the discussion of all geometrical features a threshold of three esd's (experimental standard deviations) is used. 


\subsection{Multipole Refinements}

\subsubsection{Introduction to Multipolar Modeling}

The description of the electron density in a crystal from the IAM can be enhanced significantly if the density deformations due to bonding and lone-pairs are accounted for. From the available aspherical atom models, the one implemented in the XD program package ${ }^{[172]}$ was used in the course of this research. The nucleus-centered finite multipole expansion was first developed by Stewart ${ }^{[188-191]}$ and later modified by Hansen and Coppens. ${ }^{[185]}$

The atomic electron density $\rho(\mathbf{r})$ is divided into three components.

Eq. 2-14:

$$
\rho_{q}^{\mathrm{at}}(\mathbf{r})=\rho_{\mathrm{c}}(\mathrm{r})+P_{\mathrm{v}} \rho_{\mathrm{v}}(k \mathrm{r})+\rho_{\mathrm{d}}\left(\kappa^{\prime} \mathbf{r}\right)
$$

The exclusive use of the spherical core density $\rho_{c}(r)$ from Eq. 2-14 would be equivalent to the IAM approach. $\rho_{\mathrm{v}}(\mathrm{kr})$ denotes the spherical valence density term. The density deformation is described by the aspherical valence density $\rho_{\mathrm{d}}\left(\kappa^{\prime} r\right)$. Both $\rho_{\mathrm{v}}(\kappa r)$ and $\rho_{\mathrm{d}}\left(\kappa^{\prime} \mathbf{r}\right)$ include a radial scaling parameter ( $k$ and $\left.k^{\prime}\right)$ which accounts for the radial expansion or contraction of the valence shell.

Eq. 2-15:

$$
\rho_{\mathrm{d}}\left(\kappa^{\prime} \mathbf{r}\right)=\sum_{l} R_{l}\left(\kappa^{\prime} \mathbf{r}\right) \sum_{m=-l}^{l} P_{l m} Y_{l m}(\mathbf{r} / \mathbf{r})
$$

The definition of $\rho_{\mathrm{d}}\left(\kappa^{\prime} \mathbf{r}\right)$ is given in Eq. 2-15. $Y_{I m}$ describes the density-normalized real spherical harmonics accounting for the angular dependence. $R_{/}$are simple Slater-type radial functions, so-called single-zeta orbitals, containing the energy-optimized Slater exponents $\alpha_{l}$.

\section{Eq. 2-16:}

$$
R_{l}(r)=\frac{\alpha_{l}^{n_{l}+3}}{\left(n_{l}+2\right) !} r^{n_{l}} \exp \left(-\alpha_{l} r\right)
$$

The resulting radial functions are similar to those for description of atomic orbitals. However, they only mimic the shape of the orbitals and the multipole populations do in general not directly correspond to orbital populations in a given system.

$\rho_{\mathrm{c}}(\mathrm{r})$ and $\rho_{\mathrm{v}}(\mathrm{Kr})$ are calculated from $\mathrm{HF}(\underline{\text { Hartree-Fock }})^{[192]}$ or relativistic $\mathrm{HF}^{[193]}$ atomic wave functions. Their values are tabulated in the literature. ${ }^{[179]}$ 


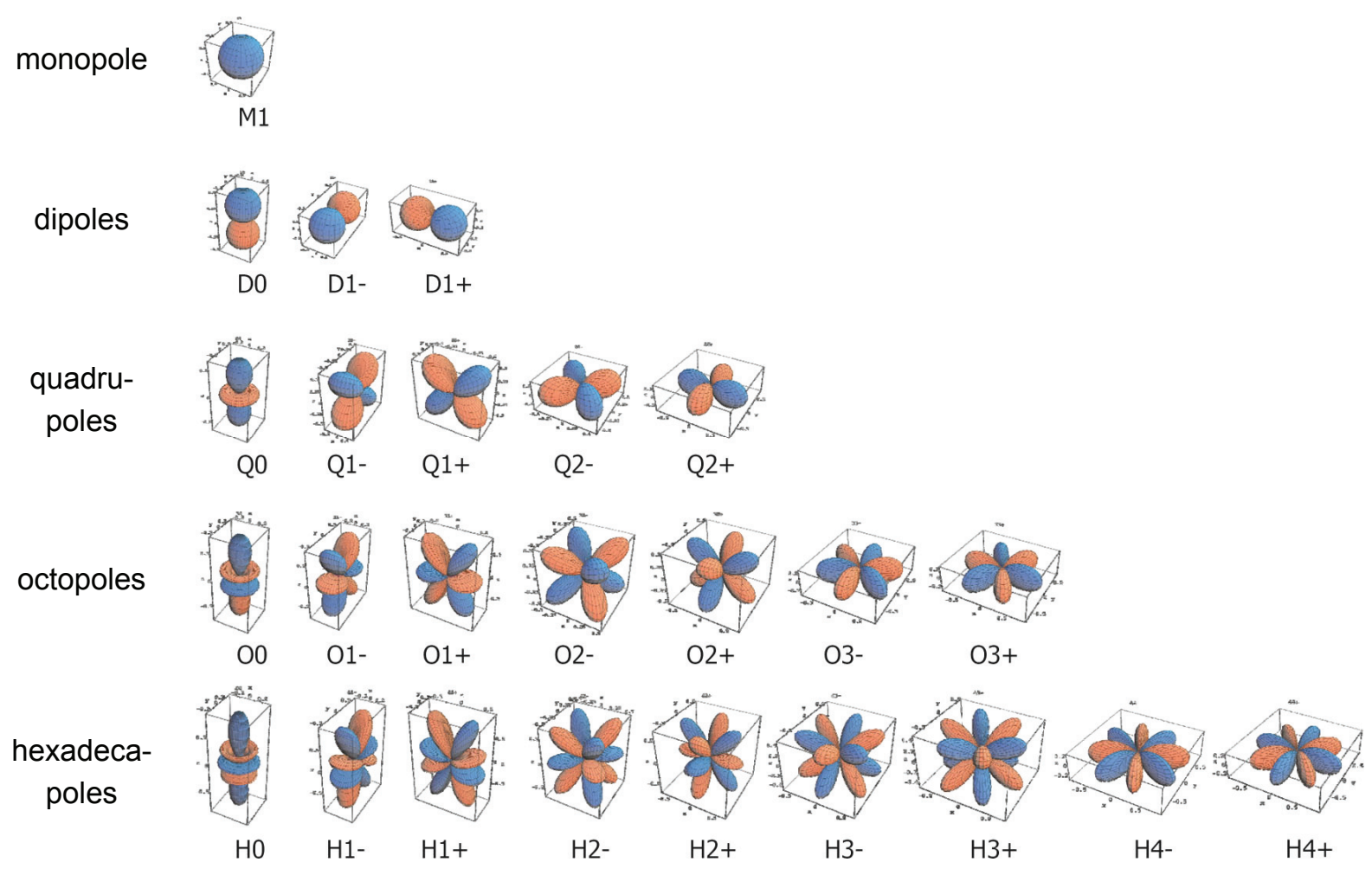

Figure 2-16: Slater-type orbital functions for description of the deformation density $\rho_{\mathrm{d}}(\mathbf{r}){ }^{\left[{ }^{162]}\right.}$

The atomic form factor $f_{\mathrm{q}}(\mathbf{H})$ is given in Eq. 2-17. $\left\langle J_{p}>\right.$ is the $t^{\text {th }}$ order Fourier-Bessel transform of $R_{I}, f_{\mathrm{c}}$ and $f_{\mathrm{v}}$ are the Fourier transforms of $\rho_{\mathrm{c}}(\mathbf{r})$ and $\rho_{\mathrm{v}}(k \mathrm{r})$, respectively.

Eq. 2-17: $\quad f_{\mathrm{q}}(\mathbf{H})=f_{\mathrm{c}}(H)+P_{\mathrm{v}} f_{\mathrm{v}}(H / \mathrm{k})+\sum_{l}\left\langle J\left(H / \kappa^{\prime}\right)_{l}\right\rangle \sum_{m=-l}^{l} P_{I m} Y_{l m}(\mathbf{H} / H)$

As a whole, within the MM (multipole model) not only the positional $(x, y, z)$ and thermal parameters $\left(U_{i j}\right)$ of the standard model (IAM) are refined, but additionally the radial expansion/contraction parameters $\left(\kappa, k^{\prime}\right)$ and the populations of the spherical and aspherical valence densities $\left(P_{\mathrm{v}}, P_{l m}\right)$. Thus, for non-hydrogen atoms up to 36 parameters are employed, instead of 9 within the IAM. This leads to a highly flexible model which is capable of describing all density deformations due to lone-pairs and atomic interactions, especially bonding.

However, in order to gain reliable results X-ray data of very high quality and up to a resolution of $\sin \theta / \lambda \geq 1.00 \AA^{-1}$ must be available. Additionally, no twinning or disorder has to be present in the crystal in order to allow a successful deconvolution of the deformation density from thermal motion.

In order to estimate the quality of the obtained model, the criteria for a standard structure are considered first. As these are not designed to check multipole models, additionally the residual density is beheld and a test on the thermal motion parameters is performed. The residual density after the standard IAM refinement 
contains strong residuals. Especially the bonding regions show missing electron density (positive residuals) and the atomic positions excessive one (negative residuals). This is due to the modeling with spherical atoms, which can not account for density deformations, as already mentioned. After multipole refinement, the residual density is expected to be flat and featureless, because the deformation density is then modeled. The residual density should ideally show random experimental noise only. If the residuals exceed this significantly at the atomic positions or in the bonding regions the model needs to be adjusted. The test on the thermal motion parameters is called DMSDA (difference of mean-square displacement amplitudes) or Hirshfeld test. The rigid-bond postulate ${ }^{[194]}$ implies that the mean-square displacement amplitudes of a pair of bonded atoms should be nearly equal in the bond direction. This is only strictly valid for atoms of the same mass. A proper deconvolution of the electron density from thermal motion is given if the DMSDA's are smaller than $1 \cdot 10^{-3} \AA^{2}$ for atoms with equal masses. If this value is significantly exceeded for homo-nuclei bias by unresolved valence density asphericities or an unrecognized disorder is indicated.

\subsubsection{Refinement Strategy and Models}

All multipole refinements presented here were performed on $F^{2}$ with the full matrix least-squares refinement program XDLSM implemented in the XD2006 program package. ${ }^{[172]}$ Again, statistical weights were used and only reflections with $I>3 \sigma(I)$ were included in the refinement. An electron-neutrality constraint for the asymmetric unit was applied to the modeling.

It was checked if the use of the SCM databank with wave functions fitted to a relativistic Dirac-Fock solution (neutral atoms up to krypton from Su and Coppens ${ }^{[195]}$ and neutral atoms rubidium to xenon and all chemically relevant ions up to iodide from Macchi and Coppens) ${ }^{[196]}$ is advantageous over the CR databank implemented in XD2006 and described above. No significant differences were observed. The CR databank was chosen for a slightly better residual density.

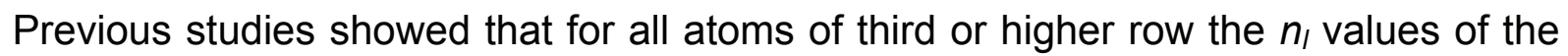
pseudo-atom model need to be optimized. ${ }^{[197-199]}$ In recent studies the optimal $n_{\text {I }}$ values for sulfur were consistently found to be $n_{l}=4,4,6,8$ for $I=1,2,3,4 .^{[80,81,185,200,201]}$ Hence, these values were chosen for sulfur. The implemented standard values were used for all other atom types of this study. ${ }^{[193]}$ 
The expansions over the spherical harmonics were truncated at the hexadecapolar level for all except the carbon atoms of the thf molecules which were only refined up to octapolar level in order to reduce the number of parameters.

The radial fit of the multipole functions was optimized by the use of the expansion/contraction coefficients $K$ and $\kappa^{\prime}$. For each atom type all multipoles $(I=1-4)$ shared the same $\kappa^{\prime}$-set.

The hydrogen atoms were treated with special care due to their diffuse density. Their deformation density was represented by a bond-directed dipole. $k$ and $\kappa^{\prime}$ were kept fix at the values suggested by Volkov, Abramov, and Coppens ${ }^{[202]}$ to derive meaningful parameters for the contraction/expansion of this atom type. The hydrogen atoms were kept at neutron diffraction distances ${ }^{[181]}$ to their pivot atom by means of the RESET command. At certain stages of the refinement (vide infra) the positions of the hydrogen atoms were refined freely with low-order data $\left(\sin \theta / \lambda \leq 0.50 \AA^{-1}\right)$. After each of these cycles the hydrogen atoms were again shifted to neutron diffraction distances along the bond vector. The thermal motion parameters of the hydrogen atoms were refined using a riding model, with $U_{\text {iso }}$ constrained to $1.5 U_{\text {eq }}$ of the pivot atom for the methyl groups and $1.2 U_{\mathrm{eq}}$ of the pivot atom for all others.

In order to reduce the number of parameters, certain similarity constraints and local (non-crystallographic) symmetry restrictions were applied. The similarity (or chemical) constraints can be used to constrain geometrically and chemically equivalent atoms. These restrictions refer only to the multipole parameters of the atoms, positions and thermal motions were refined separately. For $\left[(\operatorname{thf}) \mathrm{Li}_{2}\left\{\mathrm{H}_{2} \mathrm{CS}\left(\mathrm{N}^{t} \mathrm{Bu}\right)_{2}\right\}\right]_{2}(4)$ this type of constraint was used for the methyl groups, as their relative positions to the double-cube are equivalent $(\mathrm{C} 11=\mathrm{C} 21=\mathrm{C} 31=\mathrm{C} 41 ; \quad \mathrm{C} 13=\mathrm{C} 22=\mathrm{C} 33=\mathrm{C} 42$; $\mathrm{C} 12=\mathrm{C} 23=\mathrm{C} 32=\mathrm{C} 43)$.

Application of local symmetry reduces the number of parameters drastically as the spherical harmonics have to obey to the symmetries. If such constraints are applied, the local coordinate systems have to be chosen very carefully. $\left[(\text { thf }) \mathrm{Li}_{2}\left\{\mathrm{H}_{2} \mathrm{CS}\left(\mathrm{N}^{t} \mathrm{Bu}\right)_{2}\right\}\right]_{2}(4)$ is almost centrosymmetric with respect to the center of the common $\mathrm{Li}_{2} \mathrm{C}_{2}$ face. The connection lines of all opposing atoms except those for the thf carbon atoms run through that point (cf. Figure 2-17a). The deviation for the thf carbon atoms (cf. Figure 2-17b) is too large to lead to a higher crystal symmetry ${ }^{[66]}$ or to be neglected in this study. In consequence, a local centrosymmetry constraint was applied to all atom pairs except the thf carbon atoms. 


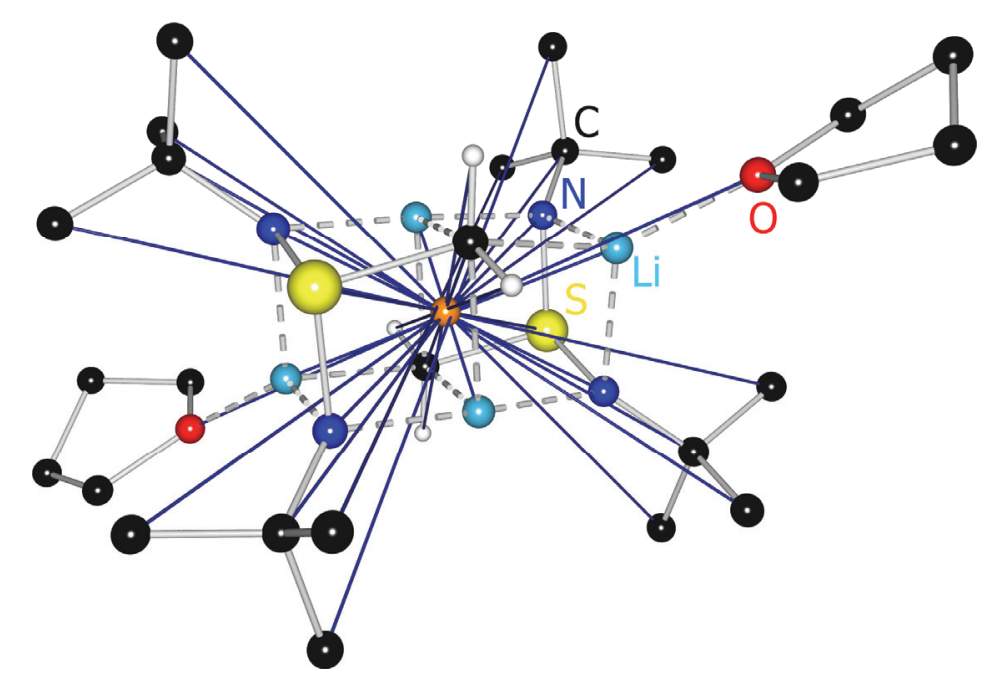

(a)

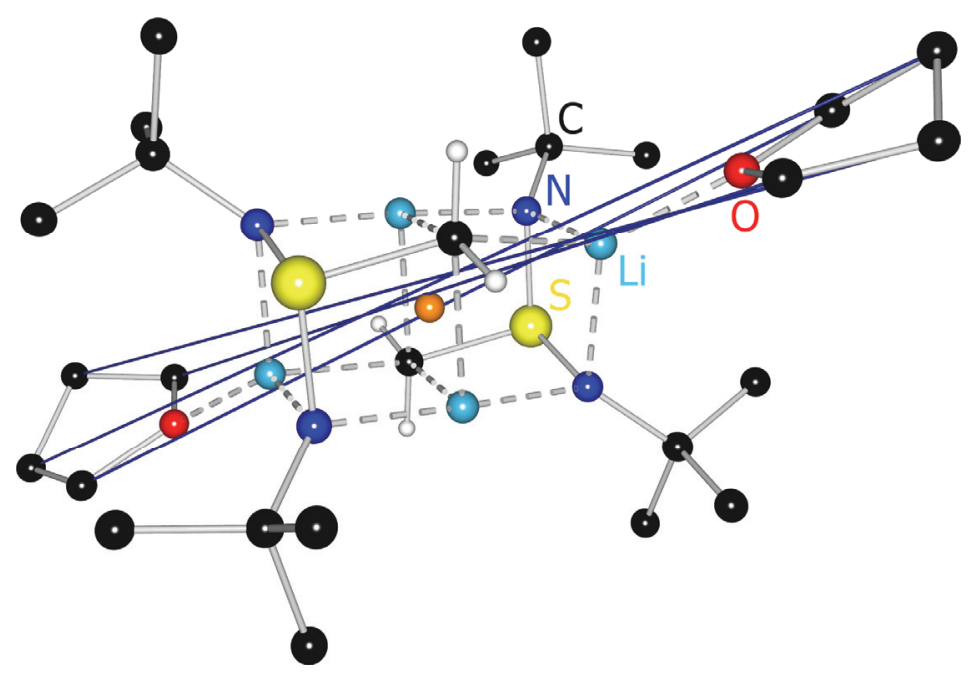

(b)

Figure 2-17: Molecular plots of $\left[(\text { thf }) \mathrm{Li}_{2}\left\{\mathrm{H}_{2} \mathrm{CS}\left(\mathrm{N}^{t} \mathrm{Bu}\right)_{2}\right\}\right]_{2}(4)$ showing that local centrosymmetry (a) is valid for all but the thf carbon atoms (b).

The applied model was compared to models of different chemical constraints and local symmetry. It was found to be the best in regard to lowest $R$ values, esd's, and a flat and featureless residual density at minimal correlations.

The use of chemical and local-symmetry constraints needs to be validated throughout the refinement. Thus, the symmetry restrictions were deactivated and the resulting model was checked for deviations from the assumed symmetry. No significant asymmetric effects were observed. The multipole populations, constrained to be zero, kept zero within the esd's even without the constraints. No model improvements were observed, on the contrary, worse esd's were found for the unconstrained model. Hence, only the constrained model will be discussed. 
To account for the electronic state of the lithium atoms correctly, three different models were examined:

I) Refinement of a neutral lithium atom with one electron in its valence shell. The distribution of the electron was modeled by a monopole function and scaled by $\kappa$.

II) Use of the scattering factor of a lithium cation $\mathrm{Li}^{+}$as starting model (no monopole refined).

III) Use of $\mathrm{Li}^{+}$scattering factors and distribution of the four valence electrons of the four lithium atoms over the bonded nitrogen atoms.

All refined models led to a converged fit at low $R$ values and flat and featureless residual densities. The properties of the density distributions were quite similar despite of the different starting points. Model I) showed almost zero monopole populations for the lithium atom. In addition, the electron density was severely contracted, resembled by a large $k$ value. Concerning II) and III), no severe net charge differences at the nitrogen atoms were observed after the refinement. This shows that the electron distribution at the nitrogen centers is not predetermined by choice of the starting model. For electro-neutrality reasons, model III) was favored.

The multipole refinement proceeded in a step-wise manner:

1. Initial adjustment of the scaling factor, due to differences in the scattering tables of SHELXL and XD2006 (In all subsequent steps the scaling factor was refined along with the other parameters.)

2. Refinement of the monopole populations $P_{\mathrm{v}}$.

3. Refinement of $P_{v}$ together with $k$ (except $k$ of the hydrogen atoms).

4. Refinement of all multipole populations $P_{I m}$.

5. Refinement of all non-hydrogen atom positions along with their anisotropic displacements $U_{i j}$ and the isotropic displacements $U_{\text {iso }}$ of the attached hydrogen atoms. (The hydrogen atoms were fixed to the movement of their pivot atom by means of the RESET command. This step was divided into two parts because of the limited number of RESET commands XD2006 can handle.)

6. Refinement of all $K^{\prime}$ parameters (except $K^{\prime}$ of the hydrogen atoms).

7. Refinement of $P_{\mathrm{v}}$ and $P_{l m}$ (to account for the changes in $\kappa^{\prime}$ ).

8. Refinement of $P_{\mathrm{v}}$ and $P_{l m}$ along with $K$ (except $k$ of the hydrogen atoms).

9. Refinement of $P_{\mathrm{v}}$ and $P_{l m}$ along with $K$ (except $\kappa$ of the hydrogen atoms) and the positional and anisotropic displacement parameters $U_{i j}$ of all non-hydrogen atoms, as well as the constrained $U_{\text {iso }}$ parameters of the hydrogen atoms. 
(Again the use of the RESET command made a division of this step into two parts necessary.)

10. Adjustment of the hydrogen atom positions by refinement on data with $\sin \theta / \lambda \leq 0.5 \AA^{-1}$. (The hydrogen atoms stayed on neutron diffraction distances within the esd's.)

11. RESET of the hydrogen bond lengths with all data and refinement of $x, y, z$, and $U_{i j}$ of the non-hydrogen atoms along with the constrained $U_{\text {iso }}$ parameters of the hydrogen atoms. (Like before the use of the RESET command made a division into two parts of this step necessary.)

12. Refinement of all $\kappa^{\prime}$ parameters (except $\kappa^{\prime}$ of the hydrogen atoms).

13. Refinement of $P_{v}$ and $P_{I m}$ along with $\kappa$ (except $\kappa$ of the hydrogen atoms) and the positional and anisotropic displacement parameters $U_{i j}$ of all non-hydrogen atoms, as well as the constrained $U_{\text {iso }}$ parameters of the hydrogen atoms. (As always the use of the RESET command made a division into two parts of this step necessary.)

14. Repetition of the steps 12 and 13 twice to ensure that convergence was reached.

This process led to a well converged model with good quality criteria (cf. Table 2-8). Although a lot of parameters are refined in the final cycle (all except $\kappa^{\prime}$ ), the data-to-parameter ratio is still very high. Thus the model is sufficiently overdetermined. The refined parameters show low esd's and little correlations.

Table 2-8: Quality criteria after the multipole refinement of $\left[(\text { thf }) \mathrm{Li}_{2}\left\{\mathrm{H}_{2} \mathrm{CS}\left(\mathrm{N}^{t} \mathrm{Bu}\right)_{2}\right\}\right]_{2}(4)$.

\begin{tabular}{lc|ll}
\hline $\begin{array}{l}\text { no. of reflections } \\
\text { no. of reflections }\end{array}$ & 34420 & $R 1(I>3 \sigma(I))$ & 0.0248 \\
$\begin{array}{l}(I>3 \sigma(I)) \\
\text { no. of parameters (final } \\
\text { cycle) }\end{array}$ & 75332 & wR2 (all data) & 0.0489 \\
data-to-parameter ratio & 39.27 & GoF & 4.0636 \\
\hline
\end{tabular}

Compared to the IAM refinement the $R$ values decreased significantly, due to the correct description of the deformation density. The GoF is also almost halved showing an improved agreement of the model with the true situation in the crystal. Nevertheless, this figure of merit stays on a relatively high level, because the esd's for the high angle reflections are still underestimated and only a statistical weighting scheme $\left(1 / \sigma^{2}\right)$ is applied. In order to avoid bias in the model, statistical weights were kept at the expense of a prominent GoF. 
The residuals have decreased significantly, as the bonding and valence densities are described correctly. The IAM modeling left residual densities of over $0.4 \mathrm{e} / \AA^{3}$, which are distributed systematically in the bonding and lone-pair regions (cf. Figure 2-18a). The residual density after multipole modeling in contrast exceeds $0.2 \mathrm{e} / \AA^{3}$ only at very few locations. The residuals are distributed statistically and reflect the experimental errors (cf. Figure 2-18c-e).

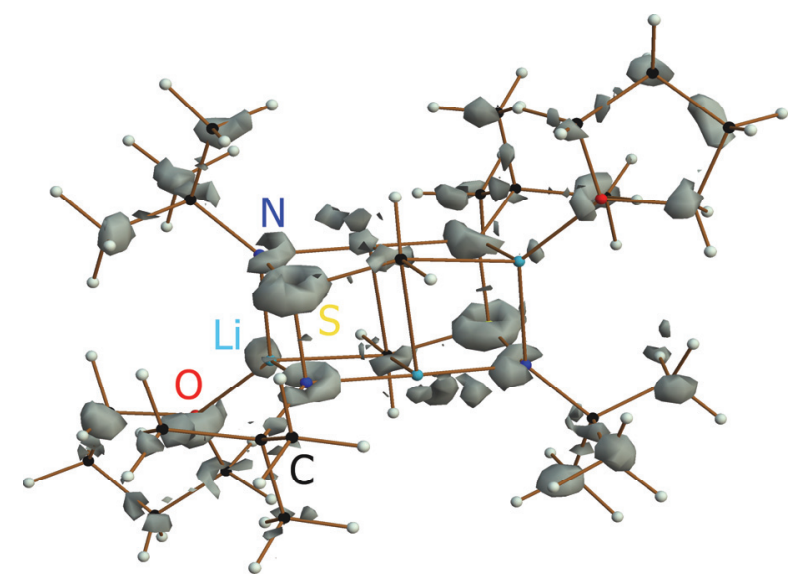

(a)

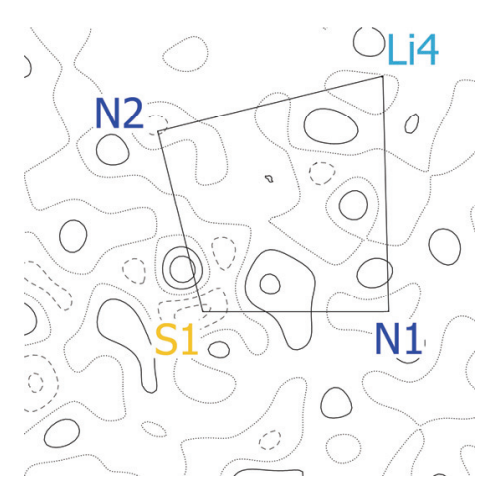

(c)

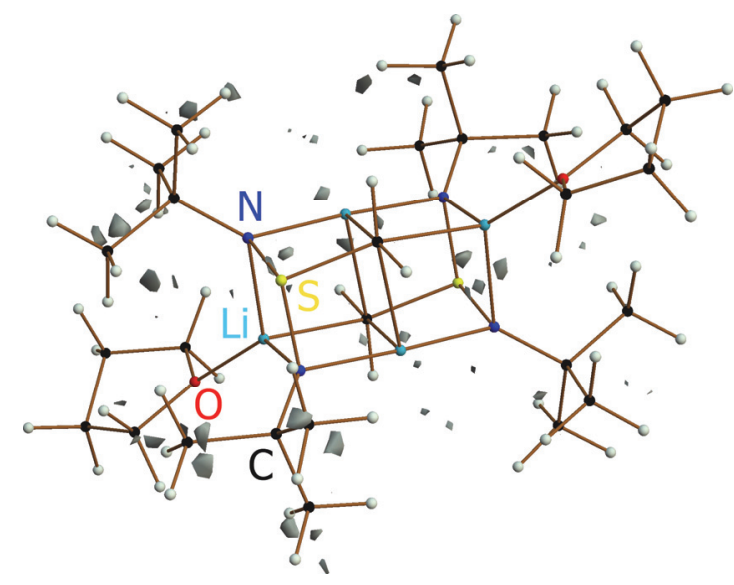

(b)

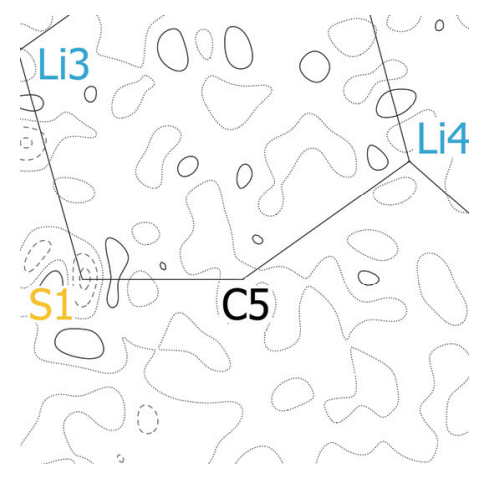

(d)

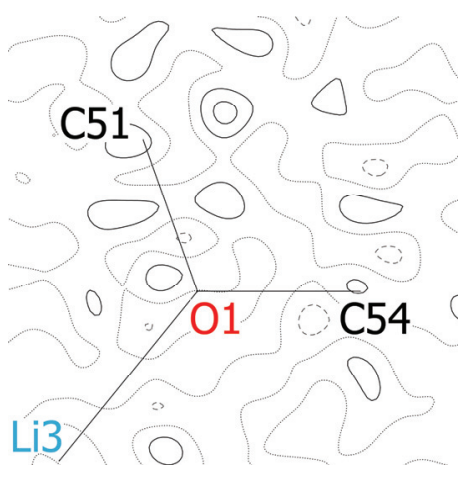

(e)

Figure 2-18: Isosurface plot of the residual density after (a) IAM refinement at $0.3 \mathrm{e} / \AA^{3}$ and (b) multipole modeling at $0.2 \mathrm{e} / \AA^{3}$ and (c)-(e) contour plots of the residual density after multipole refinement (positive values are plotted as solid lines, negative values as dashed ones and the zero value is drawn dotted; the stepsize of the contour lines is $0.1 \mathrm{e} / \AA^{3}$ ).

The results of the Hirshfeld test show that the deconvolution of thermal motion and density deformation worked (cf. Table 2-9). Only the DMSDA's for O2-C61, O1-C54, and C3-C32 are higher than expected. This should be interpreted as a sign of a very slight disorder, which is not to resolve. Other features, which will be discussed later (determinability and position of the VSCCs, vide infra), point to the same direction. 
This is not problematic, because it affects only the outer sphere of the molecule and does, thus, not influence the discussed properties.

Table 2-9: DMSDA's along interatomic vectors (an asterisk denotes a bond) of $\left[(\text { thf }) \mathrm{Li}_{2}\left[\mathrm{H}_{2} \mathrm{CS}\left(\mathrm{N}^{t} \mathrm{Bu}\right)_{2}\right\}\right]_{2}(4)$.

\begin{tabular}{|c|c|c|c|c|c|c|c|c|c|}
\hline \multicolumn{2}{|c|}{ Atom $\rightarrow$ Atom } & $\mathrm{d}[\AA \AA]$ & DMSDA & Atom & $d[\AA]]$ & DMSDA & Atom & $d[\AA]$ & DMSDA \\
\hline S1 & N1 & *1.6487 & $-1 \cdot 10^{-3}$ & $\mathrm{~N} 2$ & *1.6561 & $-3 \cdot 10^{-3}$ & C5 & *1.7804 & $10 \cdot 10^{-3}$ \\
\hline S2 & N3 & *1.6583 & $-4 \cdot 10^{-3}$ & N4 & *1.6502 & $1 \cdot 10^{-3}$ & C6 & *1.7808 & $7 \cdot 10^{-3}$ \\
\hline O1 & C51 & 1.4383 & $9 \cdot 10^{-3}$ & C54 & 1.4389 & $17 \cdot 10^{-3}$ & & & \\
\hline $\mathrm{O} 2$ & C61 & 1.4413 & $22 \cdot 10^{-3}$ & C64 & 1.4372 & $2 \cdot 10^{-3}$ & & & \\
\hline N1 & $\mathrm{C} 1$ & 1.4763 & $0 \cdot 10^{-3}$ & & & & & & \\
\hline N2 & $\mathrm{C} 2$ & 1.4726 & $2 \cdot 10^{-3}$ & & & & & & \\
\hline N3 & C3 & 1.4755 & $2 \cdot 10^{-3}$ & & & & & & \\
\hline N4 & $\mathrm{C} 4$ & 1.4755 & $4 \cdot 10^{-3}$ & & & & & & \\
\hline C1 & C11 & *1.5259 & $-6 \cdot 10^{-3}$ & $\mathrm{C} 12$ & *1.5321 & $-12 \cdot 10^{-3}$ & C13 & *1.5306 & $0 \cdot 10^{-3}$ \\
\hline $\mathrm{C} 2$ & C21 & *1.5254 & $0 \cdot 10^{-3}$ & $\mathrm{C} 22$ & *1.5271 & $-2 \cdot 10^{-3}$ & $\mathrm{C} 23$ & *1.5310 & $-4 \cdot 10^{-3}$ \\
\hline C3 & C31 & *1.5114 & $-3 \cdot 10^{-3}$ & $\mathrm{C} 32$ & *1.5262 & $16 \cdot 10^{-3}$ & C33 & *1.5214 & $8 \cdot 10^{-3}$ \\
\hline C4 & C41 & *1.5225 & $2 \cdot 10^{-3}$ & $\mathrm{C} 42$ & *1.5213 & $-1 \cdot 10^{-3}$ & $\mathrm{C} 43$ & *1.5293 & $-3 \cdot 10^{-3}$ \\
\hline C51 & C52 & *1.5142 & $-1 \cdot 10^{-3}$ & & & & & & \\
\hline C52 & C53 & *1.5216 & $3 \cdot 10^{-3}$ & & & & & & \\
\hline C53 & C54 & *1.5156 & $1 \cdot 10^{-3}$ & & & & & & \\
\hline C61 & C62 & *1.5059 & $8 \cdot 10^{-3}$ & & & & & & \\
\hline C62 & C63 & *1.5311 & $-1 \cdot 10^{-3}$ & & & & & & \\
\hline C63 & C64 & *1.5083 & $2 \cdot 10^{-3}$ & & & & & & \\
\hline
\end{tabular}

\subsection{Topological Analyses}

\subsubsection{Quantum Theory of Atoms in Molecules}

A mere look at the static deformation density itself is not sufficient to get an insight in the electronic situation of a molecule. The deformation density is dependent of the reference state (i.e. the IAM model) and the interesting features are not clearly visible. To overcome these problems an analysis according to Bader's QTAIM (quantum theory of atoms in molecules) ${ }^{[203]}$ has to be performed. Throughout this topological analysis the total density of the molecule is partitioned into atomic basins. 
These basins are separated by the so-called zero flux surfaces, where $\nabla \rho(\mathbf{r}) \cdot \mathbf{n}(\mathbf{r})$ vanishes. The atoms are allowed to exchange charge and momentum across this surface. Thus, atoms of the same type are no longer equal with respect to their electronic features and the shape of their boundaries. The analytic tools to analyze the electron density distribution in terms of QTAIM are presented in the following chapters.

\subsubsection{The Laplacian}

The electron density distribution contains all information of interest, but due to the distinct density concentrations at the nuclei, features are hard to explore within $\rho(\mathbf{r})$. Therefore, the first and second order derivatives of $\rho$ (r) (cf. Eq. 2-18 and Eq. 2-19) are investigated.

Eq. 2-18: $\nabla \rho(\mathbf{r})=\mathbf{i} \frac{\partial \rho}{\partial x}+\mathbf{j} \frac{\partial \rho}{\partial y}+\mathbf{k} \frac{\partial \rho}{\partial z} \quad$ Eq. 2-19: $\quad \nabla^{2} \rho(\mathbf{r})=\frac{\partial^{2} \rho}{\partial x^{2}}+\frac{\partial^{2} \rho}{\partial y^{2}}+\frac{\partial^{2} \rho}{\partial z^{2}}$

$\mathbf{i}, \mathbf{j}, \mathbf{k}$ are the unit vectors of the Cartesian coordinate system. $\nabla^{2} \rho(\mathbf{r})$ is the trace of the Hessian matrix, which is defined as symmetric matrix of the nine second order derivatives of $\rho(\mathbf{r})$. It is also called Laplacian.

Eq. 2-20:

$$
\mathbf{H}(\mathbf{r})=\left(\begin{array}{ccc}
\frac{\partial^{2} \rho}{\partial x^{2}} & \frac{\partial^{2} \rho}{\partial x \partial y} & \frac{\partial^{2} \rho}{\partial x \partial z} \\
\frac{\partial^{2} \rho}{\partial y \partial x} & \frac{\partial^{2} \rho}{\partial y^{2}} & \frac{\partial^{2} \rho}{\partial y \partial z} \\
\frac{\partial^{2} \rho}{\partial z \partial x} & \frac{\partial^{2} \rho}{\partial z \partial y} & \frac{\partial^{2} \rho}{\partial z^{2}}
\end{array}\right)_{\mathbf{r}}
$$

The value of the Laplacian displays whether a local charge concentration $\left(\nabla^{2} \rho(\mathbf{r})<0\right)$ or depletion $\left(\nabla^{2} \rho(\mathbf{r})>0\right)$ is present. Furthermore, due to the generation of the second derivative, small changes in the spatial distribution of the electron density become emphasized. Thus, the Laplacian is an excellent tool to analyze the shell structure of atoms or their bonding and non-bonding electron distributions (cf. Figure 2-19c). Although the Laplacian shows a shell structure for atoms, the charge density distribution does not. $\rho(\mathbf{r})$ declines monotonically in all directions away from the nucleus. 


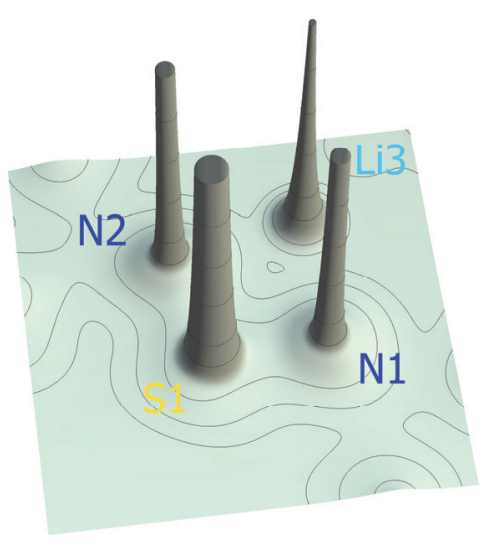

(a)

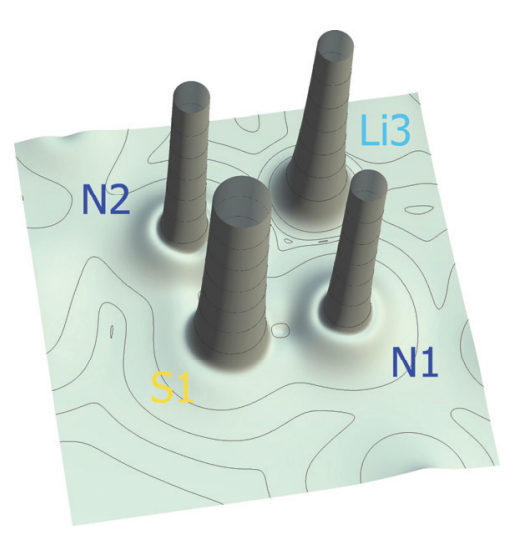

(b)

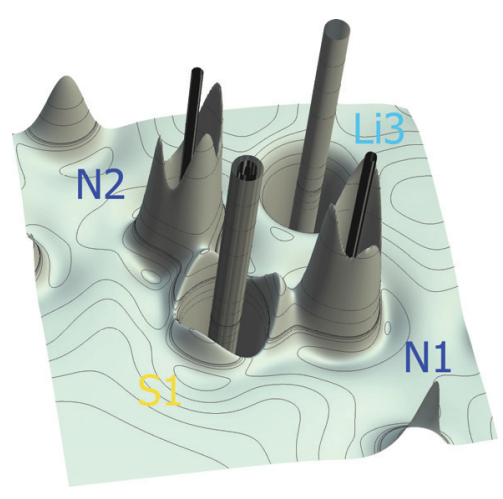

(c)

Figure 2-19: (a) Electron density $\rho(\mathbf{r})$, (b) $\nabla \rho(\mathbf{r})$, and (c) negative Laplacian $-\nabla^{2} \rho(\mathbf{r})$ in the $\mathrm{S} 1-\mathrm{N} 1-\mathrm{N} 2$ plane of $\left[(\text { thf }) \mathrm{Li}_{2}\left\{\mathrm{H}_{2} \mathrm{CS}\left(\mathrm{N}^{t} \mathrm{Bu}\right)_{2}\right\}\right]_{2}(4)$.

The Laplacian of $\rho(\mathbf{r})$ is connected to the electronic energy distribution by the local form of the virial theorem (cf. Eq. 2-21). ${ }^{[204]}$

Eq. 2-21:

$$
\left(\hbar^{2} / 4 m\right) \nabla^{2} \rho(\mathbf{r})=2 G(\mathbf{r})+V(\mathbf{r})
$$

$G(\mathbf{r})$ and $V(\mathbf{r})$ denote the electronic kinetic and potential energy density, respectively. The electronic energy density $\mathrm{H}_{/}(\mathbf{r})$ (cf. Eq. 2-22) is then a criterion to judge whether a bond is dominantly covalent or ionic. ${ }^{[204]}$

\section{Eq. 2-22:}

$$
H_{l}(\mathbf{r})=G(\mathbf{r})+V(\mathbf{r})
$$

Negative $H_{l}(\mathbf{r})$ are observed for shared interactions of covalent bonding. They are accompanied by charge density accumulations $\left(\nabla^{2} \rho(\mathbf{r})<0\right)$ in the bonding region. For the closed-shell interaction of ionic bonding $H_{/}(\mathbf{r})$ is positive and the charge density is depleted $\left(\nabla^{2} \rho(\mathbf{r})>0\right) .{ }^{[205,206]}$

\subsubsection{Critical Points}

In Bader's theory, points in space with vanishing $\nabla \rho(\mathbf{r})$, the CPs (critical points), are of great importance for the discussion of features of $\rho(\mathbf{r})$. Those points can be characterized by use of the diagonalized Hessian matrix $\mathbf{D}\left(\mathbf{r}_{\mathrm{c}}\right)$ at the critical point (Eq. 2-23).

Eq. 2-23: $\quad \mathbf{D}\left(\mathbf{r}_{\mathrm{CP}}\right)=\left(\begin{array}{ccc}\frac{\partial^{2} \rho}{\partial x^{2}} & 0 & 0 \\ 0 & \frac{\partial^{2} \rho}{\partial y^{2}} & 0 \\ 0 & 0 & \frac{\partial^{2} \rho}{\partial z^{2}}\end{array}\right)_{r=r_{c}}=\left(\begin{array}{ccc}\lambda_{1} & 0 & 0 \\ 0 & \lambda_{2} & 0 \\ 0 & 0 & \lambda_{3}\end{array}\right)$ 
The rank $m$ of $\mathbf{D}\left(r_{C P}\right)$ is defined as number of non-zero eigenvalues $\lambda_{i}$, whereas the signature $n$ of $\mathbf{D}\left(r_{C P}\right)$ is the algebraic sum of the signs of the eigenvalues $\lambda_{i}$. In a three-dimensional space $(m=3)$ there are four possible types of CPs with $(m, n)$ :

$(3,-3)$ : local maximum - all eigenvalues negative - atomic position $\rightarrow$ AP (atom position) $(3,-1)$ : saddle point, maximum in two directions and minimum in the third - two eigenvalues negative - chemical bond $\rightarrow \mathrm{BCP}$ (bond critical point)

$(3,+1)$ : minimum in two directions and maximum in the third - one eigenvalue negative - center of a ring of connected atoms $\rightarrow R C P$ (ring critical point)

$(3,+3)$ : local minimum - all eigenvalues positive - center of a cube of connected atoms $\rightarrow$ CCP (age critical point)

A BCP is the necessary and sufficient condition for the existence of a chemical bond in terms of the QTAIM. ${ }^{[203,207]}$ The electron density concentration diminishes from the atoms towards the BCP along the bond path. The bond path is a maximum of the electron density distribution in all other directions.

The CPs of $\rho(\mathbf{r})$ do not account for the electron pairs of the Lewis or VSEPR (valence shell electron pair repulsion) model. Therefore, the Laplacian has to be checked for its CPs. The $(3,-3)$ CPs in $\nabla^{2} \rho(\mathbf{r})$ are called VSCCs and indicate bonding electron pairs and non-bonding charge concentrations (lone-pairs). ${ }^{[08]}$ The VSCCs can be utilized to determine the density-related bonding geometry of an atom. ${ }^{[209-212]}$ This depicts the hybridization better than the traditional interatomic vectors do. Especially, the description of atoms involved in bent bonds is enhanced by this method. The use of the density-related bonding angles leads to a higher agreement with the ones anticipated from VSEPR. ${ }^{[213-216]}$ Actually, according to Bader, ${ }^{[217]}$ the VSEPR model can be reduced to the simple rule, that the most stable molecular geometry is the one with maximum separation of the VSCCs defined by the Laplacian. Additionally, the number of VSCCs can be used to deduce the hybridization state of the atoms.

The search for all these CP-types is very extensive because $\nabla^{2} \rho(\mathbf{r})$ changes rapidly. Thus, the numerical algorithms have to be very sensitive. The program XDPROP in the XD2006 package provides such algorithms. ${ }^{[172]}$

The plausibility of the results can be checked by the Poincaré-Hopf equation. ${ }^{[18,219]} n_{i}$ denotes the number of CPs of the type $i$ (Eq. 2-24).

Eq. 2-24:

$\mathrm{n}_{\mathrm{AP}}-\mathrm{n}_{\mathrm{BCP}}+\mathrm{n}_{\mathrm{RCP}}-\mathrm{n}_{\mathrm{CCP}}=1$ 


\subsubsection{Classification of Bonds}

Whenever a bond path connecting two atoms is found, the charge density distribution in this region can be examined to estimate the type of bonding. It is not only possible to deduce if the bonding is dominated by closed-shell or shared interactions, but to decide if single, double or triple bonds are present.

The BO (b्bond order) may be calculated from the charge density concentration $\rho\left(r_{\mathrm{BCP}}\right)$ at the BCP if similar bonds of known bond order have been investigated. $A$ and $B$ of Eq. 2-25 need to be determined from the reference bonds.

\section{Eq. 2-25:}

$$
B O=\exp \left[A\left(\rho\left(\mathbf{r}_{\mathrm{BCP}}\right)-B\right)\right]
$$

The value of the Laplacian $\nabla^{2} \rho\left(r_{\mathrm{BCP}}\right)$ is, as already mentioned, an indicator of shared (covalent bonding, $\nabla^{2} \rho\left(\mathrm{r}_{\mathrm{BCP}}\right)<0$ ) or closed-shell interactions (ionic bonding, $\left.\nabla^{2} \rho\left(\mathrm{r}_{\mathrm{BCP}}\right)>0\right)$.

A comparison of the eigenvalues $\lambda_{i}$ (cf. Figure 2-20) makes a judgment on the ellipticity possible and yields further hints to covalent $v s$. ionic bonding.

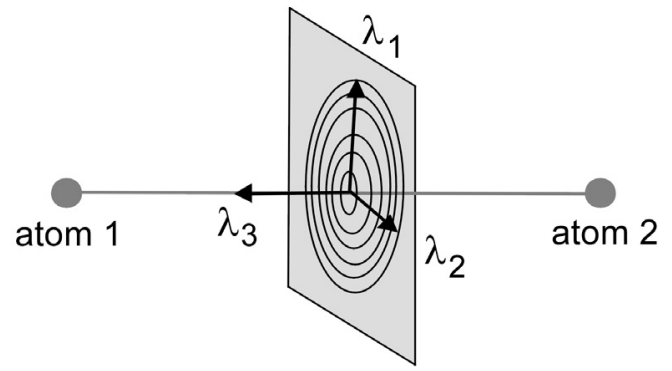

Figure 2-20: Spatial orientation of the eigenvalues $\lambda_{\mathrm{i}}$

$\left|\lambda_{1}\right| / \lambda_{3}$ is the ratio of the largest contraction of electron density perpendicular to the bond $\lambda_{1}$ to the concentration parallel to the bond $\lambda_{3} .\left|\lambda_{1}\right| / \lambda_{3} \leq 1$ is typical for closed-shell interactions. The ratio increases with bond strength and decreases with an increase of ionic contribution to the bonding.

The ellipticity of a bond is defined as $\varepsilon=\lambda_{1} / \lambda_{2}-1$. Pure $\sigma$-bonds have perfect rotational symmetry and an ellipticity of $0 . \varepsilon>0$ indicates $\pi$-contribution to the bonding. Typical $\pi$-bonds show an ellipticity above 0.2 . For triple bonds rotational symmetry is again present and $\varepsilon$ equals zero.

The above-mentioned criteria have to be examined carefully. Effects other than the discussed ones might also lead to the mentioned features. Especially the ellipticity can easily be influenced by nearby lone-pair densities, hydrogen bonding, etc. ${ }^{[81]}$ The 
characteristics of polar bonds and bonds to or between metals may also differ from the anticipated ones. ${ }^{[82,106]}$

\subsubsection{Atomic Charges}

The topological analysis allows to derive physically meaningful charges by integrating the electron density over the atomic basins separated by the zero flux condition $\nabla \rho(\mathbf{r}) \cdot \mathbf{n}(\mathbf{r})=0$. These charges originate from bond polarization effects as well as charge transfer between the atomic centers. In contrast, atomic net charges are calculated from the difference of the number of valence electrons of the element and the monopole populations of the given atom. Therefore, they result directly from electron density shifts between atoms within the refinement routine and account for atomic charge transfer in the molecule. Additionally, the net charges correspond to the charges originating from a mere monopole refinement (charge transfer and expansion/contraction, but no density deformation allowed).

The determined charges have to result in an overall charge of zero (electroneutrality) in order to be reliable. Additionally, the Lagrangian $L$ should be inspected as quality criterion. It gauges the accuracy of the integrated charges and should ideally be below $1 \cdot 10^{-4}$ au for hydrogen atoms, below $1 \cdot 10^{-3}$ au for second row atoms and might exceed this limit for atoms of higher rows. ${ }^{[172]}$

Eq. 2-26:

$$
L_{i}=-\frac{1}{4} \int_{i} \nabla^{2} \rho(\mathbf{r}) \mathrm{d} \tau
$$

\subsubsection{Topological Features of the Charge Density Distribution of 4}

The following discussion of properties will focus on one half of the double-cube dimer, as the other half is related to the first by a molecular non-crystallographic center of inversion, which is only disobeyed by the peripheral thf carbon atoms. The topological properties have been determined for both halves individually but show no significant differences.

The discussion will first focus on the properties of the critical points in $\rho(\mathbf{r})$, continue with those of the CPs in $\nabla^{2} \rho$ (r) (VSCCs) and the geometrical features thereof, and will end with a comparison of the bonding types and the Laplacian distribution along the bond paths. All of this will shed some light on the questions posed in the 
introduction: I) What kind of $S-N$ bonding is present $\left(S=N\right.$ vs. $\left.S^{+}-N\right)$ ? II) Is the $\mathrm{S}-\mathrm{C}$ bond ylenic $(\mathrm{S}=\mathrm{C})$ or ylidic $\left(\mathrm{S}^{+}-\mathrm{C}\right)$ ? III) Is, thus, the sulfur atom hypervalent? IV) What kind of interaction between the carbanion and the lithium atoms is present?

\section{Properties of the CPs in $\rho(r)$}

All BCPs for $\left[(\text { thf }) \mathrm{Li}_{2}\left\{\mathrm{H}_{2} \mathrm{CS}\left(\mathrm{N}^{t} \mathrm{Bu}\right)_{2}\right\}\right]_{2}(4)$ along with the resulting RCPs and the CCP have been determined with the routines implemented in XDPROP (cf. Figure 2-16). ${ }^{[172]}$ Some CPs could not be found with the standard routine at first hand. This is due to a tendency of the algorithm to rather find RCPs than BCPs if both are located close to each other. In these cases the positions of the CPs were determined from the trajectory plots, which are generated by another algorithm. In order to check the reliability of the approach a search with the standard routine at the determined coordinates was performed. By this method, all CPs were also found by the standard algorithm.

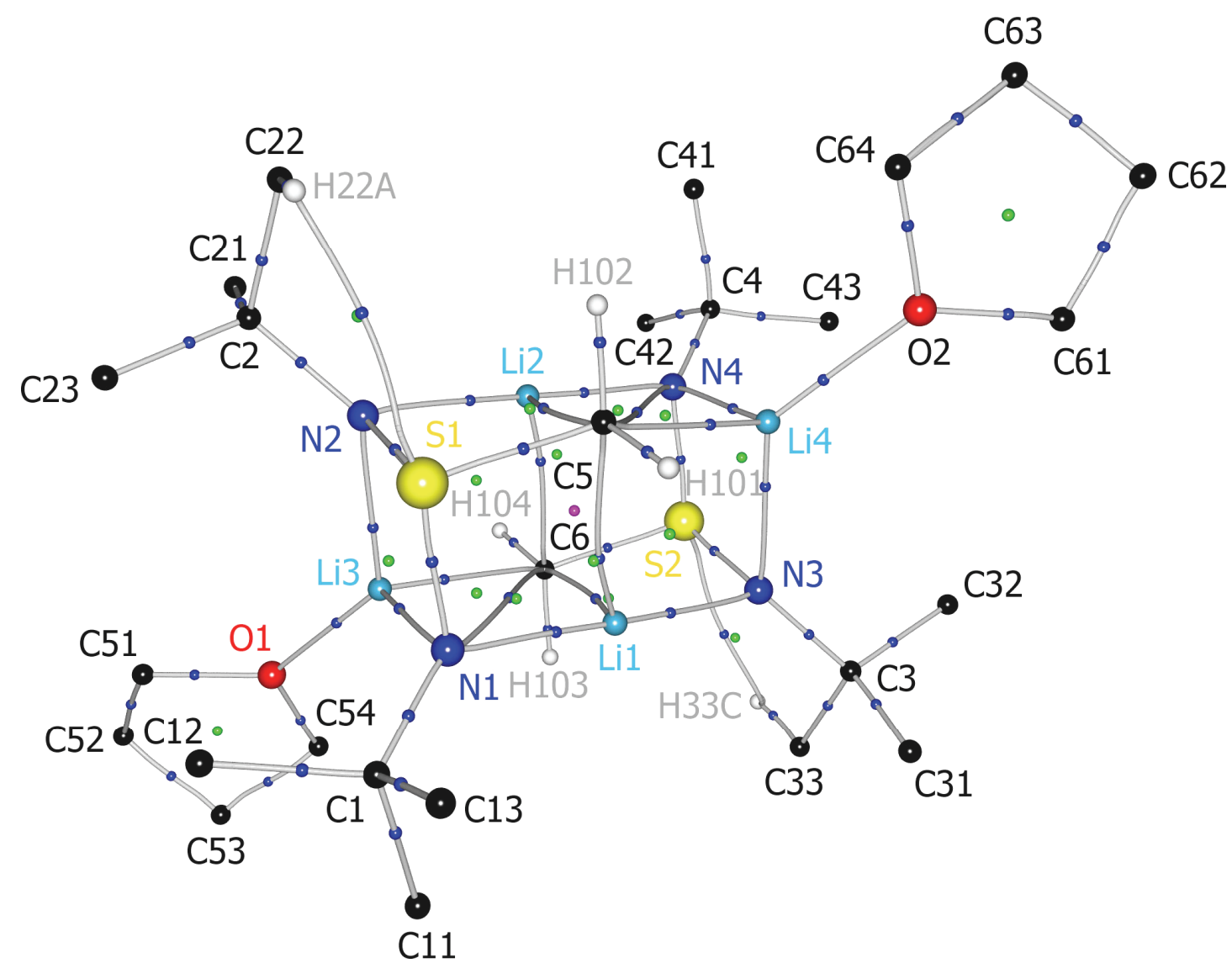

Figure 2-21: Molecular graph of $\left[(\operatorname{thf}) \mathrm{Li}_{2}\left\{\mathrm{H}_{2} \mathrm{CS}\left(\mathrm{N}^{t} \mathrm{Bu}\right)_{2}\right\}\right]_{2}$ (4); blue spheres denote the positions of the BCPs, green ones the RCPs and the magenta one the CCP; hydrogen atoms (except H101, H102, $\mathrm{H} 103, \mathrm{H} 103, \mathrm{H} 22 \mathrm{~A}, \mathrm{H} 33 \mathrm{C}$ ), their BCPs and bond paths are omitted for clarity. 
For all bond paths the topological properties were determined and are listed for all bonds inside and to the double-cube in Table 2-10.

Table 2-10: Topological properties of selected bonds in $\left[(\text { thf }) \mathrm{Li}_{2}\left[\mathrm{H}_{2} \mathrm{CS}\left(\mathrm{N}^{t} \mathrm{Bu}\right)_{2}\right\}\right]_{2}(4)$; an asterisk marks the paths not anticipated from chemical bonding.

\begin{tabular}{|c|c|c|c|c|c|c|}
\hline & $d_{\text {geom }}[\AA]$ & $\left.d_{\text {bond path }}[\AA]\right]$ & $d_{\text {atom1-BCP }}[\AA]$ & $\rho\left(\mathbf{r}_{\mathrm{BCP}}\right)\left[\mathrm{e} / \AA^{3}\right]$ & $\nabla^{2} \rho\left(\mathbf{r}_{\mathrm{BCP}}\right)\left[\mathrm{e} / \AA^{5}\right]$ & $\varepsilon$ \\
\hline S1-N1 & $1.6487(4)$ & 1.65057 & 0.7600 & $1.670(19)$ & $-11.518(56)$ & 0.07 \\
\hline $\mathrm{S} 1-\mathrm{N} 2$ & $1.6561(4)$ & 1.65952 & 0.6902 & $1.547(22)$ & $-9.774(70)$ & 0.30 \\
\hline S1-C5 & $1.7803(4)$ & 1.78210 & 0.9858 & $1.369(12)$ & $-5.214(28)$ & 0.12 \\
\hline C5-Li1 & $2.4013(9)$ & 2.42446 & 1.5580 & $0.078(1)$ & $+1.663(1)$ & 5.43 \\
\hline C5-Li2 & $2.3829(9)$ & 2.40134 & 1.5438 & $0.080(1)$ & $+1.747(1)$ & 2.21 \\
\hline C5-Li4 & $2.2753(8)$ & 2.28786 & 1.4760 & $0.107(1)$ & $+2.299(1)$ & 0.06 \\
\hline $\mathrm{N} 1-\mathrm{C} 1$ & $1.4763(6)$ & 1.47776 & 0.8211 & $1.875(9)$ & $-12.959(31)$ & 0.03 \\
\hline $\mathrm{N} 2-\mathrm{C} 2$ & $1.4726(6)$ & 1.47424 & 0.8070 & $1.835(9)$ & $-10.675(30)$ & 0.05 \\
\hline N1-Li1 & $1.9822(8)$ & 1.98375 & 1.2531 & $0.201(2)$ & $+5.166(2)$ & 0.06 \\
\hline N1-Li3 & $2.1047(9)$ & 2.10880 & 1.3280 & $0.129(2)$ & $+3.580(1)$ & 0.13 \\
\hline N2-Li2 & $2.0085(9)$ & 2.01200 & 1.2726 & $0.187(2)$ & $+4.905(2)$ & 0.08 \\
\hline N2-Li3 & $2.0589(9)$ & 2.06042 & 1.2991 & $0.154(2)$ & $+3.994(2)$ & 0.08 \\
\hline O1-Li3 & $1.9472(9)$ & 1.94745 & 1.2002 & $0.150(2)$ & $+5.110(2)$ & 0.01 \\
\hline O2-Li4 & $1.9492(9)$ & 1.94964 & 1.2025 & $0.151(2)$ & $+5.053(2)$ & 0.04 \\
\hline C5-H101 & $1.0850(4)$ & 1.08520 & 0.7426 & $1.655(16)$ & $-15.076(55)$ & 0.05 \\
\hline C5-H102 & $1.0850(4)$ & 1.08518 & 0.7425 & $1.654(8)$ & $-15.077(22)$ & 0.05 \\
\hline $\mathrm{C} 5-\mathrm{N} 4^{*}$ & $3.4525(6)$ & 3.47557 & 1.7926 & $0.045(0)$ & $+0.509(0)$ & 1.23 \\
\hline $\mathrm{C} 6-\mathrm{N} 1^{*}$ & $3.4987(7)$ & 3.52441 & 1.8160 & $0.042(0)$ & $+0.489(0)$ & 3.49 \\
\hline $\mathrm{S} 2-\mathrm{H} 33 \mathrm{C}^{*}$ & $2.7072(4)$ & 2.89245 & 1.6190 & $0.094(0)$ & $+0.872(0)$ & 0.42 \\
\hline $\mathrm{N} 2-\mathrm{H} 22 \mathrm{~A}^{*}$ & $5.0517(8)$ & 2.79846 & 3.6529 & $0.078(2)$ & $+0.793(1)$ & 1.41 \\
\hline
\end{tabular}

The molecular graph in Figure 2-21 shows, that four bond paths and their corresponding BCPs and RCPs not anticipated from chemical intuition were found (C5-N4, C6-N1, S2-H33C, N2-H22A). The nature of these intramolecular contacts between chemically non-bonded atoms is widely discussed in the literature, but no decisive point has been made so far. ${ }^{[220-222]}$ Similar contacts have also been described for nitrogen and phosphorus ylides. ${ }^{[223,224]}$ The low $\rho\left(\mathbf{r}_{\mathrm{BCP}}\right)=0.4-0.9 \mathrm{e} / \AA^{3}$ of the four mentioned BCPs matches the ones in the literature ${ }^{[223,224]}$ and implies that they are either artifacts or arise from a bonding type which is so far unknown. 
Although these bond paths occur, the model is self-consistent because the corresponding RCPs arise, too. For example, the existence of the bond path C5-N4 leads to the formation of two RCPs in the $\mathrm{CLi}_{2} \mathrm{~N}$ plane instead of just one. Thus, the Poincaré-Hopf equation (Eq. 2-24) is obeyed (cf. Eq. 2-27).

Eq. 2-27:

$$
n_{\max }-n_{B C P}+n_{R C P}-n_{C C P}=94-108+16-1=1
$$

Interestingly, just one CCP was determined for the double-cube. It is located in the center of the $\left[\mathrm{Li}_{2}\left\{\mathrm{H}_{2} \mathrm{CSN}_{2}\right\}\right]_{2}$-core and in the common $\mathrm{Li}_{2} \mathrm{C}_{2}$ face (cf. Figure 2-22).

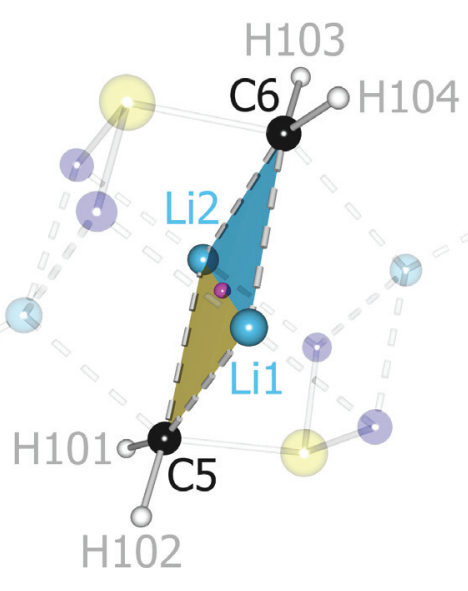

(a)

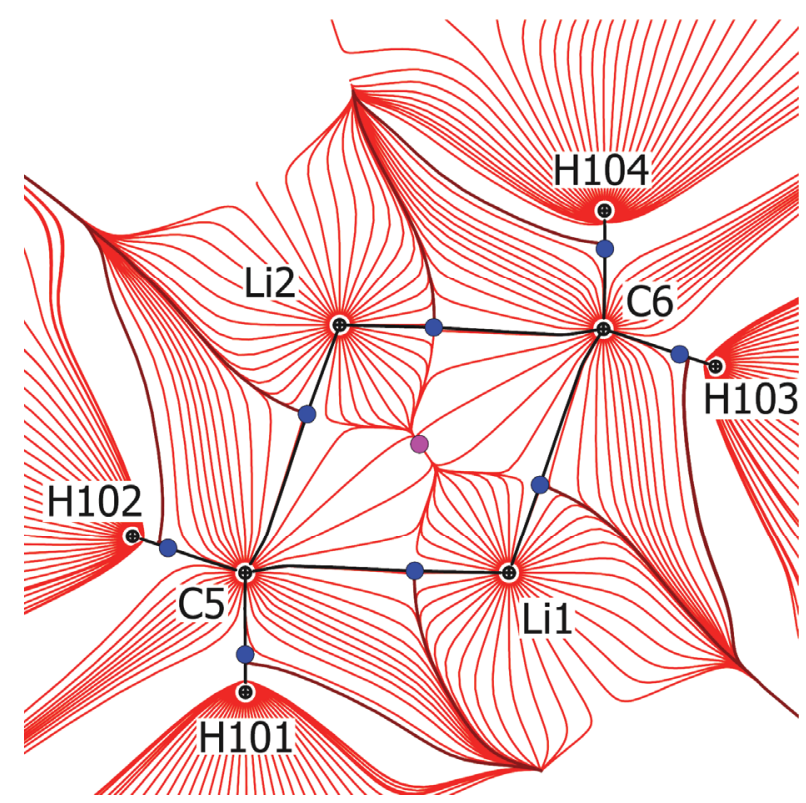

(b)

Figure 2-22: (a) Inter-cubic $\mathrm{C}_{2} \mathrm{Li}_{2}$ face in $\left[(\text { thf }) \mathrm{Li}_{2}\left\{\mathrm{H}_{2} \mathrm{CS}\left(\mathrm{N}^{t} \mathrm{Bu}\right)_{2}\right\}\right]_{2}(4)$ and (b) trajectory plot of the same plane (BCPs are plotted as blue dots, CCPs as magenta ones and bond paths as black solid lines; RCPs would appear as green dots).

One could expect two CCPs if there were two individual cubes. From the topological point of view the double-cube should hence be interpreted as a single cuboid instead of two connected individual cubes. Necessarily, no RCP was found in the face connecting the two cubes, since the position of the CCP in this face renders it impossible. In the CCP-Li1-RCP $\mathrm{SN}_{2} \mathrm{Li}$-plane the density ascends all the way from the double-cube center to the top face (cf. Figure 2-23). Hence, the necessary condition for CCPs in the individual cubes cannot be fulfilled. Starting from the cube center the density concentration first ascends due to the lone-pair density of the anionic carbon atom, but before the density of this lone pair descends again the density region of the nitrogen atoms begins and accounts for a further ascend of density concentration towards the $\mathrm{RCP}_{\mathrm{SN}_{2} \mathrm{Li}}$. 


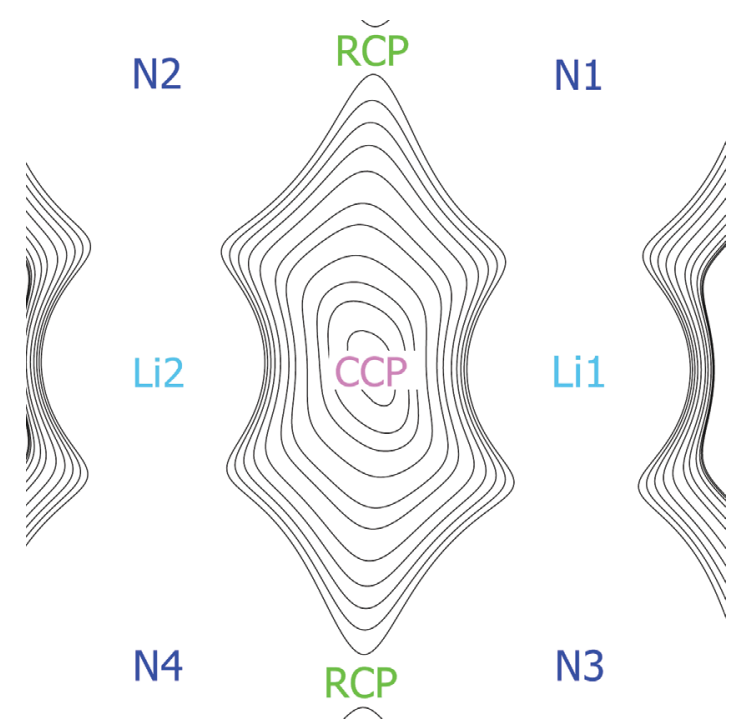

Figure 2-23: Electron density distribution in the CCP-Li1-RCP ${ }_{S N 2 L i}$-plane of $\left[(t h f) \mathrm{Li}_{2}\left\{\mathrm{H}_{2} \mathrm{CS}\left(\mathrm{N}^{t} \mathrm{Bu}\right)_{2}\right\}\right]_{2}(4)$.

In order to get a better impression of the important bonding interactions in $\left[(\text { thf }) \mathrm{Li}_{2}\left\{\mathrm{H}_{2} \mathrm{CS}\left(\mathrm{N}^{t} \mathrm{Bu}\right)_{2}\right\}\right]_{2}(4)$, another graph is depicted in Figure 2-24 showing only bonding interactions with $\rho\left(\mathbf{r}_{\mathrm{BCP}}\right)>0.1 \mathrm{e} / \AA^{3}$ and the CPs important for the discussion.

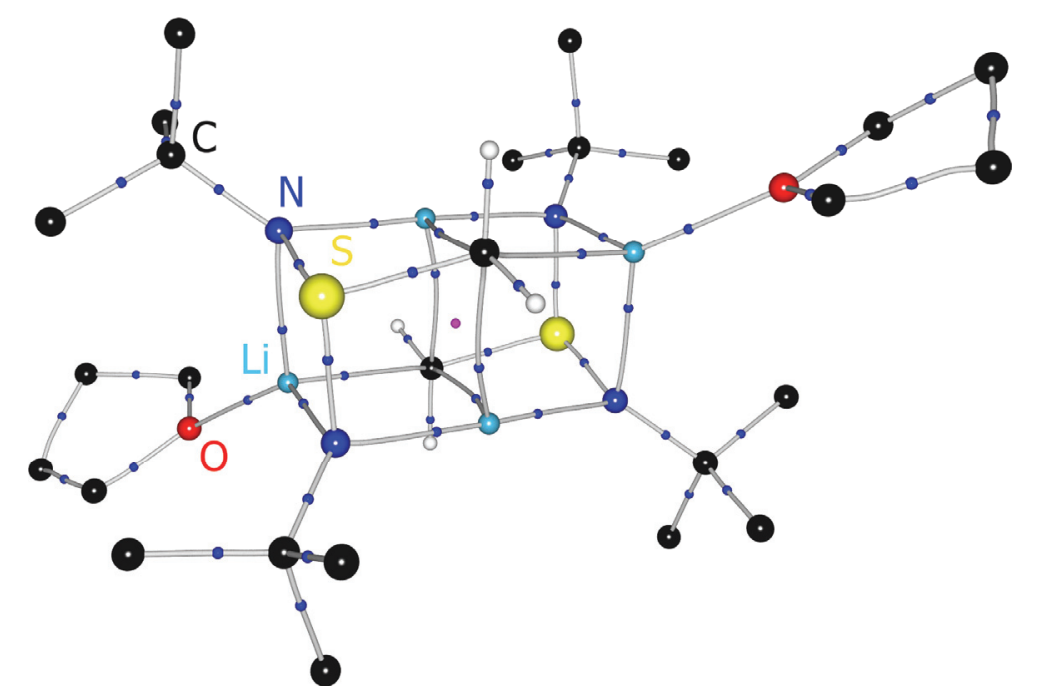

Figure 2-24: Graphical representation of the bond paths along the chemical connectivities in $\left[(\text { thf }) \mathrm{Li}_{2}\left\{\mathrm{H}_{2} \mathrm{CS}\left(\mathrm{N}^{t} \mathrm{Bu}\right)_{2}\right\}\right]_{2}(4)$; blue spheres denote the positions of the BCPs, the magenta the CCP; hydrogen atoms (except the methylene ones) and their BCPs and bond paths are omitted for clarity.

\section{VSCCs and Density-related Geometry}

By inspection of the second derivative of the charge density distribution $\nabla^{2} \rho(\mathbf{r})$ with TOPXD, ${ }^{[172]}$ the VSCCs of $\left[(\text { thf }) \mathrm{Li}_{2}\left\{\mathrm{H}_{2} \mathrm{CS}\left(\mathrm{N}^{t} \mathrm{Bu}\right)_{2}\right\}\right]_{2}(\mathbf{4})$ have been determined. This study enabled all anticipated VSCCs to be determined except for two. The missing VSCCs were expected to be present near the C61-H61A and C61-H61B vectors. 
Instead, two $(3,+1)$ CPs in $\nabla^{2} \rho(\mathbf{r})$ were found near these positions and a $(3,+3) \mathrm{CP}$ in the bisection of the $\mathrm{H}-\mathrm{C}-\mathrm{H}$ angle. This is, together with the high DMSDA's for the bonds to C61, a sign of a slight disorder, which cannot be resolved in this polymorph. Nevertheless, such an exhaustive determination of VSCCs is unprecedented. In order to refer to a $\mathrm{CC}$ unequivocally, the following nomenclature was invented: $\mathrm{CC}_{i \rightarrow j}$ denotes a charge concentration at atom $i$ in the direction of atom $j, \operatorname{LP}_{i \rightarrow j}$ accordingly a lone-pair at atom $i$ in the direction of atom $j . \mathrm{LP}_{i}$ is either an NBCC (non-bonding charge concentration) at atom $i$ or an $\mathrm{Li}_{3}$ face directed lone-pair.

On this basis, the geometrical discussion from the polymorphism paragraph can be complemented by an analysis of the density-related bonding angles (cf. Table 2-11)., which better reflect the true coordination geometry of an atom, because the VSCCS are bond-induced charge concentrations of the atomic valence shell. In addition, it is possible to deduce the hybridization state of an atom from the number and geometry of its VSCCs.

Table 2-11: Selected bond angles calculated from the atomic positional parameters and those calculated from the VSCC arrangement of $\left[(\text { thf }) L_{2}\left\{\mathrm{H}_{2} \mathrm{CS}\left(\mathrm{N}^{t} \mathrm{Bu}\right)_{2}\right\}\right]_{2}(4)$.

\begin{tabular}{|c|c|c|}
\hline & $\begin{array}{l}\text { bond } \\
\text { angle }\end{array}$ & $\begin{array}{c}\text { CC } \\
\text { angle }\end{array}$ \\
\hline $\mathrm{N} 1-\mathrm{S} 1-\mathrm{N} 2$ & $103.97(2)^{\circ}$ & \\
\hline $\mathrm{CC}_{\mathrm{S} 1 \rightarrow \mathrm{N} 1}-\mathrm{S} 1-\mathrm{CC}_{\mathrm{S} 1 \rightarrow \mathrm{N} 2}$ & & $107.5^{\circ}$ \\
\hline $\mathrm{C} 5-\mathrm{S} 1-\mathrm{N} 1$ & $99.30(2)^{\circ}$ & \\
\hline $\mathrm{CC}_{\mathrm{S} 1 \rightarrow \mathrm{C} 5}-\mathrm{S} 1-\mathrm{CC}_{\mathrm{S} 1 \rightarrow \mathrm{N} 1}$ & & $106.9^{\circ}$ \\
\hline $\mathrm{C} 5-\mathrm{S} 1-\mathrm{N} 2$ & $100.31(2)^{\circ}$ & \\
\hline $\mathrm{CC}_{\mathrm{S} 1 \rightarrow \mathrm{C} 5}-\mathrm{S} 1-\mathrm{CC}_{\mathrm{S} 1 \rightarrow \mathrm{N} 2}$ & & $102.2^{\circ}$ \\
\hline N1-S1-LP & - & \\
\hline $\mathrm{CC}_{\mathrm{S} 1 \rightarrow \mathrm{N} 1}-\mathrm{S} 1-\mathrm{LP}_{\mathrm{S} 1}$ & & $107.3^{\circ}$ \\
\hline N2-S1-LP & - & \\
\hline $\mathrm{CC}_{\mathrm{S} 1 \rightarrow \mathrm{N} 2}-\mathrm{S} 1-\mathrm{LP}_{\mathrm{S} 1}$ & & $108.6^{\circ}$ \\
\hline C5-S1-LP & - & \\
\hline $\mathrm{CC}_{\mathrm{S} 1 \rightarrow \mathrm{C} 5}-\mathrm{S} 1-\mathrm{LP}_{\mathrm{S} 1}$ & & $123.4^{\circ}$ \\
\hline
\end{tabular}

\begin{tabular}{|c|c|c|}
\hline & $\begin{array}{l}\text { bond } \\
\text { angle }\end{array}$ & $\begin{array}{c}\text { CC } \\
\text { angle }\end{array}$ \\
\hline $\mathrm{S} 1-\mathrm{N} 1-\mathrm{C} 1$ & $116.26(3)^{\circ}$ & \\
\hline $\mathrm{CC}_{\mathrm{N} 1 \rightarrow \mathrm{S} 1}-\mathrm{N} 1-\mathrm{CC}_{\mathrm{N} 1 \rightarrow \mathrm{C} 1}$ & & $101.9^{\circ}$ \\
\hline S1-N1-Li1 & $99.98(3)^{\circ}$ & \\
\hline $\mathrm{CC}_{\mathrm{N} 1 \rightarrow \mathrm{S} 1}-\mathrm{N} 1-\mathrm{LP}_{\mathrm{N} 1 \rightarrow \mathrm{Li} 1}$ & & $107.7^{\circ}$ \\
\hline S1-N1-Li3 & $88.62(3)^{\circ}$ & \\
\hline $\mathrm{CC}_{\mathrm{N} 1 \rightarrow \mathrm{S} 1}-\mathrm{N} 1-\mathrm{LP}_{\mathrm{N} 1 \rightarrow \mathrm{Li} 3}$ & & $116.1^{\circ}$ \\
\hline C1-N1-Li1 & $135.59(4)^{\circ}$ & \\
\hline $\mathrm{CC}_{\mathrm{N} 1 \rightarrow \mathrm{C} 1}-\mathrm{N} 1-\mathrm{LP}_{\mathrm{N} 1 \rightarrow \mathrm{Li} 1}$ & & $135.2^{\circ}$ \\
\hline C1-N1-Li3 & $122.88(4)^{\circ}$ & \\
\hline $\mathrm{CC}_{\mathrm{N} 1 \rightarrow \mathrm{C} 1}-\mathrm{N} 1-\mathrm{LP}_{\mathrm{N} 1 \rightarrow \mathrm{Li} 3}$ & & $106.9^{\circ}$ \\
\hline Li1-N1-Li3 & $80.39(3)^{\circ}$ & \\
\hline $\mathrm{LP}_{\mathrm{N} 1 \rightarrow \mathrm{Li} 1}-\mathrm{N} 1-\mathrm{LP}_{\mathrm{N} 1 \rightarrow \mathrm{Li} 3}$ & & $89.5^{\circ}$ \\
\hline
\end{tabular}


Table 2-11 (continued): Selected bond angles calculated from the atomic positional parameters and those calculated from the VSCC arrangement of $\left[(\text { thf }) \mathrm{Li}_{2}\left\{\mathrm{H}_{2} \mathrm{CS}\left(\mathrm{N}^{t} \mathrm{Bu}\right)_{2}\right\}\right]_{2}(4)$.

\begin{tabular}{|c|c|c|c|c|c|}
\hline & $\begin{array}{l}\text { bond } \\
\text { angle }\end{array}$ & $\begin{array}{c}\text { CC } \\
\text { angle }\end{array}$ & & $\begin{array}{l}\text { bond } \\
\text { angle }\end{array}$ & $\begin{array}{c}\text { CC } \\
\text { angle }\end{array}$ \\
\hline S1-C5-H101 & $104.16(3)^{\circ}$ & & $\mathrm{S} 1-\mathrm{N} 2-\mathrm{C} 2$ & $116.54(3)^{\circ}$ & \\
\hline $\mathrm{CC}_{\mathrm{C} 5 \rightarrow \mathrm{S} 1}-\mathrm{C} 5-\mathrm{CC}_{\mathrm{C} 5 \rightarrow \mathrm{H} 101}$ & & $110.9^{\circ}$ & $\mathrm{CC}_{\mathrm{N} 2 \rightarrow \mathrm{S} 1}-\mathrm{N} 2-\mathrm{CC}_{\mathrm{N} 2 \rightarrow \mathrm{C} 2}$ & & $105.7^{\circ}$ \\
\hline S1-C5-H102 & $103.52(3)^{\circ}$ & & $\mathrm{S} 1-\mathrm{N} 2-\mathrm{Li} 2$ & $98.40(3)^{\circ}$ & \\
\hline $\mathrm{CC}_{\mathrm{C} 5 \rightarrow \mathrm{S} 1}-\mathrm{C} 5-\mathrm{CC}_{\mathrm{C} 5 \rightarrow \mathrm{H} 102}$ & & $110.7^{\circ}$ & $\mathrm{CC}_{\mathrm{N} 2 \rightarrow \mathrm{S} 1}-\mathrm{N} 2-\mathrm{LP}_{\mathrm{N} 2 \rightarrow \mathrm{Li} 2}$ & & $108.1^{\circ}$ \\
\hline $\mathrm{H} 101-\mathrm{C} 5-\mathrm{H} 102$ & $106.47(4)^{\circ}$ & & $\mathrm{S} 1-\mathrm{N} 2-\mathrm{Li} 3$ & $90.00(3)^{\circ}$ & \\
\hline $\mathrm{CC}_{\mathrm{C} 5 \rightarrow \mathrm{H} 101}-\mathrm{C} 5-\mathrm{CC}_{\mathrm{C} 5 \rightarrow \mathrm{H} 102}$ & & $104.6^{\circ}$ & $\mathrm{CC}_{\mathrm{N} 2 \rightarrow \mathrm{S} 1}-\mathrm{N} 2-\mathrm{LP}_{\mathrm{N} 2 \rightarrow \mathrm{Li} 3}$ & & $92.4^{\circ}$ \\
\hline S1-C5-LP & - & & C2-N2-Li2 & $128.35(4)^{\circ}$ & \\
\hline $\mathrm{CC}_{\mathrm{C} 5 \rightarrow \mathrm{S} 1}-\mathrm{C} 5-\mathrm{LP}_{\mathrm{C} 5}$ & & $101.9^{\circ}$ & $\mathrm{CC}_{\mathrm{N} 2 \rightarrow \mathrm{C} 2}-\mathrm{N} 2-\mathrm{LP}_{\mathrm{N} 2 \rightarrow \mathrm{Li} 2}$ & & $113.4^{\circ}$ \\
\hline H101-C5-LP & - & & C2-N2-Li3 & $132.22(4)^{\circ}$ & \\
\hline $\mathrm{CC}_{\mathrm{C} 5 \rightarrow \mathrm{H} 101}-\mathrm{C} 5-\mathrm{LP}_{\mathrm{C} 5}$ & & $114.3^{\circ}$ & $\mathrm{CC}_{\mathrm{N} 2 \rightarrow \mathrm{C} 2}-\mathrm{N} 2-\mathrm{LP}_{\mathrm{N} 2 \rightarrow \mathrm{Li} 3}$ & & $118.1^{\circ}$ \\
\hline H102-C5-LP & - & & Li2-N2-Li3 & $80.62(3)^{\circ}$ & \\
\hline $\mathrm{CC}_{\mathrm{C} 5 \rightarrow \mathrm{H} 102}-\mathrm{C} 5-\mathrm{LP}_{\mathrm{C} 5}$ & & $114.6^{\circ}$ & $\mathrm{LP}_{\mathrm{N} 2 \rightarrow \mathrm{Li} 2}-\mathrm{N} 2-\mathrm{LP}_{\mathrm{N} 2 \rightarrow \mathrm{Li} 3}$ & & $115.8^{\circ}$ \\
\hline C51-O1-C54 & $109.70(5)^{\circ}$ & & & & \\
\hline $\mathrm{CC}_{\mathrm{O} 1 \rightarrow \mathrm{C} 51}-\mathrm{O} 1-\mathrm{CC}_{\mathrm{O} 1 \rightarrow \mathrm{C} 54}$ & & $110.3^{\circ}$ & & & \\
\hline C51-O1-LP & $129.18(5)^{\circ}$ & & & & \\
\hline $\mathrm{CC}_{\mathrm{O} 1 \rightarrow \mathrm{C} 51}-\mathrm{O} 1-\mathrm{LP}_{\mathrm{O} 1 \rightarrow \mathrm{Li} 3}$ & & $123.8^{\circ}$ & & & \\
\hline C51-O1-LP' & - & & & & \\
\hline $\mathrm{CC}_{\mathrm{O} 1 \rightarrow \mathrm{C} 51}-\mathrm{O} 1-\mathrm{LP}_{\mathrm{O} 1}$ & & $94.2^{\circ}$ & & & \\
\hline C54-O1-LP & $121.09(5)^{\circ}$ & & & & \\
\hline $\mathrm{CC}_{\mathrm{O} 1 \rightarrow \mathrm{C} 54}-\mathrm{O} 1-\mathrm{LP}_{\mathrm{O} 1 \rightarrow \mathrm{Li} 3}$ & & $117.8^{\circ}$ & & & \\
\hline C54-O1-LP' & - & & & & \\
\hline $\mathrm{CC}_{\mathrm{O} 1 \rightarrow \mathrm{C} 54}-\mathrm{O} 1-\mathrm{LP}_{\mathrm{O} 1}$ & & $104.2^{\circ}$ & & & \\
\hline LP-O1-LP' & - & & & & \\
\hline $\mathrm{LP}_{\mathrm{O} 1 \rightarrow \mathrm{Li} 3}-\mathrm{O} 1-\mathrm{LP}_{\mathrm{O} 1}$ & & $100.3^{\circ}$ & & & \\
\hline
\end{tabular}

The magnitude of the Laplacian at these CCs can be correlated to the anticipated strength of the bond (cf. Table 2-12 and Figure 2-4). This can help in determining the particular bonding type. 
Table 2-12: Laplacian of selected VSCCs in $\left[(\text { thf }) \mathrm{Li}_{2}\left\{\mathrm{H}_{2} \mathrm{CS}\left(\mathrm{N}^{t} \mathrm{Bu}\right)_{2}\right\}\right]_{2}(4)$.

\begin{tabular}{c|l|c}
\hline \multicolumn{1}{c}{ atom } & \multicolumn{1}{c}{$\mathrm{VSCC}$} & $\nabla^{2} \rho\left(\mathbf{r}_{\mathrm{VsCC}}\right)\left[\mathrm{e} / \AA^{5}\right]$ \\
\hline $\mathrm{S} 1$ & $\mathrm{CC}_{\mathrm{S} 1 \rightarrow \mathrm{N} 1}$ & -12.948 \\
& $\mathrm{CC}_{\mathrm{S} 1 \rightarrow \mathrm{N} 2}$ & -10.595 \\
& $\mathrm{CC}_{\mathrm{S} 1 \rightarrow \mathrm{C} 5}$ & -15.887 \\
& $\mathrm{LP}_{\mathrm{S} 1}$ & -18.068 \\
\hline \multirow{2}{*}{$\mathrm{C5}$} & $\mathrm{CC}_{\mathrm{C} 5 \rightarrow \mathrm{S} 1}$ & -17.330 \\
& $\mathrm{CC}_{\mathrm{C} 5 \rightarrow \mathrm{H} 101}$ & -24.953 \\
& $\mathrm{CC}_{\mathrm{C} 5 \rightarrow \mathrm{H} 102}$ & -24.955 \\
& $\mathrm{LP}_{\mathrm{C} 5}$ & -22.994 \\
\hline \multirow{2}{*}{$\mathrm{O} 1$} & $\mathrm{CC}_{\mathrm{O} 1 \rightarrow \mathrm{C} 51}$ & -111.9120 \\
& $\mathrm{CC}_{\mathrm{O} 1 \rightarrow \mathrm{C} 54}$ & -119.9303 \\
& $\mathrm{LP}_{\mathrm{O} 1}$ & -122.7456 \\
& $\mathrm{LP}_{\mathrm{O} 1}$ & -122.2583 \\
\hline
\end{tabular}

\begin{tabular}{|c|c|c|}
\hline atom & VSCC & $\nabla^{2} \rho\left(\mathbf{r}_{\mathrm{vscc}}\right)\left[\mathrm{e} / \AA^{5}\right]$ \\
\hline \multirow[t]{4}{*}{ N1 } & $\mathrm{CC}_{\mathrm{N} 1 \rightarrow \mathrm{S} 1}$ & -44.827 \\
\hline & $\mathrm{CC}_{\mathrm{N} 1 \rightarrow \mathrm{C} 1}$ & -48.898 \\
\hline & $\mathrm{LP}_{\mathrm{N} 1 \rightarrow \mathrm{Li} 1}$ & -59.594 \\
\hline & $\mathrm{LP}_{\mathrm{N} 1 \rightarrow \mathrm{L} i 3}$ & -51.264 \\
\hline \multirow[t]{4}{*}{ N2 } & $\mathrm{CC}_{\mathrm{N} 2 \rightarrow \mathrm{S} 1}$ & -46.125 \\
\hline & $\mathrm{CC}_{\mathrm{N} 2 \rightarrow \mathrm{C} 2}$ & -43.014 \\
\hline & $\mathrm{CC}_{\mathrm{N} 2 \rightarrow \mathrm{Li} 2}$ & -64.856 \\
\hline & $\mathrm{CC}_{\mathrm{N} 2 \rightarrow \mathrm{Li} 3}$ & -46.125 \\
\hline
\end{tabular}

VSCC properties and density-related geometry at the sulfur atoms:

Four VSCCs were found for the sulfur atom S1. Three of them are bond-directed CCs, one is a lone-pair density. As expected, the VSCC of the lone-pair is the strongest of these four. Interestingly, the two chemically equal S-N bonds differ in their $\nabla^{2} \rho\left(\mathbf{r}_{\mathrm{BCP}}\right)$. The difference of the nitrogen atoms will become more apparent throughout this work and will be discussed later. The four VSCCs at S1 suggest an $\mathrm{sp}^{3}$-hybridization (cf. Figure 2-25). This is supported by the geometrical features.

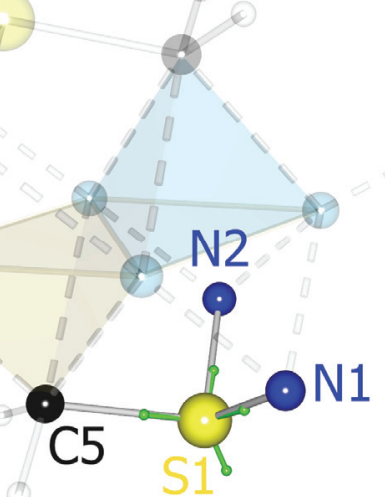

(a)

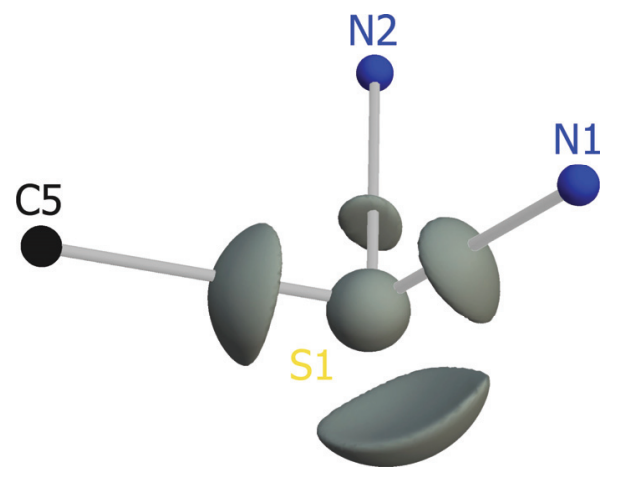

(b)

Figure 2-25: (a) Orientation of the VSCCs (green spheres) at S1 and (b) isosurface plot of $\nabla^{2} \rho\left(\mathbf{r}_{\mathrm{VscC}}\right)$ at the $-9 \mathrm{e} / \AA^{5}$ level around S1. 
The VSCC angles at S1 are very close to the tetrahedral angle. Even the VSEPR prediction that the lone-pair $L P_{S 1}$ takes up more space than the BCCs (bonding charge concentrations) is reflected in the density-related angles (A-LPS1-B $113.1^{\circ}$ on av.). In addition LP $\mathrm{S}_{\mathrm{S} 1}$ is bent farthest away from C5 $\left(123.4^{\circ}\right)$. This is in perfect agreement with the magnitude of the Laplacian at the CCs, which is largest for LP $P_{\mathrm{S} 1}$ $\left(-18.07 \mathrm{e} / \AA^{5}\right)$ followed by the BCC towards C5 $\left(-15.89 \mathrm{e} / \AA^{5}\right)$, while the nitrogen directed CCs are less pronounced $\left(-10.60\right.$ and $\left.-12.95 \mathrm{e} / \AA^{5}\right)$. Thus, the most prominent $\mathrm{CC}$ takes up the most space.

All this allows the conclusion that $\mathrm{S} 1$ is $\mathrm{sp}^{3}$-hybridized. This observation would not be possible based on angles from atomic positions, because no individual angles and no true position of the lone-pair could be determined.

VSCC properties and density-related geometry at the nitrogen atoms:

A similar situation is found for the two nitrogen atoms. Here the VSCCs towards the lithium atoms are far more pronounced (-59.59 and $\left.-51.26 \mathrm{e} / \AA^{5}\right)$ than those engaged in $\sigma$-bonding $\left(-44.83\right.$ and $\left.-48.90 \mathrm{e} / \AA^{5}\right)$. Hence, the VSCCs $L P_{\mathrm{N} 1 \rightarrow \mathrm{Li} 1}$ and $L P_{\mathrm{N} 1 \rightarrow \mathrm{L} i 3}$ seem to be connected at a low isosurface level (cf. Figure 2-26b), but are resolved at a higher level (cf. Figure 2-26 c). In addition, the shorter $\mathrm{Li}-\mathrm{N}$ bonds to the lithium atoms at the double-cube corners show more pronounced VSCCs than those to Li1 or Li2.

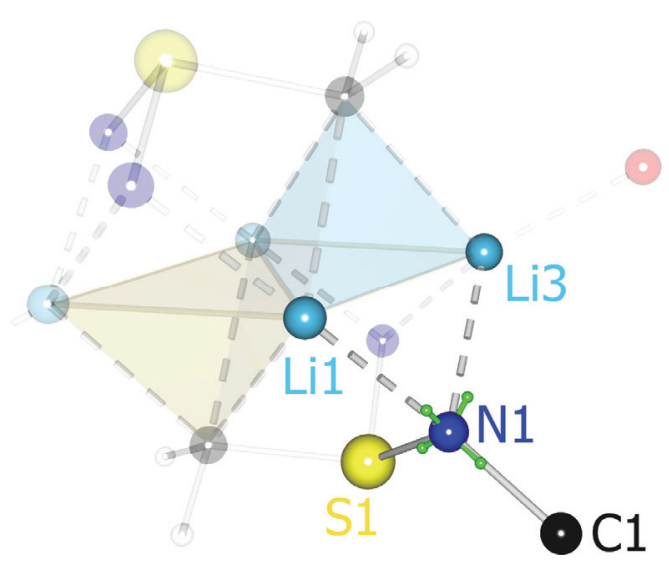

(a)

Figure 2-26: (a) Orientation of the VSCCs (green spheres) at N1 and isosurface plots of $\nabla^{2} \rho\left(\mathbf{r}_{\mathrm{vscC}}\right)$ at the $-42 \mathrm{e} / \AA^{5}$ (b) and $-50.5 \mathrm{e} / \AA^{5}$ (c) level around $\mathrm{N} 1$. 


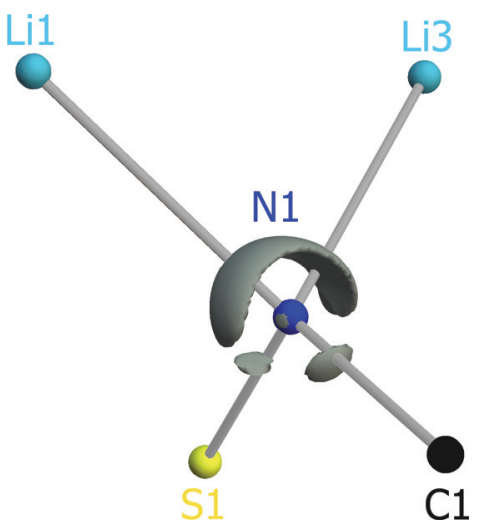

(b)

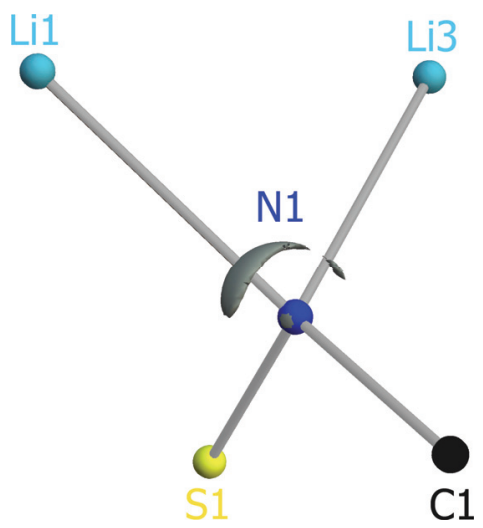

(c)

Figure 2-26 (continued): (a) Orientation of the VSCCs (green spheres) at N1 and isosurface plots of $\nabla^{2} \rho\left(\mathbf{r}_{\mathrm{vscC}}\right)$ at the $-42 \mathrm{e} / \AA^{5}(\mathrm{~b})$ and $-50.5 \mathrm{e} / \AA^{5}$ (c) level around $\mathrm{N} 1$.

The geometry does not fit the expected tetrahedral environment for a $\mathrm{sp}^{3}$-hybridized atom perfectly (cf. Table 2-11). However, the deviations do not occur due to a $\mathrm{sp}^{2}$-hybidization of the nitrogen atoms, because the VSCC angles fit the $120^{\circ}$ angle even worse. Like for S1 all deviating angles include at least one lone-pair density. But this time the angle is not always widened as the VSEPR suggests but in two cases narrowed to an almost right angle. No trend for the two nitrogen atoms could be found and thus this phenomenon keeps unclear. However, it is well-known that two lone-pair densities at one atom tend to form acute angles. The number of VSCCs at the nitrogen atoms identifies $\mathrm{sp}^{3}$-hybridization.

The difference of the VSCCs of the $\mathrm{S}-\mathrm{N}$ bonds at the sulfur atom is also present for the nitrogen VSCCs, although the bond path lengths differ less than $0.01 \AA$ (S1-N1 $1.651 \AA, S 1-\mathrm{N} 21.660 \AA$ ). $\mathrm{CC}_{\mathrm{N} 2 \rightarrow \mathrm{S} 1}$ points outwards of the $\mathrm{SN}_{2}$ angle, away from the $\mathrm{S}-\mathrm{N}$ vector, while $\mathrm{CC}_{\mathrm{S} 1 \rightarrow \mathrm{N} 2}$ is in line with the atom connection. The exact opposite is true for the BCCs of the sulfur atom ( $\mathrm{CC}_{\mathrm{S} 1 \rightarrow \mathrm{N} 1}$ outside the $\mathrm{SN}_{2}$ triangle, but $\mathrm{CC}_{S 1 \rightarrow \mathrm{N} 2}$ in line). Additionally, the two lithium-directed VSCCs at N2 (-64.86 and $\left.-52.67 \mathrm{e} / \AA^{5}\right)$ are more pronounced than those at $\mathrm{N} 1 \quad\left(-59.59\right.$ and $\left.-51.26 \mathrm{e} / \AA^{5}\right)$, whereas the ones involved in $\sigma$-bonding show the opposite trend $(-46.13$ and -43.01 vs. -48.90 and $\left.-44.83 \mathrm{e} / \AA^{5}\right)$.

VSCC properties and density-related geometry at the anionic carbon atoms:

As for the sulfur and nitrogen atoms, four VSCCs, which show the geometry of a distorted tetrahedron (cf. Figure 2-27), are found at $\mathrm{C} 5$ and C6. Again, the densityrelated angles, reaching from $101.9^{\circ}$ for $\mathrm{CC}_{\mathrm{C} 5 \rightarrow \mathrm{S} 1}-\mathrm{C} 5-\mathrm{LP} \mathrm{P}_{\mathrm{C} 5}$ to $114.6^{\circ}$ for 
$\mathrm{CC}_{\mathrm{C} 5 \rightarrow \mathrm{H} 102}-\mathrm{C} 5-\mathrm{LP} \mathrm{C}_{\mathrm{C} 5}$, are very close to the ideal values of a tetrahedron. Both extreme angles include $\mathrm{LP}_{\mathrm{C} 5}$, which is therefore inclined towards $\mathrm{S} 1$. A similar observation has been described for the $\mathrm{S}-\mathrm{N}$ bonds in $\mathrm{S}\left(\mathrm{N}^{t} \mathrm{Bu}\right)_{2} \cdot{ }^{[107]}$ This tilting is probably due to negative hyperconjugation. Possible orbitals for this interaction are the filled p-orbital at $\mathrm{C} 5$ and an empty, antibonding $\sigma^{*}$-orbital of the $\mathrm{S}-\mathrm{N}$ fragment.

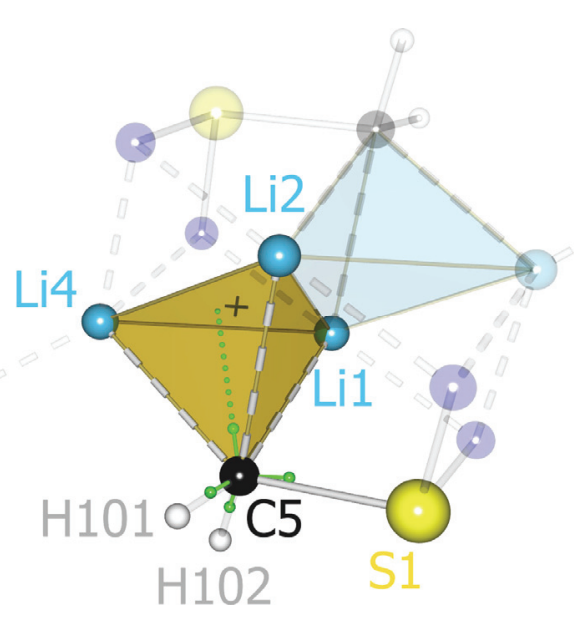

(a)

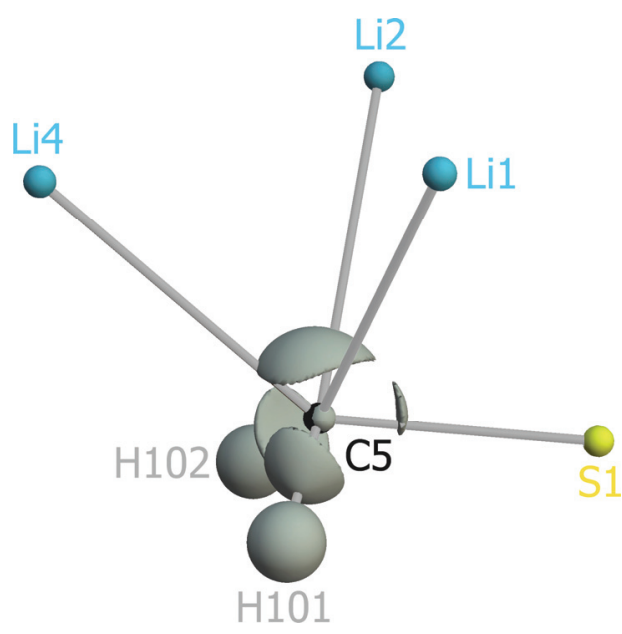

(b)

Figure 2-27: (a) Orientation of the VSCCs (green spheres) at C5 (a black cross marks the center of the $\mathrm{Li}_{3}$ triangle) and (b) isosurface plot of $\nabla^{2} \rho\left(\mathbf{r}_{\mathrm{vscC}}\right)$ at the $-16 \mathrm{e} / \AA^{5}$ level around C5.

Interestingly, three BCPs and bond paths are found for the $\mathrm{Li}_{3} \mathrm{C}$ motif, while only one VSCC at $C 5$ with a value of $-22.99 \mathrm{e} / \AA^{5}$ is present for these interactions. This shows that although $\mathrm{C} 5$ is octahedrally coordinated by the three lithium atoms, along with $\mathrm{S} 1, \mathrm{H} 101$, and $\mathrm{H} 102$, it is not hypervalent. Thus, a judgment on the hypervalency of an atom should not be based on its coordination geometry but on its charge density distribution. It also shows that the bonds of the QTAIM framework do not exactly coincide with those from the chemical two-electron definition by Lewis. ${ }^{[215,225]}$ Thus, an atom involved in more than four bond paths is not coercively hypervalent, because the bond paths might arise from other than two-electron interactions, especially in coordination chemistry. In consequence, the number of VSCCs seems to be a far better tool to estimate hybridization and hypervalency. Along this line of argumentation $\mathrm{C} 5$ is clearly $\mathrm{sp}^{3}$-hybridized.

The donation of the lone-pair to the $\mathrm{Li}_{3}$ triangle is not symmetrical as shown in Figure 2-27a. The VSCC is inclined towards the geometrically closer lithium atom Li4, which can be quantified by the shortened $L i-L P_{C 5}$ distance $\left(L i 4-L P_{C 5}=1.884 \AA\right.$, $\left.\mathrm{Li} 1-\mathrm{LP}_{\mathrm{C} 5}=2.071, \quad \mathrm{Li} 2-\mathrm{LP}_{\mathrm{C} 5}=2.074\right)$ and the wider $\mathrm{Li}-\mathrm{LP}_{\mathrm{C} 5}-\mathrm{C} 5$ angle $\left(\mathrm{Li} 4-\mathrm{LP}_{\mathrm{C} 5}-\mathrm{C} 5=138.5^{\circ}, \mathrm{Li} 1-\mathrm{LP}_{\mathrm{C} 5}-\mathrm{C} 5=127.3^{\circ}, \quad \mathrm{Li}_{2}-\mathrm{LP}_{\mathrm{C} 5}-\mathrm{C} 5=123.8^{\circ}\right)$. This shows 
that, while the nitrogen atoms favor the coordination of the central lithium atoms, the opposite is true for the carbanionic carbon atoms ( $\mathrm{Li} 3$ and $\mathrm{Li} 4$ in the corners favored). C5 is an exemplary case where the discussion of angles derived from atomic positions would lead to misleading results. The coordinative environment of $\mathrm{C} 5$ is formed like a distorted octahedron and thus $\mathrm{C} 5$ is six-fold coordinated. The attached hydrogen atoms seem to be severely inclined in respect to the double-cube. All of this becomes reasonably if the three lithium atoms are not understood as separate units, but as one group bound by just one VSCC. This consideration results in $\mathrm{sp}^{3}$-angles and the hydrogen atoms are in almost ideal positions.

VSCC properties and density-related geometry at the oxygen atoms:

In order to complete their preferred tetrahedral environment, the lithium atoms in the corner of the double-cube are coordinated by a thf molecule each. The oxygen donor atom is $\mathrm{sp}^{3}$-hybridized and hence four VSCCs are found. Although two separate lone-pair densities are present at each oxygen atom, one is much more directly oriented towards the lithium atom (cf. Figure 2-28), although it is not on the line connecting the atoms. This accounts for the deviation of the VSCC angles from $109.5^{\circ}$. Both CC-O1-LP $\mathrm{O}_{\mathrm{O} \rightarrow \mathrm{Li}}$ angles are significantly widened $\left(123.8^{\circ}\right.$ and $\left.117.8^{\circ}\right)$ and on the contrary the $\mathrm{CC}-\mathrm{O} 1-\mathrm{LP}_{\mathrm{O} 1}$ angles for the NBCC (non-bonding charge concentration) are more acute $\left(94.2^{\circ}\right.$ and $\left.104.2^{\circ}\right)$. This displays that $\mathrm{LP}_{\mathrm{O} 1}$ is inclined towards $\mathrm{C} 51$. The bifurcated coordination of an electropositive counterpart by two lone-pairs is a well-known feature already observed in inter- as well as intramolecular $\mathrm{N}^{-} \cdots \mathrm{H}$ hydrogen bonds, ${ }^{[81]} \mathrm{Li}-\mathrm{O}_{\mathrm{Et}_{2} \mathrm{O}},{ }^{[105]}$ and $\mathrm{Li}-\mathrm{O}_{\text {thf }}$ contacts. ${ }^{[104]}$

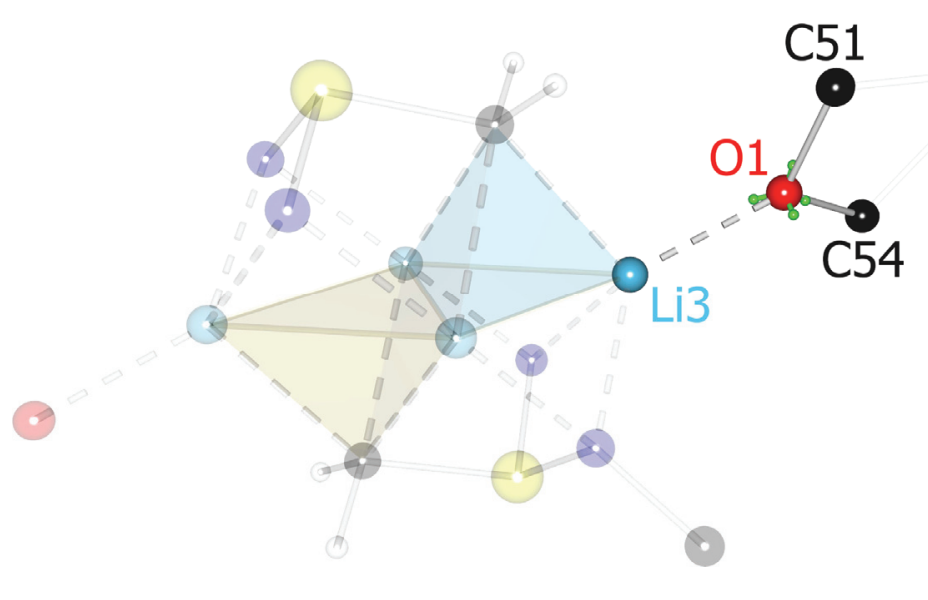

(a)

Figure 2-28: (a) Orientation of the VSCCs (green spheres) at 01 and isosurface plots of $\nabla^{2} \rho\left(\mathbf{r}_{\mathrm{VSCC}}\right)$ at the $-100 \mathrm{e} / \AA^{5}$ (b) and $-116 \mathrm{e} / \AA^{5}$ (c) level around 01. 


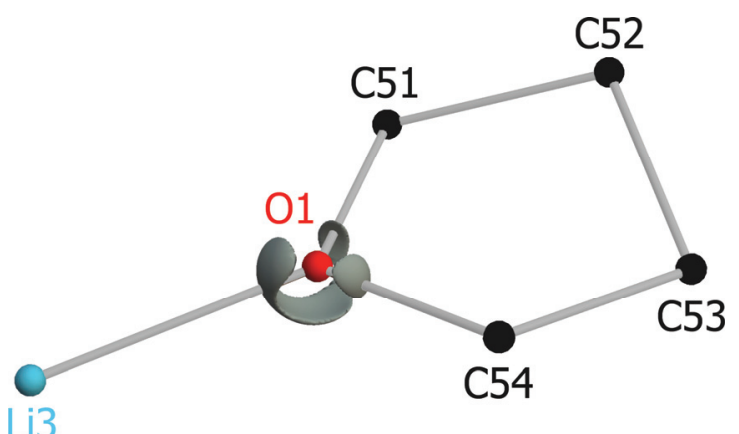

(b)

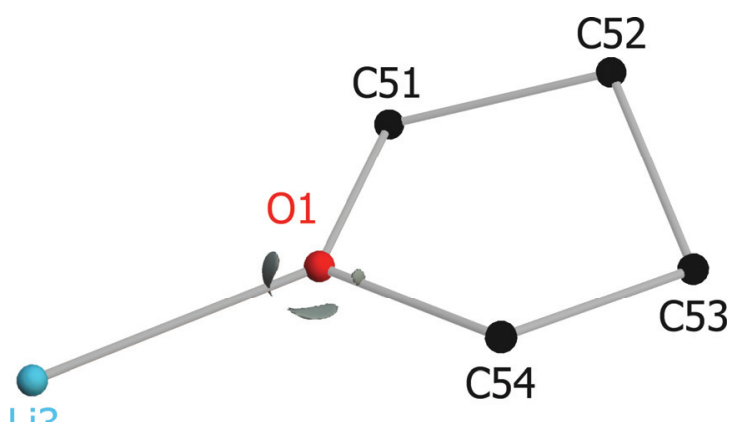

(c)

Figure 2-28 (continued): (a) Orientation of the VSCCs (green spheres) at 01 and isosurface plots of $\nabla^{2} \rho\left(\mathbf{r}_{\mathrm{vscC}}\right)$ at the $-100 \mathrm{e} / \AA^{5}(\mathrm{~b})$ and $-116 \mathrm{e} / \AA^{5}$ (c) level around 01.

The Laplacian $\nabla^{2} \rho\left(\mathbf{r}_{\mathrm{CP}}\right)$ of the lone-pair densities at the thf oxygen atoms is distinctly negative in $\left[(\text { thf }) L_{2}\left\{\mathrm{H}_{2} \mathrm{CS}\left(\mathrm{N}^{t} \mathrm{Bu}\right)_{2}\right\}\right]_{2}(4)\left(-122.26\right.$ and $\left.-122.75 \mathrm{e} / \AA^{5}\right)$. This fits the values for similar contacts in the two compounds $\left[(\text { thf })_{2} \mathrm{Li}_{2}\left(c-\mathrm{N}-\mathrm{SiMe}_{2}-\mathrm{NH}-\mathrm{SiMe}_{2}-\right)_{2}\right]_{2}$ and $\left[(\text { thf })_{2} \mathrm{LiAl}\left(c-\mathrm{N}-\mathrm{SiMe}_{2}-\right)_{4}\right]_{2}\left(-125 \mathrm{e} / \AA^{5}\right.$ on av. $) .{ }^{[104]}$

It is remarkable that the bond strength of coordinative interactions seems to be correlated to the Laplacian values of the VSCCs. The $\mathrm{Li}-\mathrm{O}_{\text {thf }}$ bonds are in general stronger than $\mathrm{Li}-\mathrm{O}_{\mathrm{Et}} \mathrm{O}$ bonds. This is reflected by the less negative $\nabla^{2} \rho\left(\mathbf{r}_{\mathrm{CP}}\right)$ of the lone-pair VSCCs in such compounds (e.g. $-105.23 \mathrm{e} / \AA^{5}$ in $\left.\left[\left(\mathrm{Et}_{2} \mathrm{O}\right) \mathrm{Li}\left\{\mathrm{Ph}_{2} \mathrm{P}(\mathrm{CHPy})\left(\mathrm{NSiMe}_{3}\right)\right\}\right]^{[105]}\right)$. Li-N interactions are even less stable and again this is reflected by less negative Laplacian values at the VSCCs (e.g. $-96.05 \mathrm{e} / \AA^{5}$ on av. in ${ }^{t} \mathrm{BuLi} \cdot(-)$-sparteine ${ }^{[103]}$ ). All this fits the chemical intuition very well, as the dipole moments of the donor molecules descend in the same order for thf $\left(\mu_{\text {thf }}=1.75 \mathrm{D}\right)^{[226]}$ and $\mathrm{Et}_{2} \mathrm{O}\left(\mu_{\mathrm{Et}_{2} \mathrm{O}}=1.15 \mathrm{D}\right) .{ }^{[226]}$ No dipole moment has been derived for (-)-sparteine, thus trimethyl amine and triethyl amine are given for comparison ( $\mu_{\mathrm{NMe}_{3}}=0.61 \mathrm{D},{ }^{[226]} \mu_{\mathrm{NEt}_{3}}=0.61 \mathrm{D}^{[227]}$ ).

This observation is in agreement with the experimental results mentioned in chapter 2.3. The high donor strength of the thf donor in $\left[(\text { thf }) L i_{2}\left\{\mathrm{H}_{2} \mathrm{CS}\left(\mathrm{N}^{t} \mathrm{Bu}\right)_{2}\right\}\right]_{2}(4)$ inhibits a donor exchange with nitrogen donors or diethyl ether.

\section{Laplacian Distribution, Charges and Determination of Bonding Types}

The determination of the $\mathrm{sp}^{3}$-hybridization for all sulfur, carbon, nitrogen, and oxygen atoms in $\left[(\text { thf }) \mathrm{Li}_{2}\left\{\mathrm{H}_{2} \mathrm{CS}\left(\mathrm{N}^{t} \mathrm{Bu}\right)_{2}\right\}\right]_{2}(4)$ unambiguously leads to non-hypervalent sulfur atoms and the formation of exclusively single bonds to the sulfur atoms. This would be sufficient to state that $\mathrm{S}^{+}-\mathrm{N}$ and $\mathrm{S}^{+}-\mathrm{C}$ bonding is present. However, the bonds 
will be discussed in detail throughout this chapter to verify these findings and to shed light on the $\mathrm{Li}_{3} \mathrm{C}$ bonding situation.

The charges for all atoms in the compound have been determined (cf. Table 2-13). The results are reliable as the electro-neutrality is fulfilled and the Lagrangian $L$ is in the range of the expectation value (see above) for all atoms. The net charges for all lithium atoms are predetermined by the chosen model, but adopt the same values within their esd's if refined freely as described above.

Table 2-13: Selected atomic charges, Lagrangian $L$ and volumes $V_{b}$ of the atomic basins for 4 .

\begin{tabular}{c|c|c|c|c}
\hline & $\begin{array}{c}\text { net } \\
\text { charge [e] }\end{array}$ & $\begin{array}{c}\text { int. } \\
\text { charge [e] }\end{array}$ & $\begin{array}{c}L \\
{\left[10^{-4}\right]}\end{array}$ & $\begin{array}{c}V_{\mathrm{b}} \\
{\left[\AA^{3}\right]}\end{array}$ \\
\hline S1 & +0.13 & +0.88 & 46.7 & 27.7 \\
N1 & -0.54 & -1.14 & -1.7 & 14.2 \\
N2 & -0.56 & -1.21 & -4.0 & 14.2 \\
C5 & -0.89 & -0.79 & 21.7 & 18.0 \\
O1 & -0.40 & -1.15 & 11.0 & 16.7 \\
\hline
\end{tabular}

\begin{tabular}{|c|c|c|c|c|}
\hline & $\begin{array}{c}\text { net } \\
\text { charge }[\mathrm{e}]\end{array}$ & $\begin{array}{c}\text { int. } \\
\text { charge [e] }\end{array}$ & $\begin{array}{c}L \\
{\left[10^{-4}\right]}\end{array}$ & $\begin{array}{c}V_{b} \\
{\left[\AA^{3}\right]}\end{array}$ \\
\hline Li1 & 1.00 & +0.92 & 0.4 & 4.3 \\
\hline Li2 & 1.00 & +0.92 & 0.7 & 4.2 \\
\hline LI3 & 1.00 & +0.92 & 0.2 & 3.7 \\
\hline Li4 & 1.00 & +0.92 & 1.1 & 3.6 \\
\hline
\end{tabular}

In addition to the charges, the properties at the BCPs and the Laplacian distribution along the bond paths will be discussed in the following.

\section{S-N bonds:}

Comparing the BCP-properties of the present $\mathrm{S}-\mathrm{N}$ bonds with those published, we find the bonding situation in perfect agreement to the $\mathrm{S}-\mathrm{N}$ single bonds in $\mathrm{MeS}\left(\mathrm{N}^{t} \mathrm{Bu}\right)_{2} \mathrm{H}$ and $\mathrm{H}_{2} \mathrm{C}\left\{\mathrm{S}\left(\mathrm{N}^{t} \mathrm{Bu}\right)_{2}\left(\mathrm{HN}^{t} \mathrm{Bu}\right)\right\}_{2 .}{ }^{[81]}$ The bond path lengths match those of the single bonds in the reference compounds very well (1.655 $\AA$ on av. in 4 vs. 1.683 and $1.650 \AA) . \rho\left(\mathbf{r}_{\mathrm{BCP}}\right)$ is also comparable to the results in the literature $\left(1.61 \mathrm{e} / \AA^{3}\right.$ on av. in 4 vs. 1.76 and $\left.1.89 \mathrm{e} / \AA^{3}\right)$, the same accounts for the associated Laplacian which varies slightly more for all described bonds (-11.52 and $-9.77 \mathrm{e} / \AA^{5}$ in 4 vs. 7.95 and $\left.13.41 \mathrm{e} / \AA^{5}\right)$. This is accompanied by distinct integrated charges on the sulfur and nitrogen atoms $(\mathrm{S} 1+0.88, \mathrm{~N} 1-1.14, \mathrm{~N} 2-1.12 \mathrm{e})$. The comparably low net charges of $\mathrm{S} 1(+0.13 \mathrm{e})$ and the nitrogen atoms (-0.54 and $-0.56 \mathrm{e})$ suggest that the charges originate mainly from polarization. All these observations fit the description as $\mathrm{S}^{+}-\mathrm{N}$ rather than as $\mathrm{S}=\mathrm{N}$ bonding.

A comparison of the $\mathrm{S}-\mathrm{N}$ bonds present in $\left[(\text { thf }) \mathrm{Li}_{2}\left\{\mathrm{H}_{2} \mathrm{CS}\left(\mathrm{N}^{t} \mathrm{Bu}\right)_{2}\right\}\right]_{2}(4)$ reveals that, although the bonds are chemically equal, they differ by almost $10 \%$ in the charge 
density at the BCP $\left(1.67\right.$ vs. $\left.1.55 \mathrm{e} / \AA^{3}\right)$. This is echoed by a more negative value for $\nabla^{2} \rho\left(\mathrm{r}_{\mathrm{BCP}}\right)\left(-11.52\right.$ vs. $\left.-9.77 \mathrm{e} / \AA^{5}\right)$ but a much less pronounced ellipticity of the bond density $(0.07$ and 0.30$)$ for $\mathrm{S} 1-\mathrm{N} 1$. This might be caused by a shift of the $\mathrm{BCP} \mathrm{S}_{\mathrm{S}-\mathrm{N} 1}$ towards the nitrogen atom compared to the $\mathrm{BCP}_{\mathrm{S} 1-\mathrm{N} 2}$ (cf. Figure 2-29), leading to an enlarged atomic basin of $\mathrm{N} 2$ in the direction of $\mathrm{S} 1$, which is reflected in the slightly higher integrated charge (-1.21 e for $\mathrm{N} 2$ vs. -1.14 e for N1).

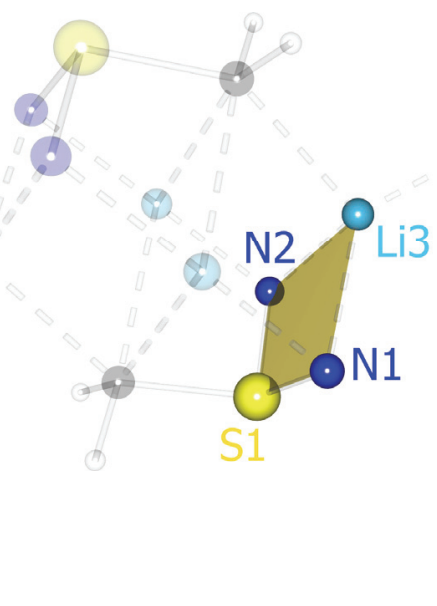

(a)

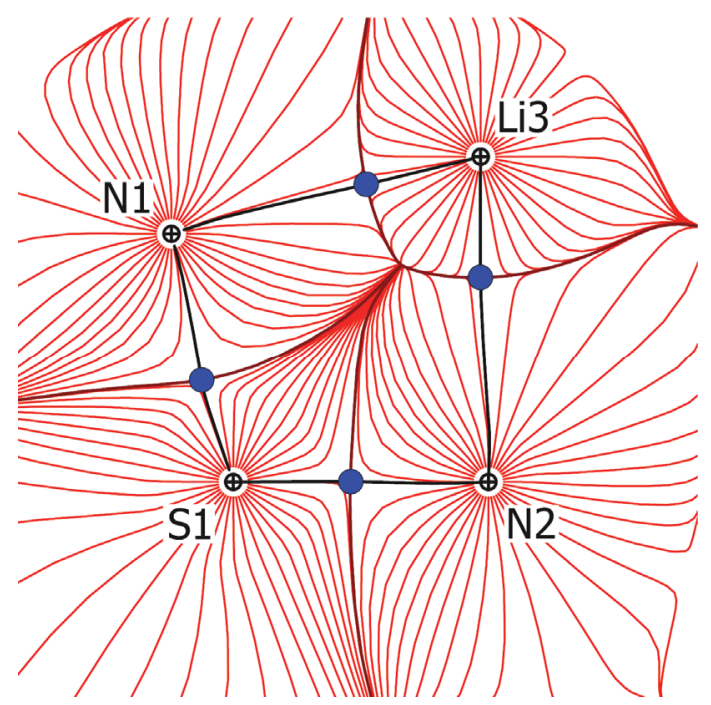

(b)

Figure 2-29: (a) $\mathrm{SN}_{2} \mathrm{Li}$ plane in [(thf) $\left.\mathrm{Li}_{2}\left\{\mathrm{H}_{2} \mathrm{CS}\left(\mathrm{N}^{t} \mathrm{Bu}\right)_{2}\right\}\right]_{2}(4)$ and (b) trajectory plot of the same plane (BCPs are plotted as blue dots and bond paths as black solid lines).

On the other hand the overall atomic volumes of the nitrogen atoms defined by their zero-flux surfaces are equal $\left(V_{b}=14.2 \AA^{3}\right)$, which makes a counterbalancing effect necessary. The $\mathrm{N}^{-} \mathrm{Bu}$ contacts can be ruled out to be responsible for that (cf. Table 2-10), since they are almost equal concerning all density-related properties $\left(\rho\left(\mathbf{r}_{\mathrm{BCP}}\right), \nabla^{2} \rho\left(\mathbf{r}_{\mathrm{BCP}}\right)\right)$ as well as the atomic properties of the tertiary carbon atoms (charge, $\mathrm{V}_{\mathrm{b}}$ ). Only the BCP is slightly closer to N2 compared to N1-C1 (0.807 vs. $0.821 \AA$ ) at equal bond path lengths. Therefore, the differences between the two $\mathrm{S}-\mathrm{N}$ bonds should be induced or at least be reflected by the $\mathrm{Li}-\mathrm{N}$ contacts, which will be discussed later.

The Laplacian distributions along the $\mathrm{S}-\mathrm{N}$ bond paths (cf. Figure 2-30c) display the shape of severely polarized shared interactions. At S1, as well as N1 and N2, minima are established and the distribution is negative over the whole bonding region. This is accompanied by a distinctly negative Laplacian at the BCP, which also indicates a shared type of interaction. 


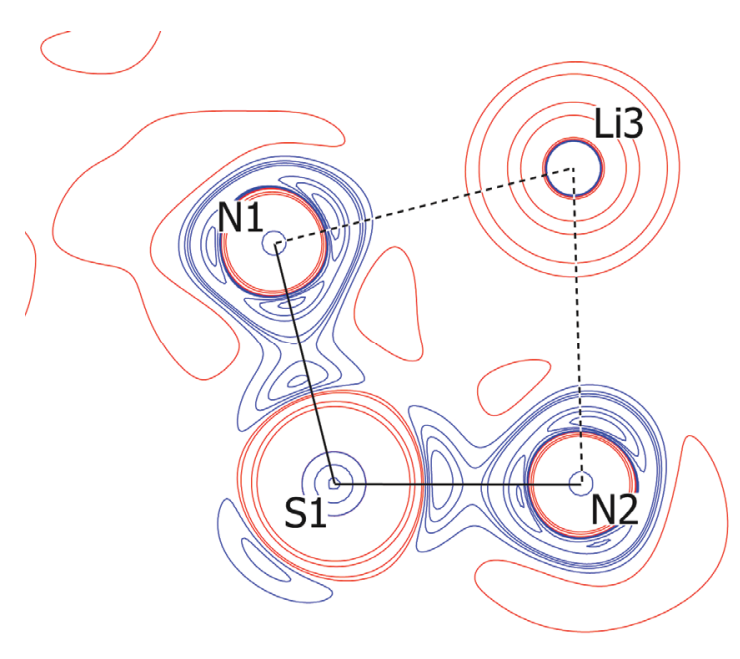

(a)

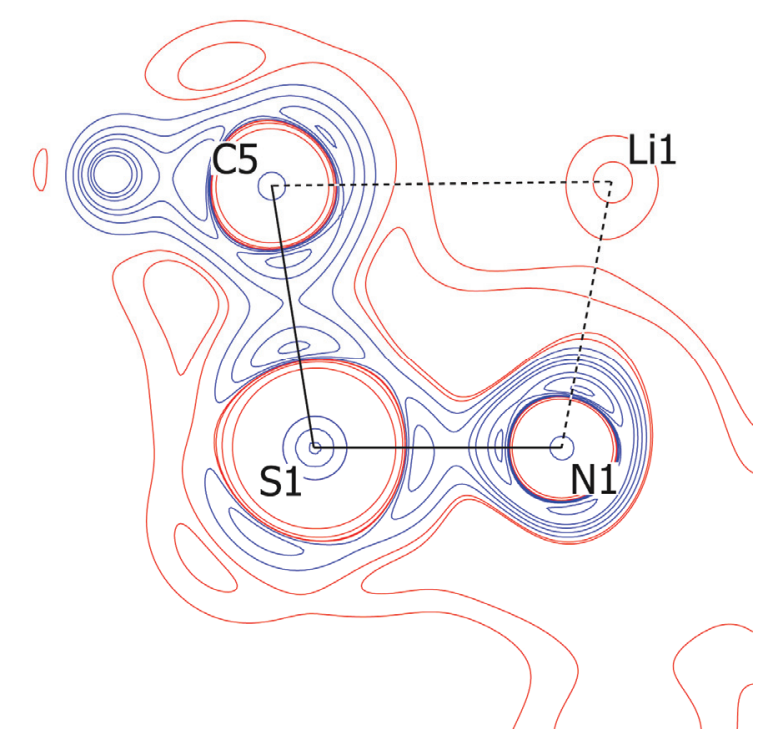

(b)

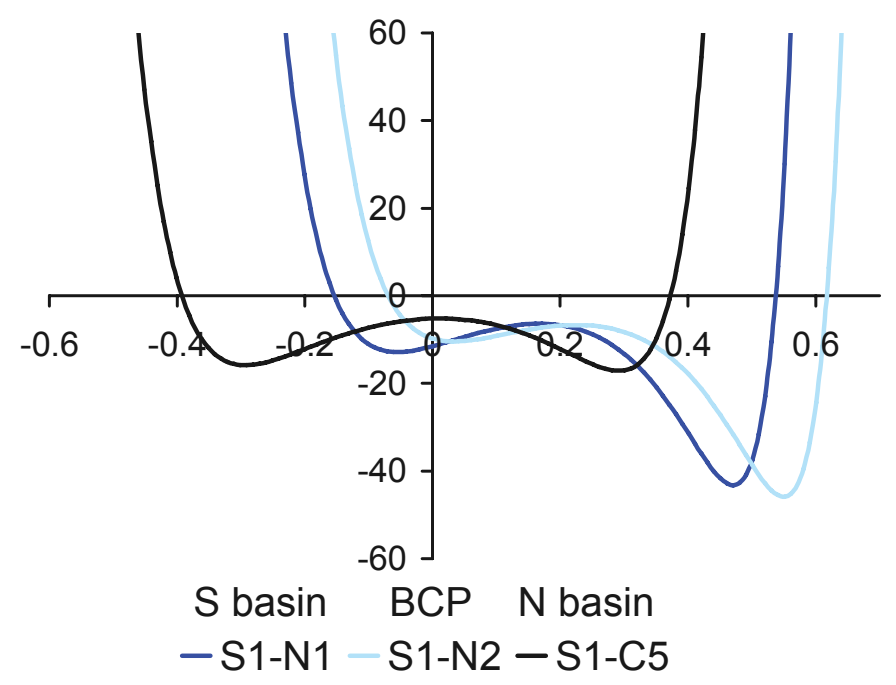

(c)

Figure 2-30: Laplacian distribution in (a) the S1N1N2, (b) the S1N1C5 plane (blue contours show electron concentrations, red ones depletions) and (c) along the S-N and S-C bond paths $\left(\nabla^{2} \rho(\mathbf{r})\left[e / \AA^{5}\right]\right.$ plotted against $\left.d_{B C P}[\AA]\right)$.

The polarization can be deduced from the position of the BCP, which is located very close to the charge concentration built up by $\mathrm{S1}$, i.e. expansion of the nitrogen basins, and from the absolute value of the minima, which are about doubled for the nitrogen atoms compared to the sulfur atom. The different topological properties at the BCPs are also reflected in the shape of the Laplacian distributions along the bond paths. The two distributions are qualitatively equal but shifted parallel with respect to the distance from the BCP (cf. Figure 2-30c). This is a well-known observation for bonds of the same type but of different lengths. However, the identical $\mathrm{S}-\mathrm{N}$ bond 
lengths allow the conclusion, that the individual distributions refer to individual topologies as described above.

\section{S-C bonds:}

Since this is the first sulfur ylide for which an experimental electron density study is presented, no real benchmark systems were found in the literature. Thus, the bonding will be discussed with respect to its accordances or differences to reported $\mathrm{S}-\mathrm{C}$ single and $\mathrm{S}=\mathrm{C}$ double bonds.

The bond path length $(1.781 \AA)$ is only slightly shorter than that of $\operatorname{MeS}\left(N^{t} B u\right)_{2} H$, $\mathrm{H}_{2} \mathrm{C}\left\{\mathrm{S}\left(\mathrm{N}^{t} \mathrm{Bu}\right)_{2}\left(\mathrm{HN}^{t} \mathrm{Bu}\right)\right\}_{2}(1.791$ and $1.817 \AA),{ }^{[80,81]}$ and in the range of other published S-C single bonds (1.739-1.818 $\AA$ ). ${ }^{[199,200,228]}$ The electron density and the Laplacian at the BCP are also comparable to these compounds $\left(\rho\left(\mathbf{r}_{\mathrm{BCP}}\right): 1.37\right.$ vs. 1.21 to 1.54 $\mathrm{e} / \AA^{3} ; \nabla^{2} \rho\left(\mathbf{r}_{\mathrm{BCP}}\right):-5.21$ vs. -3.10 to $\left.-8.70 \mathrm{e} / \AA^{5}\right)$.

In contrast to the polar bonds discussed above (S-N, Li-N), the Laplacian distribution along the bond path is almost symmetric (cf. Figure 2-30c). The minima at $\mathrm{S} 1$ and C5 are almost equal in the absolute values $\left(-15.84\right.$ and $\left.-17.12 \mathrm{e} / \AA^{5}\right)$. The Laplacian stays negative over the whole bonding region with a local maximum at the $\mathrm{BCP}$. This, together with the distinctly negative Laplacian at the BCP, indicates shared interactions. The polarization of the S-C bond is therefore solely reflected in the position of the BCP, which is shifted $0.03 \AA$ away from the non-polar midpoint (NPMP; expected position given by the ratio of the covalent radii; $d_{S 1-N P M P}=0.95 \AA$ ) towards C5. Due to the remarkably small polarization of the $\mathrm{S}-\mathrm{C}$ bond, the polarization of the valence shell of the sulfur atom seems to arise completely from the interaction with the more electronegative nitrogen atoms. This observation is supported by the carbanion charges. The similarity of the net and integrated charges ( -0.89 and -0.79 e) suggests, that they are not caused by polarization but originate from deprotonation of the carbon atom.

The amount of charge density at the BCP and the corresponding Laplacian determine this interaction to be of a shared $\sigma$-type. This is guided by the ellipticity (0.12) and the distinct charges at the atoms. Thus, the $S^{+}-^{-} C$ description of the bonding is superior to the classical $S=C$ formulation. This is in accordance with the reactivity of the ylidic compounds as described above. The small bond force constants $\left(\sim 5 \cdot 10^{-5} \mathrm{dyn}^{-1} \mathrm{~cm}^{-1}\right)^{[77]}$ and the large dipole moments $(\sim 6 \mathrm{D})^{[79]}$ are further arguments for the polar, ylidic description. In combination with the results for the $\mathrm{S}-\mathrm{N}$ bond to be of the $\mathrm{S}^{+}-\mathrm{N}$ type, this clearly favors the resonance formula with 
maximum charge separation and a non-hypervalent sulfur atom in Scheme 2-3d. This observation fits the chemical reactivity of sulfur ylides very well.

\section{Li-N contacts:}

Two groups of Li-N contacts can be distinguished from the Laplacian distributions along the bond paths (cf. Figure 2-31). The group containing the shorter $\mathrm{Li}-\mathrm{N}$ contacts (Li1-N1, Li2-N2) has more pronounced minima than the Li3-N contacts, with Li3 being in the corner of the double-cube. All of this is in accordance with the characteristics of the corresponding VSCCs at the nitrogen atoms (see above).

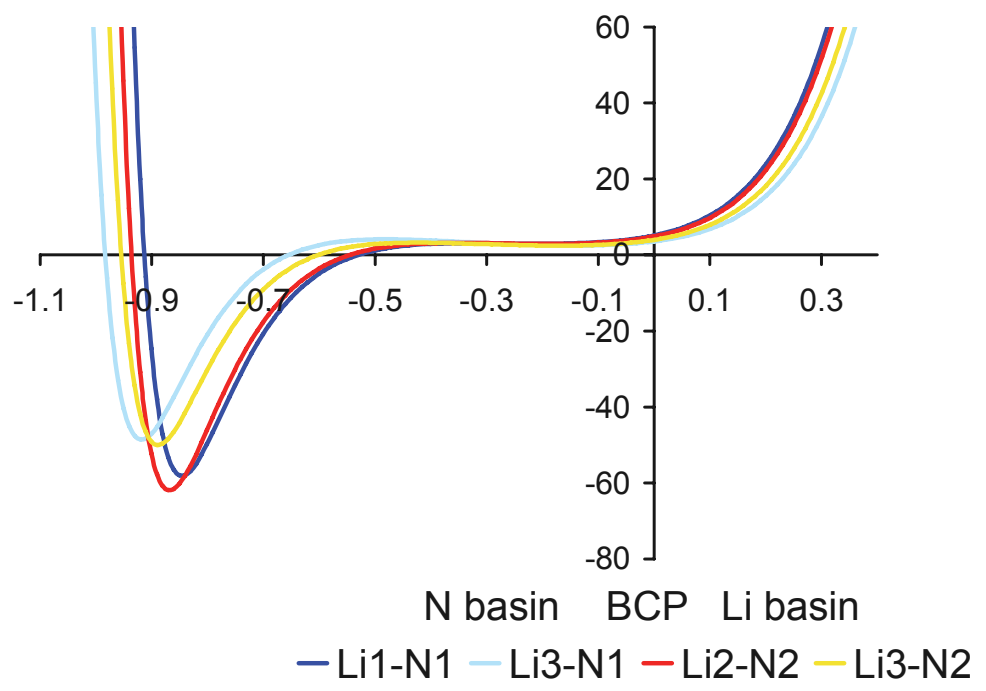

Figure 2-31: Laplacian distribution along the $\mathrm{Li}-\mathrm{N}$ bond paths $\left(\nabla^{2} \rho(\mathbf{r})\left[\mathrm{e} / \AA^{5}\right]\right.$ against $\left.\mathrm{d}_{\mathrm{BCP}}[\AA]\right)$.

Besides, the asymmetry of the $\mathrm{S}-\mathrm{N}$ bonds also affects the $\mathrm{Li}-\mathrm{N}$ bonds. While the minimum of N1-Li3 is shifted away from the BCP towards N1 compared to N2-Li3, the minimum of N1-Li1 is shifted towards the BCP compared to N2-Li2.

The low overall density at the BCP $\left(0.13\right.$ to $\left.0.20 \mathrm{e} / \AA^{3}\right)$ and the positive Laplacian (3.99 to $5.17 \mathrm{e} / \AA^{5}$ ) are obvious indicators for closed-shell interactions.

\section{Li-C interactions:}

Apart from the $\mathrm{S}-\mathrm{C}$ bonding type, the $\mathrm{Li}-\mathrm{C}$ interactions are the most interesting part of $\left[(\text { thf }) \mathrm{Li}_{2}\left\{\mathrm{H}_{2} \mathrm{CS}\left(\mathrm{N}^{t} \mathrm{Bu}\right)_{2}\right\}\right]_{2}$ (4). Within the basic $\mathrm{Li}_{3} \mathrm{C}$ motifs two groups of $\mathrm{Li}-\mathrm{C}$ interactions could be already distinguishes while discussing the VSCC features. This arrangement can be confirmed with respect to the BCP properties. The shorter $\mathrm{Li}-\mathrm{C}$ bond shows an approximately $25 \%$ increased electron density at the BCP (0.11 vs. $0.08 \mathrm{e} / \AA^{3}$ on av.) and an $35 \%$ higher associated Laplacian (2.30 vs. $1.71 \mathrm{e} / \AA^{5}$ on av.). Nevertheless, all interactions share the common features of an 
ionic closed-shell interaction (low electron density and positive Laplacian at the $\mathrm{BCP}$ ), ${ }^{[203]}$ which is no big surprise considering that all other features (charges, VSCC appearance, etc.) point to $\mathrm{Li}^{+}-\mathrm{C}$ interactions. Although the $\mathrm{Li}-\mathrm{C}$ bond paths are curved, the elongation compared to the core distance is less than $1 \%$. However, the ratios of the eigenvalues $\lambda_{i}$ at the BCPs indicate big differences in the degree of charge separation. $\lambda_{3}$ of $\mathrm{Li} 4-\mathrm{C} 5$ is almost twice that of the other two $\mathrm{Li}-\mathrm{C}$ interactions.

These results are reflected by the Laplacian distribution along the $\mathrm{Li}-\mathrm{C}$ bond paths (cf. Figure 2-32). The minimum for Li4-C5 is more distinct than the two of the inter-cubical face and shifted towards the BCP. Both is typical for a bond shortening of $0.14 \AA$. For all three distributions the Laplacian stays positive over the whole bonding region and enters the negative range not until the valence shell of $\mathrm{C} 5$ is reached.

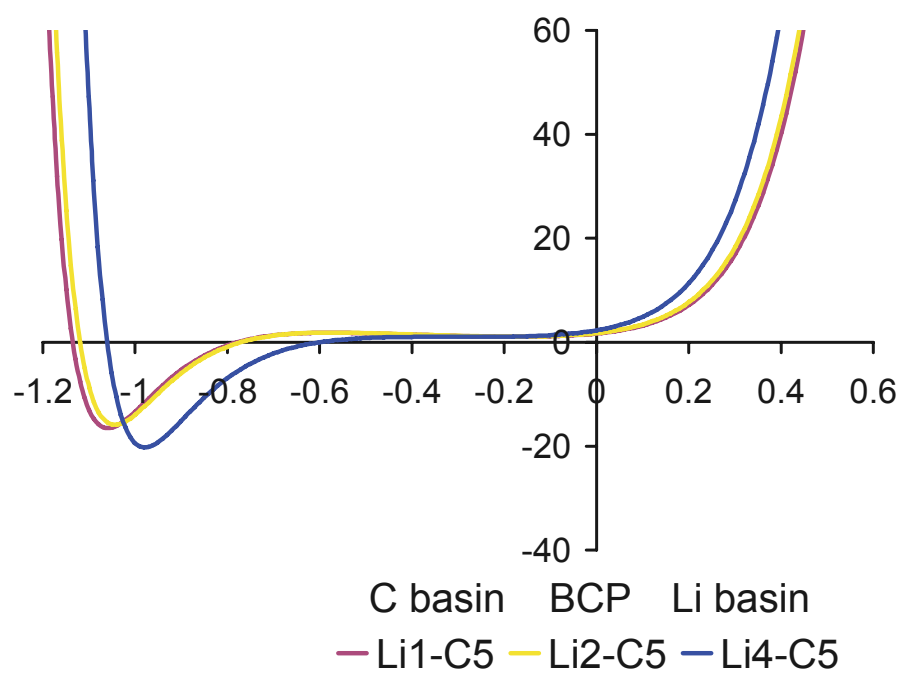

Figure 2-32: Laplacian distribution along the Li-C bond paths $\left(\nabla^{2} \rho(r)\left[e / \AA^{5}\right]\right.$ against $\left.d_{B C P}[\AA]\right)$.

These observations allow the unambiguous conclusion, that closed-shell interactions are present.

This is in accordance with the fact that only one VSCC at C5 interacts with all three lithium atoms of the capped $\mathrm{Li}_{3}$ triangle, which can be easily explained within an electrostatic model. Missing bond paths between the lithium (cf. Figure 2-21 and Figure 2-33) indicate that only the interaction of the lone-pair density at the carbon atom $\left(\mathrm{LP}_{\mathrm{C} 5}\right)$ with all three lithium atoms is responsible for the formation of the $\mathrm{Li}_{3} \mathrm{C}$ motif. 


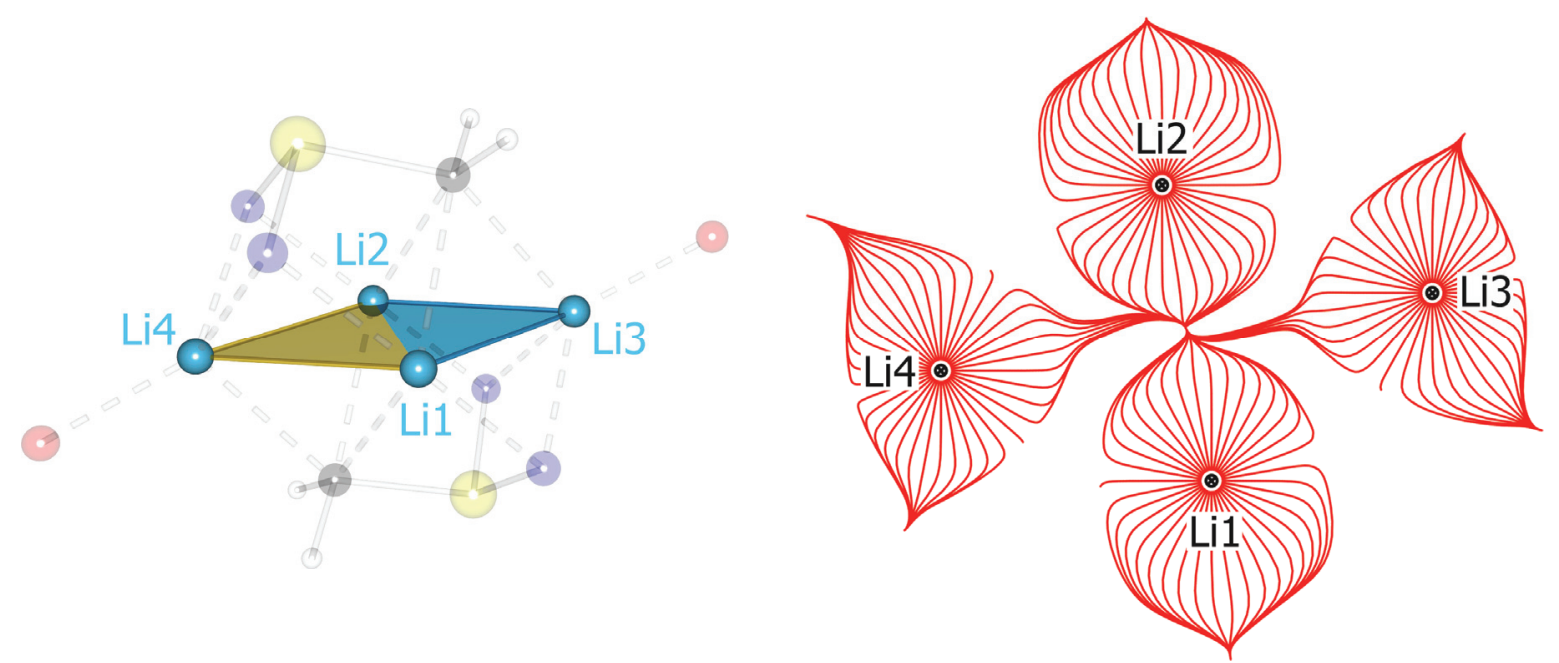

(a)

(b)

Figure 2-33: (a) $\mathrm{Li}_{4}$ plane in $\left[(\operatorname{thf}) \mathrm{Li}_{2}\left\{\mathrm{H}_{2} \mathrm{CS}\left(\mathrm{N}^{t} \mathrm{Bu}\right)_{2}\right\}\right]_{2}(4)$ and (b) trajectory plot of the same plane.

However, this is contrary to the recent theoretical results by Bickelhaupt, which predicted shared interactions for Li-C bonds. ${ }^{[110,128,133]}$ Bickelhaupt contradicts earlier results with the argument that those have deduced the ionic character mainly by determination of charges ${ }^{[111,115,118,119,128,132]}$ or rely on theoretical QTAIM $^{[115,132,229]}$ and valence bond descriptions. ${ }^{[125]}$ Nevertheless, Bickelhaupt's results rely on the same theoretical preconditions and restrictions. Therefore, the experimental topological analyses within QTAIM presented here should be favored over these results, especially because they are in accordance with the theoretical calculations. The theoretical QTAIM values at the Li-C BCP in miscellaneous alkyl lithium compounds ${ }^{[115]}$ are not far from those observed for $\left[(\text { thf }) \mathrm{Li}_{2}\left\{\mathrm{H}_{2} \mathrm{CS}\left(\mathrm{N}^{t} \mathrm{Bu}\right)_{2}\right\}\right]_{2}(4)$. The differences may easily originate from the additional sulfur substituent at the carbon atom or be due to the general deviations of theoretical and experimental values. ${ }^{[81,82]}$ In addition, Streitwieser, ${ }^{[112]}$ Bushby, and Stee ${ }^{[116,121]}$ have shown that a simple electrostatic model is able to reproduce the ratio of $\mathrm{C}-\mathrm{C}$ and $\mathrm{Li}-\mathrm{Li}$ distances in tetrameric methyl lithium. However, the experimental electron density study presented herein does not rule out a certain, but small amount of covalent contributions to the bonding situation. ${ }^{[104]}$

Li-O interactions:

The Li-O contacts in $\left[(\text { thf }) \mathrm{Li}_{2}\left\{\mathrm{H}_{2} \mathrm{CS}\left(\mathrm{N}^{t} \mathrm{Bu}\right)_{2}\right\}\right]_{2}(4)$ can be compared well to other $\mathrm{Li}-\mathrm{O}$ interactions reported in our group. The low electron density $\rho\left(\mathbf{r}_{\mathrm{BCP}}\right)\left(0.15 \mathrm{e} / \AA^{3}\right)$ 
and the distinctly positive Laplacian at the BCP $\left(\nabla^{2} \rho\left(r_{\mathrm{BCP}}\right)=5.11 \mathrm{e} / \AA^{5}\right)$ identify the interactions as polar closed-shell ones. Similar values have been found for the $\mathrm{Li}-\mathrm{O}_{\text {thf }}$ interaction in $\left[(\text { thf })_{2} \mathrm{Li}_{2}\left(c-N-\mathrm{SiMe}_{2}-\mathrm{NH}-\mathrm{SiMe}_{2}-\right)_{2}\right]_{2} \quad\left(\rho\left(\mathrm{r}_{\mathrm{BCP}}\right)=0.18 \mathrm{e} / \AA^{3}\right.$ and $\left(\nabla^{2} \rho\left(\mathrm{r}_{\mathrm{BCP}}\right)=4.85 \mathrm{e} / \AA^{5}\right.$ on av. $)$ and $\left[(\text { thf })_{2} \mathrm{LiAl}\left(c-\mathrm{N}-\mathrm{SiMe}_{2}-\right)_{4}\right]_{2}\left(\rho\left(\mathrm{r}_{\mathrm{BCP}}\right)=0.21 \mathrm{e} / \AA^{3}\right.$ and $\left(\nabla^{2} \rho\left(\mathbf{r}_{\mathrm{BCP}}\right)=5.67 \mathrm{e} / \AA^{5}\right.$ on av. $)$.

\subsection{Conclusions}

The extensive study on the polymorphism of $\left[(\text { thf }) \mathrm{Li}_{2}\left\{\mathrm{H}_{2} \mathrm{CS}\left(\mathrm{N}^{t} \mathrm{Bu}\right)_{2}\right\}\right]_{2}$ (1), presented in this chapter, revealed three polymorph solid phases. One of these, the modification with the lowest crystallization temperature, $\left[(\text { thf }) \mathrm{Li}_{2}\left\{\mathrm{H}_{2} \mathrm{CS}\left(\mathrm{N}^{t} \mathrm{Bu}\right)_{2}\right\}\right]_{2}(4)$, could be crystallized in high quality. An experimental charge density study could be performed, because neither twinning nor disorder was present in the crystals.

On the basis of this study the questions posed in the introduction could be answered. The analyses characterize the $\mathrm{S}-\mathrm{N}$ and $\mathrm{S}-\mathrm{C}$ bonds as polar single bonds, strengthened by charge separation $\left(\mathrm{S}^{+}-\mathrm{N}\right.$ and $\left.\mathrm{S}^{+}-\mathrm{C}\right)$. Thus, the resonance formula with maximum electrostatic interactions and a non-hypervalent sulfur atom as in Scheme 2-3d describes the bonding situation in $\left[(\text { thf }) \mathrm{Li}_{2}\left\{\mathrm{H}_{2} \mathrm{CS}\left(\mathrm{N}^{t} \mathrm{Bu}\right)_{2}\right\}\right]_{2}(4)$ best. The sulfur ylides should, in accordance to these observations, be depicted as ylidic $\mathrm{S}^{+}{ }^{-} \mathrm{C}$. This fits the chemical reactivity of classical sulfur ylides and polyimido sulfur ylides very well and can be used to explain and predict their reactions.

Apart from the bonding situation at the sulfur atom, information concerning the $\mathrm{Li}-\mathrm{C}$ interactions has been derived. Three bonding interactions between the carbanion and the lithium atoms in the $\mathrm{Li}_{3} \mathrm{C}$ motif have been found. All of these are closed-shell, ionic bonds. This is contradictory to recent theoretical results by Bickelhaupt, but in good agreement with other theoretical and experimental findings. No BCPs and thus no bonding interactions within the framework of QTAIM have been found for the lithium atoms. Therefore, the formation of the $\mathrm{Li}_{3} \mathrm{C}$ motif seems to be due to the interaction with the carbanion exclusively.

Supplementary to the study on the polymorphism of $\left[(\operatorname{thf}) \mathrm{Li}_{2}\left\{\mathrm{H}_{2} \mathrm{CS}\left(\mathrm{N}^{t} \mathrm{Bu}\right)_{2}\right\}\right]_{2}(1)$, crystallization of the diimido sulfur ylide with other donor bases was attempted. All reactions with nitrogen donor bases were unsuccessful. However, crystallization from diethoxy methane as donor solvent yielded a new complex. The crystal structures of the product from the reaction with one equivalent of methyl lithium, 
$\left[(\mathrm{dem}) \mathrm{Li}_{2}\left\{\mathrm{MeS}\left(\mathrm{N}^{t} \mathrm{Bu}\right)_{2}\right\}_{2}\right](\mathbf{5})$, and of the desired product $\left[(\mathrm{dem}) \mathrm{Li}_{4}\left\{\mathrm{H}_{2} \mathrm{CS}\left(\mathrm{N}^{t} \mathrm{Bu}\right)_{2}\right\}_{2}\right]_{\mathrm{n}}(\mathbf{6})$ were determined. 6 is however not suitable for an experimental electron density study because of the disordered dem donor. 


\section{Metal Complexes of Dilmido Sulfur YLides}

\subsection{Introduction}

The chemistry of polyimido sulfur ylides is relatively new, as the first examples of this compound class were simultaneously synthesized by Walfort ${ }^{[62]}$ and Hänssgen ${ }^{[61]}$ only in 2001. Up to now only nine complexes of this type have been prepared. ${ }^{[62-64]}$ The general synthetic approach is the addition of an alkyl group to sulfur diimides and triimides and the subsequent deprotonation by an organo lithium base (cf. Scheme 3-1). Hence, all known complexes contain lithium cations.

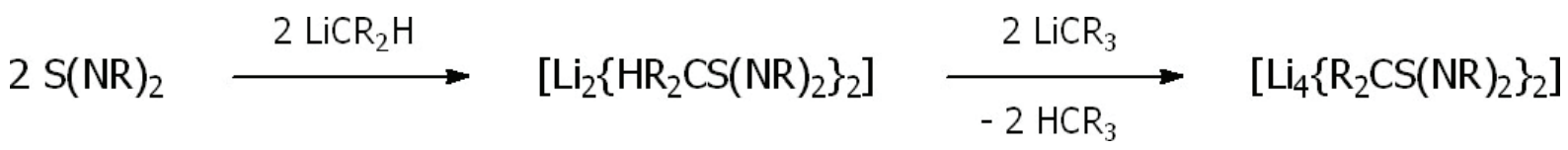

Scheme 3-1: General synthetic approach to diimido sulfur ylides with organo lithium reagents.

The dianionic, tridentate alkylene diimido sulfites can be envisaged to be versatile ligands. However, the only coordination motif observed for these complexes up to now is the formation of the double-cube discussed in chapter 2.2.3. This motif will probably be modified by metal exchange, because no other metal cations favor the formation of an $\mathrm{M}_{3} \mathrm{C}$ tetrahedron as much as lithium does. This is especially true for dications like $\mathrm{Mg}^{2+}$, despite the diagonal relationship.

Apart from the application in coordination chemistry, the reactivity of the complexes could be used to fit the reaction types mentioned in chapter 2.1 (epoxidation, cyclopropanation, transimidation, ring expansion) better or to favor one type over the others. Exchange of lithium for a soft metal ion (e.g. $\left.\mathrm{Cu}^{2+}\right)$ would on the one hand enhance interactions with soft reaction sites, while the use of transition metal ions (e.g. $\left.\mathrm{Ni}^{2+}, \mathrm{Cu}^{2+}, \mathrm{Zn}^{2+}\right)$ on the other hand would open the way to activated complexes for catalysis.

\subsection{Metal Exchange Reactions}

A simple metal exchange by addition of metal chlorides or amides to the lithium ylides, which is common for the synthesis of various metal complexes of organo diimido sulfinates, is not possible due to the redox reactivity of the compounds. ${ }^{[64,66]}$ The addition of metal salts to lithium diimido sulfur ylides leads to extensive $\mathrm{S}-\mathrm{N}$ and 
$\mathrm{S}-\mathrm{C}$ bond cleavages. A similar reactivity has been reported for the analogous triimido sulfite dianion $\mathrm{S}\left(\mathrm{N}^{t} \mathrm{Bu}\right)_{3}{ }^{2-}$ by Fleischer and Stalke (cf. Scheme 3-2). ${ }^{[102]}$ The exact reaction mechanisms stay unclear, as the products can not be isolated and identified in most cases.

$\left[(\right.$ thf $\left.) \mathrm{Li}_{4}\left\{\mathrm{~S}\left(\mathrm{~N}^{\mathrm{tBu}}\right)_{3}\right\}_{2}\right]+4$ (dioxane) $\mathrm{GeCl}_{2}$

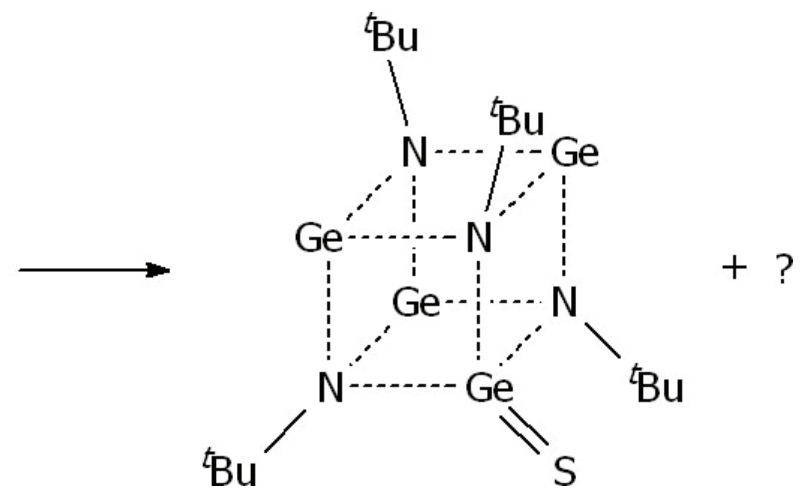

Scheme 3-2: Redox reaction of a triimido sulfite with a metal chloride.

However, the product of the addition of $\mathrm{SnCl}_{2}$ to $\left[(\text { thf }) \mathrm{Li}_{2}\left\{\mathrm{H}_{2} \mathrm{CS}\left(\mathrm{N}^{\mathrm{t}} \mathrm{Bu}\right)_{2}\right\}\right]_{2}(\mathbf{1})$ in thf $/ n$-hexane at $-78^{\circ} \mathrm{C}$ could be isolated and crystallized at the beginning of this study. As expected, S-N bond cleavage reactions occurred (cf. Scheme 3-3) and a tert.-butyl amide fragment is present in the product $\left.\left[\mathrm{Cl}_{2} \mathrm{SnO}_{2}\left\{\mathrm{Sn}_{2}\left(\mathrm{HN} \mathrm{Nu}^{t}\right)\right\} \mathrm{H}_{2} \mathrm{CS}\left(\mathrm{N}^{t} \mathrm{Bu}\right)_{2}\right\}_{2}\right](7)$. The mechanism of this reaction remains unclear, as not all side-products could be identified. Nevertheless, enough methylene diimido sulfite units were kept intact to form 7. In addition to the tin(II) ions of the parent $\mathrm{SnCl}_{2}$, tin(IV) ions of $\mathrm{SnO}_{2}$ trace impurities have been integrated, along with the associated $\mathrm{O}^{2-}$ dianions.

$$
\left[(\text { thf }) \mathrm{Li}\left\{\mathrm{H}_{2} \mathrm{CS}\left(\mathrm{N}^{\mathrm{tBu}}\right)_{2}\right\}\right]_{2}+2 \mathrm{SnCl}_{2}+\mathrm{SnO}_{2}
$$

1

$$
\stackrel{\substack{\text { thf } \\ n \text {-hexane }}}{\underset{-78^{\circ} \mathrm{C}}{\longrightarrow}} \quad\left[\mathrm{Cl}_{2} \mathrm{SnO}_{2}\left\{\mathrm{Sn}_{2}\left(\mathrm{HN}^{\mathrm{t} B u}\right)\right\}\left\{\mathrm{H}_{2} \mathrm{CS}\left(\mathrm{N}^{\mathrm{t} B u}\right)_{2}\right\}_{2}\right]+\text { ? }
$$

Scheme 3-3: Reaction of $\mathrm{SnCl}_{2}$ with the lithium diimido sulfur ylide 1 .

7 represents the first example of a non-lithium polyimido sulfur ylide. The complex is centrosymmetric with respect to Sn3 (cf. Figure 3-1). Every donor atom of the two sulfite analogues coordinates exclusively one tin atom. This is different to $\left[\text { (thf) } \mathrm{Li}_{2}\left\{\mathrm{H}_{2} \mathrm{CS}\left(\mathrm{N}^{t} \mathrm{Bu}\right)_{2}\right\}\right]_{2}(\mathbf{1})$, where each nitrogen donor atom interacts with two metal ions and the carbanions coordinate three lithium atoms each. The coordination sphere of Sn1 and Sn2 is completed by the oxide anion $\mathrm{O} 1$ and the amidic nitrogen 
atom N3 bridging the two metals. $\mathrm{O} 1$ connects all three tin atoms as it forms a bond to the central Sn3. Apart from this, the octahedral environment at Sn3 consists of two chloride anions and the ylidic carbon atoms.

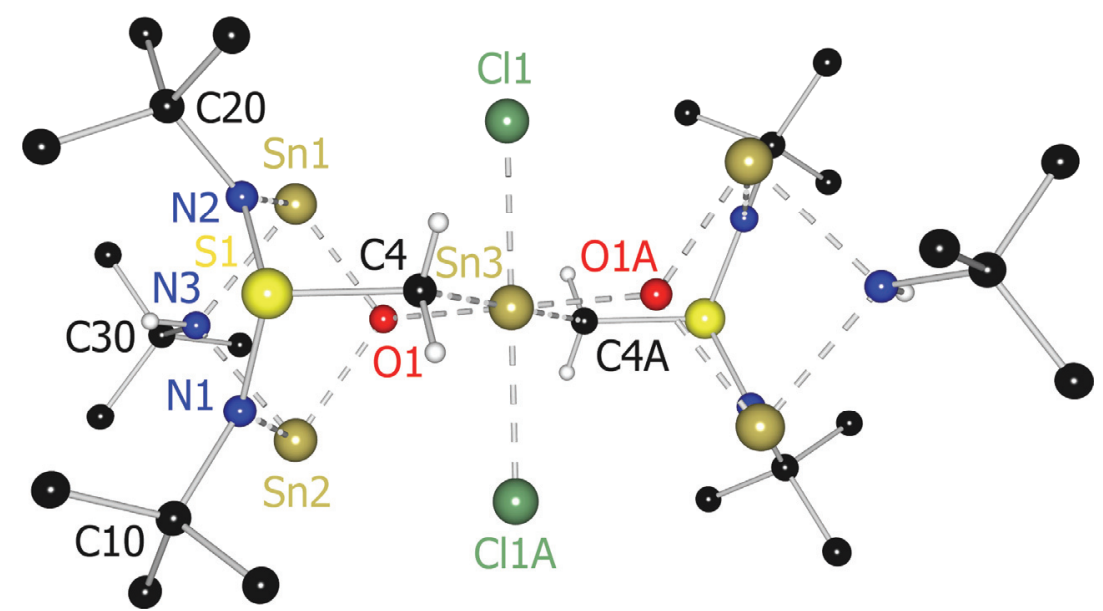

Figure 3-1: Molecular structure of $\left[\mathrm{Cl}_{2} \mathrm{SnO}_{2}\left\{\mathrm{Sn}_{2}\left(\mathrm{HN}^{t} \mathrm{Bu}\right)\right\}\left\{\mathrm{H}_{2} \mathrm{CS}\left(\mathrm{N}^{t} \mathrm{Bu}\right)_{2}\right\}_{2}\right](7)$; all methyl groups are omitted for clarity.

The coordination motif of a tridentate ligand capping three metal ions, seems to be very common for sulfite analogues. 10 molecules with this motif containing the $\mathrm{SO}_{3}{ }^{2-}$ dianion, 16 with $\mathrm{S}(\mathrm{NR})_{3}{ }^{2-}$, and 13 containing an $\mathrm{S}(\mathrm{NR})_{2}\left(\mathrm{CR}_{2}\right)^{2-}$ dianion have been analyzed by X-ray crystallography. ${ }^{[230]}\left[(\text { thf }) \mathrm{Li}_{2}\left\{\mathrm{H}_{2} \mathrm{CS}\left(\mathrm{N}^{t} \mathrm{Bu}\right)_{2}\right\}\right]_{2}(\mathbf{1})$ contains this motif, too. Figure 3-2 illustrates the coordination mode by the important structure fragments of 1 and $\left[(\operatorname{thf})_{3} \mathrm{Li}{ }_{3}(\mathrm{Br})\left\{\mathrm{S}\left(\mathrm{N}^{t} \mathrm{Bu}\right)_{3}\right\}\right] .{ }^{[231]}$ Nevertheless, other coordination patterns for the sulfite analogues are known as well. ${ }^{[102,231]}$

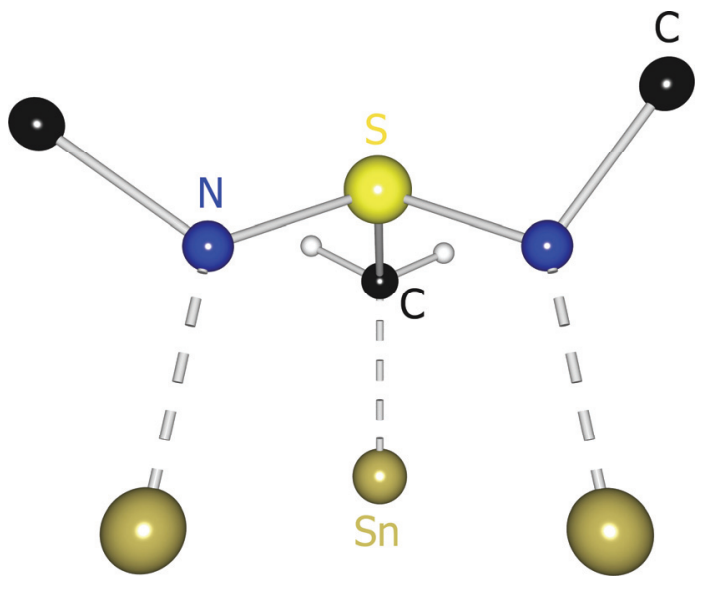

(a)

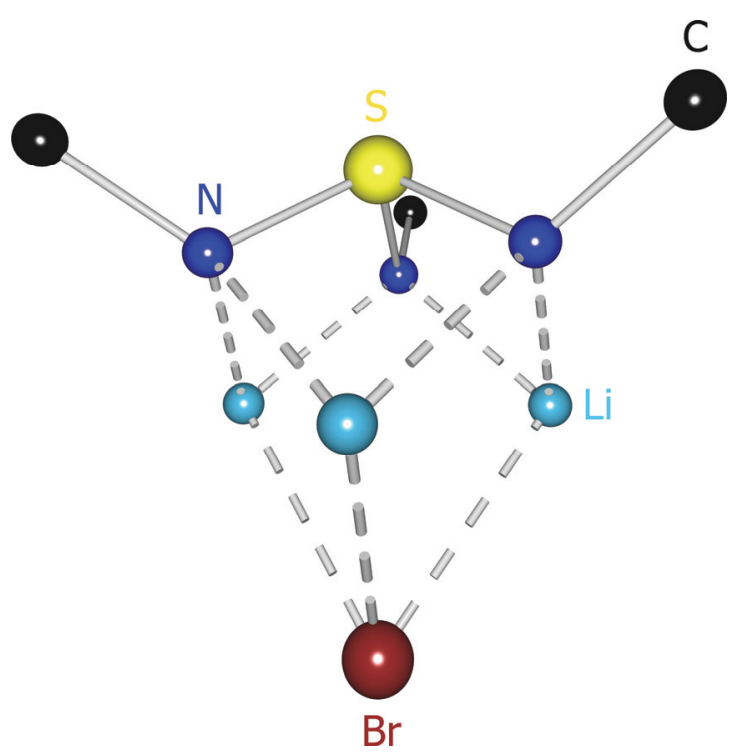

(b)

Figure 3-2: Coordination motif of sulfite analogues in (a) $\left[(\text { thf }) \mathrm{Li}_{2}\left\{\mathrm{H}_{2} \mathrm{CS}\left(\mathrm{N}^{t} \mathrm{Bu}\right)_{2}\right\}\right]_{2}$ (1) and (b) $\left[(\text { thf })_{3} \mathrm{Li}_{3}(\mathrm{Br})\left\{\mathrm{S}\left(\mathrm{N}^{t} \mathrm{Bu}\right)_{3}\right\}\right]$. 
Apart from this observation, no other statements concerning the general structure of alkylene diimido sulfite complexes are possible, because the incorporation of an $\mathrm{O}^{2-}$ dianion in the structure modifies the crystal structure.

The Sn-O distances (2.083 $\AA$ on av., cf. Table 3-1) match almost exactly the median $(2.081 \AA)$ of those reported for other compounds containing the $\mathrm{Sn}_{3}\left(\mathrm{O}^{2-}\right)$ pattern $(1.894-2.832 \AA) .{ }^{[230]}$ The $\mathrm{Sn}-\mathrm{N}$ distances of the imido groups (2.178 $\AA$ on av.) are in the range generally quoted $(2.033-2.294 \AA),{ }^{[230]}$ whereas the $\mathrm{Sn}-\mathrm{N}$ bonds to the amidic nitrogen atom N3 are longer (2.264 $\AA$ on av.) because two tin atoms compete for the negative charge. The length of the Sn3-C4 bond (2.158(3) $\AA$ ) is close to the median of comparable bonds $(2.165 \AA) .{ }^{[230]}$ The $\mathrm{S}-\mathrm{N}$ and $\mathrm{S}-\mathrm{C}$ bond lengths fit those described for the lithium diimido sulfur ylides. ${ }^{[62-64]}$

Table 3-1: Selected bond lengths $[\AA]$ and angles $\left[^{\circ}\right]$ in $\left[\mathrm{Cl}_{2} \mathrm{SnO}_{2}\left\{\mathrm{Sn}_{2}\left(\mathrm{HN}^{t} \mathrm{Bu}\right)\right\}\left\{\mathrm{H}_{2} \mathrm{CS}\left(\mathrm{N}^{t} \mathrm{Bu}\right)_{2}\right\}_{2}\right](7)$.

\begin{tabular}{|c|c|c|c|c|c|}
\hline $\mathrm{S} 1-\mathrm{N} 1$ & $1.630(3)$ & Sn3-01 & $2.094(2)$ & S1-C4-Sn3 & $121.75(18)$ \\
\hline S1-N2 & $1.635(3)$ & Sn3-C4 & $2.158(3)$ & Sn1-N3-Sn2 & $95.21(11)$ \\
\hline S1-C4 & $1.792(4)$ & $\mathrm{Sn} 3-\mathrm{Cl} 1$ & $2.5447(9)$ & Sn1-O1-Sn2 & $107.07(9)$ \\
\hline Sn1-N2 & $2.177(3)$ & & & Sn1-O1-Sn3 & $120.14(10)$ \\
\hline Sn1-N3 & $2.266(3)$ & $\mathrm{N} 1-\mathrm{S} 1-\mathrm{N} 2$ & $109.84(16)$ & Sn2-O1-Sn3 & $120.17(10)$ \\
\hline Sn2-N1 & $2.179(3)$ & $\mathrm{N} 1-\mathrm{S} 1-\mathrm{C} 4$ & $105.92(18)$ & O1-Sn3-Cl1 & $90.31(6)$ \\
\hline Sn2-N3 & $2.261(3)$ & N2-S1-C4 & $106.80(18)$ & O1-Sn3-C4 & $90.22(11)$ \\
\hline Sn1-O1 & $2.085(2)$ & S1-N1-Sn2 & $124.25(16)$ & C4-Sn3-Cl1 & $89.72(12)$ \\
\hline Sn2-01 & $2.072(2)$ & S1-N2-Sn1 & $124.54(15)$ & & \\
\hline
\end{tabular}

The angles at S1 fit a slightly distorted tetrahedral environment. Thus, the sulfur atom seems to be $\mathrm{sp}^{3}$-hybridized like in $\left[(\operatorname{thf}) \mathrm{Li}_{2}\left\{\mathrm{H}_{2} \mathrm{CS}\left(\mathrm{N}^{t} \mathrm{Bu}\right)_{2}\right\}\right]_{2}(4)$. Together with the other bond lengths and angles, which are also in the range of the lithium ylide, it can be concluded that again no hypervalency or double bonding has to be formulated.

\subsection{Reactions Employing Grignard Reagents}

All transmetalation reactions, except the one with $\mathrm{SnCl}_{2}$ described above, led to undefined products. Thus, an alternative route to non-lithium polyimido sulfur ylides was explored. It is known since 1976 that sulfur diimides readily react with Grignard reagents. ${ }^{[57]}$ Although the reaction can be used for titrating Grignard solutions, its 
chemical versatility was not explored any further. Only Freitag reported in 1993 on the reaction of phenyl magnesium bromide with $\mathrm{S}\left(\mathrm{NSiMe}_{3}\right)_{2}$ (cf. Scheme 3-4). ${ }^{[55]}$ The dimer [(thf) $\left.\mathrm{MgBr}\left\{\mathrm{PhS}\left(\mathrm{NSiMe}_{3}\right)_{2}\right\}\right]_{2}$ was formed (cf. Figure 3-3).

$$
\begin{aligned}
& \text { thf } \\
& 2 \mathrm{~S}\left(\mathrm{NSiMe}_{3}\right)_{2}+2 \mathrm{PhMgBr} \underset{-78^{\circ} \mathrm{C}}{\stackrel{n \text {-hexane }}{\longrightarrow}}\left[(\text { thf }) \mathrm{MgBr}\left\{\mathrm{PhS}\left(\mathrm{NSiMe}_{3}\right)_{2}\right\}\right]_{2}
\end{aligned}
$$

Scheme 3-4: Addition of $\mathrm{PhMgBr}$ to $\mathrm{S}\left(\mathrm{NSiMe}_{3}\right)_{2}$.

The structural motif of Scheme 2-6i containing the central $\mathrm{Mg}_{2} \mathrm{Cl}_{2}$ ring contradicts the eight-membered ring Kuyper and Vrieze postulated for his compounds, but they could not determine the structure unambiguously by X-ray crystallography at that time, but had to rely on NMR data. ${ }^{[60]}$ Thus, it is very likely that a determination of the structure would reveal the same motif nowadays.

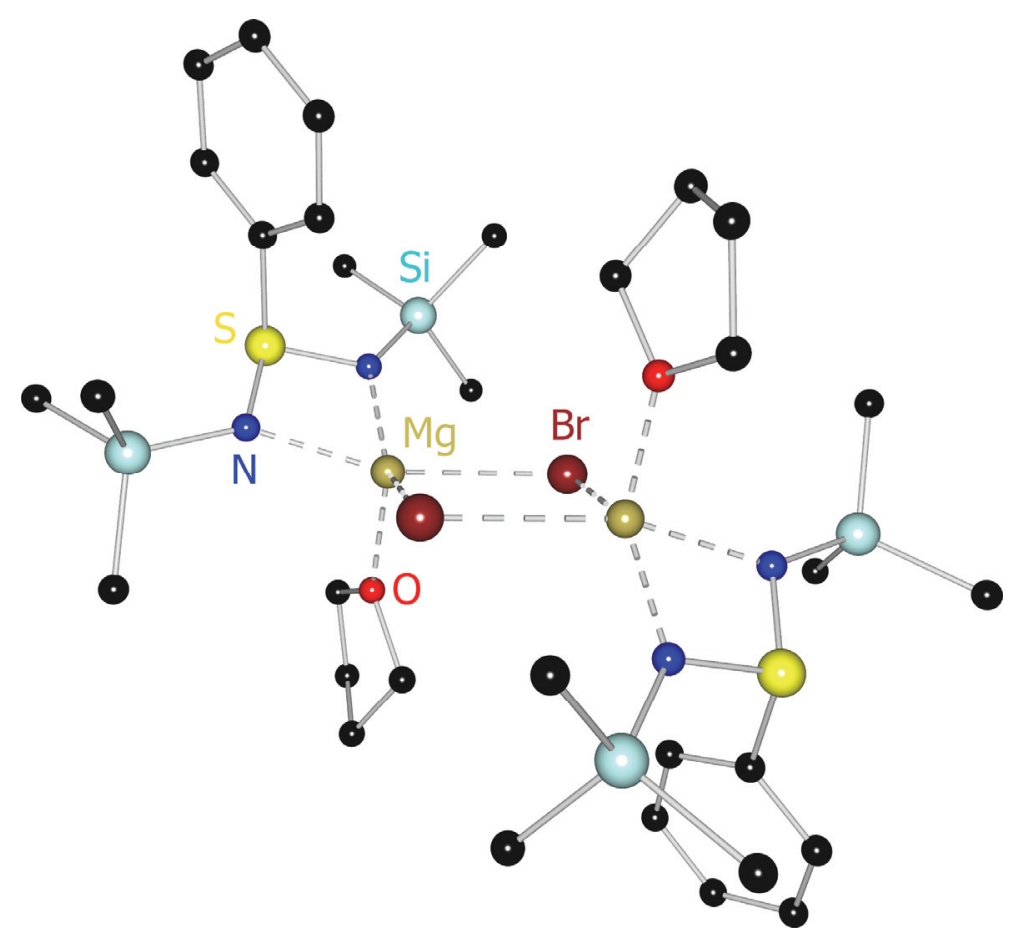

Figure 3-3: Molecular structure of $\left[(\text { thf }) \mathrm{MgBr}\left\{\mathrm{PhS}\left(\mathrm{NSiMe}_{3}\right)_{2}\right\}\right]_{2}$.

The Grignard reactions were explored further throughout the diploma thesis prior to this doctoral study. Addition of bulky substituents to $\mathrm{S}\left(\mathrm{N}^{t} \mathrm{Bu}\right)_{3}$ using organo lithium reagents is not possible due to the electronic and steric reasons described in chapter 2.1. An attack from above or below the $\mathrm{SN}_{3}$ plane is not possible because of the electron concentrations located there (cf. Figure 2-1) and the attack along the $\mathrm{SN}_{2}$ bisection is sterically hindered by the tert.-butyl groups. However, application of an HSAB-soft Grignard nucleophile allows penetration of the electronic shielding 
partially, because it matches the soft character of the sulfur atom. Thus, $n$-butyl groups could be inserted (cf. Scheme 3-5). ${ }^{[66]}$

$$
\begin{aligned}
& \text { thf } \\
& 2 \mathrm{~S}\left(\mathrm{~N}^{\mathrm{t} B u}\right)_{3}+2{ }^{n} \mathrm{BuLi} \quad \stackrel{n \text {-hexane }}{-78^{\circ} \mathrm{C}} \\
& \text { thf } \\
& 2 \mathrm{~S}\left(\mathrm{~N}^{\mathrm{t}} \mathrm{Bu}\right)_{3}+2{ }^{n} \mathrm{BuMgCl} \quad \underset{-78^{\circ} \mathrm{C}}{\stackrel{n \text {-hexane }}{\longrightarrow}}\left[(\text { thf }) M g C l\left\{{ }^{n} \mathrm{BuS}\left(\mathrm{N}^{\mathrm{t}} \mathrm{Bu}\right)_{3}\right\}\right]_{2}
\end{aligned}
$$

Scheme 3-5: Reactions of $\mathrm{S}\left(\mathrm{N}^{t} \mathrm{Bu}\right)_{3}$ with bulky organo metal compounds.

The structure in principle resembles the type shown in Scheme 2-6i. The additional imido group of the alkyl diimido sulfonate is not participating in the coordination of the metal (cf. Figure 3-4). This behavior is well-known for triimido sulfur compounds, as it is a way to avoid a sterically conflicting situation concerning the tert.-butyl groups. ${ }^{[101]}$

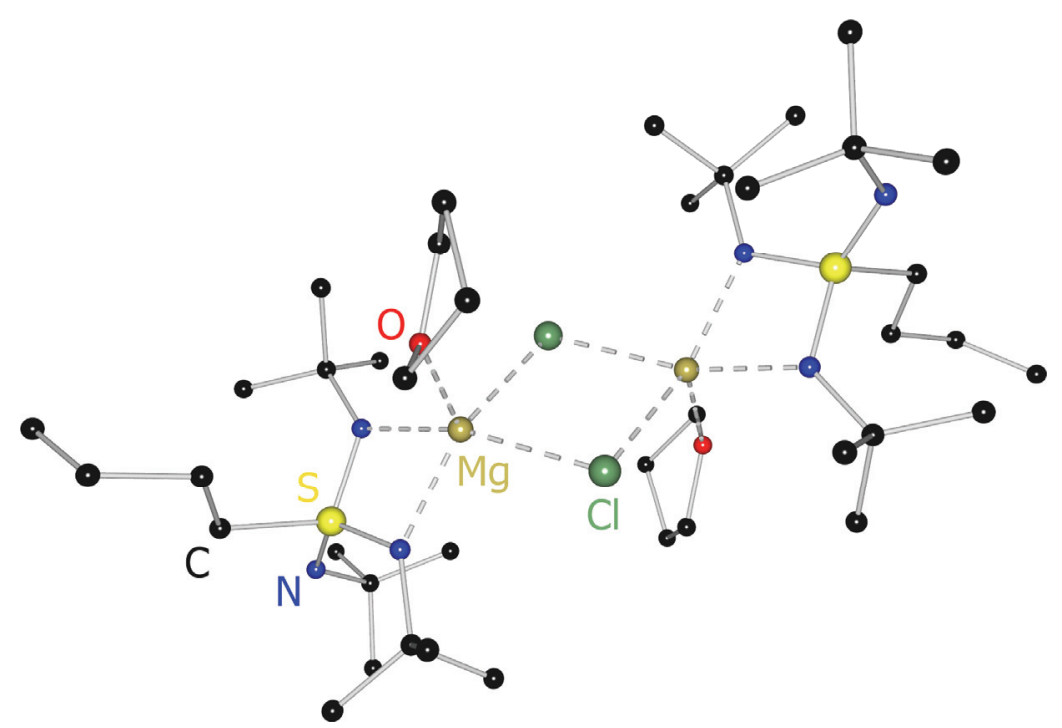

Figure 3-4: Molecular structure of $\left[(\text { thf }) \mathrm{MgCl}\left\{{ }^{n} \mathrm{BuS}\left(\mathrm{N}^{t} \mathrm{Bu}\right)_{3}\right\}\right]_{2}$.

Owing to the promising results, these reactions were used for adding an organo substituent with acidic $\alpha$-hydrogen atoms to the sulfur diimides and introducing magnesium at the same time. The obtained compounds should then be deprotonated by organo lithium reagents to yield the corresponding ylides.

The first step, addition of an organo substituent, worked well for benzyl magnesium chloride. The reaction according to Scheme $3-6$ in thf $/ n$-hexane at $-78{ }^{\circ} \mathrm{C}$ yielded $\left[(\text { thf })_{2} \mathrm{MgCl}\left\{\mathrm{BzS}\left(\mathrm{N}^{t} \mathrm{Bu}\right)_{2}\right\}\right](\mathbf{8})$. 


$$
\mathrm{S}\left(\mathrm{N}^{\mathrm{t} B u}\right)_{2}+\mathrm{BzMgCl} \underset{\substack{\text { thf } \\ \stackrel{n-h e x a n e}{\longrightarrow}}}{-78^{\circ} \mathrm{C}} \quad\left[(\text { thf })_{2} \operatorname{MgCl}\left\{\mathrm{BzS}\left(\mathrm{N}^{t} \mathrm{Bu}\right)_{2}\right\}\right]
$$

Scheme 3-6: Synthesis of $\left[(\text { thf })_{2} \mathrm{MgCl}\left\{\mathrm{BzS}\left(\mathrm{N}^{t} \mathrm{Bu}\right)_{2}\right\}\right](8)$.

Interestingly, the compound is monomeric (cf. Figure 3-5). The preferred five-fold coordination of magnesium is obtained by two $\mathrm{Mg}-\mathrm{O}$ contacts to thf donor molecules. This is contrary to the dimeric magnesium compounds reported so far. The structural motif resembles the one in Scheme 2-6g, but owing to the dication Mg1 an additional chloride anion is attached to the metal atom. The sterically demanding chlorine atom occupies the apex of the square-pyramidal environment of Mg1.

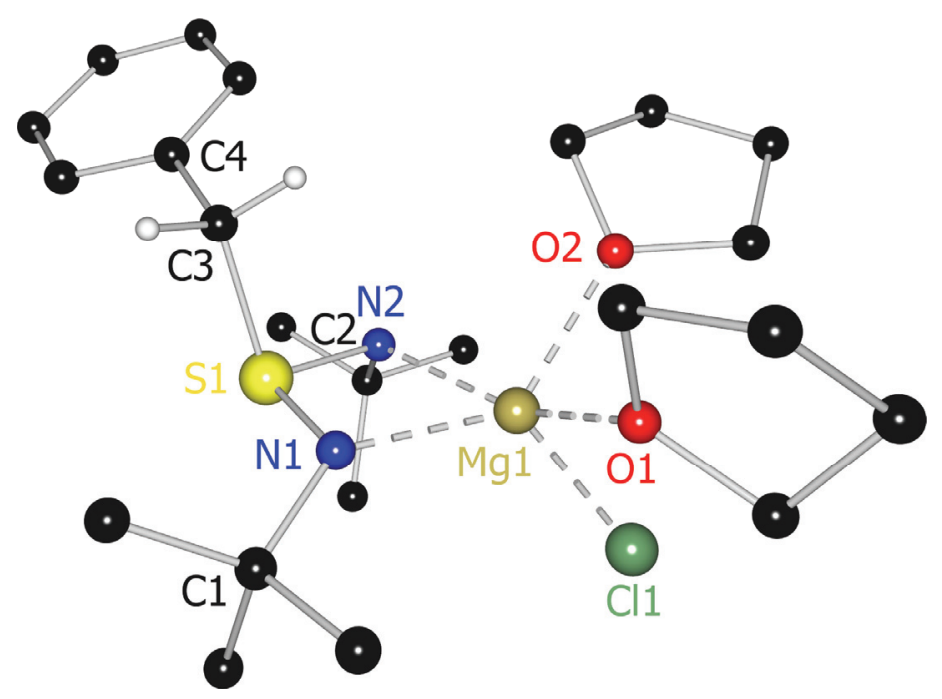

Figure 3-5: Molecular structure of $\left[(\text { thf })_{2} \mathrm{MgCl}\left\{\mathrm{BzS}\left(\mathrm{N}^{t} \mathrm{Bu}\right)_{2}\right\}\right](8)$.

Schulz succeeded in preparing the asymmetrically substituted $\left[(\text { thf })_{2} \mathrm{MgCl}\left\{\mathrm{BzS}\left(\mathrm{N}^{t} \mathrm{Bu}\right)\left(\mathrm{NSiMe}_{3}\right)\right\}\right]$ at about the same time ${ }^{[64]}$ As this compound is also monomeric and shows the same structural features as $\left[(\text { thf })_{2} \mathrm{MgCl}\left\{\mathrm{BzS}\left(\mathrm{N}^{t} \mathrm{Bu}\right)_{2}\right\}\right](8)$, it can be concluded that the additional $\mathrm{CH}_{2}$ group of the benzyl substituent is responsible for the formation of a monomer. The carbon spacer allows the phenyl group to bend away from the magnesium atom. This opens enough space in the coordination sphere of the metal for a second thf donor molecule. The thf oxygen atom is a better donor to magnesium than a chloride anion bridging two metal ions and thus no dimerization is observed.

The bond lengths and angles of $\left[(\text { thf })_{2} \mathrm{MgCl}\left\{\mathrm{BzS}\left(\mathrm{N}^{t} \mathrm{Bu}\right)\left(\mathrm{NSiMe}_{3}\right)\right\}\right]$ and $\left[(\text { thf })_{2} \mathrm{MgCl}\left\{\mathrm{BzS}\left(\mathrm{N}^{t} \mathrm{Bu}\right)_{2}\right\}\right]$ (8) (cf. Table 4-2) are the same within their standard deviations (disregarding the $\mathrm{SiMe}_{3}$ substituent). Only the $\mathrm{Mg}-\mathrm{N}$ bond lengths show a 
more distinct asymmetric coordination of the magnesium ion for 8 (2.1699(13) and $2.1021(14) \AA$ in 8 vs. 2.157 and $2.113 \AA$ ). This is especially interesting as the asymmetric diimido sulfinate coordinates in a more symmetric fashion than the symmetric compound 8 does. The chlorine atom resides at the apex of the distorted square-pyramidal coordination polyhedron around $\mathrm{Mg} 1$. The $\mathrm{Mg} 1-\mathrm{Cl} 1$ vector encloses an angle of $52.1^{\circ}$ with the $\mathrm{SN}_{2} \mathrm{Mg}$ plane and is thus closer to the thf donors.

Table 3-2: Selected bond lengths $[\AA]$ and angles $\left[{ }^{\circ}\right]$ in $\left[(\text { thf })_{2} \mathrm{MgCl}\left\{\mathrm{BzS}\left(\mathrm{N}^{t} \mathrm{Bu}\right)_{2}\right\}\right](\mathbf{8})$.

\begin{tabular}{ll}
\hline S1-N1 & $1.6285(13)$ \\
S1-N2 & $1.6218(12)$ \\
S1-C3 & $1.8440(15)$ \\
C3-C4 & $1.495(2)$ \\
Mg1-N1 & $2.1021(14)$ \\
\hline
\end{tabular}

\begin{tabular}{ll}
\hline Mg1-N2 & $2.1697(13)$ \\
Mg1-O1 & $2.1112(12)$ \\
Mg1-O2 & $2.0854(12)$ \\
Mg1-Cl1 & $2.3430(7)$ \\
& \\
\hline
\end{tabular}

\begin{tabular}{lc}
\hline N1-S1-N2 & $99.65(7)$ \\
N1-S1-C3 & $102.31(7)$ \\
N2-S1-C3 & $102.20(7)$ \\
S1-C3-C4 & $112.27(10)$ \\
N1-Mg1-N2 & $71.07(5)$ \\
\hline
\end{tabular}

In order to ensure, that the formation of a monomer is not due to the replacement of one or more $\mathrm{NSiMe}_{3}$ groups by $\mathrm{N}^{t} \mathrm{Bu}$ groups, [(thf)MgCl$\left.\left\{\mathrm{PhS}\left(\mathrm{N}^{t} \mathrm{Bu}\right)_{2}\right\}\right]_{2}$ (9), the analogue of Freitag's compound, was prepared by reaction of $\mathrm{PhMgCl}$ with $\mathrm{S}\left(\mathrm{N}^{t} \mathrm{Bu}\right)_{2}$ in thf $/ n$-hexane at $-78^{\circ} \mathrm{C}$ (cf. Scheme 3-7). As 9 is dimeric (cf. Figure 3-6), it could be ruled out, that the $\mathrm{N}^{t} \mathrm{Bu}$ groups or the use of chloride instead of bromide as anion are responsible for the formation of a monomer. Actually, apart from the central $\mathrm{Mg}_{2} \mathrm{Hal}_{2}$ ring, [(thf)MgCl\{PhS(N $\left.\left.\left.\mathrm{N}^{t} \mathrm{Bu}\right)_{2}\right\}\right]_{2} 9$ and [(thf)MgBr$\left.\left\{\mathrm{PhS}\left(\mathrm{NSiMe}_{3}\right)_{2}\right\}\right]_{2}$ exhibit the same bond lengths and angles within their standard deviations (cf. Table 3-3).

$$
\begin{aligned}
& \text { thf } \\
& 2 \mathrm{~S}\left(\mathrm{~N}^{\mathrm{t} B u}\right)_{2}+2 \mathrm{PhMgCl} \underset{-78^{\circ} \mathrm{C}}{\stackrel{n \text {-hexane }}{\longrightarrow}}\left[(\text { thf }) \mathrm{MgCl}\left\{\mathrm{PhS}\left(\mathrm{N}^{\mathrm{t}} \mathrm{Bu}\right)_{2}\right\}\right]_{2}
\end{aligned}
$$

Scheme 3-7: Synthesis of $\left[(\text { thf }) M g C l\left\{P h S\left(N^{t} B u\right)_{2}\right\}\right]_{2}(\mathbf{9})$.

The carbon atoms of the phenyl groups in $\left[(\text { thf }) \mathrm{MgCl}\left\{\mathrm{PhS}\left(\mathrm{N}^{t} \mathrm{Bu}\right)_{2}\right\}\right]_{2}(9)$ are in close vicinity to the magnesium atom (Mg1 $\cdots \mathrm{C} 23.775 \AA$ in 9 vs. Mg1 $\cdots \mathrm{C} 95.183 \AA$ in 8; cf. Table 3-3). Hence, no space for a second thf molecule is available. The dimerization over a central $\mathrm{Mg}_{2} \mathrm{Cl}_{2}$ ring completes the coordination sphere of each lithium atom. As a result, the chlorine atoms are not positioned at the sterically favorable apex of the square-pyramidal environment of the magnesium atoms, but reside in the base. The replacement of the second thf donor in the phenyl-substituted compounds compared to the monomeric benzyl ones by a less favorable halogenide 
anion leads to closer $\mathrm{Mg}-\mathrm{N}$ and $\mathrm{Mg}-\mathrm{O}$ distances, as the magnesium atom comes in closer contact to those donors improve the interaction with their electron density.

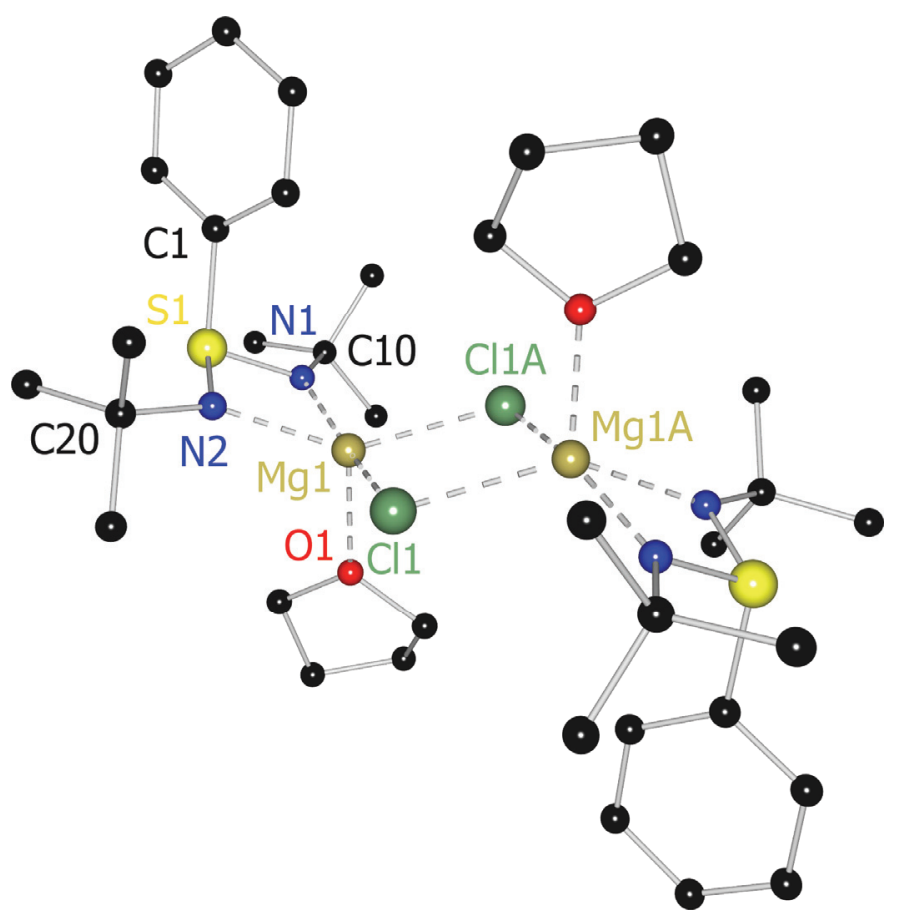

Figure 3-6: Molecular structure of $\left[(\text { thf }) \mathrm{MgCl}\left\{\mathrm{PhS}\left(\mathrm{N}^{t} \mathrm{Bu}\right)_{2}\right\}\right]_{2}(9)$.

The central $\mathrm{Mg}-\mathrm{Hal}$ coordination in 9 and $\left[(\text { thf }) \mathrm{MgBr}\left\{\mathrm{PhS}\left(\mathrm{NSiMe}_{3}\right)_{2}\right\}\right]_{2}$ shows a distinct asymmetry $(\Delta(\mathrm{Mg}-\mathrm{Cl})=0.07 \AA$ and $\Delta(\mathrm{Mg}-\mathrm{Br})=0.12 \AA)$. This has already been observed for other compounds containing a central $\mathrm{Mg}_{2} \mathrm{Hal}_{2}$ ring ${ }^{[232-236]}$ and displays that the electron density of the halogen anions is not perfectly shared between the metal ions. This is reflected by the $\mathrm{Mg}-\mathrm{N}$ contacts which show an exactly complementary trend. The same has been found in organo triimido sulfonate compounds. ${ }^{[66]}$ Like in those compounds, the $\mathrm{SN}_{2}$ planes are tilted $37^{\circ}$ towards the central $\mathrm{Mg}_{2} \mathrm{Hal}_{2}$ ring (cf. Figure 3-3 and Figure 3-6). This would lead to steric strain between the phenyl unit and the thf molecule of the opposite half of the dimer. Thus, an additional sideward twist of $14^{\circ}$ is present which allows the rings to avoid each other.

Table 3-3: Selected bond lengths $[\AA]$ and angles $\left[{ }^{\circ}\right]$ in $\left[(\text { thf }) \mathrm{MgCl}\left\{\mathrm{PhS}\left(\mathrm{N}^{t} \mathrm{Bu}\right)_{2}\right\}\right]_{2}(\mathbf{9})$.

\begin{tabular}{lllll}
\hline S1-N1 & $1.6089(17)$ & & Mg1-O1 & $2.0265(15)$ \\
S1-N2 & $1.6160(17)$ & & Mg1-Cl1 & $2.4160(8)$ \\
S1-C1 & $1.817(2)$ & & Mg1-Cl1A & $2.4841(8)$ \\
Mg1-N1 & $2.0815(18)$ & & \\
Mg1-N2 & $2.0558(17)$ & & \\
\hline
\end{tabular}

\begin{tabular}{lr}
\hline N1-S1-N2 & $94.41(8)$ \\
N1-S1-C1 & $106.04(9)$ \\
N2-S1-C1 & $105.90(9)$ \\
N1-Mg1-N2 & $69.77(7)$ \\
Cl1-Mg1-Cl1A & $84.85(3)$ \\
\hline
\end{tabular}


Interestingly, the $\mathrm{H}_{2} \mathrm{C}-\mathrm{Ph}$ bond in the benzyl substituted compounds is not in-line with the $S \cdots \mathrm{Mg}$ vector but forms an angle of $38^{\circ}$ with the vector instead. In contrast, the phenyl planes of [(thf)MgCl\{PhS(NBu $\left.\left.\left.{ }^{t} \mathrm{Bu}\right)_{2}\right\}\right]_{2} 9$ and $\left[(\text { thf }) \mathrm{MgBr}\left\{\mathrm{PhS}\left(\mathrm{NSiMe}_{3}\right)_{2}\right\}\right]_{2}$ are perfectly in line with the $S \cdots M g$ vector. The benzylic phenyl groups are additionally oriented towards one of the tert.-butyl groups. Thus, while the tertiary carbon atoms in the tert.-butyl groups of the phenyl species are in plane with the $\mathrm{N}-\mathrm{S}-\mathrm{N}$ plane, the respective carbon atoms of the benzyl compounds are tilted $45.2^{\circ}$ relative to that plane owing to the steric repulsion of the benzyl system. The S-C distances of the benzyl substituted compounds (1.844(4) $\AA$ ) are longer than those of the phenyl substituted ones (1.817 $\AA$ on av.) and other alkyl or aryl diimido sulfinates or triimido sulfonates $\left(1.800 \AA\right.$ on av.) ${ }^{[53,54,56,81,101]}$ The phenyl substituents at the benzylic carbon atoms withdraw electron density from the $\mathrm{S}-\mathrm{C}$ bonds, which are therefore destabilized and elongated.

The N-S-N bond angles in all presented compounds $\left(94.41(8)-100.05(3)^{\circ}\right)$ are more acute than those in alkali metal derivatives $\left(104.2-110.7^{\circ}\right),{ }^{[52]}$ but span almost the same range as in comparable compounds with $\mathrm{Mg}^{2+}$ or other dicationic metals (94.3-98.5). ${ }^{[56,101,237]}$ This can be attributed to the higher charge on the magnesium dication, leading to a stronger repulsion between the positively charged sulfur atom and the metal ion.

As the first step of the planned synthetic route to a non-lithium polyimido sulfur ylide was taken, attempts to deprotonate $\left[(\text { thf })_{2} \mathrm{MgCl}\left\{\mathrm{BzS}\left(\mathrm{N}^{t} \mathrm{Bu}\right)_{2}\right\}\right]$ (8) by addition of methyl lithium, $n$-butyl lithium, tert.-butyl lithium, and magnesium bis-(trimethylsilylamide) $\left[\mathrm{Mg}\left\{\left[\mathrm{N}\left(\mathrm{SiMe}_{3}\right)_{2}\right\}_{2}\right]\right.$ were undertaken (cf. Scheme 3-8).

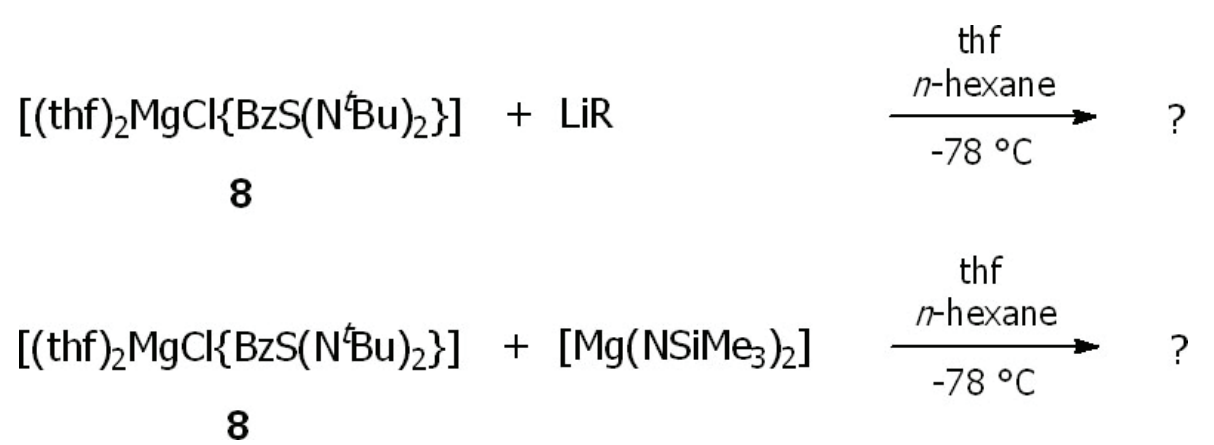

Scheme 3-8: Attempted deprotonation of $\left[(\text { thf })_{2} \operatorname{MgCl}\left\{\mathrm{BzS}\left(\mathrm{N}^{t} \mathrm{Bu}\right)_{2}\right\}\right](8) ; \mathrm{R}=\mathrm{Me},{ }^{n} \mathrm{Bu},{ }^{t} \mathrm{Bu}$.

All reactions gave crude product mixtures, which could not be crystallized or purified. The attempted characterization by NMR studies did not lead to the identification of a product but gave the impression that again $\mathrm{S}-\mathrm{N}$ and $\mathrm{S}-\mathrm{C}$ bond cleavages had taken place. Thus, no further attempts were made along this route. 


\subsection{Reactions with Dialkyl Metal Compounds}

Metal exchange on $\left[(\text { thf }) \mathrm{Li}_{2}\left\{\mathrm{H}_{2} \mathrm{CS}\left(\mathrm{N}^{t} \mathrm{Bu}\right)_{2}\right\}\right]_{2}$ (1) and deprotonation of a non-lithium organo diimido sulfinate proved to be no suitable access to diimido sulfur ylides coordinating a metal other than lithium despite all efforts. Therefore, it was attempted to mimic the well working synthesis of the lithium sulfur ylide 1.

$\left[(\text { thf }) \mathrm{Li}_{2}\left\{\mathrm{H}_{2} \mathrm{CS}\left(\mathrm{N}^{t} \mathrm{Bu}\right)_{2}\right\}\right]_{2}$ (1) can be synthesized in a one-pot reaction from $\mathrm{S}\left(\mathrm{N}^{t} \mathrm{Bu}\right)_{2}$ with two equivalents methyl lithium, because the carbanion acts as nucleophile in the first step and as base to abstract one $\alpha$-hydrogen atom in the second. This principle was applied to handle the synthetic issue mentioned above. Accordingly, main and transition metal reagents were employed which are nucleophilic, bear an $\alpha$-hydrogen atom and are basic at the same time. Di-n-butyl magnesium, dimethyl zinc, and dimethyl copper were chosen as appropriate candidates (cf. Scheme 3-9).

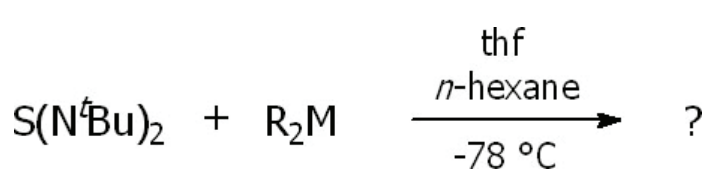

Scheme 3-9: Attempted reactions of dialkyl metal compounds with di-tert.-butyl sulfur diimide.

Interestingly, the reactions with dimethyl zinc and dimethyl copper led to similarly unidentifiable products as mentioned for the metal chlorides. Only the reaction with di- $n$-butyl magnesium was successful. Nevertheless, not only the desired addition of an $n$-butyl group and subsequent deprotonation took place, but additionally transimidation reactions occurred (cf. Scheme 3-10). The exact mechanism remains unclear as none of the side-products could be identified.

$6 \mathrm{~S}\left(\mathrm{~N}^{\mathrm{t} B u}\right)_{2}+9^{n} \mathrm{Bu}_{2} \mathrm{Mg}$

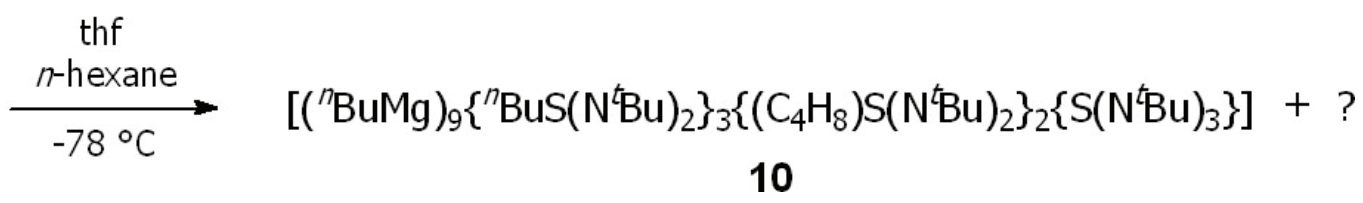

Scheme 3-10: Reaction of ${ }^{n} \mathrm{Bu}_{2} \mathrm{Mg}$ with $\mathrm{S}\left(\mathrm{N}^{t} \mathrm{Bu}\right)_{2}$ to form 10.

Three different anions were found in the product mixture, the $n$-butyl diimido sulfinate, the $n$-butylene diimido sulfite, and the triimido sulfite. The first is the product of mere addition of the $n$-butyl group to the sulfur diimide $\mathrm{S}\left(\mathrm{N}^{t} \mathrm{Bu}\right)_{2}$, the second is the deprotonation product of the first, and the triimido sulfite finally is generated by a transimidation reaction. In the crystal, one of the two sulfite dianions and a sulfinate 
monoanion cap a three-membered ring of magnesium atoms. The excessive positive charge is compensated for by $n$-butyl anions, which are attached to the metal atoms. The crystals of the formula $\left[\left({ }^{n} \mathrm{BuMg}\right)_{9}\left\{{ }^{n} \mathrm{BuS}\left(\mathrm{N}^{t} \mathrm{Bu}\right)_{2}\right\}_{3}\left\{\left(\mathrm{C}_{4} \mathrm{H}_{8}\right) \mathrm{S}\left(\mathrm{N}^{t} \mathrm{Bu}\right)_{2}\right\}_{2}\left\{\mathrm{~S}\left(\mathrm{~N}^{t} \mathrm{Bu}\right)_{3}\right\}\right](10)$ are thus composed of the discrete units $\left[\left({ }^{n} \mathrm{BuMg}\right)_{3}\left\{{ }^{n} \mathrm{BuS}\left(\mathrm{N}^{t} \mathrm{Bu}\right)_{2}\right\}\left\{\left(\mathrm{C}_{4} \mathrm{H}_{8}\right) \mathrm{S}\left(\mathrm{N}^{t} \mathrm{Bu}\right)_{2}\right\}\right](11)$ (cf: Figure 3-7a/c) containing the ylide and $\left[\left({ }^{n} \mathrm{BuMg}\right)_{3}\left[{ }^{n} \mathrm{BuS}\left(\mathrm{N}^{t} \mathrm{Bu}\right)_{2}\right\}_{3}\left\{\mathrm{~S}\left(\mathrm{~N}^{t} \mathrm{Bu}\right)_{3}\right\}\right](12)$ (cf: Figure 3-7b/d) containing the triimido sulfite. 11 and 12 are present in a 2:1 ratio in the examined crystal. The structural discussion will be limited to one molecule of 11 as the second one shows only minor differences in bond lengths and angles.

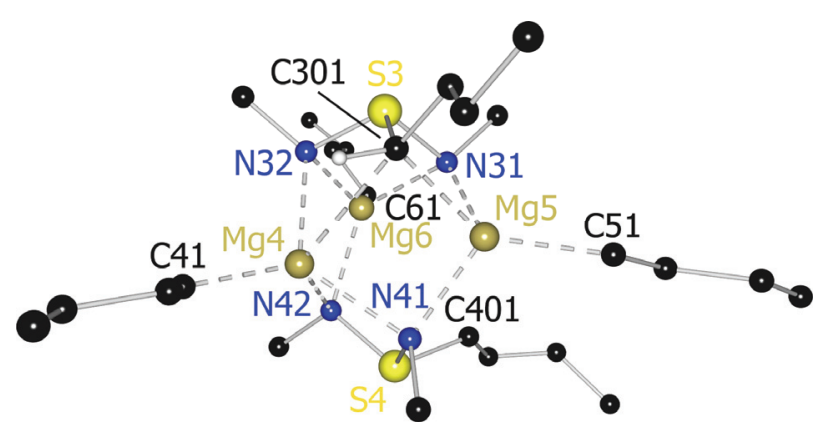

(a)

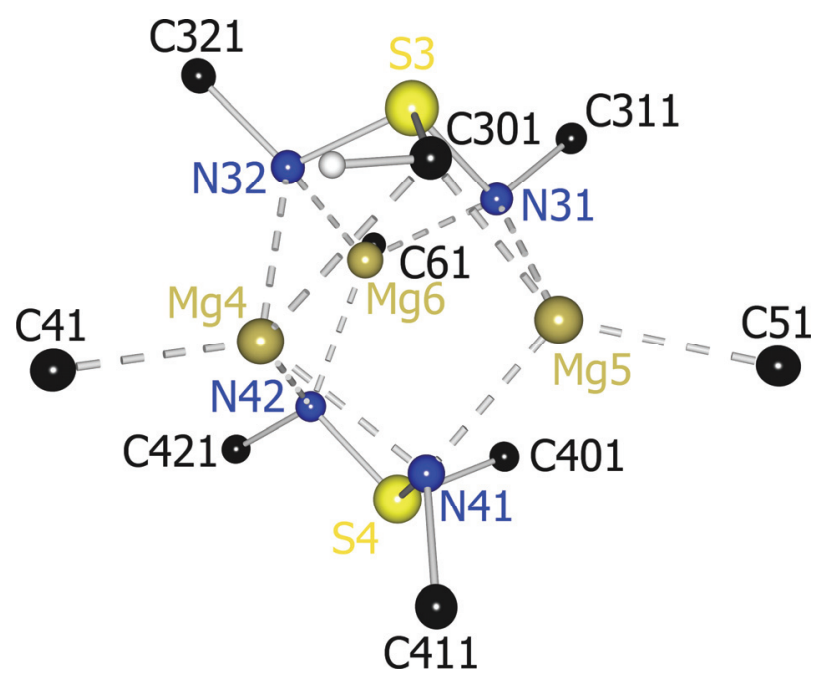

(c)

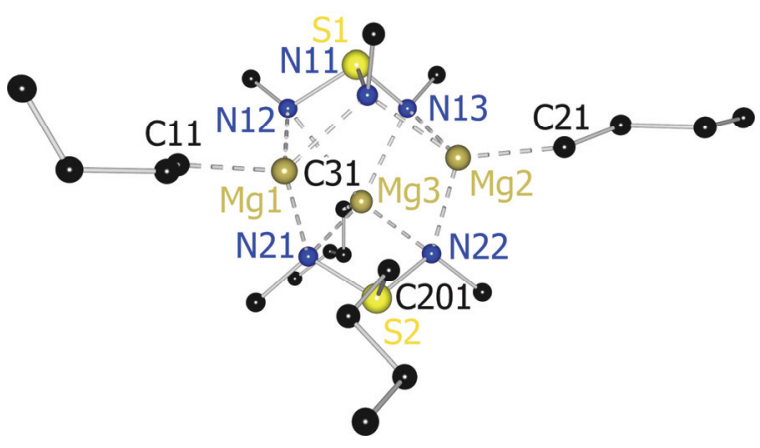

(b)

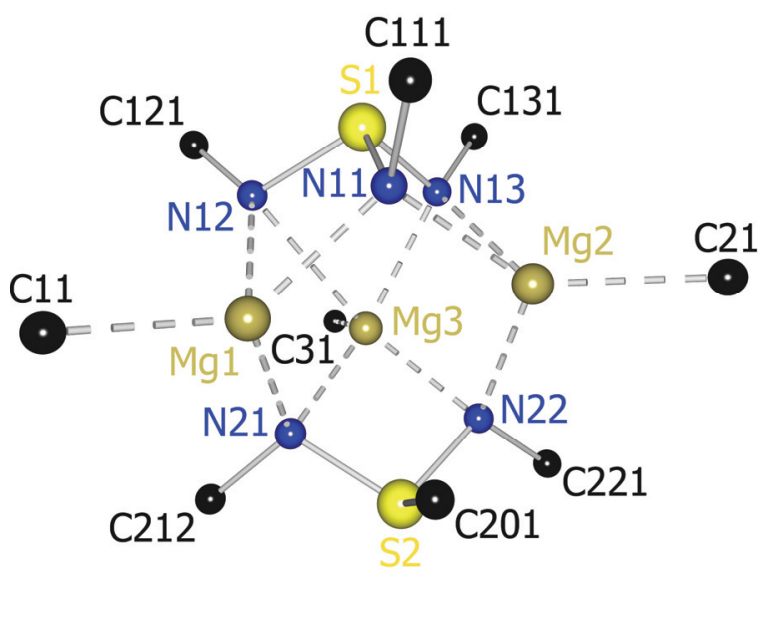

(d)

Figure 3-7: Molecular structure of (a)/(c) $\left[\left({ }^{n} \mathrm{BuMg}\right)_{3}\left\{{ }^{n} \mathrm{BuS}\left(\mathrm{N}^{t} \mathrm{Bu}\right)_{2}\right\}\left\{\left(\mathrm{C}_{4} \mathrm{H}_{8}\right) \mathrm{S}\left(\mathrm{N}^{t} \mathrm{Bu}\right)_{2}\right\}\right](11)$ and (b)/(d) $\left[\left({ }^{n} \mathrm{BuMg}\right)_{3}\left\{{ }^{n} \mathrm{BuS}\left(\mathrm{N}^{t} \mathrm{Bu}\right)_{2}\right\}_{3}\left\{\mathrm{~S}\left(\mathrm{~N}^{t} \mathrm{Bu}\right)_{3}\right\}\right](12)$ in $\left.\left[\left({ }^{n} \mathrm{BuMg}\right)_{9}{ }^{n} \mathrm{BuS}\left(\mathrm{N}^{t} \mathrm{Bu}\right)_{2}\right\}_{3}\left\{\left(\mathrm{C}_{4} \mathrm{H}_{8}\right) \mathrm{S}\left(\mathrm{N}^{t} \mathrm{Bu}\right)_{2}\right\}_{2}\left\{\mathrm{~S}\left(\mathrm{~N}^{t} \mathrm{Bu}\right)_{3}\right\}\right]$ (10); all methyl groups of tert.-butyl groups and all hydrogen atoms except those of deprotonated carbon atoms are omitted for clarity; in (c)/(d) aditionally all carbon atoms except the $\alpha$-carbon atoms are omitted..

The crystals of $\left[\left({ }^{n} \mathrm{BuMg}\right)_{9}\left\{{ }^{n} \mathrm{BuS}\left(\mathrm{N}^{t} \mathrm{Bu}\right)_{2}\right\}_{3}\left\{\left(\mathrm{C}_{4} \mathrm{H}_{8}\right) \mathrm{S}\left(\mathrm{N}^{t} \mathrm{Bu}\right)_{2}\right\}_{2}\left\{\mathrm{~S}\left(\mathrm{~N}^{t} \mathrm{Bu}\right)_{3}\right\}\right](10)$ were of poor quality. Thus, only data up to $(\sin \theta / \lambda)_{\max }=0.63 \AA^{-1}$ could be recorded. This is 
the minimal acceptable range for a reliable structure determination. Additionally, all $n$-butyl groups in the crystal are disordered over at least two sites. The same is valid for some magnesium, sulfur, and nitrogen atoms. Not all disorder could be resolved, as the refinement proved to be unstable due to the high correlation of all parameters. The resulting model does not meet all standards, but is still reliable with respect to the general coordination motif. The esd's of the bond lengths and angles are satisfactory (cf. Table 3-4 and Table 3-5), especially if the rather high quality criterion $w R 2$ of 0.3383 at an acceptable GoF of 1.340 is taken into account.

In order to verify the assignment of C301 and C501 to be ylidic, a DEPT-135 NMR experiment was performed. The signals of the carbon atoms in question were positive and are therefore $\mathrm{CH}$ or $\mathrm{CH}_{3}$ groups. The assignment as $\mathrm{CH}_{3}$ fragment is not reasonable as the $\mathrm{S}-\mathrm{C}$ and the $\mathrm{C}-\mathrm{C}$ bonds could be determined unambiguously from the $\mathrm{X}$-ray experiment. Thus, $\mathrm{C} 301$ and $\mathrm{C} 501$ are ylidic $\mathrm{CH}$ groups.

Table 3-4: Selected bond lengths $[\AA]$ and angles $\left[{ }^{\circ}\right]$ in 11; S3, N31, N32, and C301 alkylene diimido sulfite, S4, N41, N42, and C401 alkyl diimido sulfinate.

\begin{tabular}{|c|c|c|c|c|c|}
\hline S3-N31 & $1.679(5)$ & Mg5-C301 & $2.251(8)$ & N32-Mg4-C301 & $63.90(19)$ \\
\hline S3-N32 & $1.663(5)$ & Mg4-C41 & $2.141(8)$ & N41-Mg4-N42 & $68.0(3)$ \\
\hline S3-C301 & $1.766(7)$ & Mg5-C51 & $2.150(9)$ & N41-Mg4-C301 & $110.5(3)$ \\
\hline S4-N41 & $1.626(6)$ & Mg6-C61 & $2.126(8)$ & N32-Mg4-C41 & $113.6(4)$ \\
\hline S4-N42 & $1.661(9)$ & & & N41-Mg4-C41 & $125.2(4)$ \\
\hline S4-C401 & $1.774(10)$ & N31-S3-N32 & $100.2(3)$ & N42-Mg4-C41 & $126.1(3)$ \\
\hline Mg4-N32 & $2.248(6)$ & N41-S4-N42 & 101.3(4) & C301-Mg4-C41 & $110.5(3)$ \\
\hline Mg4-N41 & $2.268(8)$ & N31-S3-C301 & 101.7(3) & N31-Mg5-N41 & $106.8(2)$ \\
\hline Mg4-N42 & $2.281(7)$ & N32-S3-C301 & 103.0(3) & N31-Mg5-C301 & $73.9(2)$ \\
\hline Mg5-N31 & $2.193(5)$ & Mg5-N31-Mg6 & $113.1(2)$ & N41-Mg5-C301 & $100.2(3)$ \\
\hline Mg5-N41 & $2.155(7)$ & Mg4-N32-Mg6 & $87.5(2)$ & N31-Mg5-C51 & $122.1(3)$ \\
\hline Mg6-N31 & $2.243(6)$ & Mg4-N41-Mg5 & $91.3(2)$ & N41-Mg5-C51 & $118.1(4)$ \\
\hline Mg6-N32 & $2.176(6)$ & Mg4-N42-Mg6 & $86.8(2)$ & C301-Mg5-C51 & $126.7(4)$ \\
\hline Mg6-N42 & $2.169(6)$ & Mg4-C301-Mg5 & $77.6(2)$ & & \\
\hline Mg4-C301 & $2.759(7)$ & N32-Mg4-N42 & $88.3(2)$ & & \\
\hline
\end{tabular}

The $\mathrm{S}-\mathrm{N}$ bonds in the $n$-butyl diimido sulfinate anions span a range from 1.626(6) to 1.661(9) $\AA$. The values are in the range reported for comparable compounds $(1.598-1.657 \AA){ }^{[230]}$ The S-C bond lengths $(1.774(10)$ and $1.806(11) \AA)$ are slightly 
shortened compared to the typical value of an $\mathrm{S}-\mathrm{C}_{\mathrm{sp}}$ single bond $(1.83 \AA),{ }^{[238]}$ but match those of other reported alkyl diimido sulfinate anions $(1.718-1.868 \AA) .{ }^{[230]}$ The sulfur-bonded $n$-butyl groups of the alkyl diimido sulfinates do not take part in the coordination as they are not deprotonated.

The ylidic ligand $\left(\mathrm{C}_{4} \mathrm{H}_{8}\right) \mathrm{S}\left(\mathrm{N}^{t} \mathrm{Bu}\right)_{2}{ }^{2-}$ in 10 shows slightly elongated $\mathrm{S}-\mathrm{N}$ bonds $(1.671 \AA$ on av.) compared to the same ligand coordinated to lithium cations (1.659 $\AA$ on av. $)^{[63]}$ or the ylidic fragment of $\left[(\operatorname{thf}) \mathrm{Li}_{2}\left\{\mathrm{H}_{2} \mathrm{CS}\left(\mathrm{N}^{t} \mathrm{Bu}\right)_{2}\right\}\right]_{2}(4)(1.652 \AA$ on av.). The opposite is true for the S-C bond (1.766(7) $\AA$ in 10 vs. 1.799 and $1.780 \AA$ ). This means that the S-C bond in the $\left[\left(\mathrm{C}_{4} \mathrm{H}_{8}\right) \mathrm{S}\left(\mathrm{N}^{t} \mathrm{Bu}\right)_{2}\right]^{2-}$ dianion of 10 is shortened and strengthened at the expense of the $\mathrm{S}-\mathrm{N}$ bonds.

Table 3-5: Selected bond lengths $[\AA]$ and angles $\left[^{\circ}\right]$ in 12; S1, N11, N12, and N13 triimido sulfite, S2, N21, N22, and C201 alkyl diimido sulfinate.

\begin{tabular}{|c|c|c|c|c|c|}
\hline S1-N11 & $1.629(7)$ & Mg3-N13 & $2.287(9)$ & N11-Mg1-N12 & $69.1(3)$ \\
\hline $\mathrm{S} 1-\mathrm{N} 12$ & $1.758(12)$ & Mg1-C11 & $2.148(8)$ & N11-Mg1-N21 & $113.7(3)$ \\
\hline S1-N13 & $1.654(9)$ & Mg2-C21 & $2.140(11)$ & N12-Mg1-N21 & $88.6(4)$ \\
\hline S2-N21 & $1.647(8)$ & Mg3-C31 & $2.134(8)$ & N11-Mg1-C11 & $125.5(3)$ \\
\hline S2-N22 & $1.660(6)$ & & & N12-Mg1-C11 & $114.9(5)$ \\
\hline S2-C201 & $1.806(11)$ & N11-S1-N12 & $99.6(4)$ & N21-Mg1-C11 & $120.6(3)$ \\
\hline Mg1-N11 & $2.123(7)$ & N11-S1-N13 & 101.2(4) & N12-Mg3-N13 & $61.9(3)$ \\
\hline $\mathrm{Mg} 1-\mathrm{N} 12$ & $2.421(12)$ & N12-S1-N13 & $97.2(6)$ & N12-Mg3-N21 & $80.0(3)$ \\
\hline Mg1-N21 & $2.117(7)$ & N21-S2-N22 & $100.3(3)$ & N13-Mg3-N22 & $89.9(3)$ \\
\hline Mg2-N11 & $2.211(8)$ & N21-S2-C201 & $100.1(5)$ & N21-Mg3-N22 & $69.0(3)$ \\
\hline Mg2-N13 & $2.280(9)$ & Mg1-N11-Mg2 & 103.8(3) & N12-Mg3-C31 & $106.6(3)$ \\
\hline Mg2-N22 & $2.191(7)$ & Mg1-N12-Mg3 & $81.0(5)$ & N13-Mg3-C31 & $112.8(3)$ \\
\hline Mg3-N21 & $2.263(7)$ & Mg2-N13-Mg3 & $85.0(3)$ & N21-Mg3-C31 & $125.5(3)$ \\
\hline Mg3-N22 & $2.218(7)$ & Mg1-N21-Mg3 & $97.7(3)$ & N22-Mg3-C31 & $131.7(3)$ \\
\hline Mg3-N12 & $2.654(16)$ & Mg2-N22-Mg3 & $88.8(3)$ & & \\
\hline
\end{tabular}

The third polyimido sulfur fragment of 10 , the $\mathrm{S}\left(\mathrm{N}^{t} \mathrm{Bu}\right)_{3}{ }^{2-}$ dianion in 12 , has already been reported to be a versatile, highly reactive ligand. ${ }^{[35]} 16$ different metal complexes of this triimido sulfite have been characterized by $\mathrm{X}$-ray crystallography. ${ }^{[35,71,102,231,239-241]}$ However, none of these contains either a magnesium cation or only dicationic metal ions. The bond lengths for $\mathrm{S} 1-\mathrm{N} 11$ and S1-N13 (1.629(7) and 1.654(9) $\AA)$ are nevertheless in the range spanned by those 
compounds

(1.615-1.705 $\AA$ ). S1-N12 is distinctly elongated compared to the other S-N bonds in 10 or the model complexes. This is accompanied by longer $\mathrm{Mg}-\mathrm{N}$ distances (Mg1-N12 2.421(12), Mg3-N12 2.654(16) $\AA$ ) than for all other Mg-N bonds in 10 $(2.117(7)-2.281(7) \AA)$. The reason for this cannot be specified, as S1-N12 is not oriented parallel to the $n$-butyl group of the opposing alkyl diimido sulfinate cap, which could have been an explanation.

Every sulfur-bonded carbon and nitrogen atom of the polyimido sulfur caps in $\left[\left({ }^{n} \mathrm{BuMg}\right)_{9}\left\{{ }^{n} \mathrm{BuS}\left(\mathrm{N}^{t} \mathrm{Bu}\right)_{2}\right\}_{3}\left\{\left(\mathrm{C}_{4} \mathrm{H}_{8}\right) \mathrm{S}\left(\mathrm{N}^{t} \mathrm{Bu}\right)_{2}\right\}_{2}\left\{\mathrm{~S}\left(\mathrm{~N}^{t} \mathrm{Bu}\right)_{3}\right\}\right](10)$ coordinates two metal atoms. In contrast, the $n$-butyl groups which are not sulfur-bonded are attached to a single magnesium cation. This leads to two different magnesium environments. Those metal atoms farthest from the alkyl group of the diimido sulfinate anion (Mg3, Mg4) are five-fold coordinated and reside in the center of distorted square-pyramids with the magnesium-bonded $n$-butyl groups at the apices. All other metal atoms are only three-fold coordinated. Thus, like in the tin compound $\left[\mathrm{Cl}_{2} \mathrm{SnO}_{2}\left\{\mathrm{Sn}_{2}\left(\mathrm{HN}^{t} \mathrm{Bu}\right)\right\}\left\{\mathrm{H}_{2} \mathrm{CS}\left(\mathrm{N}^{t} \mathrm{Bu}\right)_{2}\right\}_{2}\right](7)$, the coordination pattern of the parent lithium sulfur ylide [(thf) $\left.\mathrm{Li}_{2}\left\{\mathrm{H}_{2} \mathrm{CS}\left(\mathrm{N}^{t} \mathrm{Bu}\right)_{2}\right\}\right]_{2}(1)$ is not possible as the metal ions do neither favor a tetrahedral environment nor the formation of $\mathrm{M}_{3} \mathrm{C}$ tetrahedra.

All N-S-N angles $\left(97.2(6)-101.3(4)^{\circ}\right)$ are reduced compared to those of the respective lithium complexes $\left(107.4^{\circ}\right.$ on av.). ${ }^{[230]}$ The same can be observed less distinct for the $\mathrm{N}-\mathrm{S}-\mathrm{C}$ angles $\left(100.1(5)-103.0(3)^{\circ}\right.$ in 10 vs. $103.1^{\circ}$ on av.). ${ }^{[230]}$ This can again be ascribed to the double positive charge on the metal ion and the repulsion from the positively charged sulfur atom.

The coordination of the magnesium atoms shows $\mathrm{Mg}-\mathrm{N}$ distances in the range from $2.117(7)$ to $2.287(9) \AA$. This covers the upper half of the values reported for similar compounds containing a sulfur-bonded imido nitrogen donor (2.035-2.295 A). ${ }^{\text {242-244] }}$ The Mg-C distances have to be divided into two groups. The $n$-butyl groups directly attached to the magnesium ions form contacts of $2.140 \AA$ on av. Only six out of 372 reported $\mathrm{Mg}-\mathrm{C}$ contacts are shorter than this, while the mean value $(2.306 \AA)$ is $0.16 \AA$ longer. ${ }^{[230]}$ Most carbanions of the reported structures bridge two or more metal ions and therefore the $\mathrm{Mg}-\mathrm{C}$ bond is longer. The same elongation can be observed for the second group of $\mathrm{Mg}-\mathrm{C}$ contacts in 10. The ylidic carbon atoms are on av. 2.214 $\AA$ apart from the two coordinated metal ions. Thus, they are about $0.07 \AA$ longer than the short Mg-C bonds, but are still close to the mean value of $\mathrm{Mg}-\mathrm{C}$ contacts with sulfur-attached carbanions $(2.208 \AA) .{ }^{[245-247]}$ 
The synthetic route presented herein leads to the desired products in some cases, but is not generally applicable. No reaction occurred in the cases of dimethyl zinc and dimethyl copper. In the case of di- $n$-butyl magnesium additional to the desired two-step reaction, a transimidation was observed. Nevertheless, the first magnesium complex of a polyimido sulfur ylide could be synthesized. However, the discussion of the coordination motif is limited to the present molecule, as the interaction with the $n$-butyl diimido sulfinate anion surely modifies the coordinative pattern of the ylide.

\subsection{Conclusions}

The main aim of this part of the thesis has been achieved. Two polyimido sulfur complexes containing non-lithium metals have been synthesized. The tin complex $\left[\mathrm{Cl}_{2} \mathrm{SnO}_{2}\left\{\mathrm{Sn}_{2}\left(\mathrm{HN}^{t} \mathrm{Bu}\right)\right\}\left\{\mathrm{H}_{2} \mathrm{CS}\left(\mathrm{N}^{t} \mathrm{Bu}\right)_{2}\right\}_{2}\right](7)$ contains additional oxide and tert.-butyl amide anions. In $\left[\left({ }^{n} \mathrm{BuMg}\right)_{9}\left\{{ }^{n} \mathrm{BuS}\left(\mathrm{N}^{t} \mathrm{Bu}\right)_{2}\right\}_{3}\left\{\left(\mathrm{C}_{4} \mathrm{H}_{8}\right) \mathrm{S}\left(\mathrm{N}^{t} \mathrm{Bu}\right)_{2}\right\}_{2}\left\{\mathrm{~S}\left(\mathrm{~N}^{t} \mathrm{Bu}\right)_{3}\right\}\right](10)$ the product of the first synthetic step, ${ }^{n} \mathrm{BuS}\left(\mathrm{N}^{t} \mathrm{Bu}\right)_{2}{ }^{-}$, and that from the successive deprotonation step, $\left(\mathrm{C}_{4} \mathrm{H}_{8}\right) \mathrm{S}\left(\mathrm{N}^{t} \mathrm{Bu}\right)_{2}{ }^{2-}$, coordinate three ${ }^{n} \mathrm{BuMg}^{+}$units. Additionally, a triimido sulfite dianion, $\mathrm{S}\left(\mathrm{N}^{t} \mathrm{Bu}\right)_{3}{ }^{2-}$, and the alkyl diimido sulfinate anion form a similar coordinative unit.

Although, [( $\left.\left.{ }^{n} \mathrm{BuMg}\right)_{9}\left\{{ }^{n} \mathrm{BuS}\left(\mathrm{N}^{t} \mathrm{Bu}\right)_{2}\right\}_{3}\left\{\left(\mathrm{C}_{4} \mathrm{H}_{8}\right) \mathrm{S}\left(\mathrm{N}^{t} \mathrm{Bu}\right)_{2}\right\}_{2}\left\{\mathrm{~S}\left(\mathrm{~N}^{t} \mathrm{Bu}\right)_{3}\right\}\right]$ (10) can be prepared reproducibly, the two synthetic routes presented in this chapter are no general access to metal complexes of polyimido sulfur ylides. Reactions with similar reagents failed so far. 


\section{Polydentate Polyimido Sulfur-Carbon- PHOSPHORUS LIGANDS}

\subsection{Introduction}

It has already been mentioned in the general introduction that the sulfur diimides or triimides $^{[24,40,41,44,45]}$ and furthermore the alkyl polyimido sulfinates ${ }^{[52-55]}$ and sulfonates ${ }^{[27,57-60]}$ are versatile ligands in main group and transition metal chemistry. Although Meij concluded from NMR data in 1976, that the metal atom of $\left[(\mathrm{CO})_{5} \mathrm{~W}\left\{\mathrm{~S}(\mathrm{NMe})_{2}\right\}\right]$ is most likely not nitrogen- but sulfur-bonded, ${ }^{[248,249]}$ no complexes showing such a coordination behavior have been characterized structurally by X-ray methods, yet. The donor potential of the sulfur atom in imido sulfur compounds has until now only been validated for three manganese and rhodium complexes of the RNSO type. ${ }^{[45,250,251]}$ This is disappointing because the presence of an active soft coordination site would transform the simple chelating ligand into a Janus-head ligand system.

Janus-head ligands combine hard and soft coordination sites in the same ligand. This enables them to coordinate metals of different size and HSAB hardness. The resultant bonding mode depends on the type (size and hardness) of metal coordinated. For example the P,N-Janus-head ligand di(pyrid-2-yl)phosphanide is able to coordinate metals as different as aluminium and caesium. Depending on the metal fragment offered, the ligand acts as an $\mathrm{N}, \mathrm{N}$-chelating ligand, as a $\mathrm{P}, \mathrm{N}$-chelating ligand, or as P-coordinating ligand. ${ }^{[252]}$

The presence of a single metal fragment of a given type leads to qualitatively different coordinative bonds, e.g. the hard metal atom lithium would be strongly bonded by the nitrogen donor but be weakly coordinated by the soft phosphorus atom. Therefore, the coordination is hemilabile and gives rise to catalytic activity. The strong coordinative bond prevents the catalyst from complete dissociation. ${ }^{[253]}$ Thus, high activity can be combined with a long lifetime of the catalyst. Such hybrid ligands proved their utility in oxidative addition and reductive elimination reactions as well as in many catalytic reactions in organometallic chemistry. ${ }^{\text {[254-257] }}$ If metals of different hardness are present, the Janus-head ligands coordinate the softer ones selectively via the soft coordination centers and the harder ones vice versa. This makes the Janus-head ligands ideal for catalysis as they form complexes in which the activator or co-catalyst and the catalytically active atom are in close 
proximity. In addition to nucleophile-electrophile reactions and olefin polymerization, various reactions with the active catalyst containing at least two metal centers are known. Examples are $\mathrm{CO}$ insertion reactions catalyzed by rhodium-iron clusters, ${ }^{[258]}$ asymmetric Michael reactions, ${ }^{[259,260]}$ and the activation of carbon-halide bonds. ${ }^{[261]}$ The co-operation of two metal atoms in one catalyst is also known for biological systems, e.g. the carbon monoxide dehydrogenase/Acetyl-CoA synthetases, ${ }^{[262-264]}$ purple acid phosphatases, ${ }^{[265]}$ and superoxide dismutases. ${ }^{[266]}$

This would be available to polyimido sulfur systems, if a soft phosphorus donor site would be introduced in a side-arm of the organo polyimido sulfinates (cf. Figure 4-1).
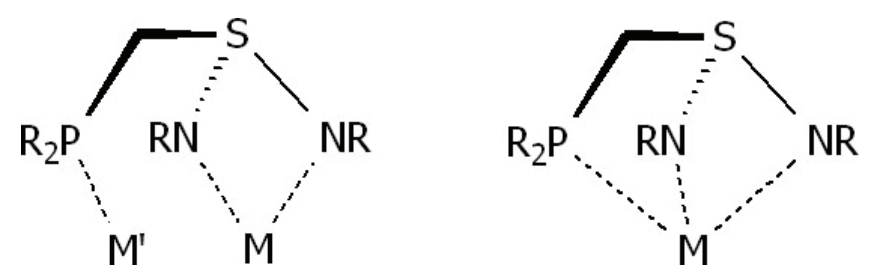

Figure 4-1: Polyimido sulfinate with side-arm donor site.

Only one such system, $\left.\left[\left(\mathrm{H}_{5} \mathrm{C}_{3}\right) \mathrm{Ni}^{t} \mathrm{Bu}_{2} \mathrm{PCH}_{2} \mathrm{~S}\left(\mathrm{NSiMe}_{3}\right)_{2}\right\}\right]$, has been reported to date. The catalytic activity seems to be remarkably good for this molecule and therefore the compound was patented for the co-polymerization of ethylene with polar co-monomers. ${ }^{[267]}$ Especially for acrylates good corporation and high productivity are reported at high ethylene pressures and surprisingly high temperatures. Nevertheless, this is the only example and the chemical field has not gained noticeable attention so far. Additionally, no crystal structure or details of the synthesis of $\left[\left(\mathrm{H}_{5} \mathrm{C}_{3}\right) \mathrm{Ni}\left\{{ }^{t} \mathrm{Bu}_{2} \mathrm{PCH}_{2} \mathrm{~S}\left(\mathrm{NSiMe}_{3}\right)_{2}\right\}\right]$ have been published.

Throughout this thesis a general access to polyimido sulfur-carbon-phosphorus $\left(\mathrm{N}_{2} \mathrm{SCP}\right.$ ) ligands was to be searched for. Two strategies were pursued: I) Reaction of lithium sulfur ylides with chlorophosphanes, yielding the product under elimination of lithium chloride. II) Addition of a lithiated trialkyl phosphane to a sulfur diimide.

The products were to be compared to reference compounds with ethylene-bridged nitrogen and phosphorus donors. These contain a carbon atom instead of the sulfur atom in the bridge between both donor atoms. Although the phosphano ethylamine complexes are more common, ${ }^{[268-271]}$ a broad variety of phosphano ethylimide complexes have also been investigated. ${ }^{[230]}$ 


\subsection{Reactions of Lithium Sulfur Ylides with Chlorophosphanes}

Coupling of the phosphano moiety to the polyimido sulfur fragment of an $\mathrm{N}_{2} \mathrm{SCP}$ ligand was first attempted by reaction of $\left[(\text { thf }) \mathrm{Li}_{2}\left\{\mathrm{H}_{2} \mathrm{CS}\left(\mathrm{N}^{t} \mathrm{Bu}\right)_{2}\right\}\right]_{2}(1)$ with diorgano chloro phosphanes (cf. Scheme 4-1).

$$
\underset{\mathbf{1}}{\left[(\text { thf }) \mathrm{Li}\left\{\mathrm{H}_{2} \mathrm{CS}\left(\mathrm{N}^{\mathrm{t} B u}\right)_{2}\right\}\right]_{2}}+2 \mathrm{R}_{2} \mathrm{PCl} \underset{\text { thf }}{\stackrel{\text {-hexane }}{\longrightarrow}} \underset{-78^{\circ} \mathrm{C}}{\longrightarrow} ?
$$

Scheme 4-1: Attempted reaction of $\left[(\text { thf }) \mathrm{Li}_{2}\left\{\mathrm{H}_{2} \mathrm{CS}\left(\mathrm{N}^{t} \mathrm{Bu}\right)_{2}\right\}\right]_{2}$ (1) with diorgano chlorophosphanes.

Reactions of 1 with $\mathrm{Me}_{2} \mathrm{PCl}, \mathrm{PhPCl}_{2}$, and $\mathrm{MePhPCl}$ led to unidentifiable product mixtures. However, one of the products from addition of 1 to $\mathrm{Ph}_{2} \mathrm{PCl}$ (cf. Scheme 4-2) could be crystallized, although it is not the main product, indicated by the low yield of $31 \%$. The reproducibility of the reaction could not be verified, though.

$\left[(\text { thf }) \mathrm{Li}\left\{\mathrm{H}_{2} \mathrm{CS}\left(\mathrm{N}^{\mathrm{t} B u}\right)_{2}\right\}\right]_{2}+2 \mathrm{R}_{2} \mathrm{PCl}$

1

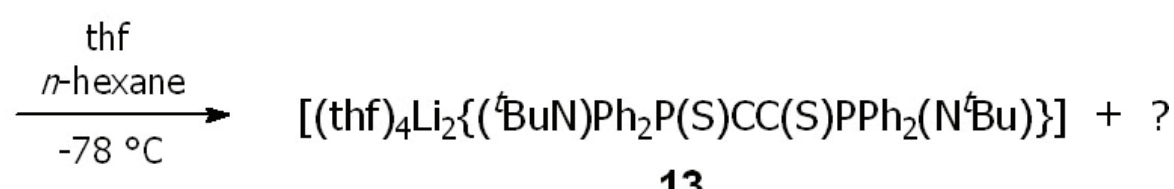

Scheme 4-2: Reaction of $\left[(\text { thf }) \mathrm{Li}_{2}\left\{\mathrm{H}_{2} \mathrm{CS}\left(\mathrm{N}^{t} \mathrm{Bu}\right)_{2}\right\}\right]_{2}$ (1) with $\mathrm{Ph}_{2} \mathrm{PCl}$.

The product, $\left[(\text { thf })_{4} \mathrm{Li}_{2}\left\{\left({ }^{t} \mathrm{BuN}\right) \mathrm{Ph}_{2} \mathrm{P}(\mathrm{S}) \mathrm{CC}(\mathrm{S}) \mathrm{PPh}_{2}\left(\mathrm{~N}^{t} \mathrm{Bu}\right)\right\}\right]$ (13), is the result of various unidentifiable redox processes. The $\mathrm{S}-\mathrm{N}$ bond cleavages, known for addition of metal chlorides to polyimido sulfur ylides as mentioned before, seem to occur with chlorophosphanes as well. Additionally, $\mathrm{C}=\mathrm{C}$ bond formation has been observed. $\mathrm{A}$ $\mathrm{P}-\mathrm{C}-\mathrm{S}$ connection is established in the product, containing a sulfur atom as a thiolate anion and an imido group attached to the phosphorus atom (cf. Figure 4-2).

The formed $\mathrm{C} 1-\mathrm{C} 1 \mathrm{~A}$ bond passes the crystallographic center of inversion. It is about as long $(1.364(4) \AA$, cf. Table $4-1)$ as a a standard $C=C$ double bond $(1.34 \AA)^{[238]}$ and significantly shorter than $\mathrm{C}-\mathrm{C}$ single bond $(1.54 \AA) \cdot{ }^{[238]}$ The S1-C1-P1 bond angle $(116.32(12) \AA)$ matches the $120^{\circ}$ for an $\mathrm{sp}^{2}$-hybridization very well. The S1-C1 $(1.757(2) \AA)$ and $P 1-C 1$ bond lengths $(1.831(2) \AA)$ resemble the typical values of the bonds between sulfur or phosphorus atoms and an $\mathrm{sp}^{2}$-hybridized carbon atom (1.76 and $1.85 \AA$, respectively). ${ }^{[238]}$ The $\mathrm{P}=\mathrm{N}$ bond has double bond 
character, as resembled by its shortness $(1.5874(19) \AA)$ and the wide C2-N1$\mathrm{P} 1$ angle of $124.94(15)^{\circ}$.

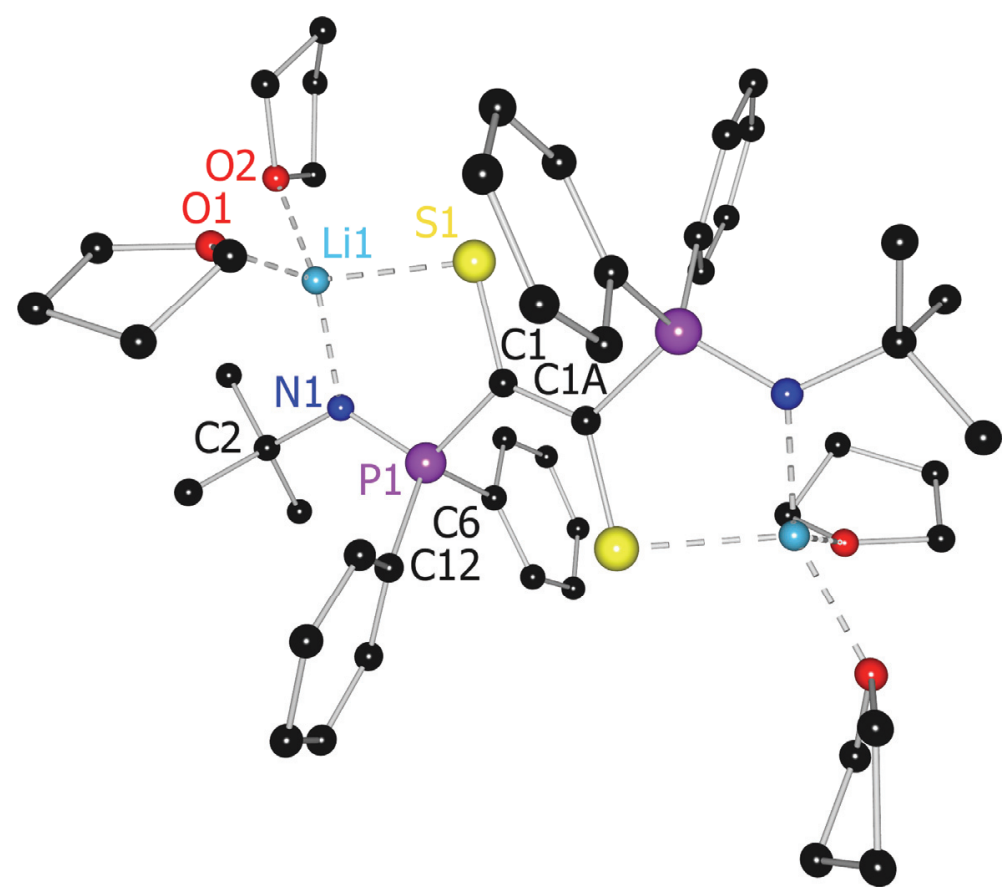

Figure 4-2: Molecular structure of $\left[(\text { thf })_{4} \mathrm{Li}_{2}\left\{\left({ }^{t} \mathrm{BuN}\right) \mathrm{Ph}_{2} \mathrm{P}(\mathrm{S}) \mathrm{CC}(\mathrm{S}) \mathrm{PPh}_{2}\left(\mathrm{~N}^{t} \mathrm{Bu}\right)\right\}\right]$ (13).

The Li1-N1 distance (1.996(4) $\AA$ ) is in the range found for similar contacts between lithium atoms and neutral imido donors (1.852-2.317 $\AA) .{ }^{[230]}$ The same accounts for Li1-S1 (2.340(4) $\AA$ ) and contacts between a lithium cation and an anionic sulfur atom $(2.324-2.744 \AA),{ }^{[230]}$ although Li1-S1 is at the short end of that range. The relatively acute S1-Li1-N1 angle $\left(92.38(17)^{\circ}\right)$ is due to the small bite of the ligand, which is caused by the double bonds of the system.

Table 4-1: Selected bond lengths $[\AA]$ and angles $\left[{ }^{\circ}\right]$ in $\left[(\text { thf })_{4} \mathrm{Li}_{2}\left\{\left({ }^{t} \mathrm{BuN}\right) \mathrm{Ph}_{2} \mathrm{P}(\mathrm{S}) \mathrm{CC}(\mathrm{S}) \mathrm{PPh}_{2}\left(\mathrm{~N}^{t} \mathrm{Bu}\right)\right\}\right](\mathbf{1 3})$.

\begin{tabular}{llllr}
\hline P1-N1 & $1.5874(19)$ & & S1-C1-P1 & $116.32(12)$ \\
P1-C1 & $1.831(2)$ & & C1-P1-N1 & $108.95(10)$ \\
S1-C1 & $1.757(2)$ & & C2-N1-P1 & $124.94(15)$ \\
C1-C1A & $1.364(4)$ & & Li1-S1-C1 & $98.18(12)$ \\
Li1-S1 & $2.340(4)$ & & Li1-N1-P1 & $117.36(15)$ \\
Li1-N1 & $1.996(4)$ & & S1-Li1-N1 & $92.38(17)$ \\
\hline
\end{tabular}




\subsection{Addition of $\mathrm{R}_{2} \mathrm{PCH}_{2} \mathrm{Li}$ to a Sulfur Diimide}

The attempt to form a $\mathrm{P}-\mathrm{C}$ bond by addition of a lithium polyimido sulfur ylide to various chlorophosphanes was unsuccessful because the same redox reactions described for metal chlorides and polyimido sulfur ylides take place. In order to bypass the problematic use of reagents containing halogenides, it was attempted to introduce the $\mathrm{P}-\mathrm{C}-\mathrm{S}$ fragment by attacking the sulfur diimide with a carbolithiated phosphane.

Therefore, lithium dimethyl phosphanyl methylide was reacted with di-tert.-butyl sulfur diimide (cf. Scheme 4-3). The desired product, [Li\{ $\left.\left\{\mathrm{Me}_{2} \mathrm{PCH}_{2} \mathrm{~S}\left(\mathrm{~N}^{t} \mathrm{Bu}\right)_{2}\right\}\right]_{2}$ (14), could be obtained and crystallized from $n$-hexane in moderate yields of $63 \%$.

$$
2 \mathrm{~S}\left(\mathrm{~N}^{\mathrm{t} B u}\right)_{2}+2\left[\mathrm{Li}\left(\mathrm{H}_{2} \mathrm{CPMe}_{2}\right)\right] \underset{-78^{\circ} \mathrm{C}}{\stackrel{n \text {-hexane }}{\longrightarrow}}\left[\mathrm{Li}\left\{\mathrm{Me}_{2} \mathrm{PCH}_{2} \mathrm{~S}\left(\mathrm{~N}^{\mathrm{t} B u}\right)_{2}\right\}\right]_{2}
$$

Scheme 4-3: $\mathrm{S}-\mathrm{C}$ bond forming reaction as access to $\left[\mathrm{Li}\left\{\mathrm{Me}_{2} \mathrm{PCH}_{2} \mathrm{~S}\left(\mathrm{~N}^{t} \mathrm{Bu}\right)_{2}\right\}\right]_{2}(14)$.

The bite of the resulting tridentate ligand seems to be inadequate for the size of the lithium cation. Thus, not a monomer is formed in which all three donor atoms participate in the bonding, but a dimer (cf. Figure 4-3).

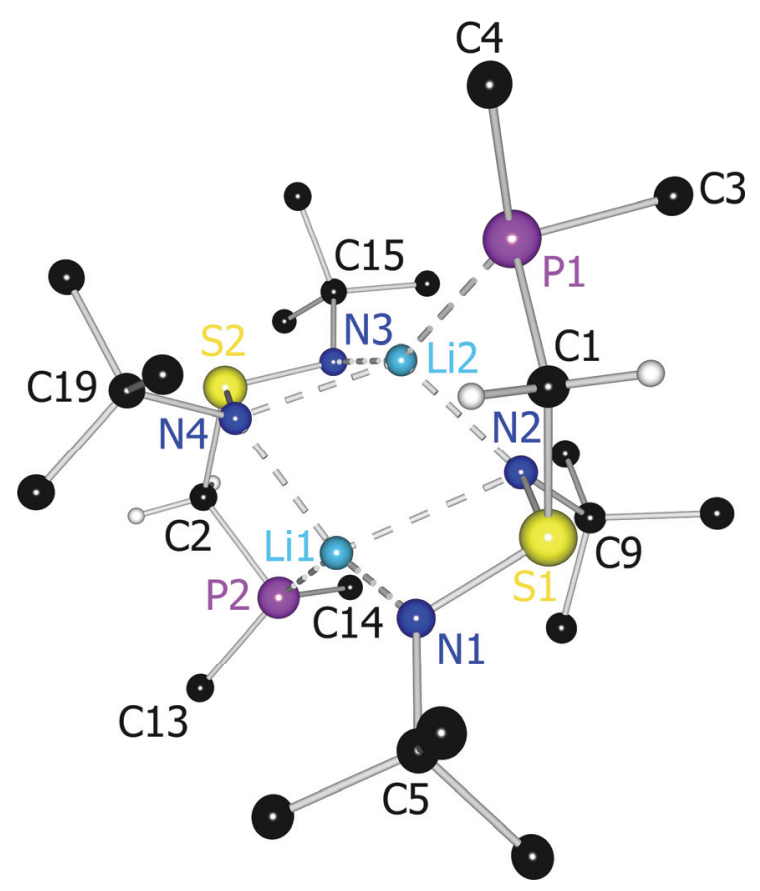

Figure 4-3: Molecular structure of $\left[\mathrm{Li}\left\{\mathrm{Me}_{2} \mathrm{PCH}_{2} \mathrm{~S}\left(\mathrm{~N}^{t} \mathrm{Bu}\right)_{2}\right\}\right]_{2}(14)$.

Both lithium atoms form four contacts to the donor atoms each. One nitrogen atom of each dimer (N2 and N4) coordinates both lithium atoms. The second nitrogen atom 
coordinates only the lithium atom of one half (Li1-N1/Li2-N3). The phosphorus atoms coordinate the lithium atom associated to the other half of the dimer (Li2-P1/Li1-P2). If a monomer would be assembled, the phosphorus atoms could not participate in the coordination of the lithium atom and the system would be less stable.

The differences in bond lengths and angles for both halves of the dimer are negligible. Hence, just one half of the dimer will be discussed, where appropriate.

All S-N distances (1.6150(9)-1.6343(9) $\AA$ ) are only slightly shorter than an average S-N single bond $(1.69 \AA)^{[238]}$ and are in the range of other alkyl diimido sulfinates $(1.598-1.657 \AA)^{[230]}$ The S1-C1 bond length of $1.8432(12) \AA$ matches that of a standard $\mathrm{S}-\mathrm{C}_{\mathrm{sp}^{3}}$ single bond $(1.83 \AA)^{[238]}$ and is also in the range of other reported alkyl diimido sulfinate anions $\left(1.718-1.868 \AA\right.$ ). ${ }^{[83,230]}$ Thus, $\mathrm{S} 1$ is surrounded by single bonds only and adopts the tetrahedral environment of an $\mathrm{sp}^{3}$-hybridized atom. The $\mathrm{N} 1-\mathrm{S} 1-\mathrm{N} 2\left(104.73(5)^{\circ}\right)$ and $\mathrm{N}-\mathrm{S}-\mathrm{C}\left(106.37(5)\right.$ and $\left.100.57(5)^{\circ}\right)$ angles are reduced with respect to the ideal tetrahedral angle. This is in accordance with the VSEPR theory, because the stereochemically active lone pair at $\mathrm{S} 1$ takes up most space.

Table 4-2: Selected bond lengths $[\AA]$ and angles $\left[^{\circ}\right]$ in $\left[\mathrm{Li}\left\{\mathrm{Me}_{2} \mathrm{PCH}_{2} \mathrm{~S}\left(\mathrm{~N}^{t} \mathrm{Bu}\right)_{2}\right\}\right]_{2}(14)$.

\begin{tabular}{|c|c|c|c|c|c|}
\hline $\mathrm{S} 1-\mathrm{N} 1$ & $1.6150(9)$ & Li1-N2 & $2.399(2)$ & $\mathrm{N} 1-\mathrm{S} 1-\mathrm{C} 1$ & $106.37(5)$ \\
\hline S1-N2 & $1.6343(9)$ & Li2-N2 & $2.061(2)$ & $\mathrm{N} 2-\mathrm{S} 1-\mathrm{C} 1$ & $100.57(5)$ \\
\hline $\mathrm{S} 1-\mathrm{C} 1$ & $1.8432(12)$ & Li2-P1 & $2.6432(19)$ & Li1-N2-Li1 & $69.20(8)$ \\
\hline $\mathrm{P} 1-\mathrm{C} 1$ & $1.8403(12)$ & & & N1-Li1-N2 & $71.86(7)$ \\
\hline Li1-N1 & $1.940(2)$ & $\mathrm{N} 1-\mathrm{S} 1-\mathrm{N} 2$ & $104.73(5)$ & N2-Li2-P1 & $76.79(6)$ \\
\hline
\end{tabular}

The shared lithium coordination of $\mathrm{N} 2$ leads to longer $\mathrm{Li}-\mathrm{N}$ distances (Li1-N2 2.399(2) and Li2-N2 2.061(2) A) compared to N1 (Li1-N1 1.940(2) A). Additionally, the coordination is asymmetric, which clearly favors Li2. Li1-N1 and Li2-N2 are in the range of typical Li-N bonds $(1.905-2.202 \AA),{ }^{[230]}$ whereas Li1-N2 seems to be a weak coordinative contact (cf. Table 4-2). The Li2-P1 distance of 2.6432(19) $\AA$ is slightly longer than the average $(2.520 \AA)$ of the Li-P distances reported for $\mathrm{Li}(\mathrm{P}-\mathrm{C}-\mathrm{C}=\mathrm{N})$ systems $(2.365-2.824 \AA){ }^{[230]}$ The acute N2-Li2-P1 angle of 76.79(6) ${ }^{\circ}$ is typical for such systems $\left(73.10-87.35^{\circ}\right) .{ }^{[230]}$

The discussion of the crystal structure of $\left[\mathrm{Li}\left\{\mathrm{Me}_{2} \mathrm{PCH}_{2} \mathrm{~S}\left(\mathrm{~N}^{t} \mathrm{Bu}\right)_{2}\right\}\right]_{2}(14)$ shows, that the $\mathrm{N}_{2} \mathrm{SCP}$ ligand is indeed tridentate. Although the bite of the ligand system is not 
optimized for lithium cations, the complex formed is surprisingly stable. Crystallization from a thf $/ n$-hexane mixture does not lead to modification of the coordinative pattern or an $\mathrm{Li}-\mathrm{O}_{\text {thf }}$ coordination. This proves that the $\mathrm{Me}_{2} \mathrm{PCH}_{2} \mathrm{~S}\left(\mathrm{~N}^{t} \mathrm{Bu}\right)_{2}{ }^{2-}$ dianion in 14 is indeed a ligand which is complexing as good as envisaged.

In order to obtain more insight into the coordinative behavior of the new $\mathrm{N}_{2} \mathrm{SCP}$ system, modifications of the substituents at the phosphorus atom, exchange of the coordinated metal and insertion of arsenic instead of phosphorus atoms were examined.

The first aim was successfully finished by deprotonation of methyl diphenyl phosphane with ${ }^{t} \mathrm{BuLi}$ in hexane and subsequent addition of $\mathrm{S}\left(\mathrm{N}^{t} \mathrm{Bu}\right)_{2}$ at $-78{ }^{\circ} \mathrm{C}$. $\left[\mathrm{Li}\left\{\mathrm{Ph}_{2} \mathrm{PCH}_{2} \mathrm{~S}\left(\mathrm{~N}^{t} \mathrm{Bu}\right)_{2}\right\}\right]_{2}$ (15) was obtained as cream-colored solid (cf. Scheme 4-4). No crystals suitable for X-ray crystallography could be obtained yet. The spectroscopic data and elemental analysis (cf. chapter 7.3.10) are in agreement with the composition of 15 . The yield of $81 \%$ is better than for the dimethyl phospino compound.

$$
\left.2 \mathrm{~S}\left(\mathrm{~N}^{t} \mathrm{Bu}\right)_{2}+2\left[\mathrm{Li}\left(\mathrm{H}_{2} \mathrm{CPPh}_{2}\right)\right] \stackrel{n \text {-hexane }}{-78^{\circ} \mathrm{C}} \quad\left[\mathrm{Li}^{\circ} \mathrm{Ph}_{2} \mathrm{PCH}_{2} \mathrm{~S}\left(\mathrm{~N}^{\mathrm{t} B u}\right)_{2}\right\}\right]_{2}
$$

15

Scheme 4-4: Synthesis of $\left[\mathrm{Li}\left\{\mathrm{Ph}_{2} \mathrm{PCH}_{2} \mathrm{~S}\left(\mathrm{~N}^{t} \mathrm{Bu}\right)_{2}\right\}\right]_{2}$ (15).

All metal exchange reactions led to the same results as reported for the polyimido sulfur ylides. The products could similarly not be isolated or identified.

The insertion of arsenic proved to be problematic, as no deprotonation reaction for trimethyl arsane is reported in the literature. All attempts to deprotonate the compound by various strong classical bases and super-bases were ineffective.

\subsection{Crystal Structure of Trimethyl Arsane Oxide (16)}

In the course of the deprotonation studies on trimethyl arsane, crystals of trimethyl arsane oxide $\mathrm{OAsMe}_{3}$ (16) were grown in a Schlenk trap from a trimethyl arsane solution containing impurities of trimethyl arsane oxide (16). The crystals were suitable for an X-ray diffraction experiment. To date, no crystal structure of noncoordinating $\mathrm{OAsMe}_{3}(16)$ has been reported. Nevertheless, seven structures containing $\mathrm{OAsMe}_{3}$ as oxygen donor are known. ${ }^{[230]}$ The new structure will therefore 
be compared to two of those $\left(\left[\left(\mathrm{OAsMe}_{3}\right)_{3}\left(\mathrm{InBr}_{3}\right)_{2}\right]^{[272]}\right.$ and $\left.\left[\left(\mathrm{OAsMe}_{3}\right)_{9} \mathrm{Ca}_{2}\left(\mathrm{ClO}_{4}\right)_{4}\right]^{[273]}\right)$ and to non-coordinating trimethyl phosphane oxide. ${ }^{[274]}$

The molecular structure of trimethyl arsane oxide (16) is depicted in Figure 4-4. The groups attached to the arsenic atom form a distorted tetrahedron. This motif is preserved in all coordination complexes of $\mathrm{OAsMe}_{3}$ as only the oxygen atoms interact with other fragments.

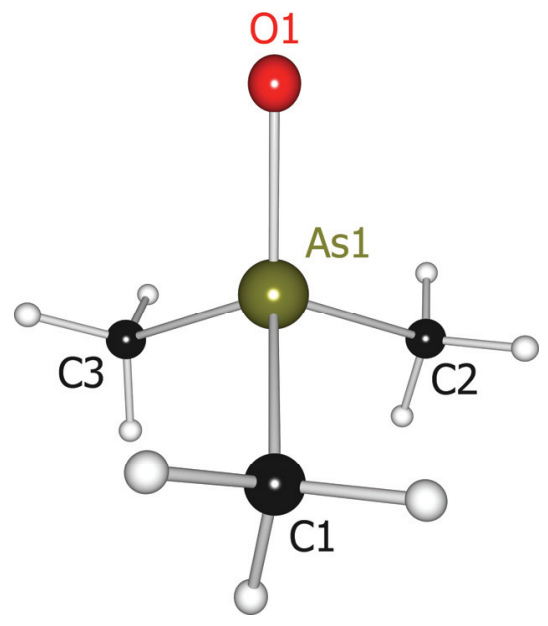

Figure 4-4: Molecular structure of $\mathrm{OAsMe}_{3}(16)$.

Three trimethyl arsane oxide molecules bridge the indium atoms in $\left[\left(\mathrm{OAsMe}_{3}\right)_{3}\left(\mathrm{InBr}_{3}\right)_{2}\right]$ (cf. Figure 4-5).

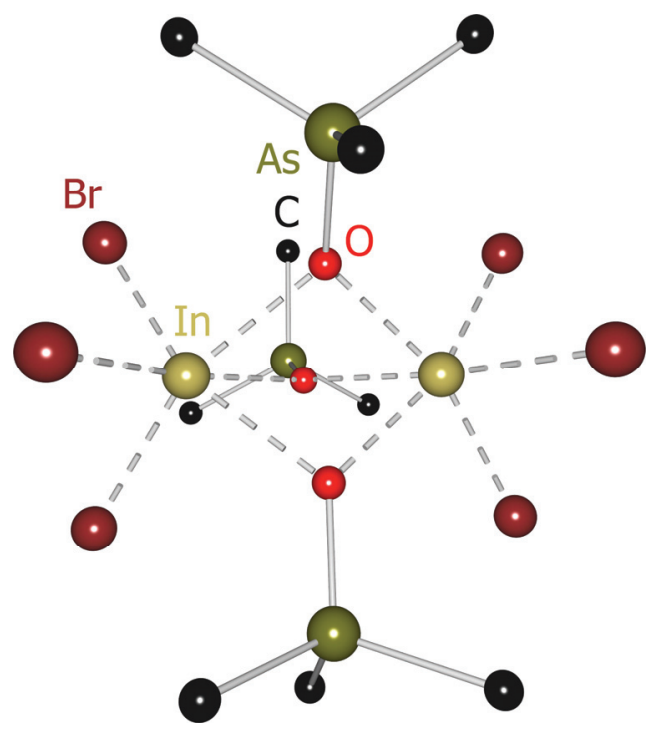

Figure 4-5: Molecular structure of $\left[\left(\mathrm{OAsMe}_{3}\right)_{3}\left(\mathrm{InBr}_{3}\right)_{2}\right]$.

In $\left.\left[(\mathrm{OAsMe})_{3}\right)_{9} \mathrm{Ca}_{2}\left(\mathrm{ClO}_{4}\right)_{4}\right]$ the trimethyl arsane oxide exhibits two different coordination modes. Three $\mathrm{OAsMe}_{3}$ donors act as bridges between the metal ions 
like in $\left[\left(\mathrm{OAsMe}_{3}\right)_{3}\left(\mathrm{InBr}_{3}\right)_{2}\right]$ (cf. Figure 4-6), the remaining $\mathrm{OAsMe}_{3}$ molecules are bonded to only one calcium atom each.

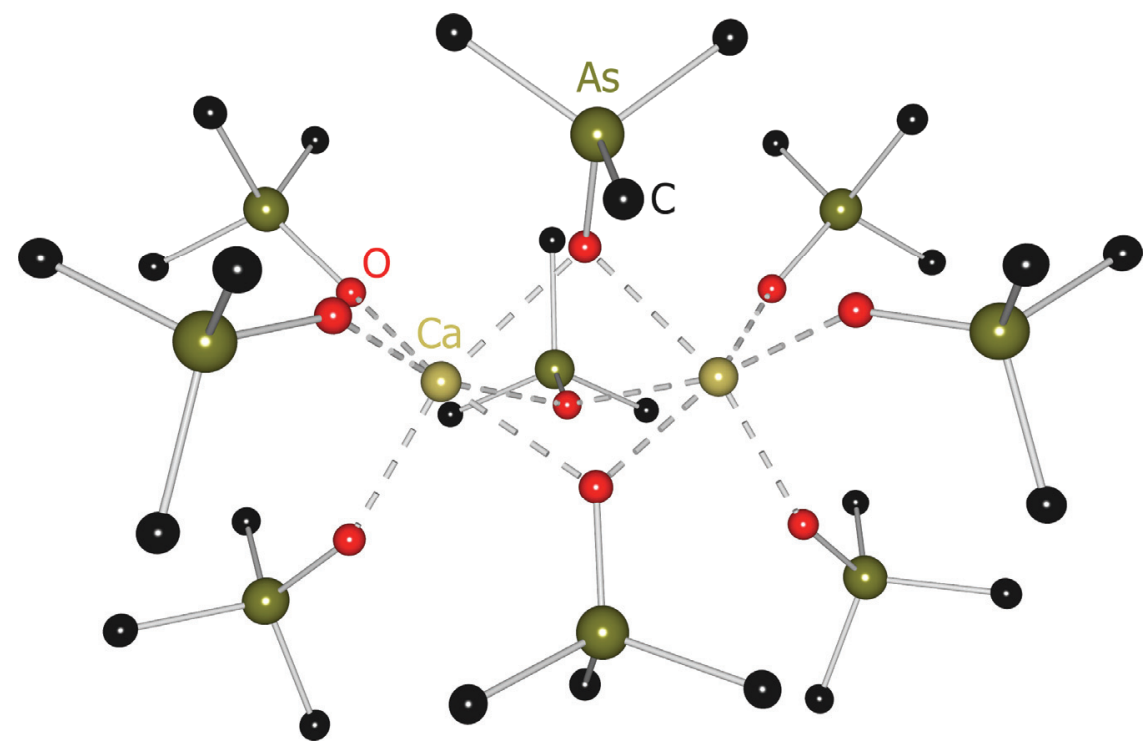

Figure 4-6: Molecular structure of $\left[\left(\mathrm{OAsMe}_{3}\right)_{9} \mathrm{Ca}_{2}\left(\mathrm{ClO}_{4}\right)_{4}\right]$; perchlorate anions are omitted for clarity.

The bond lengths and angles for all above-mentioned substances are listed in Table 4-3. It is no surprise, that the larger bond lengths in $\mathrm{OAsMe}_{3}$ (16) compared to $\mathrm{OPMe}_{3}$ lead to a less pronounced repulsion between the oxygen atom and the carbon atoms. This is expressed in more acute O-As-C angles and widened C-As-C angles.

Table 4-3: Selected bond lengths $[\AA]$ and angles $\left[^{\circ}\right]$ in $\mathrm{OAsMe}_{3}(16),\left[\left(\mathrm{OAsMe}_{3}\right)_{3}\left(\mathrm{InBr}_{3}\right)_{2}\right]$, $\left[\left(\mathrm{OAsMe}_{3}\right)_{9} \mathrm{Ca}_{2}\left(\mathrm{ClO}_{4}\right)_{4}\right]$, and $\mathrm{OPMe}_{3} ; \mathrm{M}=\mathrm{In}, \mathrm{Ca}$.

\begin{tabular}{|c|c|c|c|c|c|c|}
\hline & $\begin{array}{c}\mathrm{OAsMe}_{3} \\
(16)\end{array}$ & $\begin{array}{l}{\left[\left(\mathrm{OAsMe}_{3}\right)_{3}\right.} \\
\left.\left(\mathrm{InBr}_{3}\right)_{2}\right]\end{array}$ & $\begin{array}{l}{\left[\left(\mathrm{OAsMe}_{3}\right)_{9}\right.} \\
\left.\mathrm{Ca}_{2}\left(\mathrm{ClO}_{4}\right)_{4}\right] \\
\mu-\left(\mathrm{OAsMe}_{3}\right)\end{array}$ & $\begin{array}{l}{\left[\left(\mathrm{OAsMe}_{3}\right)_{9}\right.} \\
\left.\mathrm{Ca}_{2}\left(\mathrm{ClO}_{4}\right)_{4}\right] \\
\eta-\left(\mathrm{OAsMe}_{3}\right)\end{array}$ & & $\mathrm{OPMe}_{3}$ \\
\hline As1-O1 & $1.6577(18)$ & $1.709(23)$ & $1.649(10)$ & $1.657(7)$ & P1-O1 & $1.489(6)$ \\
\hline As1-C1 & $1.920(6)$ & $1.998(17)$ & $1.957(26)$ & $1.865(20)$ & $\mathrm{P} 1-\mathrm{C} 1$ & $1.772(6)$ \\
\hline As1-C2 & $1.898(7)$ & $1.965(21)$ & $1.926(14)$ & $1.886(19)$ & $\mathrm{P} 1-\mathrm{C} 2$ & $1.770(10)$ \\
\hline As1-C3 & $1.918(3)$ & $1.832(19)$ & $1.926(14)$ & $1.845(20)$ & P1-C3 & $1.770(10)$ \\
\hline M1-O1 & - & $2.260(22)$ & $2.424(7)$ & $2.284(7)$ & M1-O1 & - \\
\hline O1-As1-C1 & $105.49(16)$ & $106.13(12)$ & $108.4(9)$ & $112.4(7)$ & $\mathrm{O} 1-\mathrm{P} 1-\mathrm{C} 1$ & $112.2(2)$ \\
\hline $\mathrm{C} 1-\mathrm{As} 1-\mathrm{C} 2$ & $113.8(4)$ & $107.94(9)$ & $107.9(11)$ & $109.2(12)$ & $\mathrm{C} 1-\mathrm{P} 1-\mathrm{C} 2$ & $105.6(3)$ \\
\hline
\end{tabular}


It is surprising however, that this leads in $\mathbf{1 6}$ to angles that contradict the prediction from the VSEPR theory. The $\mathrm{O}=$ As double bond should require the most space. Although, similar acute angles have been found in $\left[\left(\mathrm{OAsMe}_{3}\right)_{3}\left(\mathrm{InBr}_{3}\right)_{2}\right]$, both coordinational variants in $\left[\left(\mathrm{OAsMe}_{3}\right)_{9} \mathrm{Ca}_{2}\left(\mathrm{ClO}_{4}\right)_{4}\right]$ behave VSEPR conform. The phenomenon in $\mathrm{OAsMe}_{3}(16)$ is hence not general for $\mathrm{AsMe}_{3} \mathrm{O}$ in coordination.

The As-O bond lengths vary $0.06 \AA$ in the presented arsenic compounds $(1.649(10)-1.6577(18) \AA)$. No trend can be observed as the longest contact is found for the $\mu^{2}$-bridging $\mathrm{OAsMe}_{3}$ in the calcium species, whereas the shortest is also in a $\mu^{2}$-bridging unit of the indium compound. This implicates, that no elongation of the bonds occurs, even when electron density is removed from the system. This can be taken as an evidence, that the donation does only involve the electron density of the lone-pairs of the oxygen atom and does not affect the O-As bond density. Probably, this is already a first hint, that the $\mathrm{O}-\mathrm{As}$ bond is not $\mathrm{O}=\mathrm{As}$ double bond, but should be formulated as $\mathrm{O}^{+}-{ }^{-}$As interaction. A similar description of the bonding type is found for phosphane oxides ${ }^{[275]}$ and should, thus, be even more valid for the heavier congener of phosphorus.

This is supported by the variation of the As-C bonds, which are clearly not affected by a coordination of the oxygen atom to a metal. The As-C bonds in $\mathrm{OAsMe}_{3}$ (16) (1.91 $\AA$ on av.) are in the center of the range described by the other compounds (1.832(19)-1.998(17) $\AA, 1.91 \AA$ on av.). Although no distortion from the coordinative environment is present in 16 , the As- $C$ bond lengths are slightly different, even if a threshold of three esd's is applied. This along with the orientation of the hydrogen atoms, is probably breaking the mirror symmetry in 16 , which can be found for $\mathrm{OPMe}_{3}$.

\subsection{Conclusions}

The synthetic aim of this part of the thesis was to link a phosphane donor to the diimido sulfur ligand, to gain access to a new type of Janus-head ligands. This was fulfilled by the reaction of lithium dimethyl phosphanyl methylide with di-tert.-butyl sulfur diimide. The product of this reaction could be crystallized and analyzed by $X$-ray diffraction. $\left[\mathrm{Li}\left\{\mathrm{Me}_{2} \mathrm{PCH}_{2} \mathrm{~S}\left(\mathrm{~N}^{t} \mathrm{Bu}\right)_{2}\right\}\right]_{2}(14)$ is dimeric, because all donor sites participate in coordination but exhibit a too large bite for monomeric tridentate coordination of the small lithium ion. The product of a similar reaction with phenyl 
instead of methyl groups at the phosphorus atom could also be isolated, but not crystallized. 



\section{Conclusions ANd Future ObJectives}

Three major aim have been pursued in the course of this thesis: I) Classification of the S-C, S-N and $\mathrm{Li}-\mathrm{C}$ interactions in a lithium polyimido sulfur ylide by use of an experimental electron density study. II) Synthesis of various metal complexes of a polyimido sulfur ylide. III) Design of a tridentate Janus-head ligand containing hard nitrogen and soft phosphorus donor sites.

\subsection{Charge Density Study on a Lithium Sulfur Ylide}

In this thesis a study on the polymorphism and experimental electron density of $\left[(\text { thf }) \mathrm{Li}_{2}\left\{\mathrm{H}_{2} \mathrm{CS}\left(\mathrm{N}^{t} \mathrm{Bu}\right)_{2}\right\}\right]_{2}$ (1) is presented to answer the above-mentioned question I. Compound 1 was chosen as an appropriate candidate to elucidate the $\mathrm{S}-\mathrm{C}$ bonding situation in sulfur ylides, which had so far only been investigated theoretically, because it holds the opportunity to additionally shed light on the $\mathrm{S}-\mathrm{N}$ bonding situation of a polyimido sulfite and the $\mathrm{Li}-\mathrm{C}$ one of an organo lithium compound. Although sulfur ylides are important tools in organic and inorganic chemistry, the character of the bonds is still under debate. The same accounts for the bonding mode involved in the formation of the $\mathrm{Li}_{3} \mathrm{C}$ motif well-known throughout organo lithium chemistry.

The literature-known modification, $\left[(\text { thf }) \mathrm{Li}_{2}\left\{\mathrm{H}_{2} \mathrm{CS}\left(\mathrm{N}^{t} \mathrm{Bu}\right)_{2}\right\}\right]_{2}(2)$, shows disorder of the thf groups and is therefore not suited for an experimental electron density study. Thus, it was attempted on one hand to introduce another donor, which crystallizes non-disordered, and on the other hand to find a modification of $\left[(\text { thf }) \mathrm{Li}_{2}\left\{\mathrm{H}_{2} \mathrm{CS}\left(\mathrm{N}^{t} \mathrm{Bu}\right)_{2}\right\}\right]_{2}$ (1) free of disorder by studying the polymorphism of this chemical compound.

Addition of methyl lithium in dem to di-tert.-butyl sulfur diimide leads to the formation of dimeric [(dem) $\left.\mathrm{Li}_{2}\left\{\mathrm{MeS}\left(\mathrm{N}^{t} \mathrm{Bu}\right)_{2}\right\}_{2}\right]$ (5). Deprotonation with a second equivalent of methyl lithium yields the desired diimido sulfur ylide $\left[(\mathrm{dem}) \mathrm{Li}_{4}\left\{\mathrm{H}_{2} \mathrm{CS}\left(\mathrm{N}^{t} \mathrm{Bu}\right)_{2}\right\}_{2}\right]_{\mathrm{n}}(6)$. Although the dem molecule bridges two double-cube units and is therefore fixed, it retains one degree of rotational freedom and is disordered over two sites. Hence, 6 is not suitable for an experimental electron density study.

The investigation of the polymorphism of $\left[(\operatorname{thf}) \mathrm{Li}_{2}\left\{\mathrm{H}_{2} \mathrm{CS}\left(\mathrm{N}^{t} \mathrm{Bu}\right)_{2}\right\}\right]_{2}(1)$ led to the discovery of two polymorphs $(3,4)$ of the literature-known modification (2). The 
polymorph transitions show the characteristics of displacement transitions, as only little atom rearrangement occurs. They are of first order, which was determined by DSC and deduced from their space group symmetries. Whereas 3 contains disordered and non-disordered thf molecules, no disorder is present in 4. Hence, a high-order X-ray diffraction experiment was performed on crystals of the low-temperature modification 4 . The resultant data were used for a multipole refinement and a subsequent topological analyses.

By analyzing the topological properties of the experimentally obtained electron density distribution according to Bader's QTAIM, it was possible to specify the S-N and $\mathrm{S}-\mathrm{C}$ bonds in $\mathbf{3}$ as classical single bonds strengthened by electrostatic interactions $\left(\mathrm{S}^{+}-\mathrm{N}\right.$ and $\left.\mathrm{S}^{+}-\mathrm{C}\right)$. This, together with the observation that four VSCCs are present at the sulfur atom, clearly rules out hypervalency, which is in good agreement to the previous findings in our group for other formally hypervalent $\mathrm{SN}$-compounds. Hence, [(thf) $\left.\mathrm{Li}_{2}\left\{\mathrm{H}_{2} \mathrm{CS}\left(\mathrm{N}^{t} \mathrm{Bu}\right)_{2}\right\}\right]_{2}(1)$ should be formulated as ylidic rather than ylenic. This describes best the electronic situation and explains the reactivity of the compound.

Furthermore, the interaction of the carbanion with the $\mathrm{Li}_{3}$ triangle was determined to be of a $\mathrm{CH}_{2}{ }^{-}-\left(\mathrm{Li}^{+}\right)_{3}$ kind. The carbon atom forms a bond to each of the three lithium atoms, although one interaction is preferred. Thus, the VSCC at the carbanion, that represents the lone-pair, is tilted away from the center of the $\mathrm{Li}_{3}$ triangle towards the lithium atom at the tip of the isosceles triangle. This is also reflected by the characteristics of the BCPs. No BCPs and thus no bonding interactions between the lithium atoms in the framework of QTAIM were determined. Therefore, the driving force for the formation of an $\mathrm{Li}_{3}$ triangle seems to be the interaction of the lithium cations with the carbanion exclusively.

The knowledge gained from the experiment can be used to synthesize sulfur ylide and organo lithium reagents, which better fit the needs of the desired reactions. Thus, higher yields and higher selectivity of the reactions can be envisaged.

An electron density study should be performed on the modification 3 of $\left[(\text { thf }) \mathrm{Li}_{2}\left\{\mathrm{H}_{2} \mathrm{CS}\left(\mathrm{N}^{t} \mathrm{Bu}\right)_{2}\right\}\right]_{2}$ (1), which contained disordered and non-disordered fragments. The results from the non-disordered part ought to be compared to the ones presented in this thesis. This should provide a good estimate of the influence of disordered groups on the properties of non-disordered fragments. The knowledge can be used to decide if it is sensible to perform electron density studies on compounds with a certain amount of disordered atoms. Up to date, no such 
comparative studies have been performed and thus even slight disorder prohibit an investigation of the electron density distribution with the multipole model as long as the influence of the disorder can not be specified.

\subsection{Metal Complexes of Diimido Sulfur Ylides}

The attempts to synthesize polyimido sulfur ylides coordinating metals other than lithium were successful. A tin complex of $\mathrm{H}_{2} \mathrm{CS}\left(\mathrm{N}^{t} \mathrm{Bu}\right)_{2}{ }^{2-}$ and a magnesium complex of $\mathrm{H}_{8} \mathrm{C}_{4} \mathrm{~S}\left(\mathrm{~N}^{t} \mathrm{Bu}\right)_{2}{ }^{2-}$ could be synthesized. However, no general access to the coordination chemistry of organo polyimido sulfites has been found.

Transmetalation reactions employing metal chlorides or amides led only in the case of $\mathrm{SnCl}_{2}$ to an identifiable product. $\left[\mathrm{Cl}_{2} \mathrm{SnO}_{2}\left\{\mathrm{Sn}_{2}\left(\mathrm{HN}^{t} \mathrm{Bu}\right)\right\}\left\{\mathrm{H}_{2} \mathrm{CS}\left(\mathrm{N}^{t} \mathrm{Bu}\right)_{2}\right\}_{2}\right](7)$ arose not only from transmetalation of $\left[(\text { thf }) \mathrm{Li}_{2}\left\{\mathrm{H}_{2} \mathrm{CS}\left(\mathrm{N}^{t} \mathrm{Bu}\right)_{2}\right\}\right]_{2}$ (1). Tin dioxide from traceimpurities in the tin dichloride is incorporated and $\mathrm{S}-\mathrm{N}$ bond cleavages must have taken place to form $\mathrm{HN}^{t} \mathrm{Bu}^{-}$. A further purification of the tin dichloride led only to non-identifiable products.

The second synthetic route to the desired complexes failed, because the alkyl diimido sulfinates prepared from reaction of di-tert.-butyl sulfur diimide with Grignard reagents could not be deprotonated with non-lithium bases. Nevertheless, the alkyl diimido sulfinates [(thf) $\left.)_{2} \mathrm{MgCl}\left\{\mathrm{BzS}\left(\mathrm{N}^{t} \mathrm{Bu}\right)_{2}\right\}\right]$ (8) and [(thf)MgCl$\left.\left\{\mathrm{PhS}\left(\mathrm{N}^{t} \mathrm{Bu}\right)_{2}\right\}\right]_{2}$ (9) could be synthesized. While 9 is dimeric as observed for all other magnesium complexes of polyimido sulfinates and sulfonates, 8 is monomeric. The additional $\mathrm{CH}_{2}$ group of the substituent at the sulfur atom leaves space at the metal ion for an additional thf molecule which is electronically favored over a bridging chloride ion.

The third attempted route, reaction of di-tert.-butyl sulfur diimide with the alkylation reagent $\left({ }^{n} \mathrm{Bu}_{2} \mathrm{Mg}\right)$, which acts as deprotonation agent in the second step, did not lead exclusively to the desired product. The formed magnesium ylide adds a non-deprotonated alkyl diimido sulfinate to establish a dimer coordinating three magnesium ions. Additionally, transimidation took place, yielding the triimido sulfite dianion. The resulting $\left[\left({ }^{n} \mathrm{BuMg}\right)_{9}\left\{{ }^{n} \mathrm{BuS}\left(\mathrm{N}^{t} \mathrm{Bu}\right)_{2}\right\}_{3}\left\{\left(\mathrm{C}_{4} \mathrm{H}_{8}\right) \mathrm{S}\left(\mathrm{N}^{t} \mathrm{Bu}\right)_{2}\right\}_{2}\left\{\mathrm{~S}\left(\mathrm{~N}^{t} \mathrm{Bu}\right)_{3}\right\}\right](10)$ is nevertheless interesting due to its coordination chemistry, but is a product mixture on its own. The reactions with other, similar reagents $\left(\mathrm{Me}_{2} \mathrm{Zn}, \mathrm{Me}_{2} \mathrm{Cu}\right)$ gave no identifiable products. 
As expected, the coordinative pattern of the polyimido sulfur ylides changes, as soon as a dicationic metal is involved. Unfortunately, no final conclusion could be drawn. The other anions involved in the two complexes presented here probably modify a more general pattern. However, it can be stated, that the formation of dimers seems to be favored as it helps to balance the electron deficiency of the metal cations.

The application of a nucleophile, which is able to deprotonate the addition product, seems to be a promising strategy, although $\mathrm{S}-\mathrm{N}$ bond cleavage reactions were observed for di- $n$-butyl magnesium. This principal access to metal complexes of polyimido sulfur ylides ought to be pursued in further studies.

\subsection{Polydentate Polyimido Sulfur-Carbon-Phosphorus Ligands}

In the course of this thesis the first Janus-head ligands of an $\mathrm{N}_{2} \mathrm{SCP}$ type have been prepared. The phosphane donor atom was linked to the polyimido sulfur moiety by reaction of lithium dimethyl phosphanyl methylide with di-tert.-butyl sulfur diimide. The structure of $\left[\mathrm{Li}\left\{\mathrm{Me}_{2} \mathrm{PCH}_{2} \mathrm{~S}\left(\mathrm{~N}^{t} \mathrm{Bu}\right)_{2}\right\}\right]_{2}(14)$ reveals that all donor sites participate in the coordination of the lithium atoms. The large bite of the tridentate ligand leads to the formation of a dimer. The second $\mathrm{N}_{2} \mathrm{SCP}$ complex, [ $\left.\left.\mathrm{Li}_{2} \mathrm{Ph}_{2} \mathrm{PCH}_{2} \mathrm{~S}\left(\mathrm{~N}^{t} \mathrm{Bu}\right)_{2}\right\}\right]_{2}(15)$, could not be crystallized, but was characterized spectroscopically.

The reaction of chloro diorgano phosphanes with polyimido sulfur ylides proved to be no alternative route to the desired ligand complexes. Extensive redox reactions, as well as $\mathrm{S}-\mathrm{N}$ and $\mathrm{S}-\mathrm{C}$ bond cleavages led to product mixtures. Isolation and crystallization worked only for [(thf $\left.)_{4} \mathrm{Li}_{2}\left\{\left({ }^{t} \mathrm{BuN}\right) \mathrm{Ph}_{2} \mathrm{P}(\mathrm{S}) \mathrm{CC}(\mathrm{S}) \mathrm{PPh}_{2}\left(\mathrm{~N}^{t} \mathrm{Bu}\right)\right\}\right]$ (13).

First attempts to exchange the metal cation in $\left[\mathrm{Li}\left\{\mathrm{Me}_{2} \mathrm{PCH}_{2} \mathrm{~S}\left(\mathrm{~N}^{t} \mathrm{Bu}\right)_{2}\right\}\right]_{2}(14)$ were not successful, because redox reactions, as well as $\mathrm{S}-\mathrm{N}$ and $\mathrm{S}-\mathrm{C}$ bond cleavages occurred. This can probably be bypassed by insertion of the desired metal ion right at the step of the formation of the ligand. Many main group and transition metal complexes of methylene diorgano phosphanes are known and can be employed in these reactions.

The tripodal, anionic ligands ought to be checked for their catalytic activity. A similar system, $\left.\left[\left(\mathrm{H}_{5} \mathrm{C}_{3}\right) \mathrm{Ni}^{t}{ }^{t} \mathrm{Bu}_{2} \mathrm{PCH}_{2} \mathrm{~S}\left(\mathrm{NSiMe}_{3}\right)_{2}\right\}\right]$, was already successfully used in olefin polymerization reactions. 
It was examined if the same coordination behavior in analogy to 14 can also be observed for the arsenic analogue. However, the addition of an arsane group failed. In the course of these attempts $\mathrm{OAsMe}_{3}(16)$ could be structurally analyzed for the first time without interactions with a metal atom. The molecule shows bond angles, which are contra-intuitive with respect to the VSEPR theory. This has to be investigated either by theoretical methods or by comparison to similar arsanes and arsane oxides for reasoning. This was not possible during this thesis, because no series containing closely related and structurally characterized compounds are available for comparison. 



\section{ZUSAMMENFASSUNG UND ZUKÜNFTIGE ZIELE}

Im Rahmen dieser Doktorarbeit wurden hauptsächlich drei Ziele verfolgt: I) Charakterisierung der S-C-, S-N- und Li-C-Wechselwirkungen in einem Polyimidoschwefelylid mittels einer experimentellen Elektronendichteuntersuchung. II) Synthese verschiedener Metallkomplexe eines Polyimidoschwefelylids. III) Darstellung eines tridentaten Januskopf-Liganden, der harte Stickstoff- und weiche Phosphordonorgruppen enthält.

\subsection{Elektronendichteuntersuchung eines Lithium-Schwefel- Ylids}

In dieser Doktorarbeit wurde eine Studie zum Polymorphismus und der experimentellen Elektronendichteverteilung von $\left[(\text { thf }) \mathrm{Li}_{2}\left\{\mathrm{H}_{2} \mathrm{CS}\left(\mathrm{N}^{t} \mathrm{Bu}\right)_{2}\right\}\right]_{2}(1)$ vorgestellt, um die erwähnte Fragestellung I) zu klären. Verbindung 1 bietet hierbei die Möglichkeit, die Art der S-C-Bindung in Schwefelyliden, die bislang nur theoretisch bestimmt worden war, experimentell zu untersuchen. Gleichzeitig kann die S-N-Bindung eines Polyimidosulfits und die Li-C-Bindung einer lithiumorganischen Verbindung charakterisiert werden. Obwohl die Schwefelylide wichtige Elemente der organischen und anorganischen Chemie sind, ist die S-C-Bindungsituation nicht abschließend geklärt. Auch die Kräfte, welche zur Bildung des $\mathrm{Li}_{3} \mathrm{C}$-Tetraeders, des grundlegenden Strukturmotivs der lithiumorganischen Chemie, führen, sind nicht näher bekannt.

Die literaturbekannte Modifikation von $\left[(\operatorname{thf}) \mathrm{Li}_{2}\left\{\mathrm{H}_{2} \mathrm{CS}\left(\mathrm{N}^{t} \mathrm{Bu}\right)_{2}\right\}\right]_{2}, \quad(2)$, enthält fehlgeordnete THF-Gruppen und ist daher nicht für experimentelle Elektronendichteuntersuchungen geeignet. Es wurde versucht einen Donor zu verwenden, der fehlordnungsfrei eingebaut wird. Zusätzlich wurde der Polymorphismus von $\left[(\text { thf }) \mathrm{Li}_{2}\left\{\mathrm{H}_{2} \mathrm{CS}\left(\mathrm{N}^{t} \mathrm{Bu}\right)_{2}\right\}\right]_{2}$ (2) untersucht, um eine Modifikation zu finden, die keine Fehlordnung enthält.

Di-tert.-butylschwefeldiimid reagiert mit Methyllithium in DEM zu $\left[(\mathrm{dem}) \mathrm{Li}_{2}\left\{\mathrm{MeS}\left(\mathrm{N}^{t} \mathrm{Bu}\right)_{2}\right\}_{2}\right](5)$. Dieses lässt sich mit einem weiteren Äquivalent Methyllithium zum Schwefelylid [(dem) $\left.\mathrm{Li}_{4}\left\{\mathrm{H}_{2} \mathrm{CS}\left(\mathrm{N}^{t} \mathrm{Bu}\right)_{2}\right\}_{2}\right]_{\mathrm{n}}(\mathbf{6})$ deprotonieren. Obwohl das DEM-Molekül in der Kristallstruktur zwei Ylid-Doppelkuben verbindet und damit fixiert ist, führt der verbleibende Rotations-Freiheitsgrad zur Fehlordnung über zwei 
Positionen. 6 ist daher wie 2 nicht für eine experimentelle Elektronendichtebestimmung geeignet.

Die Untersuchung des Polymorphismus von $\left[(\text { thf }) \mathrm{Li}_{2}\left\{\mathrm{H}_{2} \mathrm{CS}\left(\mathrm{N}^{t} \mathrm{Bu}\right)_{2}\right\}\right]_{2}$ (1) führte zur Entdeckung zweier neuer Polymorphe $(\mathbf{3}, \mathbf{4})$. Die Übergänge zwischen den Polymorphen zeigen die Charakteristika von Verschiebungsübergängen, da nur eine geringe Reorganisation der Atome stattfindet. Eine DSC-Analyse und der Vergleich der Raumgruppen-Symmetrien bestätigten zudem, dass Übergänge erster Ordnung vorliegen. Verbindung 3 enthält sowohl fehlgeordnete, als auch nicht-fehlgeordnete THF-Moleküle. Hingegen kristallisiert die Tieftemperaturphase $\mathbf{4}$ frei von Fehlordnungen. Somit konnte ein Röntgenbeugungsexperiment bis zu hohen Winkeln an diesen Kristallen durchgeführt werden. Anhand der gesammelten Daten konnten eine Multipolverfeinerung der Verbindung und Analysen der Topologie der Elektronendichteverteilung durchgeführt werden.

Die Analysen anhand von Bader's QTAIM ermöglichten es, die $\mathrm{S}-\mathrm{N}$ - und S-C-Bindungen als klassische Einfachbindungen, verstärkt durch elektrostatische Wechselwirkungen $\left(\mathrm{S}^{+}-\mathrm{N}\right.$ und $\left.\mathrm{S}^{+}-\mathrm{C}\right)$, zu spezifizieren. Zusammen mit der Anwesenheit von vier VSCCs am Schwefelatom schließt dies eine Hypervalenz aus. Dies stimmt mit den Beobachtungen bei anderen formal hypervalenten SN-Verbindungen überein. [(thf) $\left.\mathrm{Li}_{2}\left\{\mathrm{H}_{2} \mathrm{CS}\left(\mathrm{N}^{t} \mathrm{Bu}\right)_{2}\right\}\right]_{2}$ (1) sollte somit besser ylidisch als ylenisch dargestellt werden, da dies die elektronischen Gegebenheiten und die Reaktivität der Verbindung am Besten beschreibt.

Zusätzlich konnte die Bindung zwischen dem Carbanion und dem $\mathrm{Li}_{3}$-Dreieck als ionische $\mathrm{CH}_{2}{ }^{-}-\left(\mathrm{Li}^{+}\right)_{3}$-Wechselwirkung charakterisiert werden. Das Kohlenstoffatom bildet dabei eine Bindung zu jedem der drei Lithiumatome aus. Da eine Wechselwirkung bevorzugt wird, ist das Elektronenpaar, charakterisiert durch das entsprechende VSCC, von der Mitte des $\mathrm{Li}_{3}$-Dreiecks weg und zu dem Lithiumatom an der Spitze des gleichschenkligen Dreieckes hin geneigt. Dies spiegelt sich in den Charakteristika der BCP wider. Keine BCP und Bindungspfade und damit auch keine bindenden Wechselwirkungen im Rahmen der QTAIM konnten zwischen den Lithiumatomen festgestellt werden. Die treibende Kraft zur Ausbildung des $\mathrm{Li}_{3}$-Dreiecks scheint also ausschließlich die Wechselwirkung der Lithiumatome mit dem Carbanion zu sein.

Die gewonnenen Erkenntnisse können genutzt werden, um Schwefelylide und lithiumorganische Reagenzien zu synthetisieren, welche auf die gewünschten Reaktionen besser abgestimmt sind. 
Zusätzlich zur vorliegenden Arbeit sollte eine Elektronendichteuntersuchung an der teilweise fehlgeordneten Modifikation 3 durchgeführt werden. Die Ergebnisse des nicht-fehlgeordneten Teils könnten dann mit den hier präsentierten verglichen werden, um zu bestimmen, welchen Einfluss die Anwesenheit fehlgeordneter Gruppen auf nicht-fehlgeordnete Fragmente ausübt. Somit könnte entschieden werden, ob Elektronendichteuntersuchungen an Verbindungen mit teilweiser Fehlordnung sinnvoll sind. Bis heute wurden keine solchen Vergleichsstudien durchgeführt, weshalb schon das Vorhandensein geringer Fehlordnungseffekte eine Multipolmodellierung der Elektronendichte verbietet, da der Einfluss der Fehlordnung nicht spezifiziert werden kann.

\subsection{Metallkomplexe der Diimidoschwefelylide}

Die Versuche, neue Metallkomplexe eines Polyimidoschwefelylids darzustellen, waren erfolgreich. Dabei konnten ein Zinnkomplex des Anions $\mathrm{H}_{2} \mathrm{CS}\left(\mathrm{N}^{t} \mathrm{Bu}\right)_{2}{ }^{2-}$ und ein Magnesiumkomplex des Anions $\mathrm{H}_{8} \mathrm{C}_{4} \mathrm{~S}\left(\mathrm{~N}^{t} \mathrm{Bu}\right)_{2}{ }^{2-}$ isoliert werden. Allerdings stellen die beschriebenen Synthesen keinen allgemeinen Zugang zur Koordinationschemie der Organopolyimidoschefelylide dar.

Die Transmetallierungsreaktionen mit Metallchloriden oder -amiden führten nur im Fall von $\mathrm{SnCl}_{2}$ zu einem identifizierbaren Produkt. Allerdings ist $\left[\mathrm{Cl}_{2} \mathrm{SnO}_{2}\left\{\mathrm{Sn}_{2}\left(\mathrm{HN}^{t} \mathrm{Bu}\right)\right\}\left\{\mathrm{H}_{2} \mathrm{CS}\left(\mathrm{N}^{t} \mathrm{Bu}\right)_{2}\right\}_{2}\right](7)$ nicht rein aus der Transmetallierung von $\left[(\text { thf }) \mathrm{Li}_{2}\left\{\mathrm{H}_{2} \mathrm{CS}\left(\mathrm{N}^{t} \mathrm{Bu}\right)_{2}\right\}\right]_{2}(1)$ hervorgegangen. Zusätzlich ist Zinnoxid aus Verunreinigungen des Zinnchlorids eingebaut und S-N-Bindungsspaltungen haben stattgefunden, wodurch $\mathrm{HN}^{t} \mathrm{Bu}^{-}$gebildet wurde. Eine Durchführung der Reaktion mit gereinigtem Zinnchlorid führte zu nicht-identifizierbaren Produkten.

Der zweite synthetische Zugang zu den gewünschten Komplexen erwies sich als ungeeignet, da sich die Alkyldiimidosulfinate, dargestellt mittels Reaktion von Di-tert.-butylschwefeldiimid mit Grignard-Reagenzien, nicht deprotonieren ließen. Allerdings konnten die neuen Alkyldiimidosulfinatkomplexe $\left[(\text { thf })_{2} \mathrm{MgCl}\left\{\mathrm{BzS}\left(\mathrm{N}^{t} \mathrm{Bu}\right)_{2}\right\}\right](8)$ und $\left[(\text { thf }) \mathrm{MgCl}\left\{\mathrm{PhS}\left(\mathrm{N}^{t} \mathrm{Bu}\right)_{2}\right\}\right]_{2}$ (9) dargestellt werden. Während 9 als Dimer kristallisiert, ist $\mathbf{8}$ monomerisch, was im Gegensatz zu allen bekannten Magnesiumkomplexen der Diimidosulfinate und Triimidosulfonate steht. Die zusätzliche $\mathrm{CH}_{2}$-Gruppe des Benzylsubstituenten macht die Koordination eines 
weiteren THF-Moleküls am Metallion sterisch möglich. Dies ist elektronisch günstiger als die Ausbildung eines $\mathrm{Mg}_{2} \mathrm{Cl}_{2}$-Ringes bei der Dimerisierung.

Die Reaktionen von Di-tert.-butylschwefeldiimid mit Alkylierungsreagenzien, die in einem zweiten Schritt als Base agieren (z. B. ${ }^{n} \mathrm{Bu}_{2} \mathrm{Mg}$ ), führte nicht ausschließlich zum gewünschten Produkt. Der Magnesiumkomplex des Diimidoschwefelylids lagert sich mit einem nicht-deprotonierten Alkyldiimidosulfinat unter Koordination von drei Metallatomen zusammen. Zusätzlich bildete sich mittels Transimidierung ein Triimidosulfitdianion. [( $\left.\left.{ }^{n} \mathrm{BuMg}\right)_{9}\left\{{ }^{n} \mathrm{BuS}\left(\mathrm{N}^{t} \mathrm{Bu}\right)_{2}\right\}_{3}\left\{\left(\mathrm{C}_{4} \mathrm{H}_{8}\right) \mathrm{S}\left(\mathrm{N}^{t} \mathrm{Bu}\right)_{2}\right\}_{2}\left\{\mathrm{~S}\left(\mathrm{~N}^{t} \mathrm{Bu}\right)_{3}\right\}\right](10)$ ist aufrund der vorliegenden Koordinationschemie interessant, obwohl es selbst ein Produktgemisch darstellt. Die Reaktionen mit anderen, ähnlichen Reagenzien $\left(\mathrm{Me}_{2} \mathrm{Zn}, \mathrm{Me}_{2} \mathrm{Cu}\right)$ führten zu keinen identifizierbaren Produkten.

Wie erwartet, wurde in allen gezeigten Komplexen das Koordinationsmuster der Lithiumkomplexe modifiziert, da ein dikationisches Metall eingebaut wird. Allerdings ist keine Schlussfolgerung bezüglich eines allgemeingültigen Koordinationsmotivs möglich, da dieses durch die Anwesenheit weiterer Anionen modifiziert wird. Es kann jedoch gefolgert werden, dass die Bildung dimerer Komplexe die elektronische Situation des Metallkations verbessert und damit begünstigt ist.

Die Verwendung eines Nucleophils, das fähig ist, das Additionsprodukt zu deprotonieren, scheint eine erfolgversprechende Strategie zu sein, obwohl S-N-Bindungsspaltungen für Di-n-butylmagnesium beobachtet wurden. Dieser prinzipielle Zugang zu Metallkomplexen der Polyimidoschwefelylide sollte in weiteren Untersuchungen verfolgt werden.

\subsection{Polydentate Polyimido-Schwefel-Kohlenstoff-Phosphor- Liganden}

Im Rahmen dieser Arbeit wurde der erste Januskopf-Ligand vom Typus $\mathrm{N}_{2} \mathrm{SCP}$ dargestellt. Der Phosphan-Donor wurde dabei an die Polyiimidoschwefel-Einheit mittels Reaktion von Lithiumdimethylphosphanylmethylid mit Di-tert.-butylschwefeldiimid gekoppelt. Durch die Bestimmung der Mokekülstruktur von $\left[\mathrm{Li}\left\{\mathrm{Me}_{2} \mathrm{PCH}_{2} \mathrm{~S}\left(\mathrm{~N}^{t} \mathrm{Bu}\right)_{2}\right\}\right]_{2}(14)$ konnte gezeigt werden, dass alle Donorgruppen an der Koordination des Metallatoms teilnehmen. Der große Biss des tridentaten Liganden führt allerdings zur Ausbildung eines Dimers. Ein weiterer $\mathrm{N}_{2} \mathrm{SCP}$-Komplex, 
$\left[\mathrm{Li}\left\{\mathrm{Ph}_{2} \mathrm{PCH}_{2} \mathrm{~S}\left(\mathrm{~N}^{t} \mathrm{Bu}\right)_{2}\right\}\right]_{2}(15)$, konnte synthetisiert, aber nicht kristallisiert werden. Die Zusammensetzung wurde spektroskopisch verifiziert.

Es zeigte sich, dass die Reaktionen von Chlordiorganophosphanen mit Polyimidoschwefelyliden keinen alternativen Zugang zu dem gewünschten Ligandensystem darstellen, da Redox-Reaktionen und $\mathrm{S}-\mathrm{N}$ - sowie $\mathrm{S}-\mathrm{C}$-Bindungsspaltungen zu Produktgemischen führten. Nur $\left[(\text { thf })_{4} \mathrm{Li}_{2}\left\{\left({ }^{t} \mathrm{BuN}\right) \mathrm{Ph}_{2} \mathrm{P}(\mathrm{S}) \mathrm{CC}(\mathrm{S}) \mathrm{PPh}_{2}\left(\mathrm{~N}^{t} \mathrm{Bu}\right)\right\}\right]$ (13) konnte isoliert und strukturell charakterisiert werden.

Erste Versuche, das Metallkation in $\left[\mathrm{Li}\left\{\mathrm{Me}_{2} \mathrm{PCH}_{2} \mathrm{~S}\left(\mathrm{~N}^{t} \mathrm{Bu}\right)_{2}\right\}\right]_{2}(14)$ auszutauschen, führten zu den oben schon erwähnten Redox-Reaktionen und $\mathrm{S}-\mathrm{N}$ - und $\mathrm{S}-\mathrm{C}$-Bindungsspaltungen. Dies kann wahrscheinlich vermieden werden, wenn das gewünschte Metallatom direkt bei der Bildung des Liganden eingeführt wird. Dazu bieten sich die vielen bekannten Hauptgruppen- und Übergangsmetallkomplexe der Methylendiorganophosphane an.

Die tripodalen, anionischen Liganden sollten auf ihre katalytische Aktivität hin untersucht werden. [ $\left.\left.\left(\mathrm{H}_{5} \mathrm{C}_{3}\right) \mathrm{Ni}^{t}{ }^{t} \mathrm{Bu}_{2} \mathrm{PCH}_{2} \mathrm{~S}\left(\mathrm{NSiMe}_{3}\right)_{2}\right\}\right]$, ein ähnliches System, wird bereits erfolgreich bei der Olefinpolymerisation eingesetzt.

Untersuchungen zu der Fragestellung, ob auch ein Arsenatom im Seitenarm eingeführt werden kann, schlugen fehl. Im Rahmen dieser Versuche konnte jedoch erstmalig freies $\mathrm{OAsMe}_{3}(16)$ strukturell charakterisiert werden. Das Molekül weist Bindungswinkel auf, die der VSEPR-Theorie widersprechen. Um hierfür eine Begründung zu finden, müssen entweder theoretische Untersuchungen angestellt werden oder ein Vergleich mit ähnlichen Arsanen und Arsanoxiden durchgeführt werden. Dies war im Rahmen der vorliegenden Arbeit nicht möglich, da keine passende Reihe eng verwandter und strukturell charakterisierter Verbindungen zur Verfügung stand. 



\section{EXPERIMENTAL SECTION}

\subsection{General}

All experiments were carried out either in an atmosphere of purified, dry nitrogen or argon by using modified Schlenk techniques or in an argon drybox. The glass vessels were dried for several hours at $120^{\circ} \mathrm{C}$, assembled hot, and cooled down under vacuum. The solvents were freshly distilled from sodium-potassium alloy $\left(\mathrm{Et}_{2} \mathrm{O}\right.$, $n$-pentane) or potassium (dem, thf, $n$-hexane) prior to use and degassed. The reactants were commercially available or synthesized according to published procedures $\left(\mathrm{S}\left(\mathrm{N}^{t} \mathrm{Bu}\right)_{2},{ }^{[18]}\left[(\text { thf }) \mathrm{Li}_{2}\left\{\mathrm{H}_{2} \mathrm{CS}\left(\mathrm{N}^{t} \mathrm{Bu}\right)_{2}\right\}\right]_{2}(1),{ }^{[62,66]} \mathrm{Me}_{3} \mathrm{P},{ }^{[276]} \mathrm{MePh}_{2} \mathrm{P}^{\left[{ }^{[276]}\right.}\right.$ $\left[\mathrm{Li}\left(\mathrm{H}_{2} \mathrm{CPMe}_{2}\right)\right],{ }^{[277]}\left[\mathrm{Li}\left(\mathrm{H}_{2} \mathrm{CPPh}_{2}\right],{ }^{[278]} \mathrm{BzMgCl}^{[279]}\right)$. The phosphanes, arsanes, and arsenane oxides are hazardous compounds and should be handled with caution in a well ventilated hood only.

\subsection{Analytical Methods}

\subsubsection{Melting and Decomposition Points}

The melting and decomposition points were determined on Büchi Melting Point B-540 in sealed glass capillaries $(\varnothing=1.4 \mathrm{~mm})$ with a heating rate of $5^{\circ} \mathrm{C} / \mathrm{min}$ or via DTA (differential thermo analysis) on Du Pont Thermal Analyzer 9000 and a DSC (differential scanning calorimetry) cell.

\subsubsection{Differential Scanning Calorimetry}

The DSC (differential scanning calorimetry) measurements were performed by the Mikroanalytisches Labor des Instituts für Anorganische Chemie der Universität Göttingen. The cooling/heating rate was set to $5 \mathrm{~K} / \mathrm{min}$ and the temperature range from $120 \mathrm{~K}$ to $250 \mathrm{~K}$ was scanned several times. The results of all scans were averaged. Aluminium oxide $\left(\mathrm{Al}_{2} \mathrm{O}_{3}\right)$ was used as external standard. No low-temperature standard was available. 


\subsubsection{Mass Spectrometry}

Mass spectra were recorded with the electron ionization method (EI-MS: $70 \mathrm{eV}$ ) on a Finnigan MAT 95 spectrometer. The mass-to-charge ratios $(\mathrm{m} / \mathrm{z})$ of the fragment ions are based on the molecular masses of the isotopes with the highest natural abundance.

Most spectra were unspecific as the ionic character and the lability of the synthesized compounds made the measurement difficult. Due to the reactivity and solubility of the compounds no electron spray ionization (ESI-MS) or fast atom bombardment (FAB-MS) mass spectra could be recorded.

\subsubsection{NMR Spectroscopy}

The substances were transferred into NMR tubes in an argon drybox and dissolved in $\mathrm{C}_{6} \mathrm{D}_{6}$ in order to get $5-10 \%$ solutions. All spectra were recorded at room temperature on Bruker Avance 300 and 500 spectrometers. The measurement frequencies are given with the analyses.

The chemical shifts $\delta$ are given in ppm with positive values for low-field shifts relative to tetramethyl silane $\left({ }^{1} \mathrm{H},{ }^{13} \mathrm{C}\right)$ or $85 \%$ phosphoric acid $\left({ }^{31} \mathrm{P}\right)$ as external standards.

\subsubsection{Elemental Analyses}

Elemental analyses were performed by the Mikroanalytisches Labor des Instituts für Anorganische Chemie der Universität Würzburg and the Mikroanalytisches Labor des Instituts für Anorganische Chemie der Universität Göttingen with an elementar Vario EL3 apparatus.

The determined values deviate more than usual from the calculated ones, as the substances were highly sensible to oxygen and moisture. The inclusion of argon, from canning in an argon drybox, led to systematic errors. 


\subsection{Syntheses and Characterizations}

\subsection{1 [(thf) $\left.\mathrm{Li}_{2}\left\{\mathrm{H}_{2} \mathrm{CS}\left(\mathrm{N}^{t} \mathrm{Bu}\right)_{2}\right\}\right]_{2}(1,2-4)$}

$\operatorname{DSC}(5 \mathrm{~K} / \mathrm{min}): \mathrm{Q}_{2 \rightarrow 3}=-280.1 \mathrm{~J} / \mathrm{mol} ; \mathrm{Q}_{3 \rightarrow 4}=-185.1 \mathrm{~J} / \mathrm{mol}$.

All other analytics can be found in the literature. ${ }^{[62,66]}$

\subsection{2 [(dem) $\left.\mathrm{Li}_{2}\left\{\mathrm{MeS}\left(\mathrm{N}^{t} \mathrm{Bu}\right)_{2}\right\}_{2}\right](5)$}

$3.4 \mathrm{~mL}(5.5 \mathrm{mmol})$ commercially available $\mathrm{MeLi}$ in $\mathrm{Et}_{2} \mathrm{O}(1.6 \mathrm{M})$ were dried in vacuo. The resulting solid was dissolved in $20 \mathrm{~mL} n$-hexane and $3.5 \mathrm{~mL}(25 \mathrm{mmol})$ DEM. $0.87 \mathrm{~g}(5.0 \mathrm{mmol}) \mathrm{S}\left(\mathrm{N}^{\mathrm{t}} \mathrm{Bu}\right)_{2}$ were added at $-78^{\circ} \mathrm{C}$ over a period of $5 \mathrm{~min}$ via syringe. The solution was allowed to warm to room temperature and stirred for another $5 \mathrm{~d}$. The color of the solution turned from colorless to opaque yellow. The small amount of precipitate was filtered off. Storage of the clear solution at $-24{ }^{\circ} \mathrm{C}$ for $10 \mathrm{~d}$ yielded colorless crystals.

Formula hill: $\quad \mathrm{C}_{23} \mathrm{H}_{54} \mathrm{Li}_{2} \mathrm{~N}_{4} \mathrm{O}_{2} \mathrm{~S}_{2}$

Molecular weight: $496.70 \mathrm{~g} / \mathrm{mol}$

Yield:

$1.14 \mathrm{~g}(2.3 \mathrm{mmol}) 92 \%$

Melting point:

$96{ }^{\circ} \mathrm{C}$

Elemental analysis (found (calc.) [\%]): C 52.6 (55.6), H 10.0 (11.0), N 10.5 (11.3), S 12.0 (12.9).

${ }^{1} \mathrm{H}$-NMR (500.134 MHz, $\left.\mathbf{C}_{6} \mathbf{D}_{6}\right): \delta=1.08\left(\mathrm{t}, 6 \mathrm{H}, \mathrm{OCH}_{2} \mathrm{CH}_{3}\right), 1.30\left(\mathrm{~s}, 36 \mathrm{H}, \mathrm{C}\left(\mathrm{CH}_{3}\right)\right)$, 2.40 (s, $3 \mathrm{H}, \mathrm{SCH}_{3}$ ), 3.45 (q, $4 \mathrm{H}, \mathrm{OCH}_{2} \mathrm{Me}$ ), $4.57 \mathrm{ppm}\left(\mathrm{s}, 2 \mathrm{H}, \mathrm{OCH}_{2} \mathrm{O}\right.$ ).

${ }^{13} \mathrm{C}$-NMR (121.494 MHz, $\left.\mathrm{C}_{6} \mathrm{D}_{6}\right): \delta=15.0\left(\mathrm{OCH}_{2} \mathrm{CH}_{3}\right), 32.8\left(\mathrm{C}\left(\mathrm{CH}_{3}\right)\right), 33.4\left(\mathrm{SCH}_{3}\right)$, $53.0\left(\mathrm{CMe}_{3}\right), 62.8\left(\mathrm{OCH}_{2} \mathrm{Me}\right), 94.5 \mathrm{ppm}\left(\mathrm{OCH}_{2} \mathrm{O}\right)$.

MS (70 eV): m/z (\%): 392 (M-DEM-2Li, 1), 377 (M-DEM-Me-2Li, 1), 203, 190 $\left(\mathrm{N}_{2} \mathrm{SH}\left({ }^{t} \mathrm{Bu}\right)_{2}, 18\right), 175\left(\mathrm{~N}_{2} \mathrm{SH}\left({ }^{t} \mathrm{Bu}\right)_{2}-\mathrm{Me}, 90\right), 119\left(\mathrm{H}_{2} \mathrm{NSN}^{t} \mathrm{Bu}, 86\right), 103\left(\mathrm{SN}^{t} \mathrm{Bu}, 42\right), 88$ $\left(\mathrm{SNC}\left(\mathrm{CH}_{3}\right)_{2}, 10\right), 70\left(\mathrm{C}_{4} \mathrm{H}_{8} \mathrm{~N}, 12\right), 63\left(\mathrm{MeSNH}_{2}, 100\right), 58\left({ }^{t} \mathrm{BuH}, 44\right)$.

\subsection{3 $\left[(\mathrm{dem}) \mathrm{Li}_{4}\left\{\mathrm{H}_{2} \mathrm{CS}\left(\mathrm{N}^{t} \mathrm{Bu}\right)_{2}\right\}_{2}\right]_{\mathrm{n}}(6)$}

$2.9 \mathrm{~mL}(5.5 \mathrm{mmol}){ }^{t} \mathrm{BuLi}$ in $n$-pentane $(1.9 \mathrm{M})$ were added to a solution of $1.27 \mathrm{~g}$ $(2.5 \mathrm{mmol})$ [(dem) $\left.\mathrm{Li}_{2}\left\{\mathrm{MeS}\left(\mathrm{N}^{t} \mathrm{Bu}\right)_{2}\right\}_{2}\right](5)$ in $30 \mathrm{~mL}$ DEM at $-78{ }^{\circ} \mathrm{C}$ over a period of $15 \mathrm{~min}$. After stirring $15 \mathrm{~min}$ at $-78^{\circ} \mathrm{C}$ the mixture was allowed to warm to room temperature and stirred overnight. The solvent was removed in vacuo and the 
residual solid re-dissolved in DEM. The solution was filtered and stored for 2 weeks at $+4{ }^{\circ} \mathrm{C}$ for crystallization.

Formula hill: $\quad \mathrm{C}_{23} \mathrm{H}_{52} \mathrm{Li}_{4} \mathrm{~N}_{4} \mathrm{O}_{2} \mathrm{~S}_{2}$

Molecular weight: $508.57 \mathrm{~g} / \mathrm{mol}$

Yield:

$1.13 \mathrm{~g}(2.2 \mathrm{mmol}) 89 \%$

Melting point:

$127^{\circ} \mathrm{C}$ (decomp.)

Elemental analysis (found (calc.) [\%]): C 53.4 (54.3), H 10.6 (10.3), N 10.8 (11.0), S 12.3 (12.6).

${ }^{1} \mathrm{H}-\mathrm{NMR}\left(\mathbf{5 0 0 . 1 3 4} \mathrm{MHz}, \mathrm{C}_{6} \mathrm{D}_{6}\right): \delta=0.98\left(\mathrm{~s}, 2 \mathrm{H}, \mathrm{SCH}_{2}\right), 1.09\left(\mathrm{t}, 6 \mathrm{H}, \mathrm{OCH}_{2} \mathrm{CH}_{3}\right), 1.40$ (s, $\left.36 \mathrm{H}, \mathrm{C}\left(\mathrm{CH}_{3}\right)\right), 3.45$ (q, $\left.4 \mathrm{H}, \mathrm{OCH}_{2} \mathrm{Me}\right), 4.56 \mathrm{ppm}\left(\mathrm{s}, 2 \mathrm{H}, \mathrm{OCH}_{2} \mathrm{O}\right.$ ).

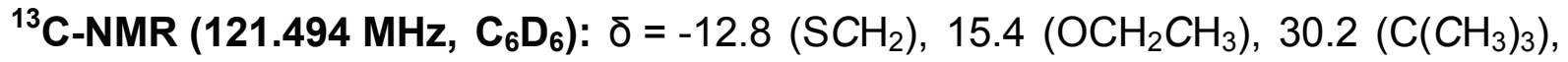
$53.8\left(\mathrm{CMe}_{3}\right), 63.0\left(\mathrm{OCH}_{2} \mathrm{Me}\right), 95.0 \mathrm{ppm}\left(\mathrm{OCH}_{2} \mathrm{O}\right)$.

\subsection{4 $\left[\mathrm{Cl}_{2} \mathrm{SnO}_{2}\left\{\mathrm{Sn}_{2}\left(\mathrm{HN}^{t} \mathrm{Bu}\right)\right\}\left\{\mathrm{H}_{2} \mathrm{CS}\left(\mathrm{N}^{t} \mathrm{Bu}\right)_{2}\right\}_{2}\right](7)$}

$0.54 \mathrm{~g}(1.0 \mathrm{mmol})\left[(\text { thf }) \mathrm{Li}_{2}\left\{\mathrm{H}_{2} \mathrm{CS}\left(\mathrm{N}^{\mathrm{t}} \mathrm{Bu}\right)_{2}\right\}\right]_{2}$ (1) were dissolved in $30 \mathrm{~mL} \mathrm{Et}_{2} \mathrm{O}$. $0.38 \mathrm{~g}$ (2.0 mmol) $\mathrm{SnCl}_{2}$ in $30 \mathrm{~mL} \mathrm{Et}_{2} \mathrm{O}$ were added to this solution at room temperature over a period of $5 \mathrm{~min}$. The mixture was stirred overnight. After removal of the solvent, the solid was re-dissolved in $40 \mathrm{~mL} \mathrm{Et} 2 \mathrm{O}$ and was crystallized at $+4{ }^{\circ} \mathrm{C}$ over a period of 2 months.

Formula hill: $\mathrm{C}_{22} \mathrm{H}_{50} \mathrm{Cl}_{2} \mathrm{~N}_{5} \mathrm{O}_{2} \mathrm{~S}_{2} \mathrm{Sn}_{3} \quad$ Molecular weight: $907.76 \mathrm{~g} / \mathrm{mol}$

Yield: $\quad 0.05 \mathrm{~g}(0.05 \mathrm{mmol}) 5 \% \quad$ Melting point: $\quad 94{ }^{\circ} \mathrm{C}$

${ }^{1} \mathrm{H}-\mathrm{NMR}\left(\mathbf{5 0 0 . 1 3 4} \mathrm{MHz}, \mathrm{C}_{6} \mathrm{D}_{6}\right): \delta=1.27\left(\mathrm{br}, 18 \mathrm{H}, \mathrm{C}\left(\mathrm{CH}_{3}\right)_{3}\right), 1.36\left(\mathrm{br}, 2 \mathrm{H}, \mathrm{SCH}_{2}\right)$,, $3.8 \mathrm{ppm}(\mathrm{s}, 1 \mathrm{H}, \mathrm{NH})$.

No further analyses could be performed due to the low yield and the high reactivity of the compound.

\subsection{5 [(thf $\left.)_{2} \mathrm{MgCl}\left\{\mathrm{BzS}\left(\mathrm{N}^{t} \mathrm{Bu}\right)_{2}\right\}\right](8)$}

$0.87 \mathrm{~g}(5.0 \mathrm{mmol}) \mathrm{S}\left(\mathrm{N}^{t} \mathrm{Bu}\right)_{2}$ in $20 \mathrm{~mL}$ THF were reacted with $3.2 \mathrm{~mL} \mathrm{BzMgCl}$ in THF $(1.57 \mathrm{M})$ at $-78{ }^{\circ} \mathrm{C}$ over a period of $10 \mathrm{~min}$. The solvent was removed in vacuo after stirring overnight at room temperature. The product was re-dissolved in $10 \mathrm{~mL}$ $n$-hexane and $10 \mathrm{~mL}$ THF. The resulting solution was filtered and 8 was crystallized at $-24{ }^{\circ} \mathrm{C}$ over a period of $2 \mathrm{~d}$. 
Formula hill: $\quad \mathrm{C}_{23} \mathrm{H}_{41} \mathrm{CIMgN}_{2} \mathrm{O}_{2} \mathrm{~S}$

Yield:

$1.71 \mathrm{~g}(3.7 \mathrm{mmol}) 73 \%$

Molecular weight: $\quad 469.40 \mathrm{~g} / \mathrm{mol}$

Elemental analysis (found (calc.) [\%]): C 56.1 (58.9), H 7.7 (8.8), N 6.4 (6.0), S 8.0 (6.8).

${ }^{1} \mathrm{H}-\mathrm{NMR}\left(\mathbf{5 0 0 . 1 3 4} \mathrm{MHz}, \mathrm{C}_{6} \mathrm{D}_{6}\right)$ : $\delta=1.21\left(\mathrm{br}, 18 \mathrm{H}, \mathrm{C}\left(\mathrm{CH}_{3}\right)_{3}\right), 1.29\left(\mathrm{br}, 2 \mathrm{H}, \mathrm{SCH}_{2}\right)$, $1.73\left(\mathrm{t}, 8 \mathrm{H}, \mathrm{OCH}_{2} \mathrm{CH}_{2}\right), 3.59\left(\mathrm{t}, 8 \mathrm{H}, \mathrm{OCH}_{2}\right), 7.1 \mathrm{ppm}\left(\mathrm{br}, 5 \mathrm{H}, \mathrm{C}_{6} \mathrm{H}_{5}\right)$.

${ }^{13} \mathrm{C}-\mathrm{NMR}\left(121.494 \mathrm{MHz}, \mathrm{C}_{6} \mathrm{D}_{6}\right): \delta=25.9\left(\mathrm{OCH}_{2} \mathrm{CH}_{2}\right), 32.8\left(\mathrm{C}\left(\mathrm{CH}_{3}\right)_{3}\right), 52.6\left(\mathrm{CMe}_{3}\right)$, $68.3\left(\mathrm{OCH}_{2}\right), 127.4-132.7 \mathrm{ppm}\left(\mathrm{C}_{6} \mathrm{H}_{5}\right)$.

\subsection{6 $\left[(\text { thf }) \mathrm{Mg}(\mathrm{Cl})\left\{\mathrm{PhS}\left(\mathrm{N}^{t} \mathrm{Bu}\right)_{2}\right\}\right]_{2}(9)$}

$0.87 \mathrm{~g}(5.0 \mathrm{mmol}) \mathrm{S}\left(\mathrm{N}^{t} \mathrm{Bu}\right)_{2}$ were dissolved in $30 \mathrm{~mL}$ THF. $1.9 \mathrm{~mL}(5.0 \mathrm{mmol}) \mathrm{PhMgCl}$ in THF $(2.65 \mathrm{M})$ were added to this solution at $-78{ }^{\circ} \mathrm{C}$ over a period of $10 \mathrm{~min}$. The mixture was allowed to warm to room temperature and stirred overnight. The solvent was removed in vacuo, the residual solid was re-dissolved in $30 \mathrm{~mL} n$-hexane and $8 \mathrm{~mL}$ THF and insoluble particles were filtered off. The resulting solution was stored at $-24{ }^{\circ} \mathrm{C}$ and yielded colorless crystals after $3 \mathrm{~d}$.

Formula hill: $\quad \mathrm{C}_{36} \mathrm{H}_{62} \mathrm{Cl}_{2} \mathrm{Mg}_{2} \mathrm{~N}_{4} \mathrm{O}_{2} \mathrm{~S}_{2} \quad$ Molecular weight: $766.54 \mathrm{~g} / \mathrm{mol}$

Yield: $\quad 1.55 \mathrm{~g}(2.0 \mathrm{mmol}) 81 \% \quad$ Melting point: $\quad 132{ }^{\circ} \mathrm{C}$

Elemental analysis (found (calc.) [\%]): C 56.0 (56.4), H 7.8 (8.2), N 7.3 (7.3), S 8.5 (8.4).

${ }^{1} \mathrm{H}-N M R\left(500.134 \mathrm{MHz}, \mathrm{C}_{6} \mathrm{D}_{6}\right): \delta=1.26\left(\mathrm{br}, 36 \mathrm{H}, \mathrm{C}\left(\mathrm{CH}_{3}\right)_{3}\right), 1.58\left(\mathrm{t}, 8 \mathrm{H}, \mathrm{OCH}_{2} \mathrm{CH}_{2}\right)$, $3.80\left(\mathrm{t}, 8 \mathrm{H}, \mathrm{OCH}_{2}\right), 7.0 \mathrm{ppm}\left(\mathrm{br}, 10 \mathrm{H}, \mathrm{C}_{6} \mathrm{H}_{5}\right)$.

${ }^{13} \mathrm{C}-\mathrm{NMR}\left(121.494 \mathrm{MHz}, \mathrm{C}_{6} \mathrm{D}_{6}\right): \delta=25.4\left(\mathrm{OCH}_{2} \mathrm{CH}_{2}\right), 30.4\left(\mathrm{C}\left(\mathrm{CH}_{3}\right)_{3}\right), 56.6\left(\mathrm{CMe}_{3}\right)$, $68.8\left(\mathrm{OCH}_{2}\right), 127.8-128.3 \mathrm{ppm}\left(\mathrm{C}_{6} \mathrm{H}_{5}\right)$.

\subsection{7 [( $\left.\left.{ }^{n} \mathrm{BuMg}\right)_{9}\left\{{ }^{n} \mathrm{BuS}\left(\mathrm{N}^{t} \mathrm{Bu}\right)_{2}\right\}_{3}\left\{\left(\mathrm{C}_{4} \mathrm{H}_{8}\right) \mathrm{S}\left(\mathrm{N}^{t} \mathrm{Bu}\right)_{2}\right\}_{2}\left\{\mathrm{~S}\left(\mathrm{~N}^{t} \mathrm{Bu}\right)_{3}\right\}\right](10)$}

$1.71 \mathrm{~g}(10 \mathrm{mmol}) \mathrm{S}\left(\mathrm{N}^{t} \mathrm{Bu}\right)_{2}$ were dissolved in $20 \mathrm{~mL}$ THF. The solution turned purple on addition of $11.0 \mathrm{~mL}(11 \mathrm{mmol}){ }^{n} \mathrm{Bu}_{2} \mathrm{Mg}$ in $n$-heptane $(1.0 \mathrm{M})$ at $-78{ }^{\circ} \mathrm{C}$. The mixture was allowed to warm up to room temperature after $15 \mathrm{~min}$ and stirred overnight. The solution had turned yellow by that time. The solvent was removed and the remaining solid was re-dissolved in $5 \mathrm{~mL} n$-hexane. Crystallization at room temperature yielded yellow crystals after 3 month. 
Formula hill 10: $\quad \mathrm{C}_{108} \mathrm{H}_{241} \mathrm{Mgg}_{9} \mathrm{~N}_{13} \mathrm{~S}_{6}$

Formula hill 11: $\quad \mathrm{C}_{36} \mathrm{H}_{80} \mathrm{Mg}_{3} \mathrm{~N}_{4} \mathrm{~S}_{2}$

Formula hill 12: $\quad \mathrm{C}_{36} \mathrm{H}_{81} \mathrm{Mg}_{3} \mathrm{~N}_{5} \mathrm{~S}_{2}$

Yield:
Molecular weight 10: $2133.29 \mathrm{~g} / \mathrm{mol}$

Molecular weight 11: $706.09 \mathrm{~g} / \mathrm{mol}$

Molecular weight 12: $721.10 \mathrm{~g} / \mathrm{mol}$

Melting point: $\quad 78^{\circ} \mathrm{C}$

Elemental analysis (found (calc.) [\%]): C 59.0 (60.8), H 9.8 (11.4), N 7.3 (8.5), S 8.1 (9.0).

${ }^{1} \mathrm{H}-\mathrm{NMR}\left(\mathbf{5 0 0 . 1 3 4} \mathrm{MHz}, \mathrm{C}_{6} \mathrm{D}_{6}\right): \delta=0.97(\mathrm{t}, 2 \mathrm{H}, \mathrm{SCH}), 1.12\left(\mathrm{br}, 42 \mathrm{H}, \mathrm{CH}_{2} \mathrm{CH}_{3}\right), 1.18$ $\left(\mathrm{t}, 18 \mathrm{H}, \mathrm{MgCH}_{2}\right), 1.20$ (br, $\left.117 \mathrm{H}, \mathrm{C}\left(\mathrm{CH}_{3}\right)_{3}\right), 1.32\left(\mathrm{br}, 56 \mathrm{H}, \mathrm{SCHCH}_{2} \mathrm{CH}_{2}\right.$, $\left.\mathrm{SCH}_{2} \mathrm{CH}_{2} \mathrm{CH}_{2}, \mathrm{MgCH}_{2} \mathrm{CH}_{2} \mathrm{CH}_{2}\right) 2.65 \mathrm{ppm}$ (t, $6 \mathrm{H}, \mathrm{SCH}_{2}$ ).

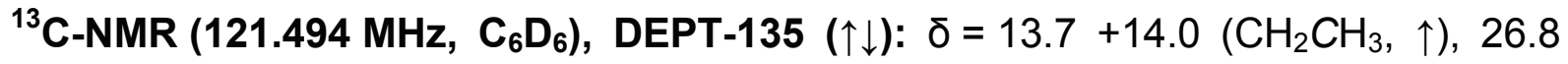

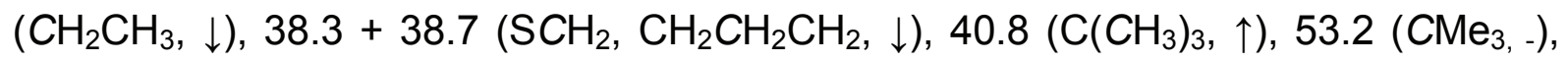
$60.7\left(\mathrm{MgCH}_{2}, \downarrow\right), 62.1 \mathrm{ppm}\left(\mathrm{SCHCH}_{2}, \uparrow\right)$.

\subsection{8 [(thf) $\left.{ }_{4} \mathrm{Li}_{2}\left\{\left({ }^{t} \mathrm{BuN}\right) \mathrm{Ph}_{2} \mathrm{P}(\mathrm{S}) \mathrm{CC}(\mathrm{S}) \mathrm{PPh}_{2}\left(\mathrm{~N}^{t} \mathrm{Bu}\right)\right\}\right](13)$}

A solution of $0.54 \mathrm{~g}(1.0 \mathrm{mmol})\left[(\text { thf }) \mathrm{Li}_{2}\left\{\mathrm{H}_{2} \mathrm{CS}\left(\mathrm{N}^{t} \mathrm{Bu}\right)_{2}\right\}\right]_{2}$ (1) in $15 \mathrm{~mL} \mathrm{Et}{ }_{2} \mathrm{O}$ was treated with $0.44 \mathrm{~g}(2.0 \mathrm{mmol}) \mathrm{Ph}_{2} \mathrm{PCl}$ in $5 \mathrm{~mL} \mathrm{Et} 2 \mathrm{O}$ at $-78{ }^{\circ} \mathrm{C}$ over a period of $15 \mathrm{~min}$. The mixture was allowed to warm to room temperature and stirred for $5 \mathrm{~d}$. The solution turned slowly from yellow to light brown. The solvent was removed in vacuo and the remaining solid was re-dissolved in a mixture of $n$-hexane and THF (3:1). Storage of the solution at $-24^{\circ} \mathrm{C}$ for 2 months yielded yellow crystals.

Formula hill: $\mathrm{C}_{50} \mathrm{H}_{70} \mathrm{Li}_{2} \mathrm{~N}_{2} \mathrm{O}_{4} \mathrm{P}_{2} \mathrm{~S}_{2} \quad$ Molecular weight: $903.06 \mathrm{~g} / \mathrm{mol}$

Yield: $\quad 0.29 \mathrm{~g}(0.32 \mathrm{mmol}) 32 \% \quad$ Melting point: $\quad 96{ }^{\circ} \mathrm{C}$ (decomp.)

Elemental analysis (found (calc.) [\%]): C 37.8 (66.5), H 7.8 (7.8), N 4.3 (3.1), S 8.4 (7.1).

${ }^{1} \mathrm{H}-\mathrm{NMR}\left(\mathbf{5 0 0 . 1 3 4} \mathrm{MHz}, \mathrm{C}_{6} \mathrm{D}_{6}\right): \delta=1.32\left(\mathrm{br}, 36 \mathrm{H}, \mathrm{C}\left(\mathrm{CH}_{3}\right)_{3}\right), 1.67\left(\mathrm{t}, 8 \mathrm{H}, \mathrm{OCH}_{2} \mathrm{CH}_{2}\right)$, 3.84 (t, $\left.8 \mathrm{H}, \mathrm{OCH}_{2}\right), 7.0$ ppm (br, $\left.10 \mathrm{H}, \mathrm{C}_{6} \mathrm{H}_{5}\right)$.

${ }^{13} \mathrm{C}$-NMR (121.494 MHz, $\left.\mathrm{C}_{6} \mathrm{D}_{6}\right): \delta=26.2\left(\mathrm{OCH}_{2} \mathrm{CH}_{2}\right), 31.6\left(\mathrm{C}\left(\mathrm{CH}_{3}\right)_{3}\right), 51.3\left(\mathrm{CMe}_{3}\right)$, $67.9\left(\mathrm{OCH}_{2}\right), 125.6\left(3,4,5-\mathrm{C} \mathrm{C}_{6} \mathrm{H}_{5}\right), 128.7\left(2,6-\mathrm{C} \mathrm{C}_{6} \mathrm{H}_{5}\right), 132.4\left(1-\mathrm{C} \mathrm{C}_{6} \mathrm{H}_{5}\right)$, 


\subsection{9 $\left[\mathrm{Li}\left\{\mathrm{Me}_{2} \mathrm{PCH}_{2} \mathrm{~S}\left(\mathrm{~N}^{t} \mathrm{Bu}\right)_{2}\right\}\right]_{2}(14)$}

$1.67 \mathrm{~g}(9.6 \mathrm{mmol}) \mathrm{S}\left(\mathrm{N}^{t} \mathrm{Bu}\right)_{2}$ were added to a slurry of $0.79 \mathrm{~g}(9.6 \mathrm{mmol})$ [Li $\left.\left(\mathrm{H}_{2} \mathrm{CPMe}_{2}\right)\right]$ in $30 \mathrm{~mL} n$-pentane at $-78^{\circ} \mathrm{C}$ over a period of $30 \mathrm{~min}$. The mixture turned light red at first and became light orange after stirring overnight at room temperature. The clear solution was reduced to half the volume in vacuo. Storage at $-24{ }^{\circ} \mathrm{C}$ for $5 \mathrm{~d}$ yielded colorless crystals.

Formula hill: $\quad \mathrm{C}_{22} \mathrm{H}_{52} \mathrm{Li}_{2} \mathrm{~N}_{4} \mathrm{P}_{2} \mathrm{~S}_{2}$

Molecular weight: $\quad 512.63 \mathrm{~g} / \mathrm{mol}$

Yield: $\quad 1.65 \mathrm{~g}(3.2 \mathrm{mmol}) 67 \% \quad$ Melting point: $\quad 143^{\circ} \mathrm{C}$ (decomp.)

Elemental analysis (found (calc.) [\%]): C 48.7 (51.6), H 7.8 (10.2), N 8.6 (10.9), S 8.6 (12.5).

${ }^{1} \mathrm{H}-\mathrm{NMR}\left(\mathbf{3 0 0 . 1 3 2} \mathbf{M H z}, \mathrm{C}_{6} \mathbf{D}_{6}\right): \delta=0.89\left(\mathrm{~s}, 12 \mathrm{H}, \mathrm{P}\left(\mathrm{CH}_{3}\right)_{2}\right), 1.01\left(\mathrm{br}, 36 \mathrm{H}, \mathrm{C}\left(\mathrm{CH}_{3}\right)_{3}\right)$, $3.68 \mathrm{ppm}\left(\mathrm{s}, 4 \mathrm{H}, \mathrm{PCH}_{2} \mathrm{~S}\right)$.

${ }^{31}$ P-NMR (121.494 MHz, $\left.\mathrm{C}_{6} \mathrm{D}_{6}\right): \delta=-27.3 \mathrm{ppm}\left(\mathrm{PMe}_{2}\right)$.

\subsubsection{0 $\left[\mathrm{Li}\left\{\mathrm{Ph}_{2} \mathrm{PCH}_{2} \mathrm{~S}\left(\mathrm{~N}^{t} \mathrm{Bu}\right)_{2}\right\}\right]_{2}(15)$}

$1.74 \mathrm{~g}(10 \mathrm{mmol}) \mathrm{S}\left(\mathrm{N}^{t} \mathrm{Bu}\right)_{2}$ were added to a slurry of $2.06 \mathrm{~g}(10 \mathrm{mmol})\left[\mathrm{Li}\left(\mathrm{H}_{2} \mathrm{CPPh}\right)\right]$ in $30 \mathrm{~mL} n$-pentane at $-78{ }^{\circ} \mathrm{C}$ over a period of $30 \mathrm{~min}$. The mixture turned dark purple at first and became dark orange after stirring overnight at room temperature. The solvent was removed in vacuo and the residue re-dissolved in $n$-pentane. After $5 \mathrm{~d}$ at $-24{ }^{\circ} \mathrm{C}$ the beige, amorphous product was filtered off, washed with $n$-pentane and dried in vacuo.

Formula hill: $\quad \mathrm{C}_{22} \mathrm{H}_{52} \mathrm{Li}_{2} \mathrm{~N}_{4} \mathrm{P}_{2} \mathrm{~S}_{2}$

Molecular weight: $760.91 \mathrm{~g} / \mathrm{mol}$

Yield: $\quad 6.16 \mathrm{~g}(8.1 \mathrm{mmol}) 81 \% \quad$ Melting point: $\quad 123{ }^{\circ} \mathrm{C}$ (decomp.)

Elemental analysis (found (calc.) [\%]): C 64.6 (66.3), H 7.7 (8.0), N 6.5 (7.4), S 8.1 (8.4).

${ }^{1} \mathrm{H}-\mathrm{NMR}\left(\mathbf{3 0 0 . 1 3 2} \mathrm{MHz}, \quad \mathbf{C}_{6} \mathrm{D}_{6}\right): \delta=0.97\left(\mathrm{~s}, \quad 36 \mathrm{H}, \quad \mathrm{C}\left(\mathrm{CH}_{3}\right)_{3}\right), \quad 3.68 \mathrm{ppm} \quad(\mathrm{s}, \quad 4 \mathrm{H}$, $\left.\mathrm{PCH}_{2} \mathrm{~S}\right), 7.02 \mathrm{ppm}\left(\mathrm{br}, 20 \mathrm{H}, \mathrm{P}\left(\mathrm{C}_{6} \mathrm{H}_{5}\right)\right.$.

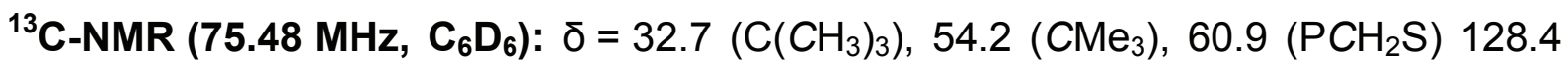
$\left(3,4,5-\mathrm{C} \mathrm{C}_{6} \mathrm{H}_{5}\right), 133.7\left(2,6-\mathrm{C} \mathrm{C}_{6} \mathrm{H}_{5}\right), 139.4 \mathrm{ppm}\left(1-\mathrm{C} \mathrm{C}_{6} \mathrm{H}_{5}\right)$.

${ }^{31} \mathrm{P}-\mathrm{NMR}$ (121.494 MHz, $\left.\mathrm{C}_{6} \mathrm{D}_{6}\right): \delta=-25.8 \mathrm{ppm}\left(\mathrm{PPh}_{2}\right)$. 


\subsubsection{1 $\mathrm{OAsMe}_{3}(16)$}

$\mathrm{OAsMe}_{3}$ was crystallized from $\mathrm{AsMe}_{3}$ at room temperature in 3 months.

Formula hill: $\mathrm{C}_{3} \mathrm{H}_{9} \mathrm{AsO} \quad$ Molecular weight: $136.02 \mathrm{~g} / \mathrm{mol}$ All analyses were in accordance to the literature. 


\section{Crystallographic Section}

\subsection{Crystal Application}

The crystals were taken from the mother liquor using standard Schlenk techniques and placed in perfluorinated polyether oil on a microscope slide. An appropriately sized crystal of high quality was picked under a polarization microscope (for detection of twinning and the presence of satellites) with help of the X-TEMP2 cooling device. ${ }^{[164,168]}$ It was mounted on a glass fibre glued to the magnetic pin of the goniometer head in a way that it was completely coated with the perfluorinated polyether oil. ${ }^{[167]}$ Oil and crystal were shock-cooled in the cold gas stream of an open flow nitrogen cooling device attached to the diffractometer. The amorphous frozen oil served as glue and protected the sensitive compounds along with the nitrogen gas stream from moisture and oxygen. The measurement temperatures varied for the different compounds as the presence of polymorph transitions prohibited cooling to $100 \mathrm{~K}$ for some compounds. The experimental conditions of each measurement are given in the crystallographic tables of section 8.5.10.

\subsection{Data Collection and Processing}

Bruker diffractometers:

The compounds 7, 9, and 16 have been measured using graphite monochromated MoK $_{\alpha}$ radiation $(0.71073 \AA)$ from a SIEMENS sealed tube on a Bruker D8 goniometer platform, equipped with a SMART APEX I CCD camera. The diffractometer was re-equipped with a SMART APEX II CCD camera in the second half of this thesis. After this modification, the compounds 5, 6, 13, and 14 have been measured with the new setup.

$\left[\left({ }^{n} \mathrm{BuMg}\right)_{9}\left\{{ }^{n} \mathrm{BuS}\left(\mathrm{N}^{t} \mathrm{Bu}\right)_{2}\right\}_{3}\left\{\left(\mathrm{C}_{4} \mathrm{H}_{8}\right) \mathrm{S}\left(\mathrm{N}^{t} \mathrm{Bu}\right)_{2}\right\}_{2}\left\{\mathrm{~S}\left(\mathrm{~N}^{t} \mathrm{Bu}\right)_{3}\right\}\right](\mathbf{1 0})$ was measured on a rotating anode device. The Bruker TXS Mo rotating anode is equipped with an APEX II CCD detector, mounted on a three-circle D8 goniometer, and INCOATEC Helios mirrors as monochromator optics, which supplies very intense and brilliant MoK $_{\alpha}$ radiation $(0.71073 \AA)$.

All crystals were centered optically by use of a video camera after being mounted on the diffractometer. 
Data collection was controlled with the SMART ${ }^{[280]}$ or APEX2 $2^{[169]}$ packages according to the detectors and goniometer platforms used. A test run (usually 50 frames in $\omega$-scan mode at $\varphi=0^{\circ}$ ) was recorded prior to each experiment to check the crystal quality, to get a rough estimate of the cell parameters, and to determine the optimum exposure time. All scans of the data collections were performed in an $\omega$-scan mode with a step-width of $-0.3^{\circ}$ at fixed $\varphi$-angles.

The determinations of the unit cells and orientation matrices were performed with the tools supplied in the SMART ${ }^{[280]}$ and APEX ${ }^{[169]}$ packages. The collected frames were integrated with SAINT ${ }^{[170,281]}$ using the $3 d$ profiling method described by Kabsch. ${ }^{[165]}$

All data sets were corrected for absorption and scaled using SADABS. [282,283] XPREP $^{[157]}$ was used to determine the space group prior to the SADABS data procession, as this is crucial for a correct treatment. SADABS refines an empirical model function by symmetry-equivalent reflections.

Data merging according to the determined symmetry and setup of the files for structure solution and refinement was performed with XPREP. ${ }^{[157]}$

\section{Stoe diffractometer:}

The X-ray structure determination for $\left[(\text { thf })_{2} \mathrm{MgCl}\left\{\mathrm{BzS}\left(\mathrm{N}^{t} \mathrm{Bu}\right)_{2}\right\}\right]$ (8) was performed on a Stoe IPDS II diffractometer using graphite monochromated $\mathrm{MoK}_{\alpha}$ radiation $(0.71073 \AA)$ from a sealed tube and an image plate detector.

The crystal was centered optically with use of a video camera after mounting on the diffractometer.

All operations from data collection over monitoring up to the data reduction were conducted with the X-AREA software package supplied by Stoe \& Cie. ${ }^{[284]} \mathrm{A}$ test run (20 frames in $\omega$-scan mode at $\varphi=0^{\circ}$ ) was recorded prior to the experiment to check the crystal quality, to get a rough estimate of the cell parameters and to determine the optimum exposure time. All scans of the data collection were performed in an $\omega$-scan mode with a step-width of $-1.0^{\circ}$ at fixed $\varphi$-angles. The data collection strategy was chosen in a way that $100 \%$ of the reflections were recorded up to $\sin \theta / \lambda=0.8 \AA$ at an overall redundancy of at least 5 . 


\subsection{Structure Solution and Refinement}

The structures were solved with direct methods using SHELXS. ${ }^{[186]}$ All IAM refinements were performed on $F^{2}$ with SHELXL. ${ }^{[187]}$

If not stated otherwise, the hydrogen atoms of the compounds were refined using a riding model. The positions were geometrically optimized and the $U_{\text {iso }}$ were constrained to $1.2 U_{\text {eq }}$ of the pivotal atom or $1.5 U_{\text {eq }}$ of the methyl carbon atom.

In all refinements the function $M\left(p_{i}, k\right)$ (Eq. 8-1) was minimized using the weights $w_{H}$ defined in Eq. 8-2. The variables $g 1$ and $g 2$ are given in the crystallographic tables.

Eq. 8-1:

$$
M\left(p_{i}, k\right)=\sum_{\mathbf{H}} w_{\mathbf{H}}\left[k\left|F_{\text {obs }}(\mathbf{H})\right|^{2}-\left|F_{\text {calc }}(\mathbf{H})\right|^{2}\right]^{2}=\min
$$

Eq. 8-2: $\quad w_{H}{ }^{-1}=\sigma_{H}{ }^{2}{F_{\mathrm{obs}}}^{2}+(g 1 \cdot P)^{2}+g 2 \cdot P$ with $P=\left(\frac{{F_{\text {obs }}}^{2}+2{F_{\text {calc }}}^{2}}{3}\right)$

The results of the refinements were verified by comparison of the calculated to the observed structure factors. Commonly used criteria are the residuals $R 1$ (Eq. 8-3) and $w R 2$ (Eq. 8-4). The $w R 2$ is more significant, because the model is refined against $F^{2}$.

Eq. 8-3: $\quad R 1=\frac{\sum_{H} w_{H}\left(\left|F_{\text {obs }}\right|-\left|F_{\text {calc }}\right|\right)}{\sum_{H} w_{H}\left|F_{\text {obs }}\right|} \quad$ Eq. 8-4: $\quad w R 2=\frac{\sum_{H} w_{H}\left(\left|F_{\text {obs }}\right|^{2}-\left|F_{\text {calc }}\right|^{2}\right)^{2}}{\sum_{H} w_{H}\left|F_{\text {obs }}\right|^{4}}$

Additionally, the GoF (goodness of fit, Eq. 8-5), a figure of merit showing the relation between deviation of $F_{\text {calc }}$ from $F_{\text {obs }}$ and the over-determination of refined parameters, is calculated.

Eq. 8-5:

$$
\mathrm{GoF}=\sqrt{\frac{\sum_{H} w_{H}\left(\left|F_{\text {obs }}\right|-\left|F_{\text {calc }}\right|\right)^{2}}{N-n}}
$$

The residual densities from difference Fourier analysis should be low. Due to the model restrictions the residuals are normally found in the bonding regions (see chapter 2.5 for further details). Higher residuals for heavy scatterers are acceptable as they arise mainly from absorption effects and Fourier truncation errors due to the limited recorded resolution range. The highest peak and deepest hole from difference Fourier analysis are listed in the crystallographic tables.

Additionally, the orientation, size and ellipticity of the ADP's show the quality of the model. Ideally, the ADP's should be oriented perpendicular to the bonds, be equal in 
size and show little ellipticity. The ADP's for all atoms of the asymmetric units of the compounds are depicted in section 8.5. All graphics were generated with the ORTEP-III program ${ }^{[285]}$ at the $50 \%$ probability level and plotted with the POV-Ray program. ${ }^{[286]}$

\subsection{Treatment of Disorder}

Structures containing disordered fragments were refined using constraints and restraints. A constraint is a mathematical operation fixing structural parameters on exact values. Restraints introduce additional chemical or crystallographical information in the model. Restraints add to the data of the refinement and have to be observed within their standard deviations.

The geometries of chemically equivalent but crystallographically independent fragments can be fitted to each other by distance restraints. Especially the 1,2 distances (bond lengths) and 1,3 distances (bond angles) are set to be equal within their effective standard deviations. This is helpful for refining disordered positions as the averaging of equivalent fragments implements chemical information and stabilizes the refinement.

Restraints affecting the anisotropic displacement parameters are often essential for the anisotropic refinement of disordered atomic positions. The rigid bond restraints $\left(D E L U\right.$ in SHELXL) ${ }^{[187]}$ fit the components of the anisotropic displacement parameters along the bonds within esd's. Similarity restraints (SIMU in SHELXL) ${ }^{[187]}$ adjust the ADPs of neighboring atoms within a certain radius to be equal according to their esd's. The ISOR command in SHELXL ${ }^{[187]}$ forces the ADPs to adapt a more spherical, isotropic behavior, which is sometimes necessary to refine positions with minor occupation factors. All restraints of this type are applied as weak restraints with relatively large esd's, as the affected parameters are not perfectly equal. 


\subsection{Refinements of the Compounds $5-10,13,14$, and 16}

\subsection{1 [(dem) $\left.\mathrm{Li}_{2}\left\{\mathrm{MeS}\left(\mathrm{N}^{t} \mathrm{Bu}\right)_{2}\right\}_{2}\right](5)$}

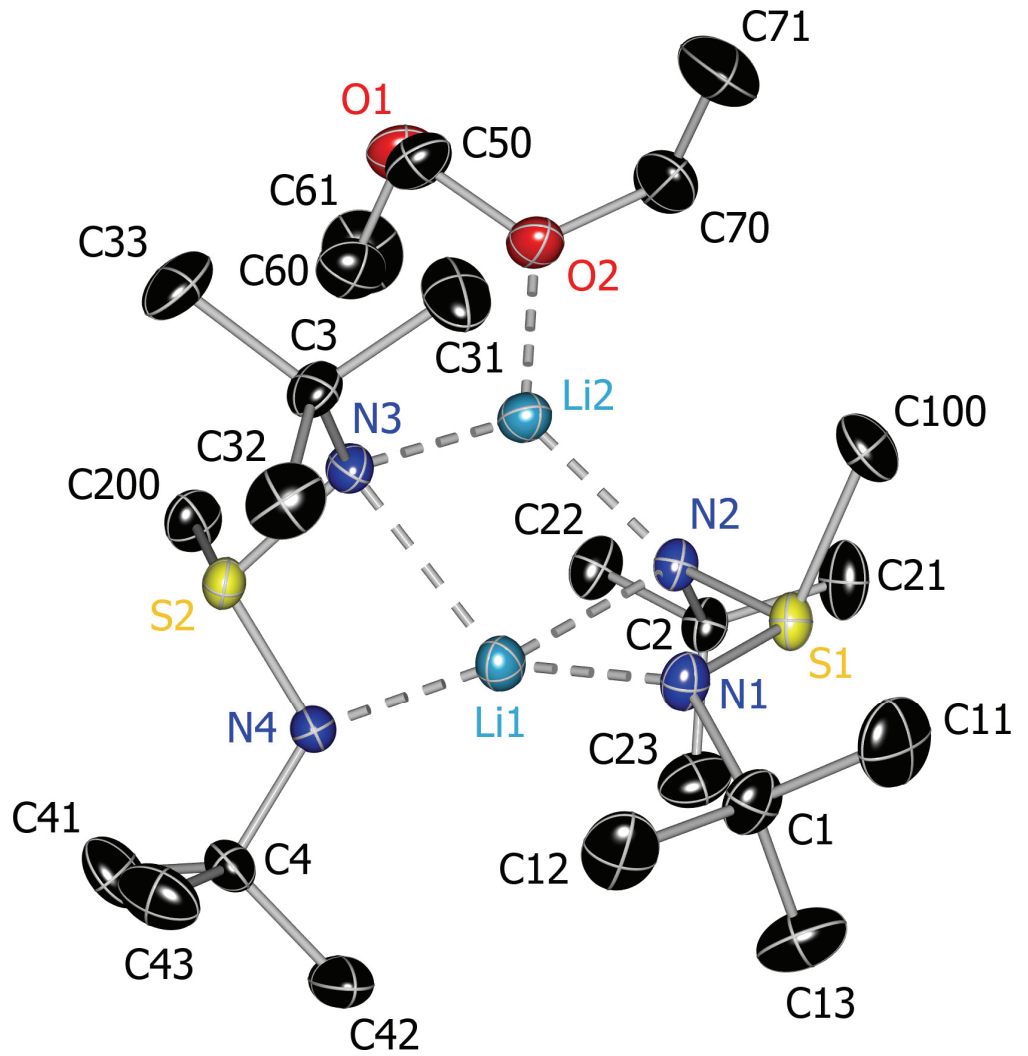

Figure 8-1: ADP representation of the asymmetric unit of $\left[(\mathrm{dem}) \mathrm{Li}_{2}\left\{\mathrm{MeS}\left(\mathrm{N}^{t} \mathrm{Bu}\right)_{2}\right\}_{2}\right](5)$; all hydrogen atoms are omitted for clarity, the ADP's are depicted at the $50 \%$ probability level.

The crystals of $\left[(\mathrm{dem}) \mathrm{Li}_{2}\left\{\mathrm{MeS}\left(\mathrm{N}^{t} \mathrm{Bu}\right)_{2}\right\}_{2}\right](5)$ are of plate-like shape. One complete dimer is present in the asymmetric unit. As a result of the $2{ }_{1}$ axis at $\langle 0 ; 0 ; z\rangle$ in the space group $\mathrm{P} 2{ }_{1}$, two molecules are present in the unit cell. 


\subsection{2 $\left[(\mathrm{dem}) \mathrm{Li}_{4}\left\{\mathrm{H}_{2} \mathrm{CS}\left(\mathrm{N}^{t} \mathrm{Bu}\right)_{2}\right\}_{2}\right]_{\mathrm{n}}(6)$}

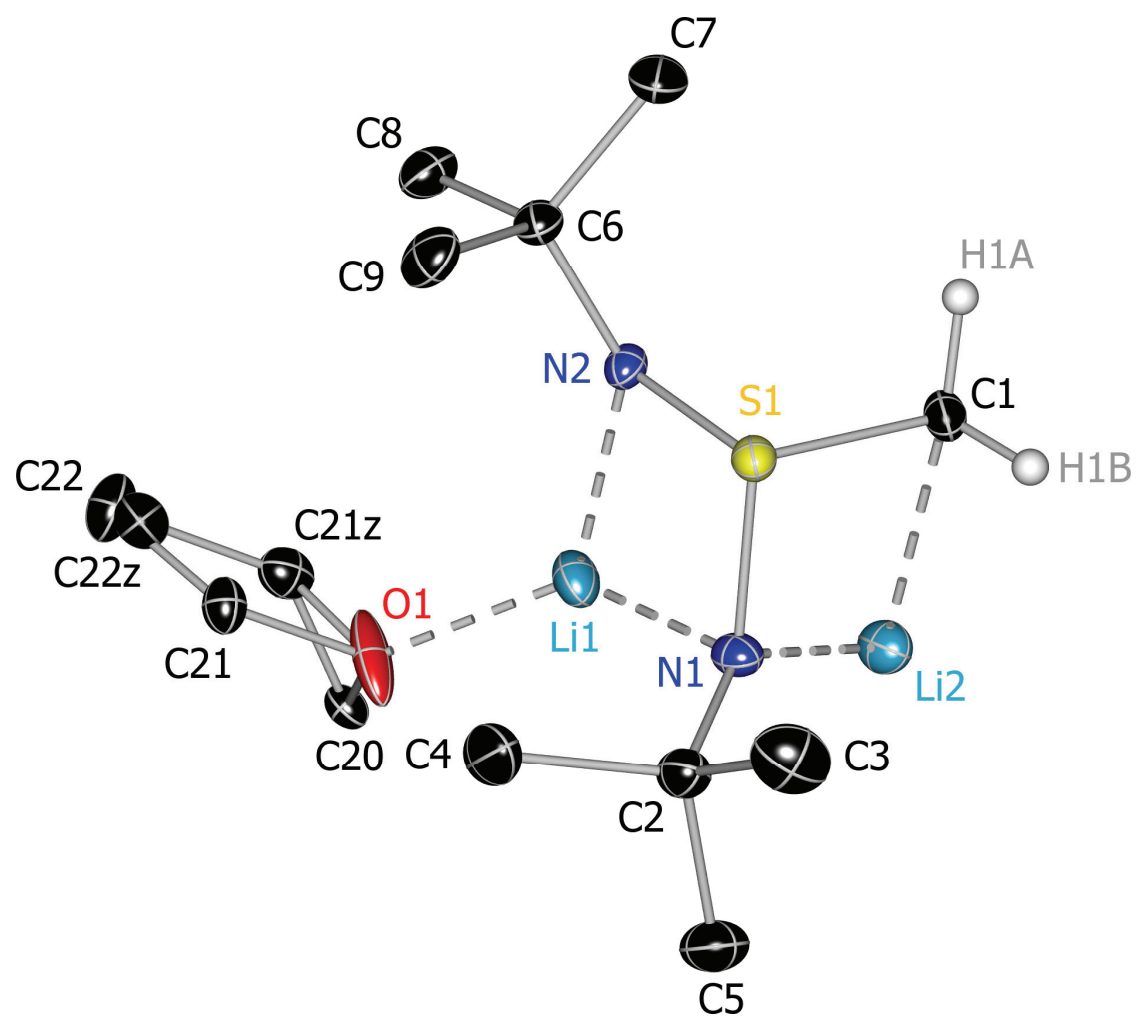

Figure 8-2: ADP representation of the asymmetric unit of $\left[(\mathrm{dem}) \mathrm{Li}_{4}\left\{\mathrm{H}_{2} \mathrm{CS}\left(\mathrm{N}^{t} \mathrm{Bu}\right)_{2}\right\}_{2}\right](6)$; all non-methylene hydrogen atoms are omitted for clarity, the ADP's are depicted at the $50 \%$ probability level.

$\left[(\mathrm{dem}) \mathrm{Li}_{4}\left\{\mathrm{H}_{2} \mathrm{CS}\left(\mathrm{N}^{t} \mathrm{Bu}\right)_{2}\right\}_{2}\right]_{\mathrm{n}}(\mathbf{6})$ crystallizes as pale yellow, cube-like blocks in the space group $P \overline{1}$. The asymmetric unit contains only one half of the double-cube dimer. The other half is completed by inversion at the origin and translation by $<1 ; 2 ; 1>$.

The hydrogen atoms of the carbanion $\mathrm{C} 1$ were located in a difference Fourier map. The positions of $\mathrm{H} 1 \mathrm{~A}$ and $\mathrm{H} 1 \mathrm{~B}$ were refined freely, whereas their $U_{\text {iso }}$ were constraint to 1.2 times the $U_{\text {eq }}$ of the pivotal carbon atom.

The dem molecule is disordered over two positions. While C20 needs no special handling because the second position is symmetry generated, C21/C21Z and C22/C22Z were refined with split occupancies of 0.5 .

It was checked if treating $\mathrm{O} 1$ as disordered improves the refinement. This is not the case because the resulting oxygen atoms can only be refined if a rigid ISOR constraint is applied. Thus, the slightly enlarged ADPs of $\mathrm{O} 1$ were not accounted for. 


\subsection{3 $\left[\mathrm{Cl}_{2} \mathrm{SnO}_{2}\left\{\mathrm{Sn}_{2}\left(\mathrm{HN}^{t} \mathrm{Bu}\right)\right\}\left\{\mathrm{H}_{2} \mathrm{CS}\left(\mathrm{N}^{t} \mathrm{Bu}\right)_{2}\right\}_{2}\right](7)$}

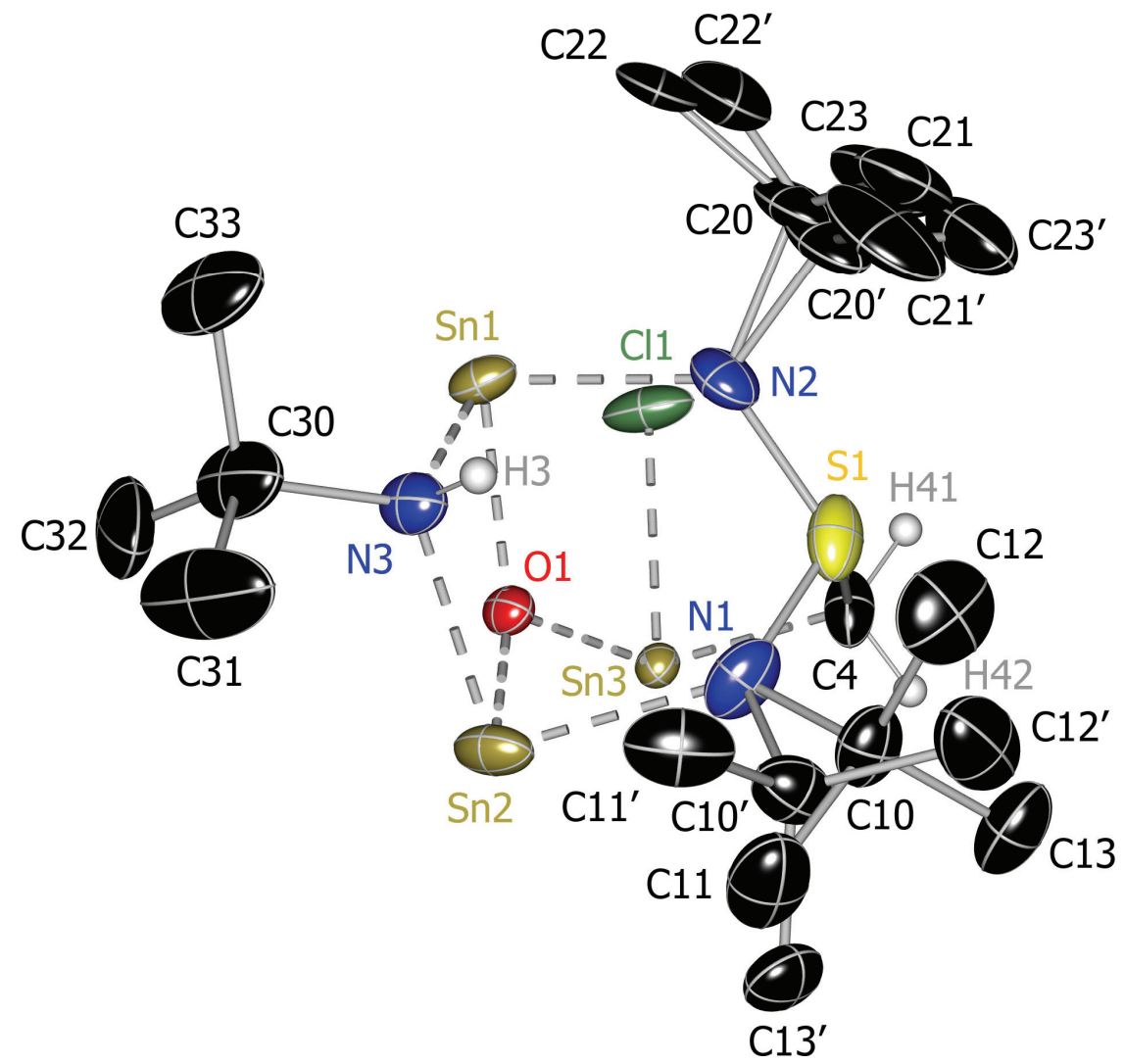

Figure 8-3: ADP representation of the asymmetric unit of $\left[\mathrm{Cl}_{2} \mathrm{SnO}_{2}\left\{\mathrm{Sn}_{2}\left(\mathrm{HN} \mathrm{N}^{t} \mathrm{Bu}\right)\right\}\left\{\mathrm{H}_{2} \mathrm{CS}\left(\mathrm{N}^{t} \mathrm{Bu}\right)_{2}\right\}_{2}\right]$ (7); all hydrogen atoms, except the amidic and methylene ones, are omitted for clarity, the ADP's are depicted at the $50 \%$ probability level.

$\left[\mathrm{Cl}_{2} \mathrm{SnO}_{2}\left\{\mathrm{Sn}_{2}\left(\mathrm{HN}^{t} \mathrm{Bu}\right)\right\}\left\{\mathrm{H}_{2} \mathrm{CS}\left(\mathrm{N}^{t} \mathrm{Bu}\right)_{2}\right\}_{2}\right](7)$ crystallizes as orange, brick-like blocks in the monoclinic space group $\mathrm{P} 2{ }_{1} / \mathrm{c}$. The asymmetric unit contains half a molecule. Sn3 resides on the crystallographic center of inversion and is therefore only occupied by $50 \%$. Inversion at this point generates the other half of the molecule. Both tert.-butyl groups are disordered over two sites. The disorder is not of a rotational kind but the $\mathrm{N}-\mathrm{C}$ vector is tilted. The site occupancy factors of both tert.-butyl groups refine to 0.62 and 0.38 , without being constrained to the same values. SIMU, DELU and SAME commands were applied in SHELXL ${ }^{[187]}$ to restrain all tert.-butyl groups in the molecule to the same geometry and thermal motion behavior. 


\subsection{4 [(thf $\left.)_{2} \mathrm{MgCl}\left\{\mathrm{BzS}\left(\mathrm{N}^{t} \mathrm{Bu}\right)_{2}\right\}\right](8)$}

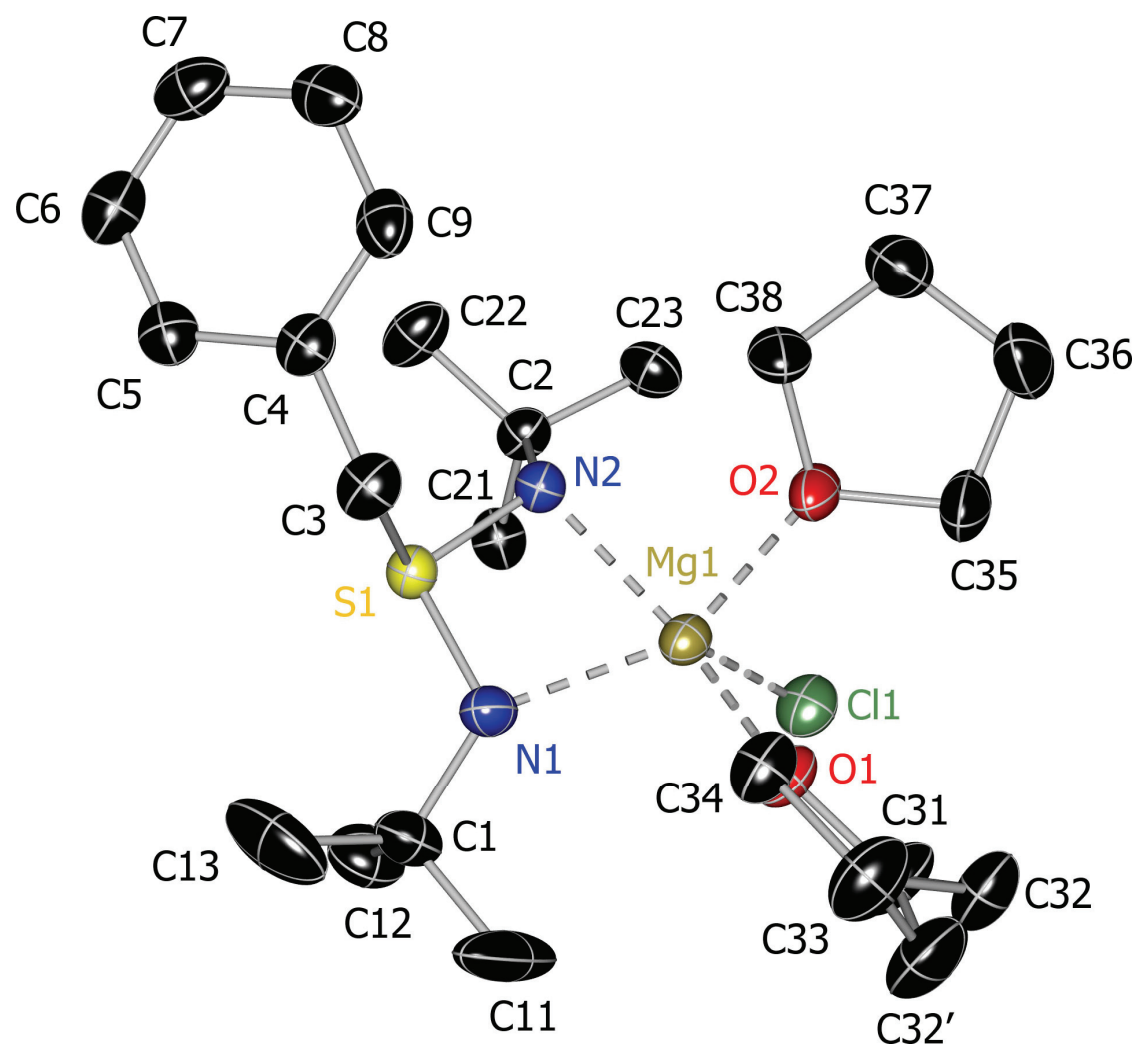

Figure 8-4: ADP representation of the asymmetric unit of $\left[(\operatorname{thf})_{2} \mathrm{MgCl}\left\{\mathrm{BzS}\left(\mathrm{N}^{t} \mathrm{Bu}\right)_{2}\right\}\right](8)$; all hydrogen atoms are omitted for clarity, the ADP's are depicted at the $50 \%$ probability level.

The colorless, cube-like crystals of $\left[(\text { thf })_{2} \mathrm{MgCl}\left\{\mathrm{BzS}\left(\mathrm{N}^{t} \mathrm{Bu}\right)_{2}\right\}\right](8)$ contain one complete molecule in the asymmetric unit. The symmetry operations of the monoclinic space group $\mathrm{P} 2{ }_{1} / \mathrm{c}$ generate three additional ones in the unit cell.

One thf molecule contains a disordered $\mathrm{CH}_{2}$ group. The site occupancy factors for C32 and C32' refined to values of 0.84 and 0.16 , respectively. 


\subsection{5 [(thf) $\left.M g(\mathrm{Cl})\left\{\mathrm{PhS}\left(\mathrm{N}^{t} \mathrm{Bu}\right)_{2}\right\}\right]_{2}(9)$}

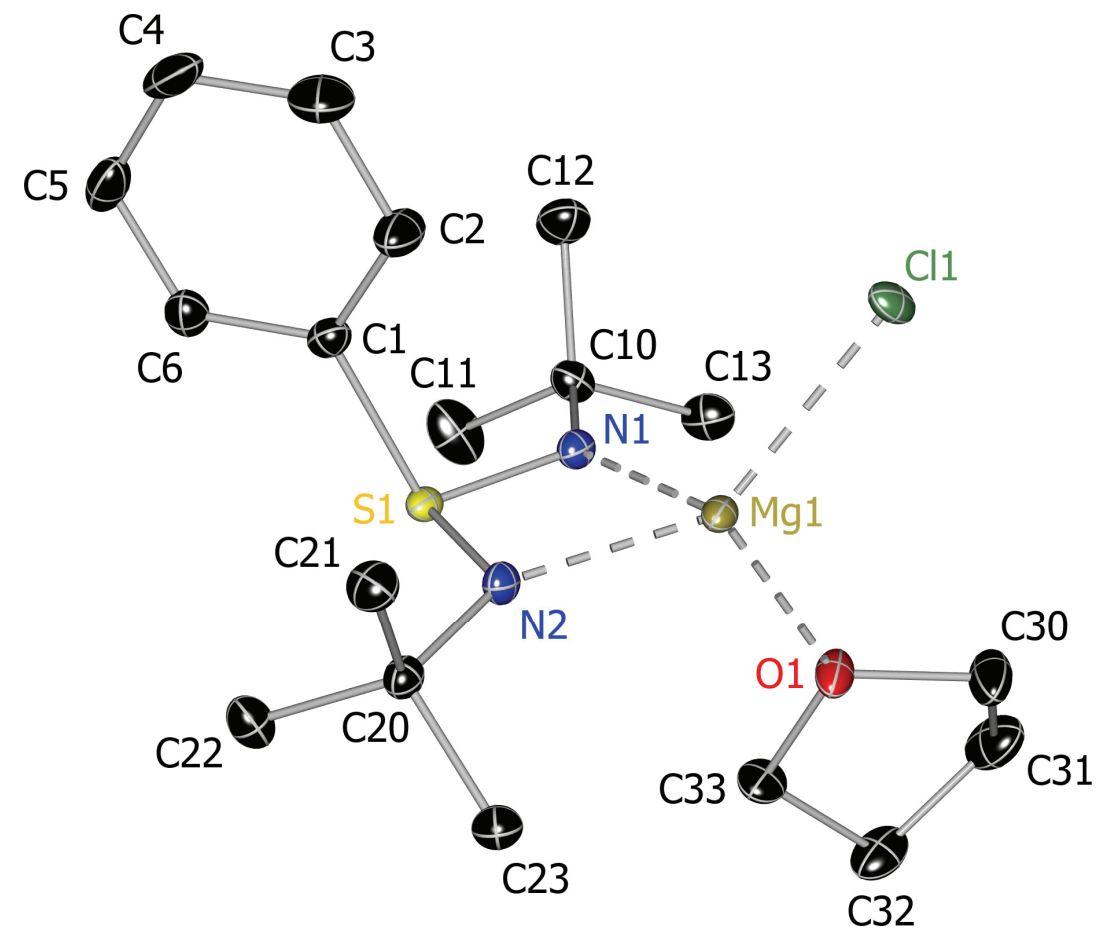

Figure 8-5: ADP representation of the asymmetric unit of $\left[(\text { thf }) \mathrm{Mg}(\mathrm{Cl})\left\{\mathrm{PhS}\left(\mathrm{N}^{t} \mathrm{Bu}\right)_{2}\right\}\right]_{2}$ (9); all hydrogen atoms are omitted for clarity, the ADP's are depicted at the $50 \%$ probability level.

$\left[(\text { thf }) \mathrm{Mg}(\mathrm{Cl})\left\{\mathrm{PhS}\left(\mathrm{N}^{t} \mathrm{Bu}\right)_{2}\right\}\right]_{2}$ (9) crystallizes as colorless plates in the triclinic space group $P \overline{1}$. Only half a molecule is present in the asymmetric unit. The dimer is completed by inversion of the asymmetric unit at the origin and subsequent translation by $<1 ; 1 ; 1>$. 


\subsection{6 $\left[\left({ }^{n} \mathrm{BuMg}\right)_{9}\left\{{ }^{n} \mathrm{BuS}\left(\mathrm{N}^{t} \mathrm{Bu}\right)_{2}\right\}_{3}\left\{\left(\mathrm{C}_{4} \mathrm{H}_{8}\right) \mathrm{S}\left(\mathrm{N}^{t} \mathrm{Bu}\right)_{2}\right\}_{2}\left\{\mathrm{~S}\left(\mathrm{~N}^{t} \mathrm{Bu}\right)_{3}\right\}\right](10)$}

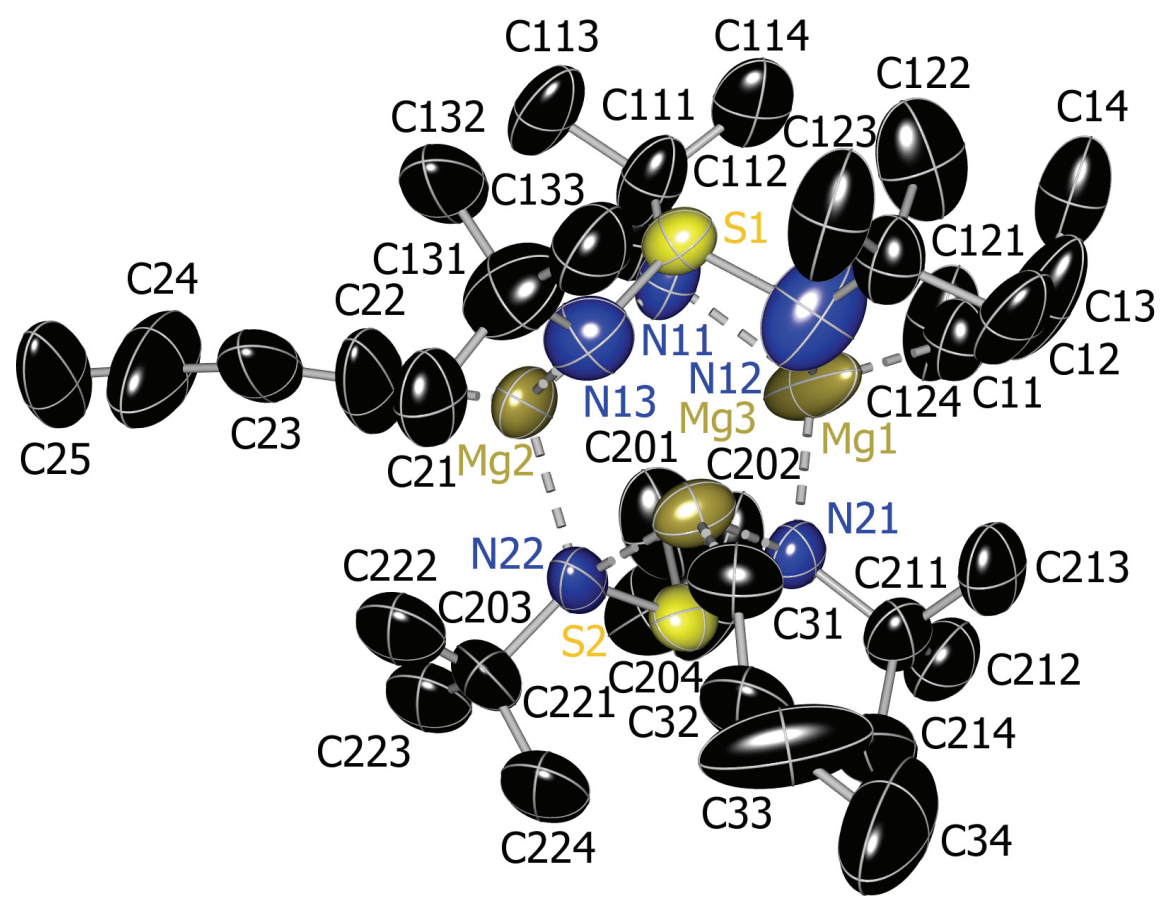

Figure 8-6: ADP representation of $\left.\left[\left({ }^{n} \mathrm{BuMg}\right)_{3}{ }^{n} \mathrm{BuS}\left(\mathrm{N}^{t} \mathrm{Bu}\right)_{2}\right\}\left\{\left(\mathrm{C}_{4} \mathrm{H}_{8}\right) \mathrm{S}\left(\mathrm{N}^{t} \mathrm{Bu}\right)_{2}\right\}\right](11)$ in the asymmetric unit of $\left[\left({ }^{n} \mathrm{BuMg}\right)_{9}\left\{{ }^{n} \mathrm{BuS}\left(\mathrm{N}^{t} \mathrm{Bu}\right)_{2}\right\}_{3}\left\{\left(\mathrm{C}_{4} \mathrm{H}_{8}\right) \mathrm{S}\left(\mathrm{N}^{t} \mathrm{Bu}\right)_{2}\right\}_{2}\left\{\mathrm{~S}\left(\mathrm{~N}^{t} \mathrm{Bu}\right)_{3}\right\}\right](10)$; all hydrogen atoms are omitted for clarity, the ADP's are depicted at the $50 \%$ probability level.

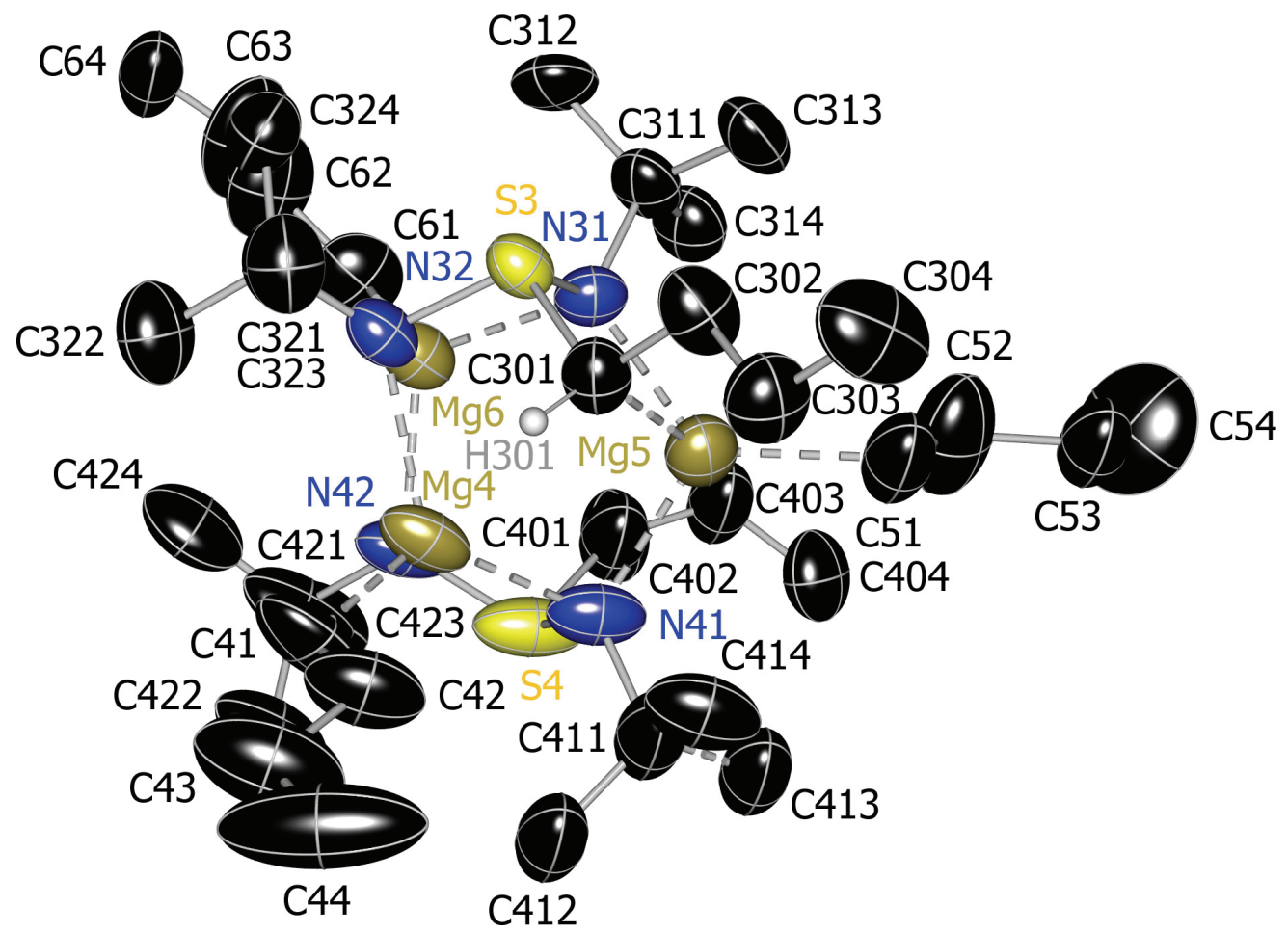

Figure 8-7: ADP representation of the first unit $\left[\left({ }^{n} \mathrm{BuMg}\right)_{3}\left\{{ }^{n} \mathrm{BuS}\left(\mathrm{N}^{t} \mathrm{Bu}\right)_{2}\right\}_{3}\left\{\mathrm{~S}\left(\mathrm{~N}^{t} \mathrm{Bu}\right)_{3}\right\}\right](12)$ in the asymmetric unit of $\left.\left[\left({ }^{n} \mathrm{BuMg}\right)_{9}{ }^{n} \mathrm{BuS}\left(\mathrm{N}^{t} \mathrm{Bu}\right)_{2}\right\}_{3}\left\{\left(\mathrm{C}_{4} \mathrm{H}_{8}\right) \mathrm{S}\left(\mathrm{N}^{t} \mathrm{Bu}\right)_{2}\right\}_{2}\left\{\mathrm{~S}\left(\mathrm{~N}^{t} \mathrm{Bu}\right)_{3}\right\}\right](10)$; all hydrogen atoms, except the ylidic one, are omitted for clarity, the ADP's are depicted at the $50 \%$ probability level. 


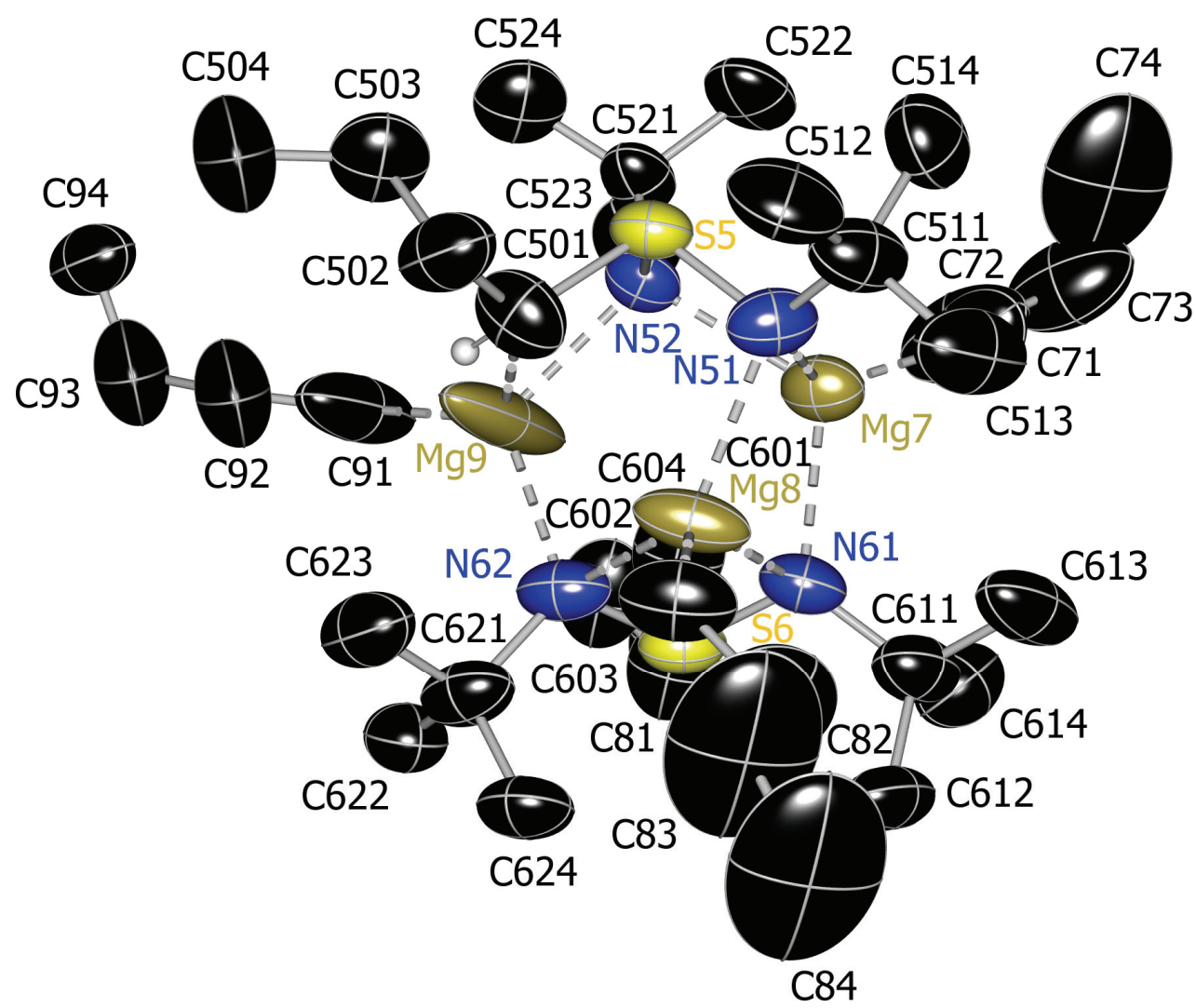

Figure 8-8: ADP representation of the second unit of $\left.\left[\left({ }^{n} \mathrm{BuMg}\right)_{3}{ }^{n} \mathrm{BuS}\left(\mathrm{N}^{t} \mathrm{Bu}\right)_{2}\right\}_{3}\left\{\mathrm{~S}\left(\mathrm{~N}^{t} \mathrm{Bu}\right)_{3}\right\}\right](12)$ in the asymmetric unit of $\left.\left[\left({ }^{n} \mathrm{BuMg}\right)_{9}{ }^{n} \mathrm{BuS}\left(\mathrm{N}^{t} \mathrm{Bu}\right)_{2}\right\}_{3}\left\{\left(\mathrm{C}_{4} \mathrm{H}_{8}\right) \mathrm{S}\left(\mathrm{N}^{t} \mathrm{Bu}\right)_{2}\right\}_{2}\left\{\mathrm{~S}\left(\mathrm{~N}^{t} \mathrm{Bu}\right)_{3}\right\}\right](10)$; all hydrogen atoms, except the ylidic one, are omitted for clarity, the ADP's are depicted at the $50 \%$ probability level.

$\left.\left[\left({ }^{n} \mathrm{BuMg}\right)_{9}{ }^{n} \mathrm{BuS}\left(\mathrm{N}^{t} \mathrm{Bu}\right)_{2}\right\}_{3}\left\{\left(\mathrm{C}_{4} \mathrm{H}_{8}\right) \mathrm{S}\left(\mathrm{N}^{t} \mathrm{Bu}\right)_{2}\right\}_{2}\left\{\mathrm{~S}\left(\mathrm{~N}^{t} \mathrm{Bu}\right)_{3}\right\}\right](10)$ crystallizes as colorless blocks in the orthorhombic space group P $2{ }_{1} 2{ }_{1} 2_{1}$. Three separate molecular units are present in the asymmetric unit. These are presented in the three separate figures 8-6, 8-7, and 8-8 for the benefit of clarity.

The partially large ADP's are caused by disorder, which could not be resolved due to the data quality and the high correlation of parameters. This leads to a not perfectly converged model and rather high quality criteria $(R 1, w R 2$, GoF). Nevertheless, the connectivities are out of doubts and even the bond lengths and angles show acceptable esd's. 


\subsection{7 [(thf) $\left.{ }_{4} \mathrm{Li}_{2}\left\{\left({ }^{t} \mathrm{BuN}\right) \mathrm{Ph}_{2} \mathrm{P}(\mathrm{S}) \mathrm{CC}(\mathrm{S}) \mathrm{PPh}_{2}\left(\mathrm{~N}^{t} \mathrm{Bu}\right)\right\}\right](13)$}

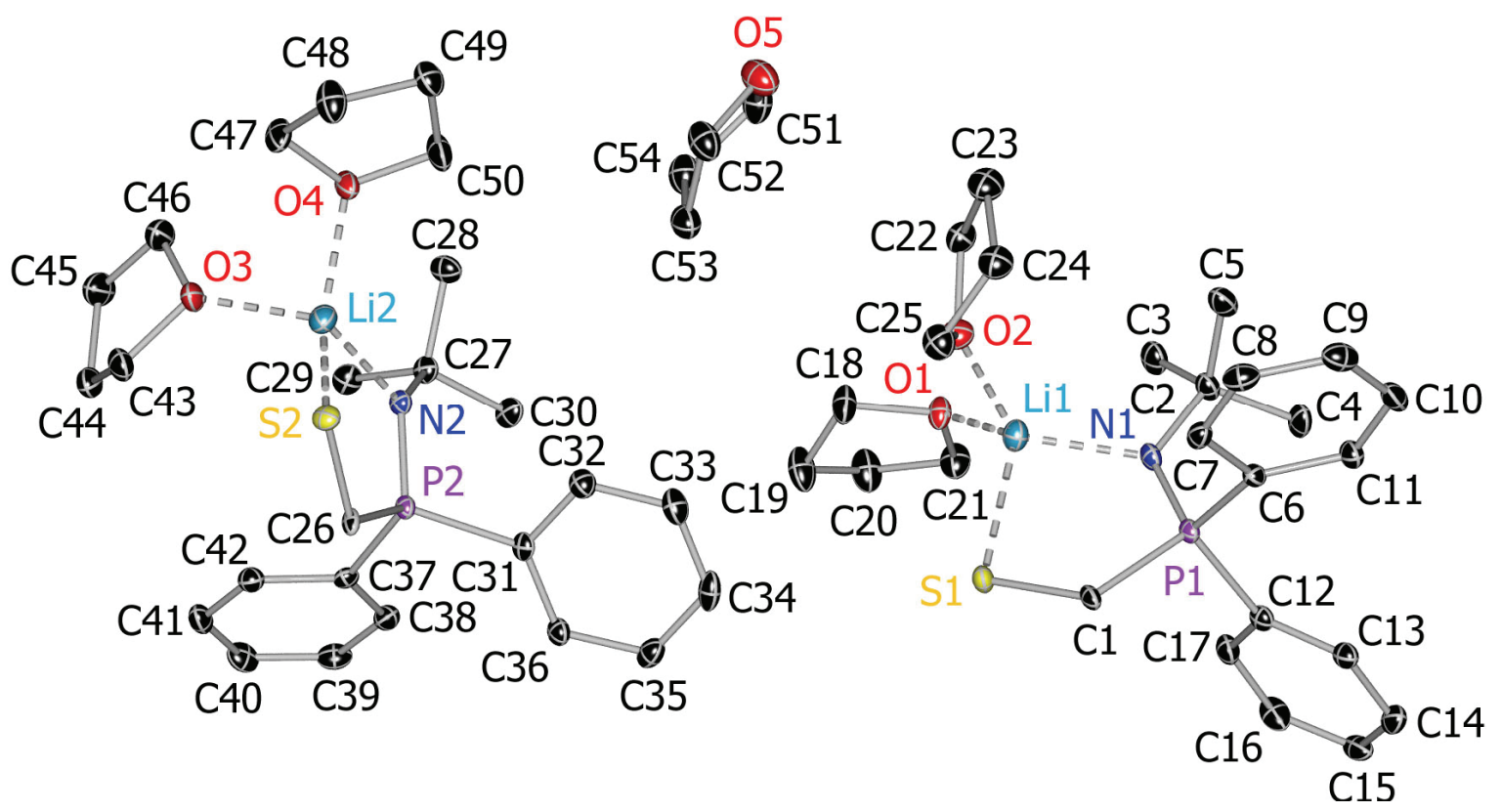

Figure 8-9: ADP representation of the asymmetric unit of $\left[(\text { thf })_{4} \mathrm{Li}_{2}\left\{\left({ }^{t} \mathrm{BuN}\right) \mathrm{Ph}_{2} \mathrm{P}(\mathrm{S}) \mathrm{CC}(\mathrm{S}) \mathrm{PPh}_{2}\left(\mathrm{~N}^{t} \mathrm{Bu}\right)\right\}_{2}\right]$ (13); all hydrogen atoms are omitted for clarity, the ADP's are depicted at the $50 \%$ probability level.

$\left[(\text { thf })_{4} \mathrm{Li}_{2}\left\{\left({ }^{t} \mathrm{BuN}\right) \mathrm{Ph}_{2} \mathrm{P}(\mathrm{S}) \mathrm{CC}(\mathrm{S}) \mathrm{PPh}_{2}\left(\mathrm{~N}^{t} \mathrm{Bu}\right)\right\}\right]$ (13) forms block-shaped, orange crystals of the triclinic space group $P \overline{1}$. The asymmetric unit contains two molecule halves and a free lattice solvent molecule. Inversion at the origin of the unit cell and translation by $<0 ; 0 ; 1>$ completes the molecules.

The crystalline sample was non-merohedrally twinned. The orientation matrices of the two components and the initial cell were determined using CELL_NOW. ${ }^{[287]}$ Those matrices were then used for integrating the domains separately with SAINT. ${ }^{[281]}$ Subsequent absorption correction with TWINABS ${ }^{[288]}$ lead to a HKLF4 file for structure solution and a HKLF5 file for further refinement. The data batches were scaled using the BASF instruction in SHELXL ${ }^{[187]}$ with 2 parameters for no, complete or partial overlap of the reflections. 


\subsection{8 $\left[\mathrm{Li}\left\{\mathrm{Me}_{2} \mathrm{PCH}_{2} \mathrm{~S}\left(\mathrm{~N}^{t} \mathrm{Bu}\right)_{2}\right\}\right]_{2}(14)$}

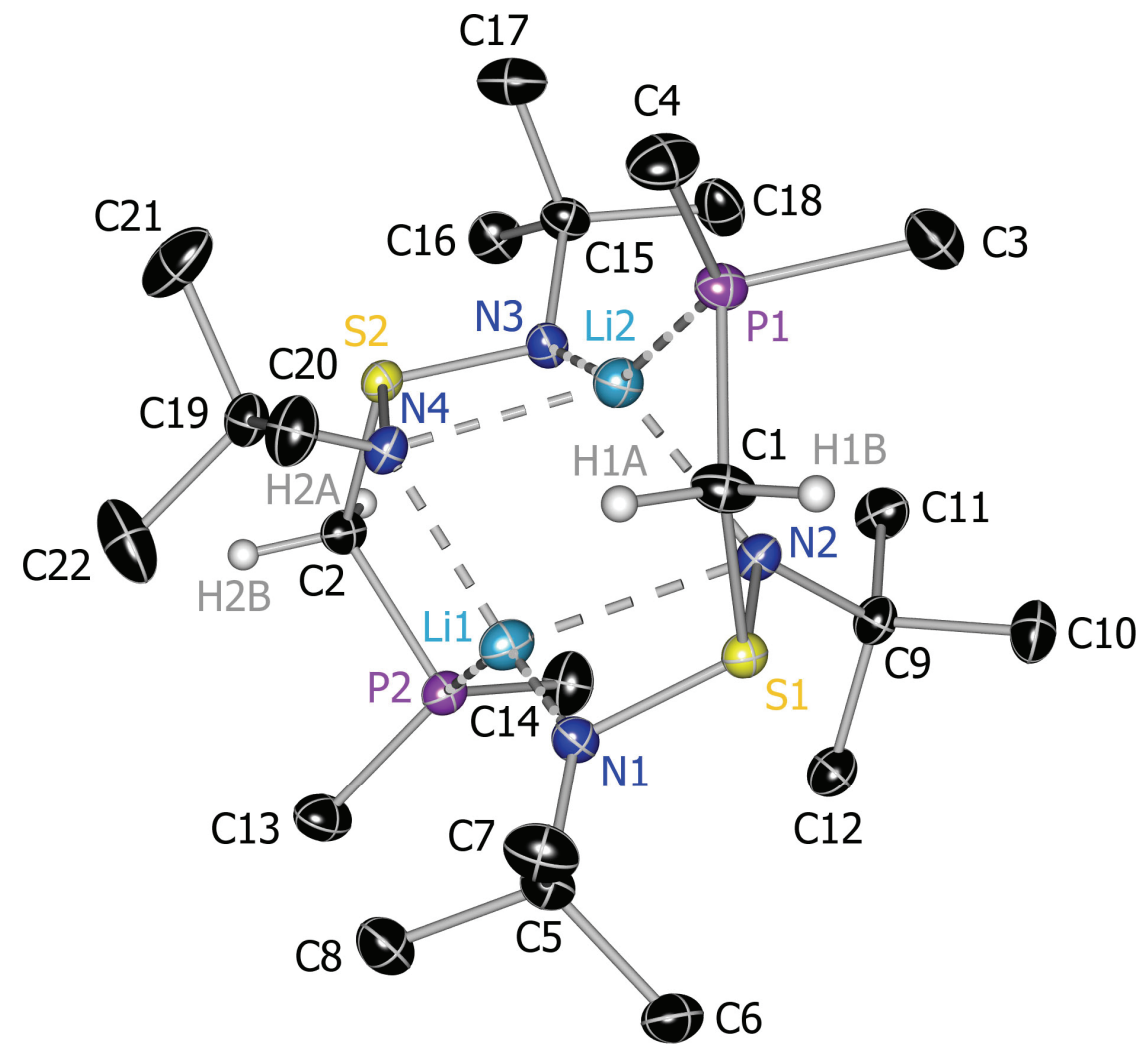

Figure 8-10: ADP representation of the asymmetric unit of $\left[\mathrm{Li}\left\{\mathrm{Me}_{2} \mathrm{PCH}_{2} \mathrm{~S}\left(\mathrm{~N}^{t} \mathrm{Bu}\right)_{2}\right\}\right]_{2}(14)$; all hydrogen atoms of ${ }^{t} \mathrm{Bu}$ and Me groups are omitted for clarity, the ADP's are depicted at the $50 \%$ probability level.

$\left[\mathrm{Li}\left\{\mathrm{Me}_{2} \mathrm{PCH}_{2} \mathrm{~S}\left(\mathrm{~N}^{t} \mathrm{Bu}\right)_{2}\right\}\right]_{2}(14)$ crystallizes as pale yellow blocks in the triclinic space group $P \overline{1}$. The asymmetric unit contains a complete molecule. The second molecule of the unit cell is generated by inversion at the origin and translation by $<1 ; 1 ; 1>$. 


\subsection{9 $\mathrm{OAsMe}_{3}(16)$}

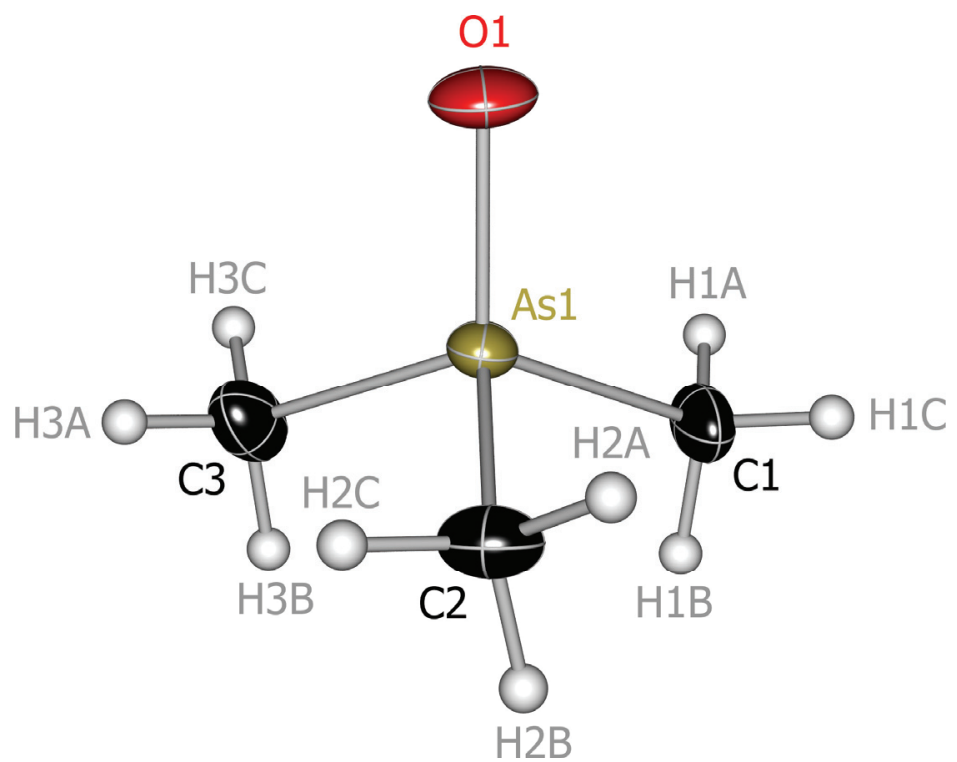

Figure 8-11: ADP representation of the asymmetric unit of $\mathrm{OAsMe}_{3}(16)$; the ADP's are depicted at the $50 \%$ probability level.

$\mathrm{OAsMe}_{3}$ (16) forms colorless, block-shaped crystals of the monoclinic space group C2. The asymmetric unit contains a complete molecule. Three additional molecules are generated in the unit cell by the symmetry operations.

It was checked if the hydrogen atom positions of $\mathbf{1 6}$ could be refined freely but no convergence and no reasonable bond lengths were obtained, even if the DFIX instruction in SHELXL ${ }^{[187]}$ was employed.

The crystal of 16 was a racemic twin. This was accounted for by the TWIN instruction (matrix of inversion) and a BASF (batch s scaling factor, 0.54) in SHELXL. 


\subsubsection{Crystallographic Tables for Compounds 5-10, 13, 14, and 16}

Table 8-1: Crystal data and structure refinement for compounds 5-7.

\begin{tabular}{|c|c|c|c|}
\hline compound & 5 & 6 & 7 \\
\hline identification code & Demlich & Neulich & Hexe \\
\hline formula hill & $\mathrm{C}_{23} \mathrm{H}_{54} \mathrm{Li}_{2} \mathrm{~N}_{4} \mathrm{O}_{2} \mathrm{~S}_{2}$ & $\mathrm{C}_{23} \mathrm{H}_{52} \mathrm{Li}_{4} \mathrm{~N}_{4} \mathrm{O}_{2} \mathrm{~S}_{2}$ & $\mathrm{C}_{26} \mathrm{H}_{60} \mathrm{Cl}_{2} \mathrm{~N}_{6} \mathrm{O}_{2} \mathrm{~S}_{2} \mathrm{Sn}_{5}$ \\
\hline molecular mass $[\mathrm{g} / \mathrm{mol}]$ & 496.70 & 508.57 & 304.32 \\
\hline crystal size [mm] & $0.2 \times 0.15 \times 0.05$ & $0.30 \times 0.25 \times 0.25$ & $0.45 \times 0.3 \times 0.3$ \\
\hline temperature $[\mathrm{K}]$ & $143(2)$ & $100(2)$ & $100(2)$ \\
\hline crystal system & monoclinic & triclinic & monoclinic \\
\hline space group & $\mathrm{P} 2_{1}$ & $P \overline{1}$ & $\mathrm{P} 2{ }_{1} / \mathrm{c}$ \\
\hline $\mathrm{a}[\AA]]$ & $9.9541(2)$ & $9.0609(8)$ & $9.3193(13)$ \\
\hline $\mathrm{b}[\AA]]$ & $16.5066(3)$ & $9.5437(8)$ & $17.366(3)$ \\
\hline$c[\AA]$ & $10.1566(2)$ & $9.9581(8)$ & $13.5955(19)$ \\
\hline$\alpha\left[^{\circ}\right]$ & 90.00 & $73.5010(10)$ & 90.00 \\
\hline$\beta\left[{ }^{\circ}\right]$ & $107.1110(10)$ & $79.7430(10)$ & $103.285(2)$ \\
\hline $\mathrm{V}\left[{ }^{\circ}\right]$ & 90.00 & $66.6130(10)$ & 90.00 \\
\hline $\mathrm{V}\left[\AA^{3}\right]$ & $1594.95(5)$ & $755.74(11)$ & $2141.4(5)$ \\
\hline Z & 2 & 1 & 2 \\
\hline$\rho_{\text {calc }}\left[\mathrm{Mg} / \mathrm{m}^{3}\right]$ & 1.034 & 1.117 & 1.888 \\
\hline$\mu\left[\mathrm{mm}^{-1}\right]$ & 0.189 & 0.200 & 3.128 \\
\hline$F(000)$ & 548 & 278 & 1180 \\
\hline$\theta$ range $\left[{ }^{\circ}\right]$ & $2.10-35.32$ & $2.14-27.16$ & $2.35-25.12$ \\
\hline reflections collected & 46258 & 16545 & 24316 \\
\hline unique reflections & 11157 & 3323 & 3802 \\
\hline min./max. transmission & $0.928396 / 0.982478$ & $0.907865 / 0.99$ & $0.7404 / 0.91$ \\
\hline$R_{\text {int }}$ & 0.0285 & 0.0318 & 0.0268 \\
\hline data/restraints/parameters & $11157 / 1 / 314$ & $3323 / 0 / 195$ & $3802 / 270 / 296$ \\
\hline$g 1 / g 2$ & $0.0505 / 0.0312$ & $0.0430 / 0.2562$ & $0.0206 / 5.0117$ \\
\hline$R 1$ (all data) & 0.0414 & 0.0374 & 0.0243 \\
\hline$R 1(/>2 \sigma(I))$ & 0.0343 & 0.0327 & 0.0228 \\
\hline$w R 2$ (all data) & 0.0821 & 0.0879 & 0.0529 \\
\hline$w R 2(I>2 \sigma(I))$ & 0.0794 & 0.0852 & 0.0524 \\
\hline GoF & 1.036 & 1.088 & 1.097 \\
\hline largest diff. peak/hole [e/Å3] & $0.358 /-0.148$ & $0.338 /-0.431$ & $0.916 /-0.983$ \\
\hline
\end{tabular}


Table 8-2: Crystal data and structure refinement for compounds 8-10.

\begin{tabular}{|c|c|c|c|}
\hline compound & 8 & 9 & 10 \\
\hline identification code & HoMg & Schorsch & DoppelBu \\
\hline formula hill & $\mathrm{C}_{23} \mathrm{H}_{41} \mathrm{CIMgN}_{2} \mathrm{O}_{2} \mathrm{~S}$ & $\mathrm{C}_{36} \mathrm{H}_{62} \mathrm{Cl}_{2} \mathrm{Mg}_{2} \mathrm{~N}_{4} \mathrm{O}_{4} \mathrm{~S}_{2}$ & $\mathrm{C}_{108} \mathrm{H}_{241} \mathrm{Mg}_{9} \mathrm{~N}_{13} \mathrm{~S}_{6}$ \\
\hline molecular mass $[\mathrm{g} / \mathrm{mol}]$ & 469.40 & 798.54 & 2133.29 \\
\hline crystal size $\left[\mathrm{mm}^{3}\right]$ & $0.6 \times 0.6 \times 0.6$ & $0.3 \times 0.25 \times 0.15$ & $0.5 \times 0.4 \times 0.25$ \\
\hline temperature $[\mathrm{K}]$ & $133(2)$ & $100(2)$ & $100(2)$ \\
\hline crystal system & monoclinic & triclinic & orthorhombic \\
\hline space group & $\mathrm{P} 2{ }_{1} / \mathrm{c}$ & $P \overline{1}$ & $\mathrm{P} 2{ }_{1} 2_{1} 2_{1}$ \\
\hline$a[\AA]$ & $10.116(2)$ & $10.1291(14)$ & $15.0983(14)$ \\
\hline $\mathrm{b}[\AA]$ & $18.081(4)$ & $10.2985(15)$ & $17.9093(16)$ \\
\hline$c[\AA]$ & $14.635(3)$ & $11.8239(17)$ & $47.751(4)$ \\
\hline$\alpha\left[^{\circ}\right]$ & 90.00 & $88.269(2)$ & 90.00 \\
\hline$\beta\left[^{\circ}\right]$ & $97.38(3)$ & $69.403(2)$ & 90.00 \\
\hline$Y\left[^{\circ}\right]$ & 90.00 & $64.525(2)$ & 90.00 \\
\hline $\mathrm{V}\left[\AA^{3}\right]$ & $2654.7(9)$ & $1031.6(3)$ & $12912(2)$ \\
\hline Z & 4 & 1 & 4 \\
\hline$\rho_{\text {calc }}\left[\mathrm{Mg} / \mathrm{m}^{3}\right]$ & 1.174 & 1.285 & 1.097 \\
\hline$\mu\left[\mathrm{mm}^{-1}\right]$ & 0.267 & 0.331 & 0.196 \\
\hline$F(000)$ & 1016 & 428 & 4736 \\
\hline$\theta$ range $\left[{ }^{\circ}\right]$ & $1.80-24.71$ & $2.21-25.07$ & $0.85 / 26.40$ \\
\hline reflections collected & 40812 & 15492 & 77364 \\
\hline unique reflections & 4496 & 3637 & 26376 \\
\hline min./max. transmission & $-/-$ & $0.72 / 0.98$ & $0.702 / 0.99$ \\
\hline$R_{\mathrm{int}}$ & 0.0375 & 0.0325 & 0.0438 \\
\hline data/restraints/parameters & $4496 / 0 / 287$ & $3637 / 0 / 223$ & $26376 / 711 / 1288$ \\
\hline$g 1 / g 2$ & $0.0391 / 1.1079$ & $0.0466 / 0.6406$ & $0.15 / 0.30$ \\
\hline$R 1$ (all data) & 0.0325 & 0.0460 & 0.1348 \\
\hline$R 1(/>2 \sigma(I))$ & 0.0297 & 0.0398 & 0.1129 \\
\hline$w R 2$ (all data) & 0.0790 & 0.0957 & 0.3383 \\
\hline$w R 2(I>2 \sigma(I))$ & 0.0775 & 0.0931 & 0.3216 \\
\hline GoF & 1.034 & 1.098 & 1.340 \\
\hline largest diff. peak/hole [e/Å3] & $0.280 /-0.222$ & $0.516 /-0.221$ & $0.975 /-0.943$ \\
\hline
\end{tabular}


Table 8-3: Crystal data and structure refinement for compounds 13, 14, and 16.

\begin{tabular}{|c|c|c|c|}
\hline compound & 13 & 14 & 16 \\
\hline identification code & Trouble & Schnecke & Spitze \\
\hline formula hill & $\mathrm{C}_{108} \mathrm{H}_{156} \mathrm{Li}_{4} \mathrm{~N}_{4} \mathrm{O}_{10} \mathrm{P}_{4} \mathrm{~S}_{4}$ & $\mathrm{C}_{22} \mathrm{H}_{52} \mathrm{Li}_{2} \mathrm{~N}_{4} \mathrm{P}_{2} \mathrm{~S}_{2}$ & $\mathrm{C}_{3} \mathrm{H}_{9} \mathrm{AsO}$ \\
\hline molecular mass $[\mathrm{g} / \mathrm{mol}]$ & 1950.24 & 512.62 & 136.02 \\
\hline crystal size $\left[\mathrm{mm}^{3}\right]$ & $0.20 \times 0.18 \times 0.15$ & $0.45 \times 0.3 \times 0.2$ & $0.3 \times 0.2 \times 0.2$ \\
\hline temperature $[\mathrm{K}]$ & $100(2)$ & $100(2)$ & $173(2)$ \\
\hline crystal system & triclinic & triclinic & monoclinic \\
\hline space group & $P \overline{1}$ & $P \overline{1}$ & $\mathrm{C} 2$ \\
\hline$a[\AA]]$ & $10.1164(16)$ & $9.4906(6)$ & $10.9874(15$ \\
\hline $\mathrm{b}[\AA]$ & $14.839(2)$ & $9.6780(7)$ & $8.9192(13)$ \\
\hline$c[\AA]$ & $18.944(3)$ & $18.7998(13)$ & $5.3594(7)$ \\
\hline$\alpha\left[^{\circ}\right]$ & $103.947(4)$ & $98.7830(10)$ & 90.00 \\
\hline$\beta\left[^{\circ}\right]$ & $90.644(5)$ & $91.9800(10)$ & $92.734(2)$ \\
\hline$Y\left[^{\circ}\right]$ & $107.028(5)$ & $114.8040(10)$ & 90.00 \\
\hline $\mathrm{V}\left[\AA^{3}\right]$ & $2628.8(7)$ & $1539.70(18)$ & $524.62(13)$ \\
\hline Z & 1 & 2 & 4 \\
\hline$\rho_{\text {calc }}\left[\mathrm{Mg} / \mathrm{m}^{3}\right]$ & 1.232 & 1.106 & 1.722 \\
\hline$\mu\left[\mathrm{mm}^{-1}\right]$ & 0.210 & 0.293 & 6.323 \\
\hline$F(000)$ & 1048 & 560 & 272 \\
\hline$\theta$ range $\left[{ }^{\circ}\right]$ & $1.48 / 28.24$ & $2.21 / 26.38$ & $2.94 / 42.45$ \\
\hline reflections collected & 71262 & 31193 & 7640 \\
\hline unique reflections & 16699 & 6252 & 3232 \\
\hline min./max. transmission & $0.6536 / 0.9692$ & $0.771 / 0.987$ & $0.48 / 0.98$ \\
\hline$R_{\text {int }}$ & 0.0932 & 0.0092 & 0.0191 \\
\hline data/restraints/parameters & $16699 / 0 / 612$ & $6252 / 0 / 305$ & $3232 / 1 / 50$ \\
\hline$g 1 / g 2$ & $0.0676 / 0.1494$ & $0.0335 / 0.5216$ & 0.1010/- \\
\hline$R 1$ (all data) & 0.0715 & 0.0282 & 0.0517 \\
\hline$R 1(\mid>2 \sigma(I))$ & 0.0438 & 0.0253 & 0.0472 \\
\hline$w R 2$ (all data) & 0.1164 & 0.0689 & 0.1275 \\
\hline$w R 2(1>2 \sigma(I))$ & 0.1030 & 0.0667 & 0.1236 \\
\hline GoF & 1.022 & 1.094 & 1.047 \\
\hline largest diff. peak/hole [e/Å3] & $0.591 /-0.454$ & $0.424 /-0.219$ & $1.913 /-1.515$ \\
\hline
\end{tabular}




\subsection{Crystallographic Cooperations}

During this doctoral study 16 molecular structures have been determined by X-ray crystallography as part of the cooperation with other groups. The cooperations with the groups of Dr. Breuning, Prof. Dr. Christl, Prof. Dr. Klingebiel, and Prof. Dr. Kost lead to five already printed publications ${ }^{[289-293]}$ and two additional publications are in preparation or submitted.

The discussion of these structures will be limited to the crystallographic information in this chapter, because all other information can be found in the publications.

\subsection{1 $\mathrm{C}_{15} \mathrm{H}_{27} \mathrm{~B}_{2} \mathrm{~N}_{2}$ (Breuning1)}

$\mathrm{Br} 1$

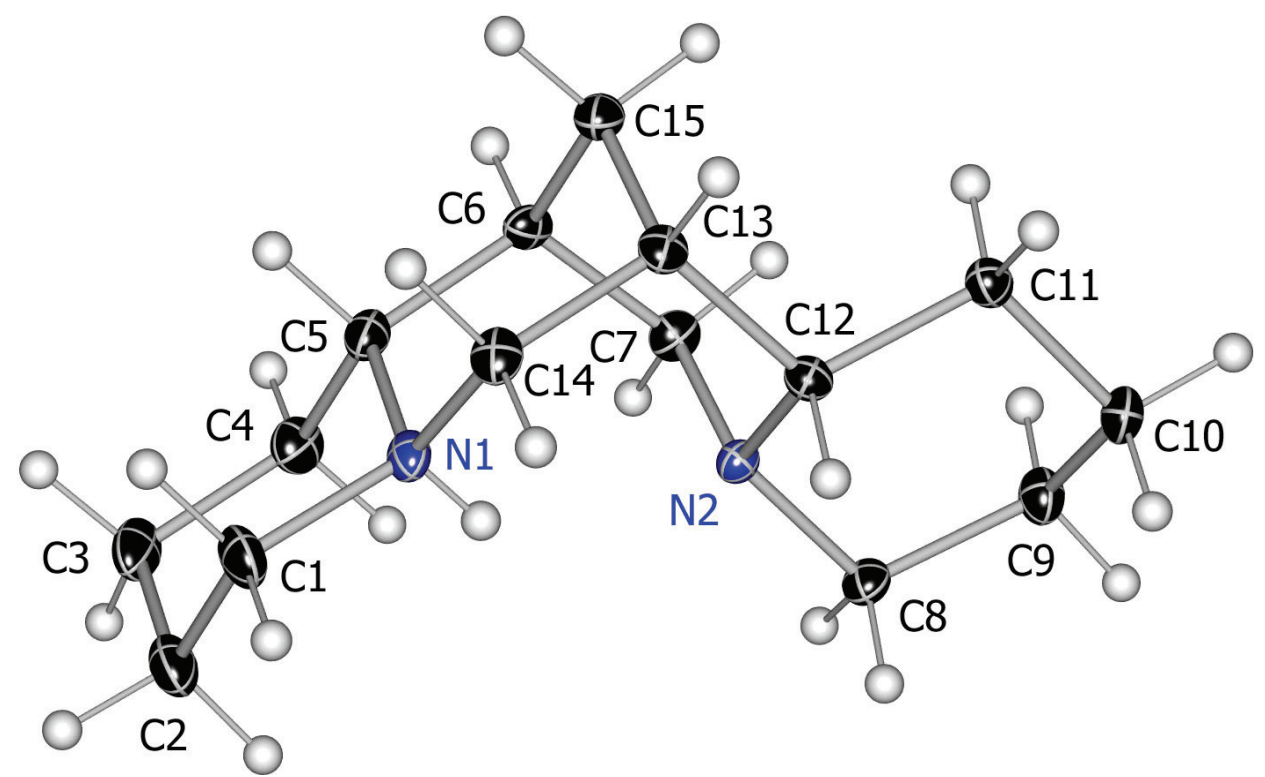

Figure 8-12: ADP representation of the asymmetric unit of $\mathrm{C}_{15} \mathrm{H}_{27} \mathrm{~B}_{2} \mathrm{~N}_{2}$ (Breuning1); the ADP's are depicted at the $50 \%$ probability level.

$\mathrm{C}_{15} \mathrm{H}_{27} \mathrm{~B}_{2} \mathrm{~N}_{2}$ (Breuning1) crystallizes in the monoclinic space group $\mathrm{P} 2{ }_{1}$. One complete molecule is contained in the asymmetric unit.

The hydrogen atom $\mathrm{H} 100$ at $\mathrm{N} 1$ has been refined freely.

The presence of a bromide atom facilitated the determination of the absolute structure (Flack parameter: $-0.007(6)$ ). 


\subsection{2 $\mathrm{C}_{19} \mathrm{H}_{22} \mathrm{O}$ (Christl1)}

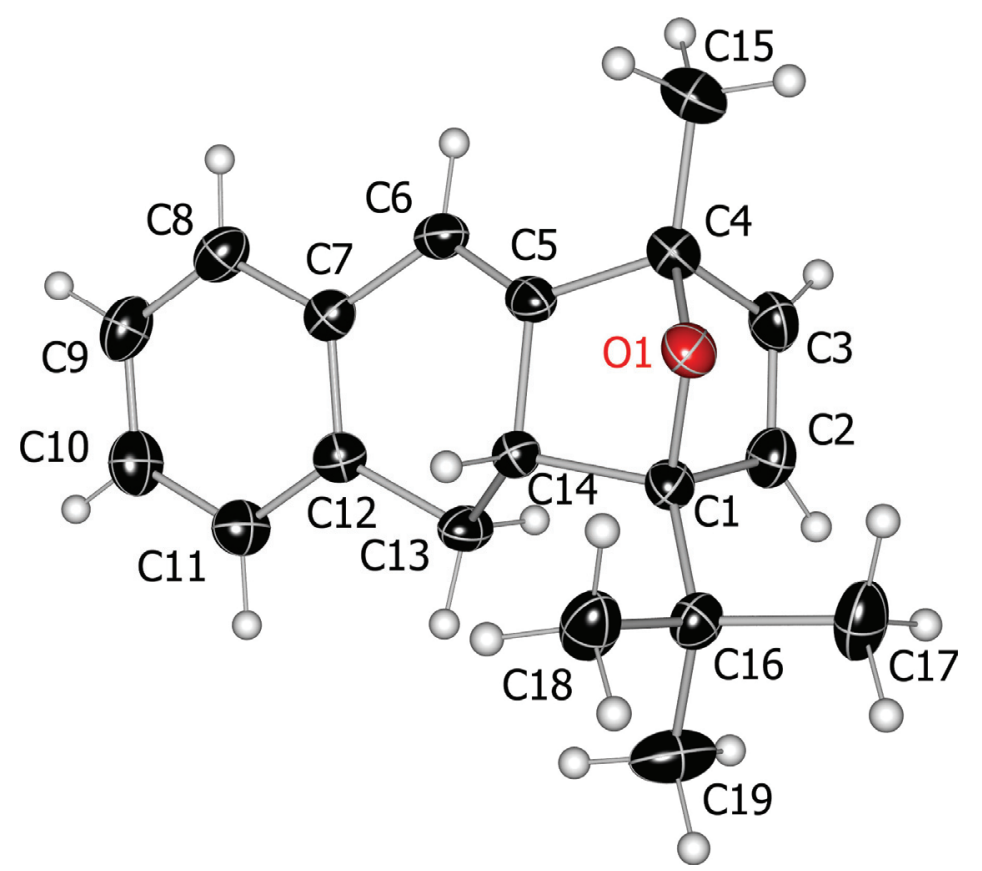

Figure 8-13: ADP representation of the asymmetric unit of $\mathrm{C}_{19} \mathrm{H}_{22} \mathrm{O}$ (Christl1); the ADP's are depicted at the $50 \%$ probability level.

The asymmetric unit of $\mathrm{C}_{19} \mathrm{H}_{22} \mathrm{O}$ (Christl1) contains a complete molecule. The symmetry operation of the monoclinic space group $\mathrm{P} 2{ }_{1}$ generates a second molecule in the unit cell.

All hydrogen atoms have been refined freely. 


\subsection{3 $\mathrm{C}_{20} \mathrm{H}_{27} \mathrm{~N}_{3}$ (Christl3)}

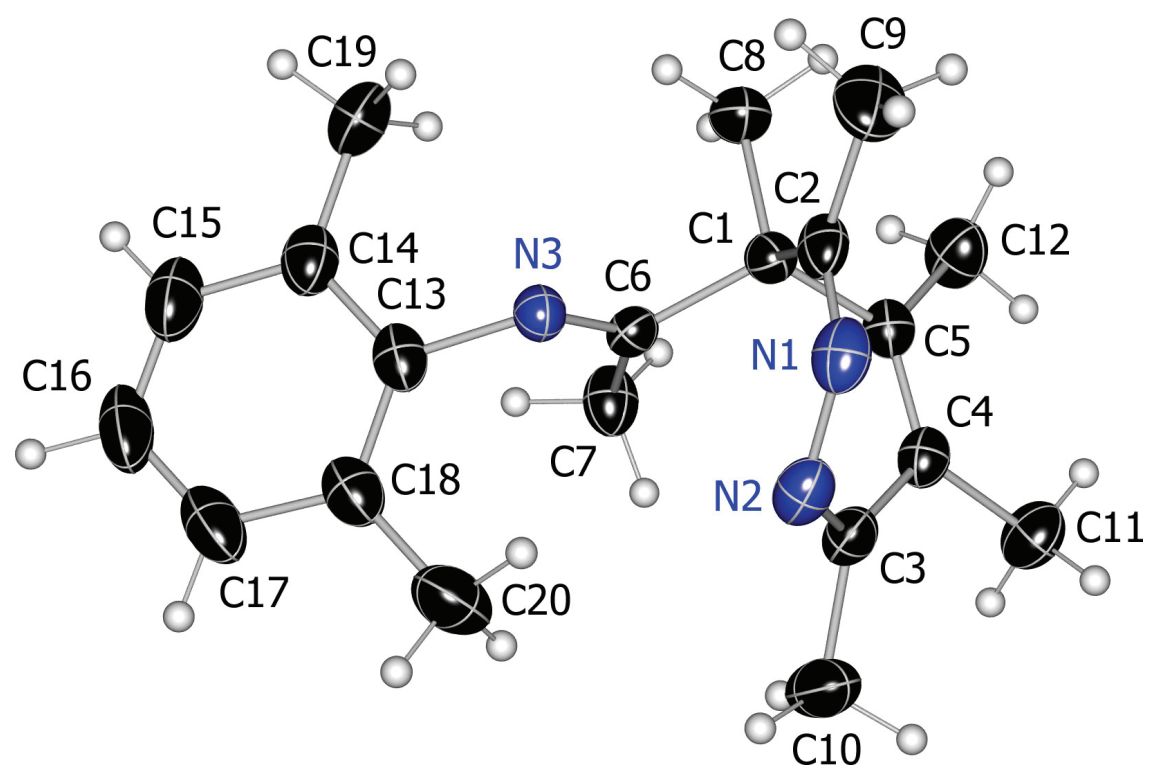

Figure 8-14: ADP representation of the asymmetric unit of $\mathrm{C}_{20} \mathrm{H}_{27} \mathrm{~N}_{3}$ (Christl3); the ADP's are depicted at the $50 \%$ probability level.

$\mathrm{C}_{20} \mathrm{H}_{27} \mathrm{~N}_{3}$ (Christl3) crystallizes in the monoclinic space group $\mathrm{P} 2_{1} / \mathrm{c}$ with one complete molecule in the asymmetric unit. 


\subsection{4 $\mathrm{C}_{18} \mathrm{H}_{22} \mathrm{~N}_{4} \mathrm{O}_{2}$ (Christl5)}

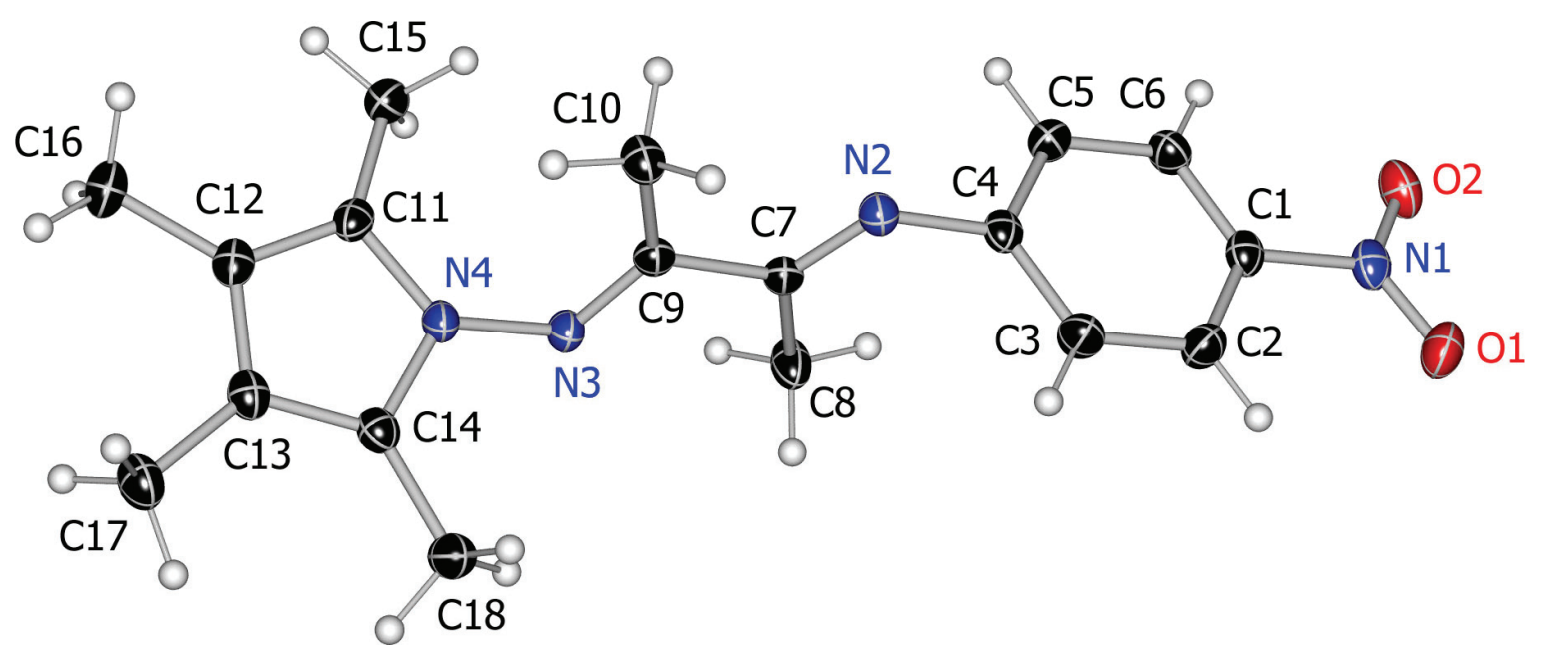

Figure 8-15: ADP representation of the asymmetric unit of $\mathrm{C}_{18} \mathrm{H}_{22} \mathrm{~N}_{4} \mathrm{O}_{2}$ (Christl5); the ADP's are depicted at the $50 \%$ probability level.

The asymmetric unit of $\mathrm{C}_{18} \mathrm{H}_{22} \mathrm{~N}_{4} \mathrm{O}_{2}$ (Christl5) contains a complete molecule. The symmetry operations of the orthorhombic space group Pbca generate seven additional molecules in the unit cell. 


\subsection{5 $\mathrm{C}_{19} \mathrm{H}_{16}$ (Christl6)}

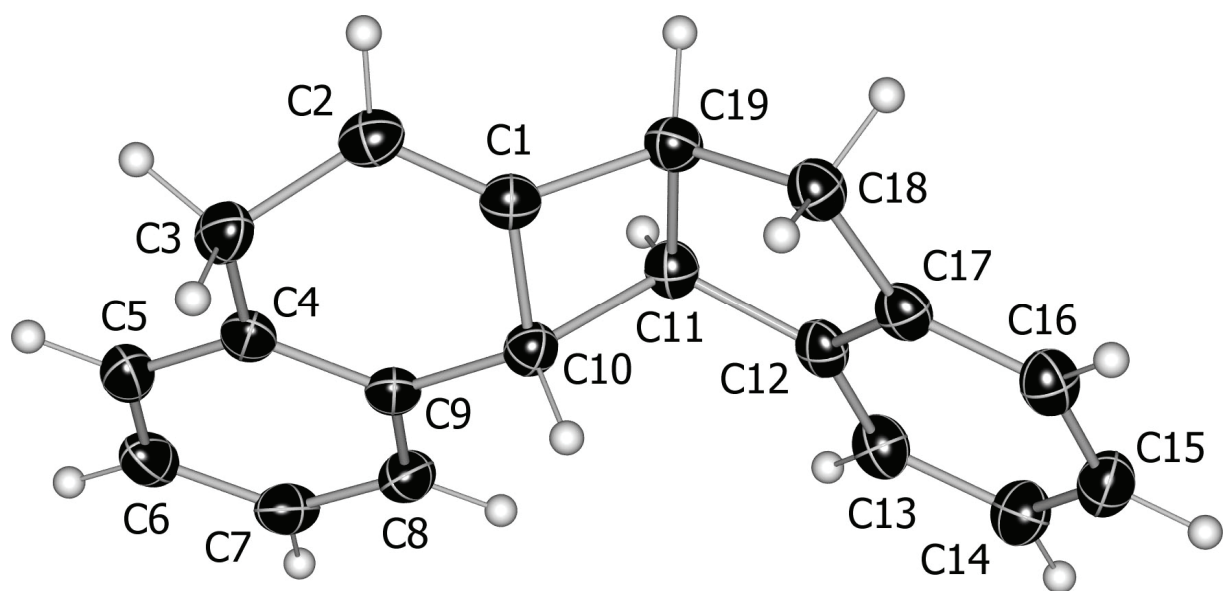

Figure 8-16: ADP representation of the asymmetric unit of $\mathrm{C}_{19} \mathrm{H}_{16}$ (Christl6); the ADP's are depicted at the $50 \%$ probability level.

$\mathrm{C}_{19} \mathrm{H}_{16}$ (Christl6) crystallizes in the monoclinic space group P2 $1 / \mathrm{n}$ with one complete molecule in the asymmetric unit. 


\subsection{6 $\mathrm{C}_{36} \mathrm{H}_{36}$ (Christl7)}

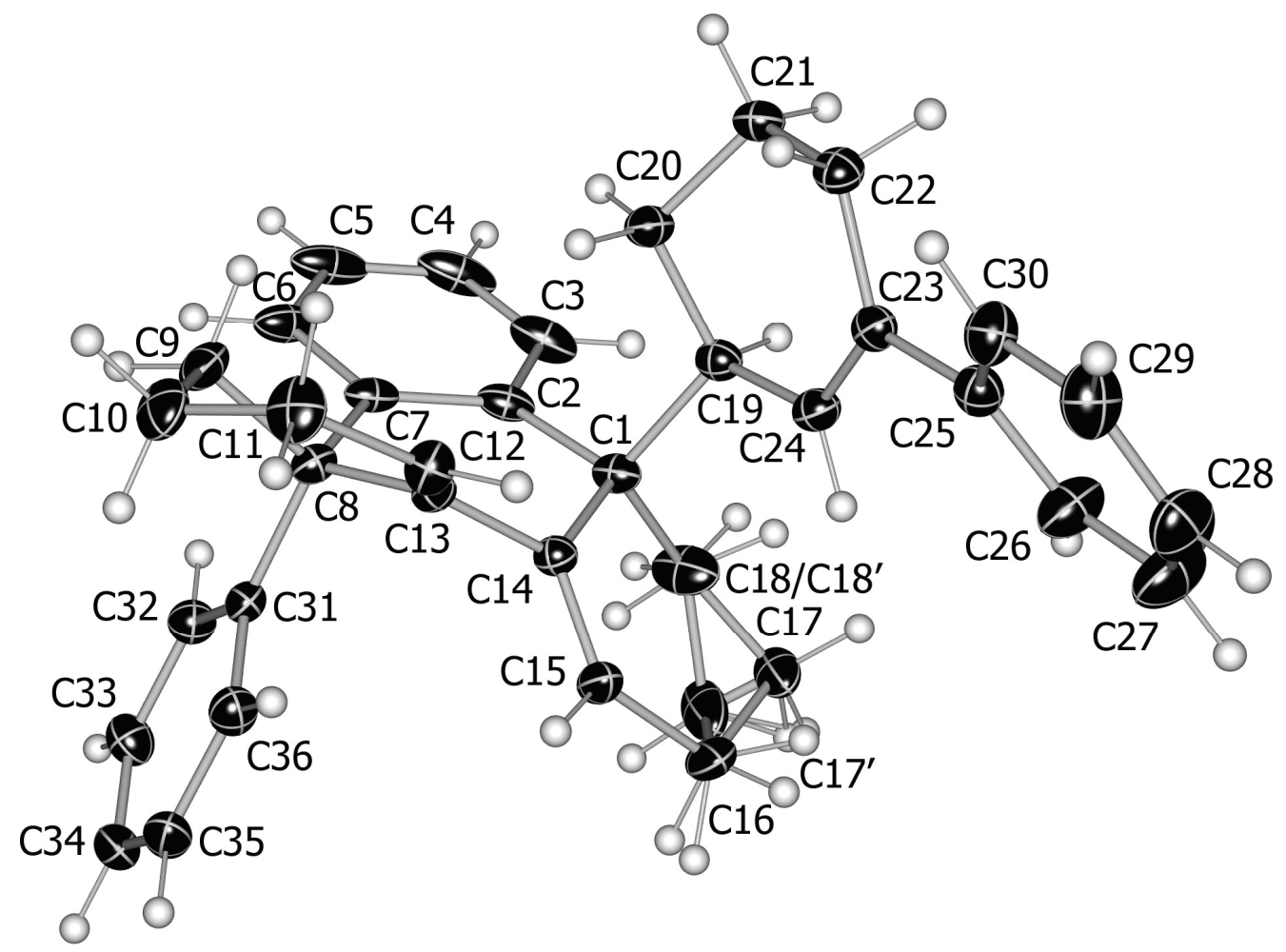

Figure 8-17: ADP representation of the asymmetric unit of $\mathrm{C}_{36} \mathrm{H}_{36}$ (Christl7); the ADP's are depicted at the $50 \%$ probability level.

The asymmetric unit of $\mathrm{C}_{36} \mathrm{H}_{36}$ (Christl7) contains a complete molecule. The symmetry operations of the monoclinic space group $\mathrm{P} 2{ }_{1} / \mathrm{n}$ generate three additional molecules in the unit cell.

The atoms $\mathrm{C} 16, \mathrm{C} 17$ and $\mathrm{C} 18$ of one cyclohexenyl ring and the attached hydrogen atoms are disordered over two positions. The site occupation factors refine to 0.84 and 0.16 . 


\subsection{7 $\mathrm{C}_{16} \mathrm{H}_{20} \mathrm{Cl}_{2} \mathrm{~N}_{2} \mathrm{Si}$ (Klingebiel277)}

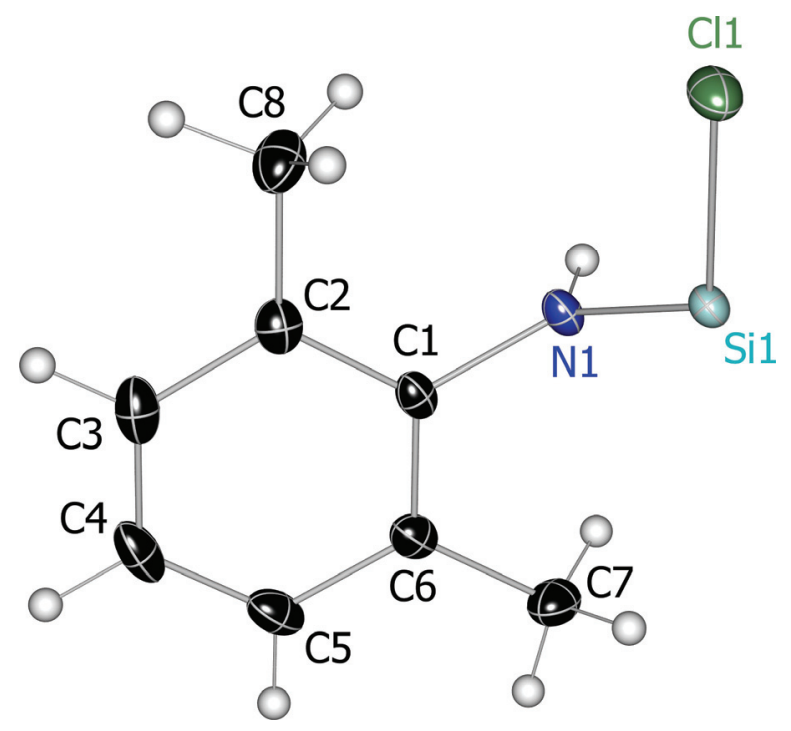

Figure 8-18: ADP representation of the asymmetric unit of $\mathrm{C}_{16} \mathrm{H}_{20} \mathrm{Cl}_{2} \mathrm{~N}_{2} \mathrm{Si}$ (Klingebiel277); the ADP's are depicted at the $50 \%$ probability level.

$\mathrm{C}_{16} \mathrm{H}_{20} \mathrm{Cl}_{2} \mathrm{~N}_{2} \mathrm{Si}$ (Klingebiel277) crystallizes in the monoclinic space group $\mathrm{C} 2 / \mathrm{c}$. Only one half of the molecule is present in the asymmetric unit. The other half is generated by inversion at the center of symmetry, which is located at the position of $\mathrm{Si} 1$.

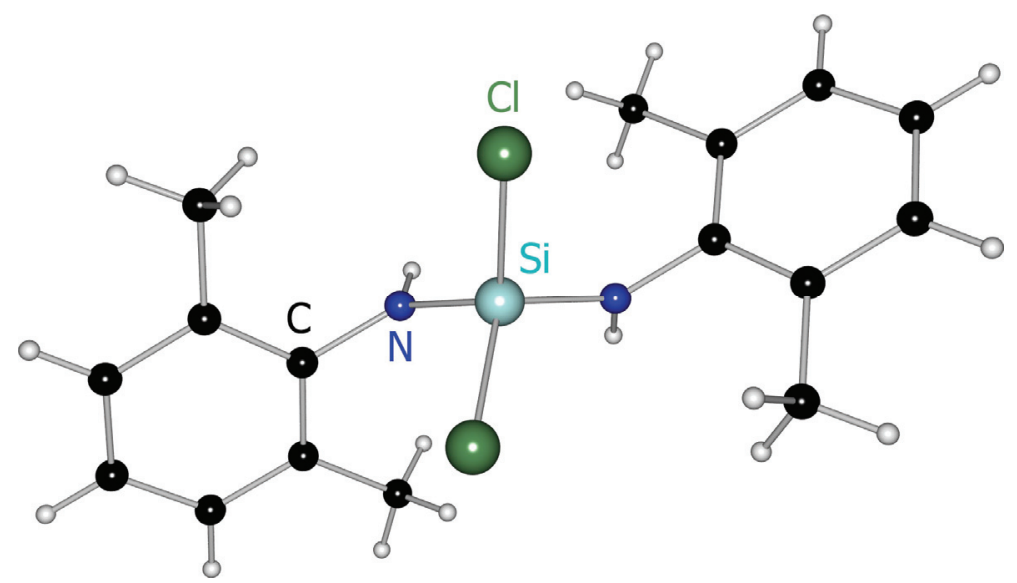

Figure 8-19: Molecular structure of $\mathrm{C}_{16} \mathrm{H}_{20} \mathrm{Cl}_{2} \mathrm{~N}_{2} \mathrm{Si}$ (Klingebiel277). 


\subsection{8 $\mathrm{C}_{24} \mathrm{H}_{54} \mathrm{~B}_{2} \mathrm{~N}_{4} \mathrm{Si}_{2}$ (Klingebiel282)}

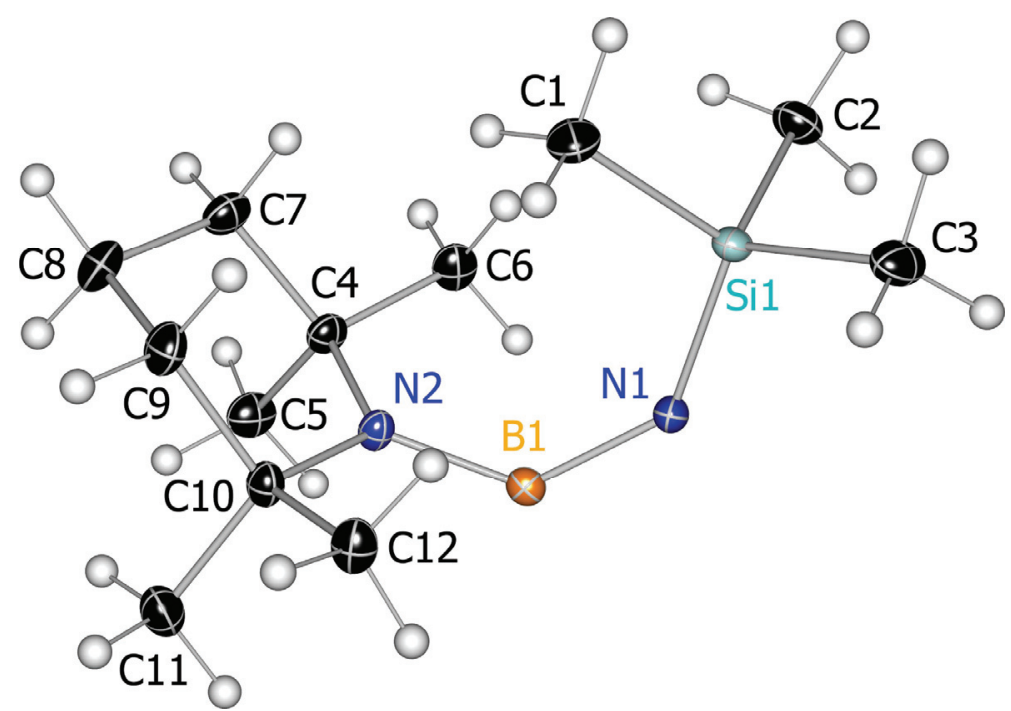

Figure 8-20: ADP representation of the asymmetric unit of $\mathrm{C}_{24} \mathrm{H}_{54} \mathrm{~B}_{2} \mathrm{~N}_{4} \mathrm{Si}_{2}$ (Klingebiel282); the ADP's are depicted at the $50 \%$ probability level.

$\mathrm{C}_{24} \mathrm{H}_{54} \mathrm{~B}_{2} \mathrm{~N}_{4} \mathrm{Si}_{2}$ (Klingebiel282) crystallizes in the orthorhombic spacegroup Pbca. The molecule is completed by inversion of the asymmetric unit, which contains one half of the molecule, at the center of symmetry.

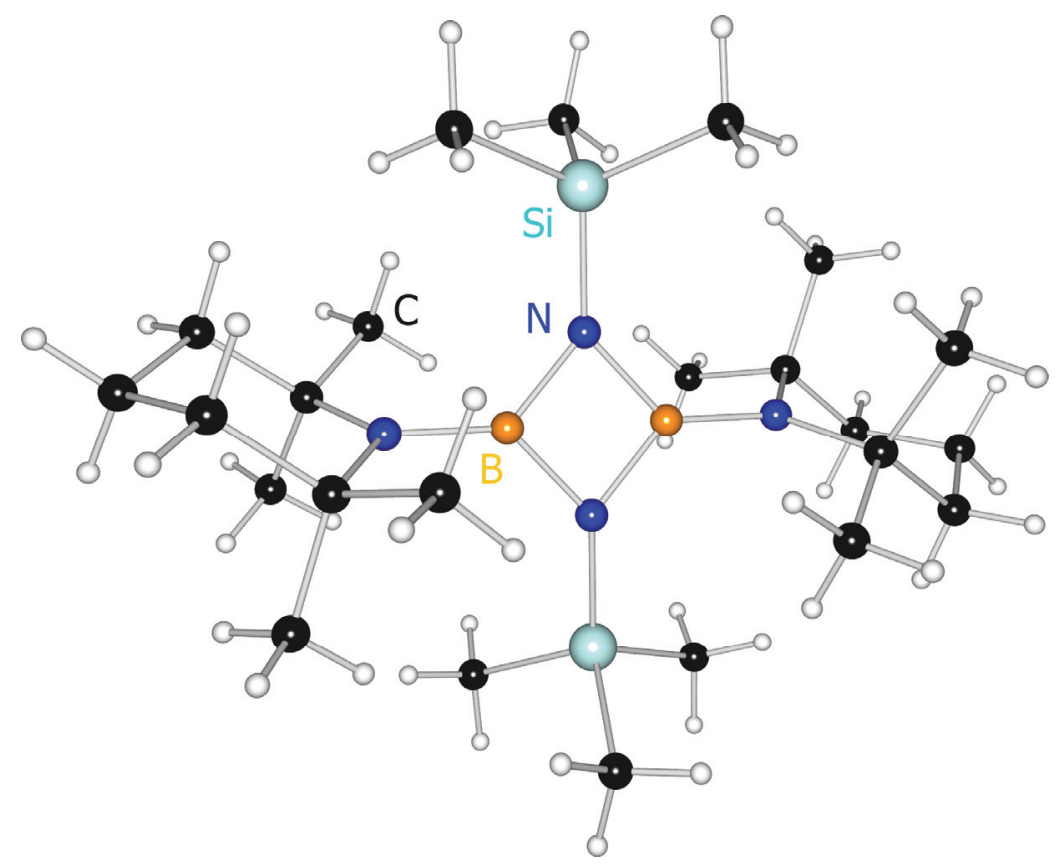

Figure 8-21: Molecular structure of $\mathrm{C}_{24} \mathrm{H}_{54} \mathrm{~B}_{2} \mathrm{~N}_{4} \mathrm{Si}_{2}$ (Klingebiel282). 


\subsection{9 $\mathrm{C}_{36} \mathrm{H}_{88} \mathrm{~B}_{2} \mathrm{~F}_{2} \mathrm{~N}_{6} \mathrm{Si}_{6}$ (Klingebiel3140)}
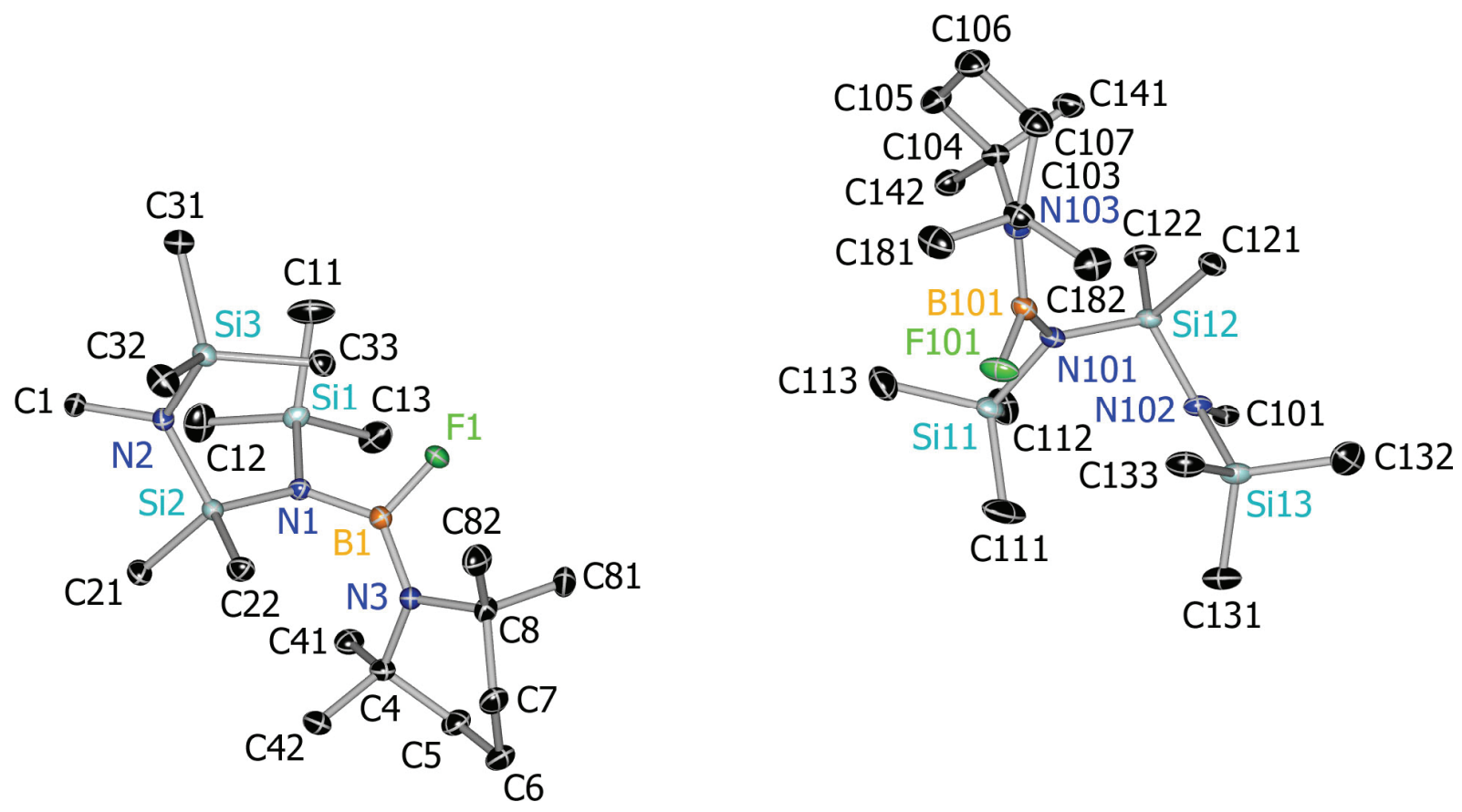

Figure 8-22: ADP representation of the asymmetric unit of $\mathrm{C}_{36} \mathrm{H}_{88} \mathrm{~B}_{2} \mathrm{~F}_{2} \mathrm{~N}_{6} \mathrm{Si}_{6}$ (Klingebiel3140); all hydrogen atoms are omitted for clarity, the ADP's are depicted at the $50 \%$ probability level.

The asymmetric unit of $\mathrm{C}_{36} \mathrm{H}_{88} \mathrm{~B}_{2} \mathrm{~F}_{2} \mathrm{~N}_{6} \mathrm{Si}_{6}$ (Klingebiel3140) contains two molecule halves. Inversion at the origin of the space group $\mathrm{P} \overline{1}$ completes the molecules.

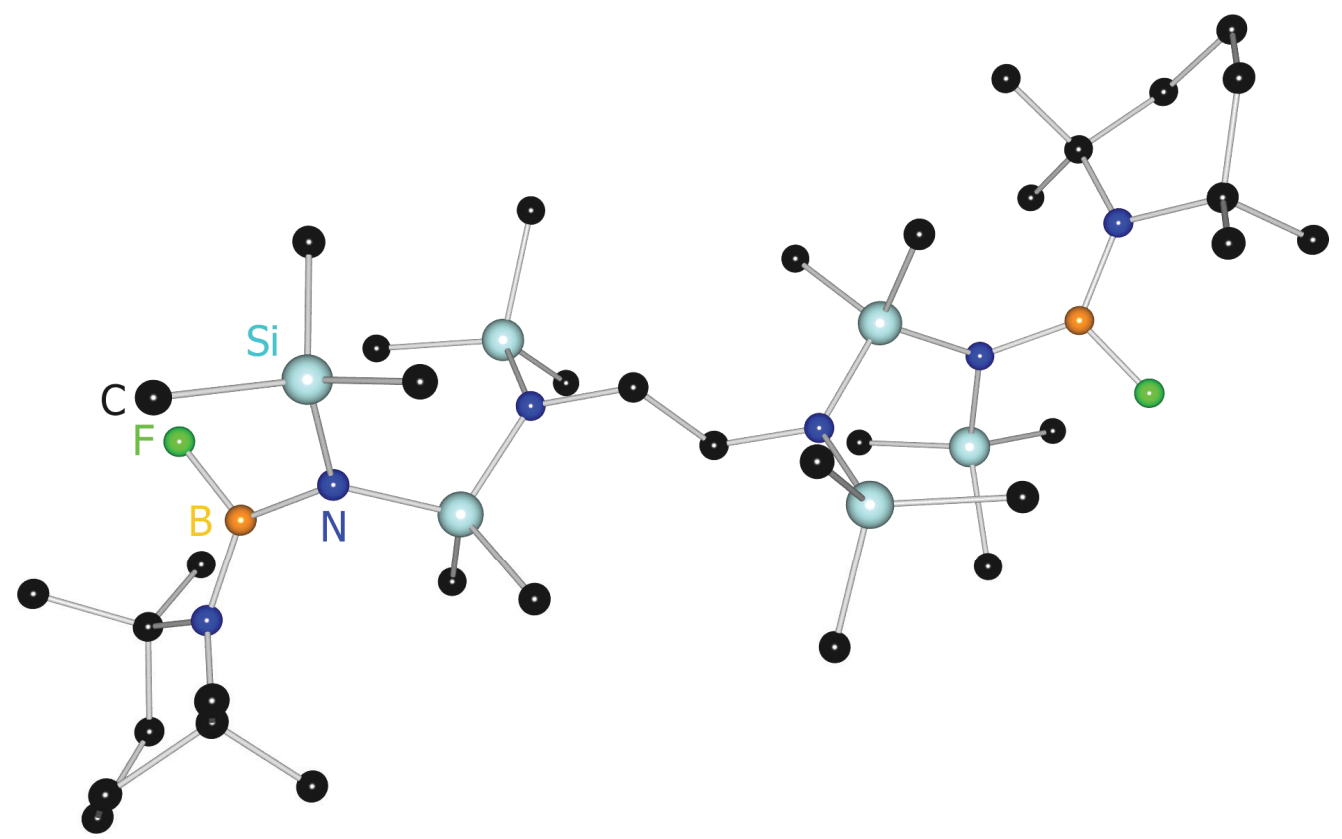

Figure 8-23: Molecular structure of $\mathrm{C}_{36} \mathrm{H}_{88} \mathrm{~B}_{2} \mathrm{~F}_{2} \mathrm{~N}_{6} \mathrm{Si}_{6}$ (Klingebiel3140). 


\subsubsection{0 $\quad \mathrm{C}_{26} \mathrm{H}_{70} \mathrm{~F}_{4} \mathrm{~N}_{4} \mathrm{Si}_{8}$ (Klingebiel3161)}

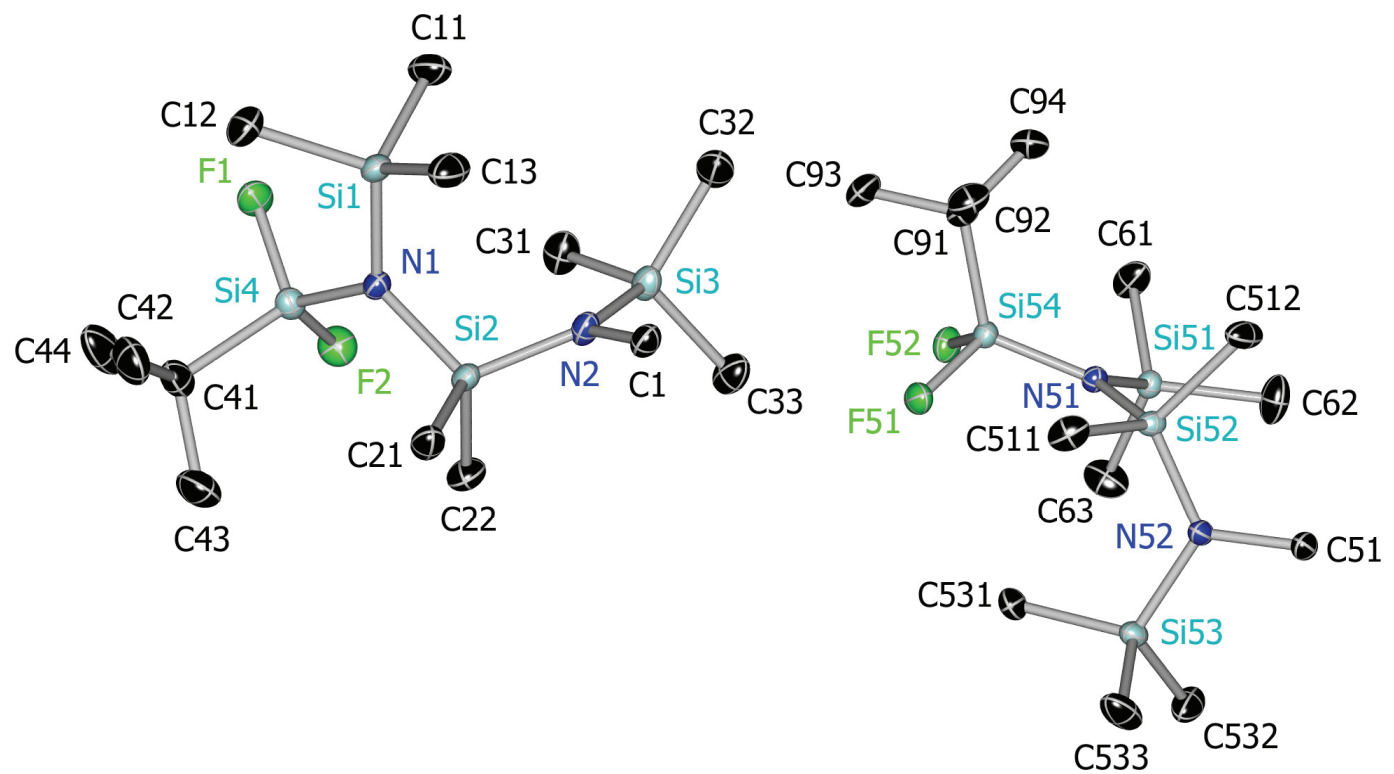

Figure 8-24: ADP representation of the asymmetric unit of $\mathrm{C}_{26} \mathrm{H}_{70} \mathrm{~F}_{4} \mathrm{~N}_{4} \mathrm{Si}_{8}$ (Klingebiel3161); all hydrogen atoms are omitted for clarity, the ADP's are depicted at the $50 \%$ probability level.

The asymmetric unit of $\mathrm{C}_{26} \mathrm{H}_{70} \mathrm{~F}_{4} \mathrm{~N}_{4} \mathrm{Si}_{8}$ (Klingebiel3161) contains two molecule halves. Inversion at the origin of the space group $\mathrm{P} \overline{1}$ completes the molecules.

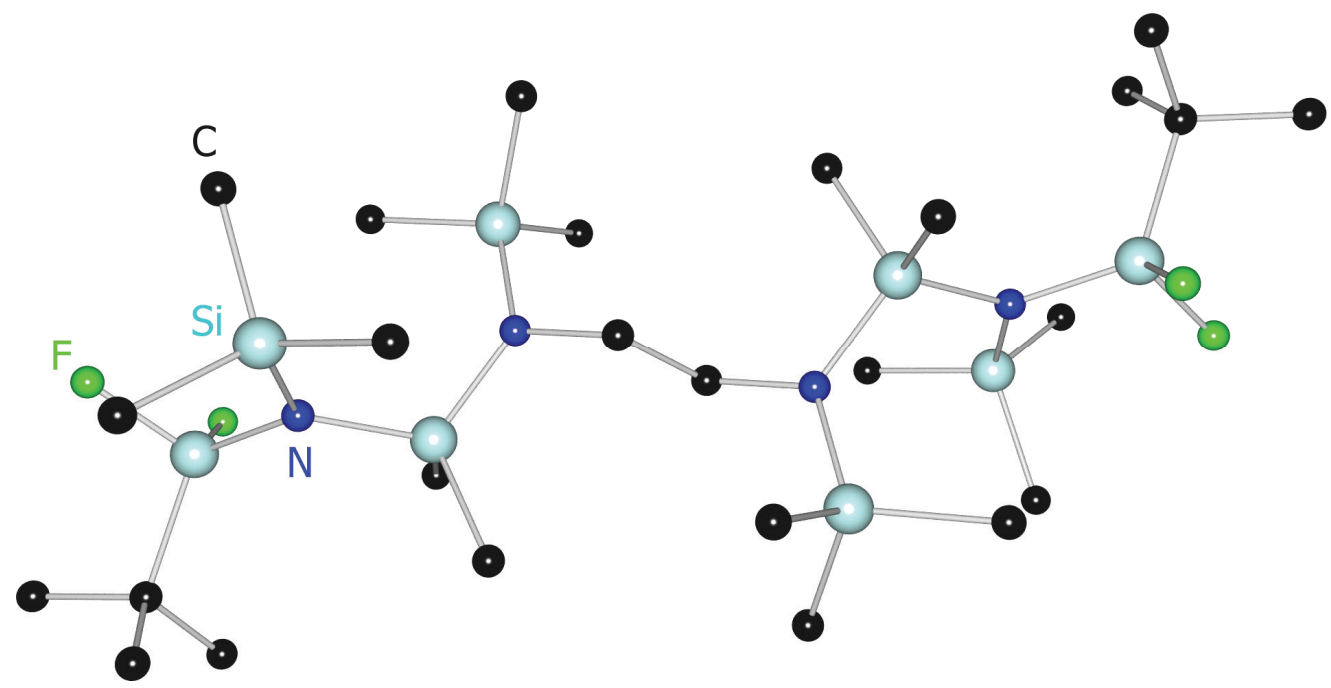

Figure 8-25: Molecular structure of $\mathrm{C}_{26} \mathrm{H}_{70} \mathrm{~F}_{4} \mathrm{~N}_{4} \mathrm{Si}_{8}$ (Klingebiel3161). 


\subsubsection{1 $\quad \mathrm{C}_{24} \mathrm{H}_{34} \mathrm{BFN}_{2} \mathrm{Si}_{3}$ (Klingebiel4524)}

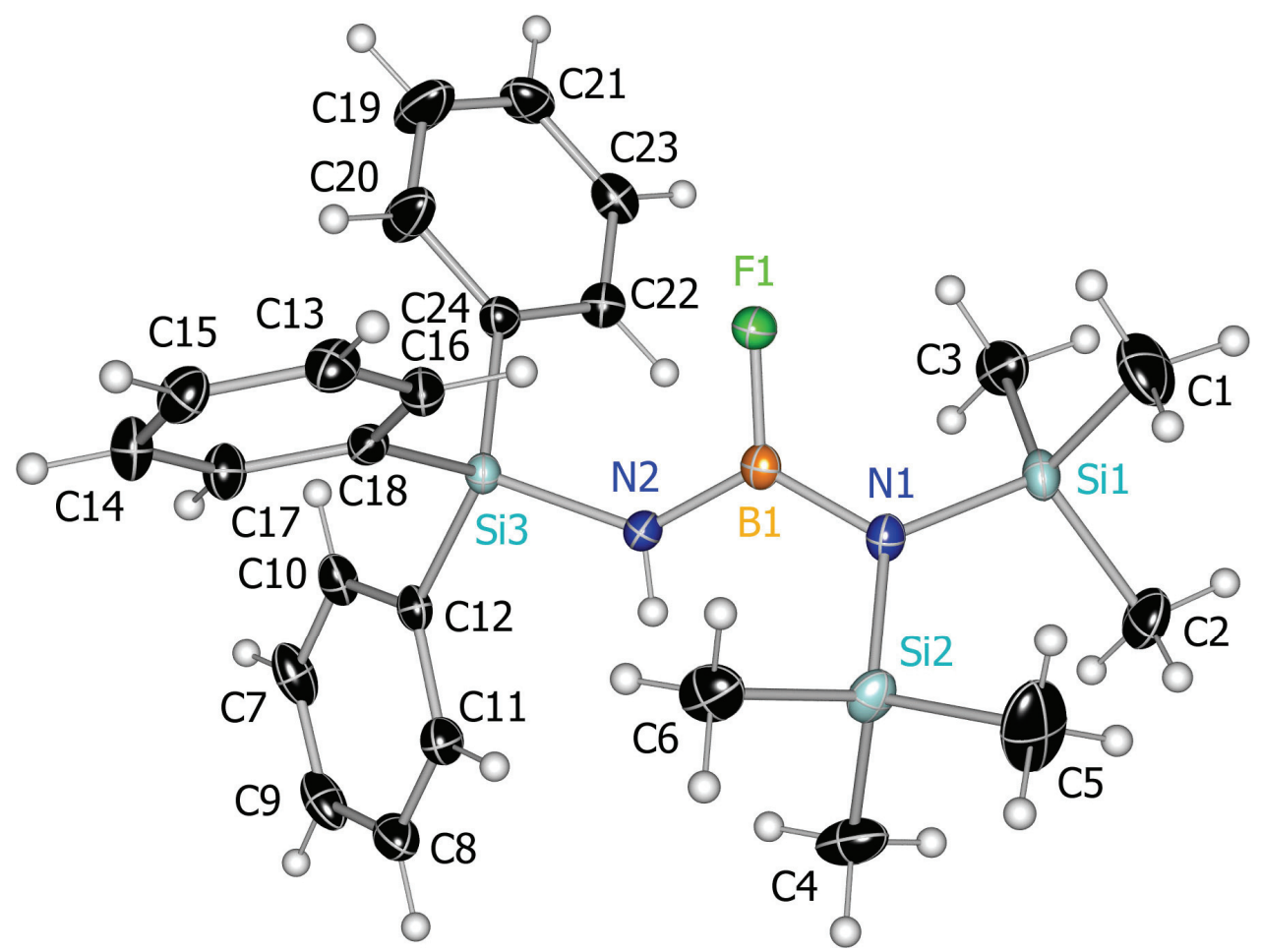

Figure 8-26: ADP representation of the asymmetric unit of $\mathrm{C}_{24} \mathrm{H}_{34} \mathrm{BFN}_{2} \mathrm{Si}_{3}$ (Klingebiel4524); the ADP's are depicted at the $50 \%$ probability level.

$\mathrm{C}_{24} \mathrm{H}_{34} \mathrm{BFN}_{2} \mathrm{Si}_{3}$ (Klingebiel4524) crystallizes in the monoclinic space group $\mathrm{P} 2{ }_{1} / \mathrm{n}$. One complete molecule is contained in the asymmetric unit.

The hydrogen atom at $\mathrm{N} 2$ has been refined freely. 


\subsubsection{2 $\mathrm{C}_{8} \mathrm{H}_{20} \mathrm{AlCl}_{4} \mathrm{NSi}$ (Klingebiel7065)}

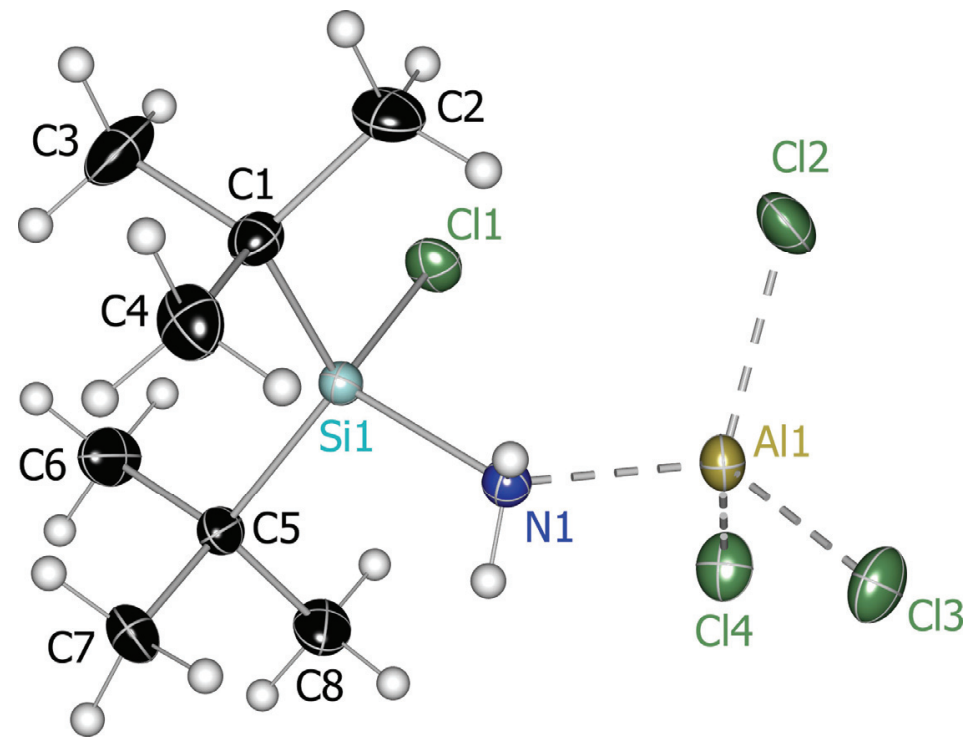

Figure 8-27: ADP representation of the asymmetric unit of $\mathrm{C}_{8} \mathrm{H}_{20} \mathrm{AlCl}_{4} \mathrm{NSi}$ (Klingebiel7065); the ADP's are depicted at the $50 \%$ probability level.

The asymmetric unit of the crystals of $\mathrm{C}_{8} \mathrm{H}_{20} \mathrm{AlCl}_{4} \mathrm{NSi}$ (Klingebiel7065) in the tetragonal space group $\mathrm{P} 4_{2} / \mathrm{n}$ contains a complete molecule. The other three molecules of the unit cell are generated by the symmetry operations of the space group.

The hydrogen atoms at N1 have been refined freely. 


\subsubsection{3 $\mathrm{C}_{28} \mathrm{H}_{31} \mathrm{CIN}_{4} \mathrm{O}_{2} \mathrm{Si}$ (Kost50)}

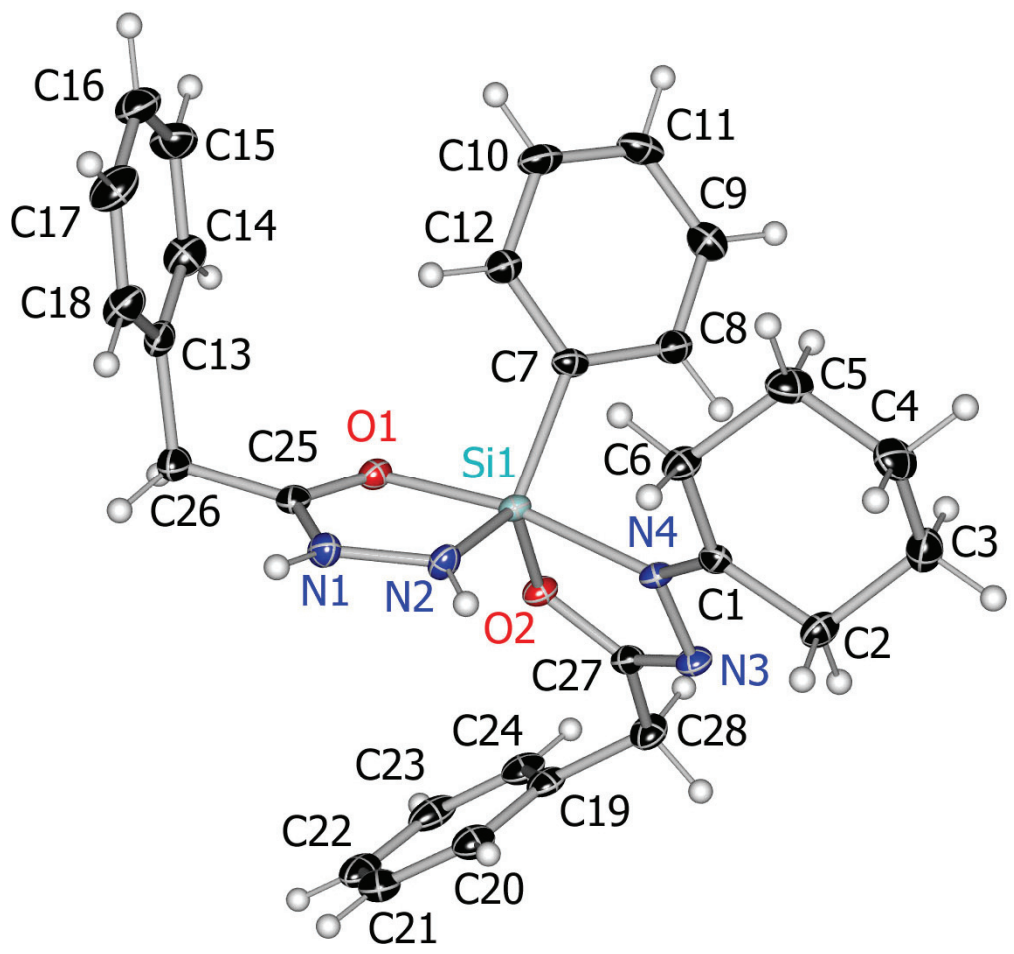

Figure 8-28: ADP representation of the asymmetric unit of $\mathrm{C}_{28} \mathrm{H}_{31} \mathrm{CIN}_{4} \mathrm{O}_{2} \mathrm{Si}$ (Kost50); the ADP's are depicted at the $50 \%$ probability level.

The asymmetric unit of $\mathrm{C}_{28} \mathrm{H}_{31} \mathrm{CIN}_{4} \mathrm{O}_{2} \mathrm{Si}$ (Kost50), which crystallizes in the monoclinic space group $\mathrm{P} 2 / 1 / n$, contains a complete molecule. Three additional molecules are generated in the unit cell by the symmetry operations of the space group.

The hydrogen atoms attached to N1 and N2 have been refined freely. 


\subsubsection{4 $\mathrm{C}_{27} \mathrm{H}_{36} \mathrm{Cl}_{2} \mathrm{~N}_{4} \mathrm{O}_{2} \mathrm{Si}$ (Kost51)}

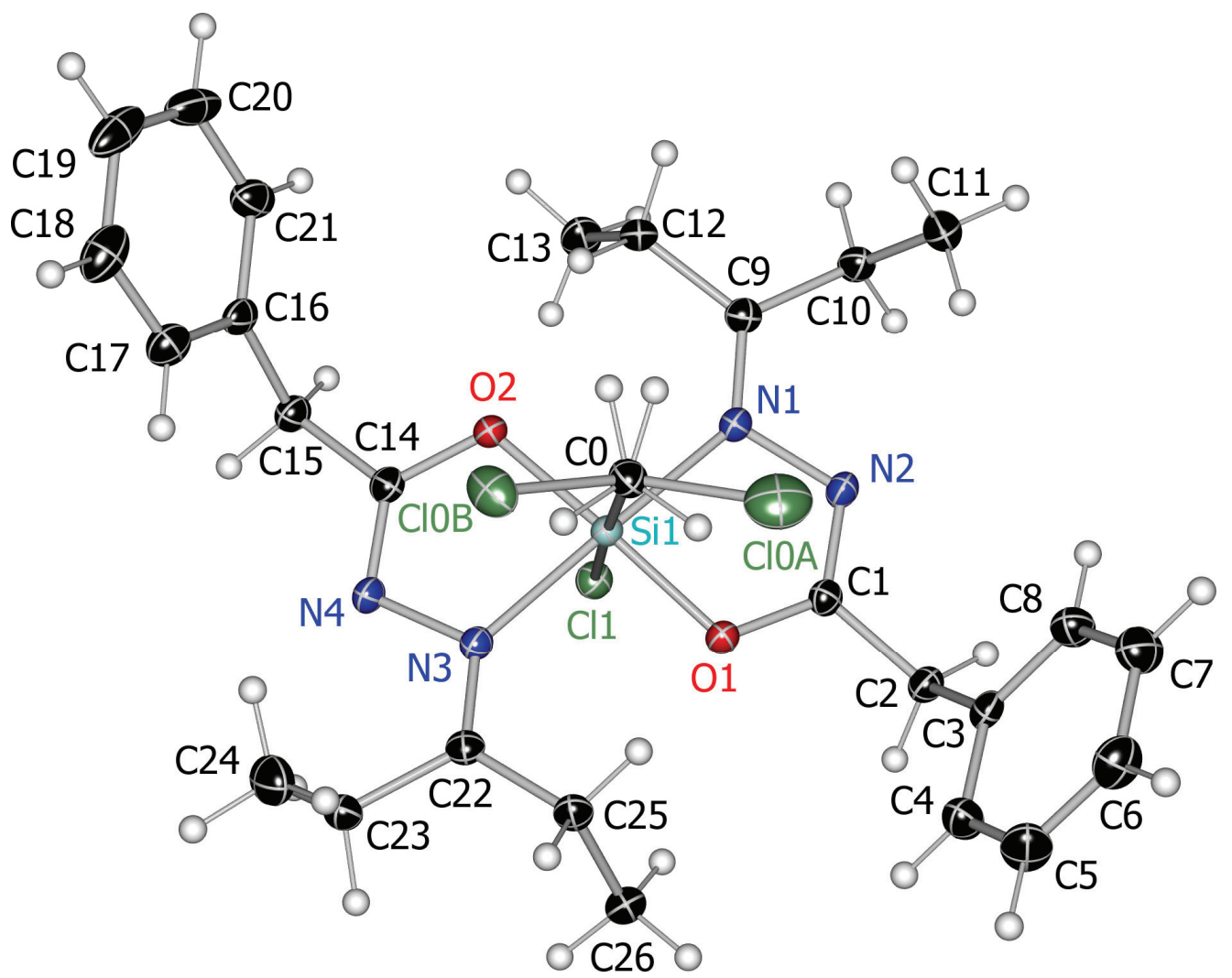

Figure 8-29: ADP representation of the asymmetric unit of $\mathrm{C}_{27} \mathrm{H}_{36} \mathrm{Cl}_{2} \mathrm{~N}_{4} \mathrm{O}_{2} \mathrm{Si}$ (Kost51); the ADP's are depicted at the $50 \%$ probability level.

$\mathrm{C}_{27} \mathrm{H}_{36} \mathrm{Cl}_{2} \mathrm{~N}_{4} \mathrm{O}_{2} \mathrm{Si}$ (Kost51) crystallizes in the triclinic space group $P \overline{1}$. The asymmetric unit contains a complete molecule, which is duplicated by inversion at the center of symmetry.

The organo group attached to Si1 is rotationally disordered over two sites. The sof's refine to 0.94 and 0.06 . 


\subsubsection{5 $\mathrm{C}_{28} \mathrm{H}_{34} \mathrm{Cl}_{2} \mathrm{~N}_{4} \mathrm{O}_{2} \mathrm{Si}$ (Kost52)}

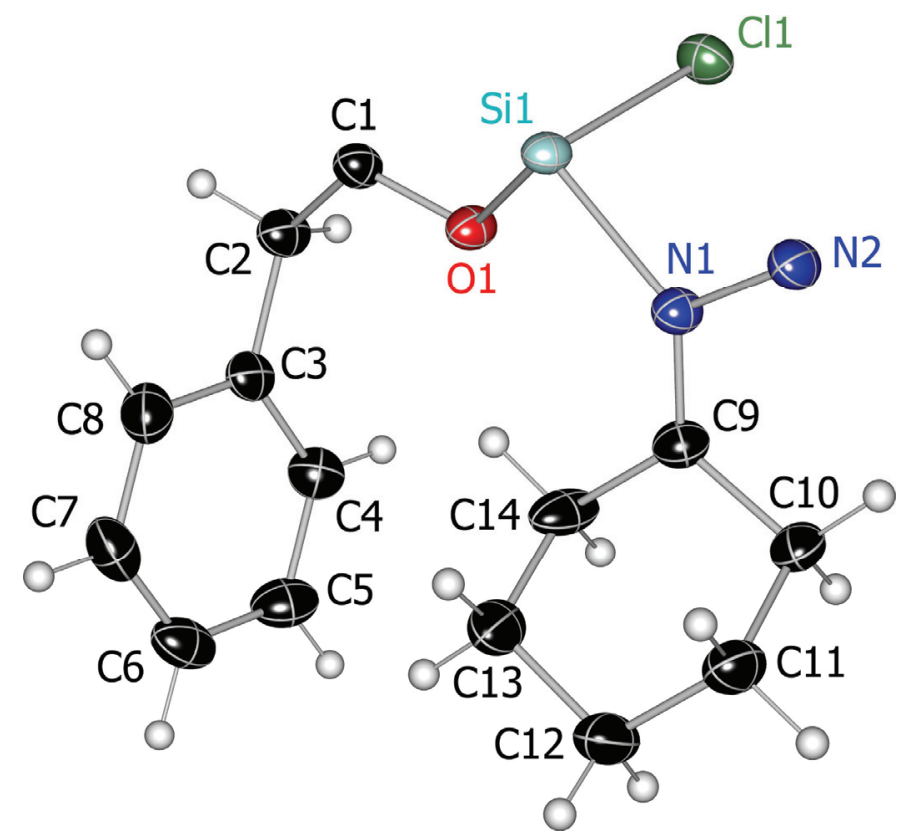

Figure 8-30: ADP representation of the asymmetric unit of $\mathrm{C}_{28} \mathrm{H}_{34} \mathrm{Cl}_{2} \mathrm{~N}_{4} \mathrm{O}_{2} \mathrm{Si}$ (Kost52); the ADP's are depicted at the $50 \%$ probability level.

$\mathrm{C}_{28} \mathrm{H}_{34} \mathrm{Cl}_{2} \mathrm{~N}_{4} \mathrm{O}_{2} \mathrm{Si}$ (Kost52) crystallizes in the triclinic space group $\mathrm{P} \overline{1}$. The asymmetric unit contains only one half of the molecule. Inversion at the center of symmetry completes the cell content.

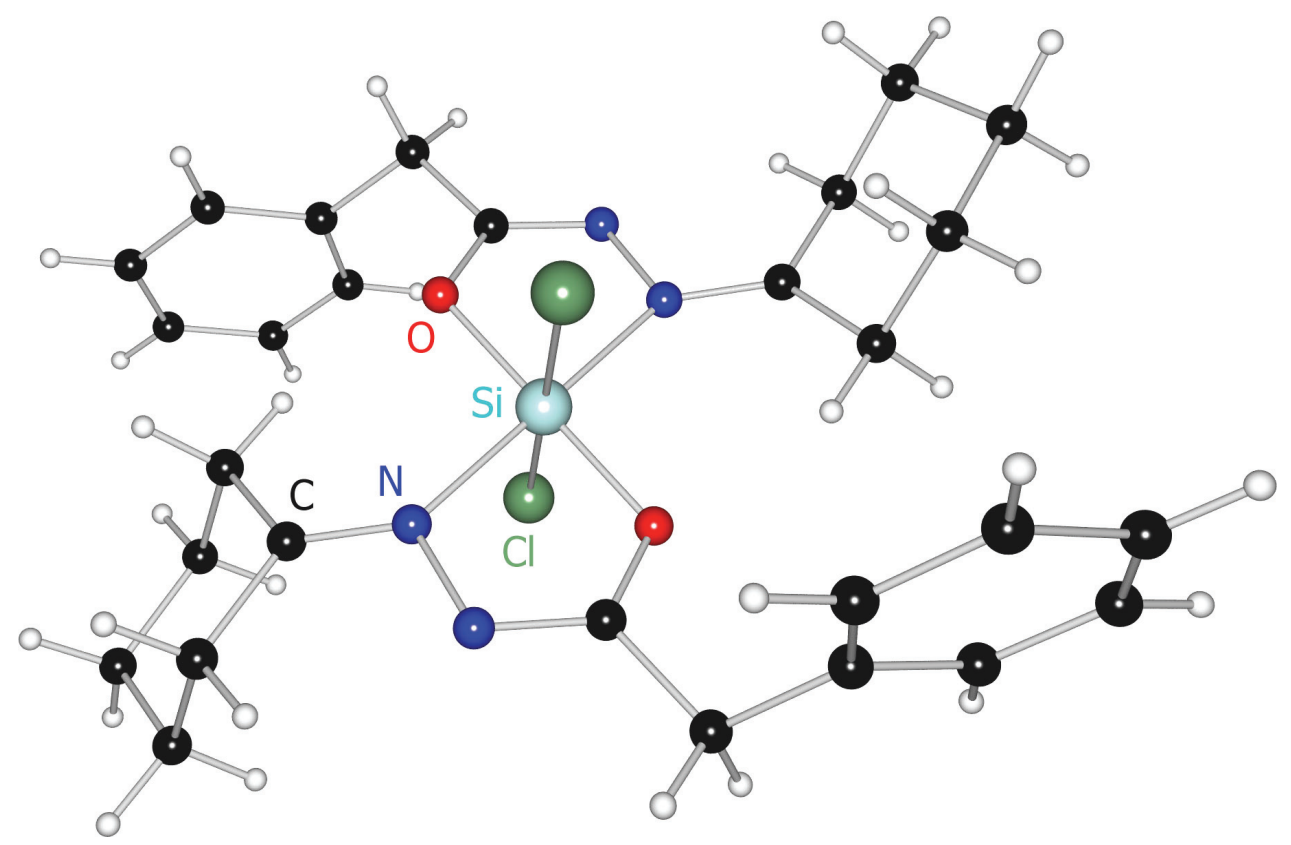

Figure 8-31: Molecular structure of $\mathrm{C}_{28} \mathrm{H}_{34} \mathrm{Cl}_{2} \mathrm{~N}_{4} \mathrm{O}_{2} \mathrm{Si}$ (Kost52). 


\subsubsection{6 $\mathrm{C}_{31} \mathrm{H}_{27} \mathrm{~F}_{9} \mathrm{~N}_{6} \mathrm{O}_{3} \mathrm{Si}($ Kost59)}

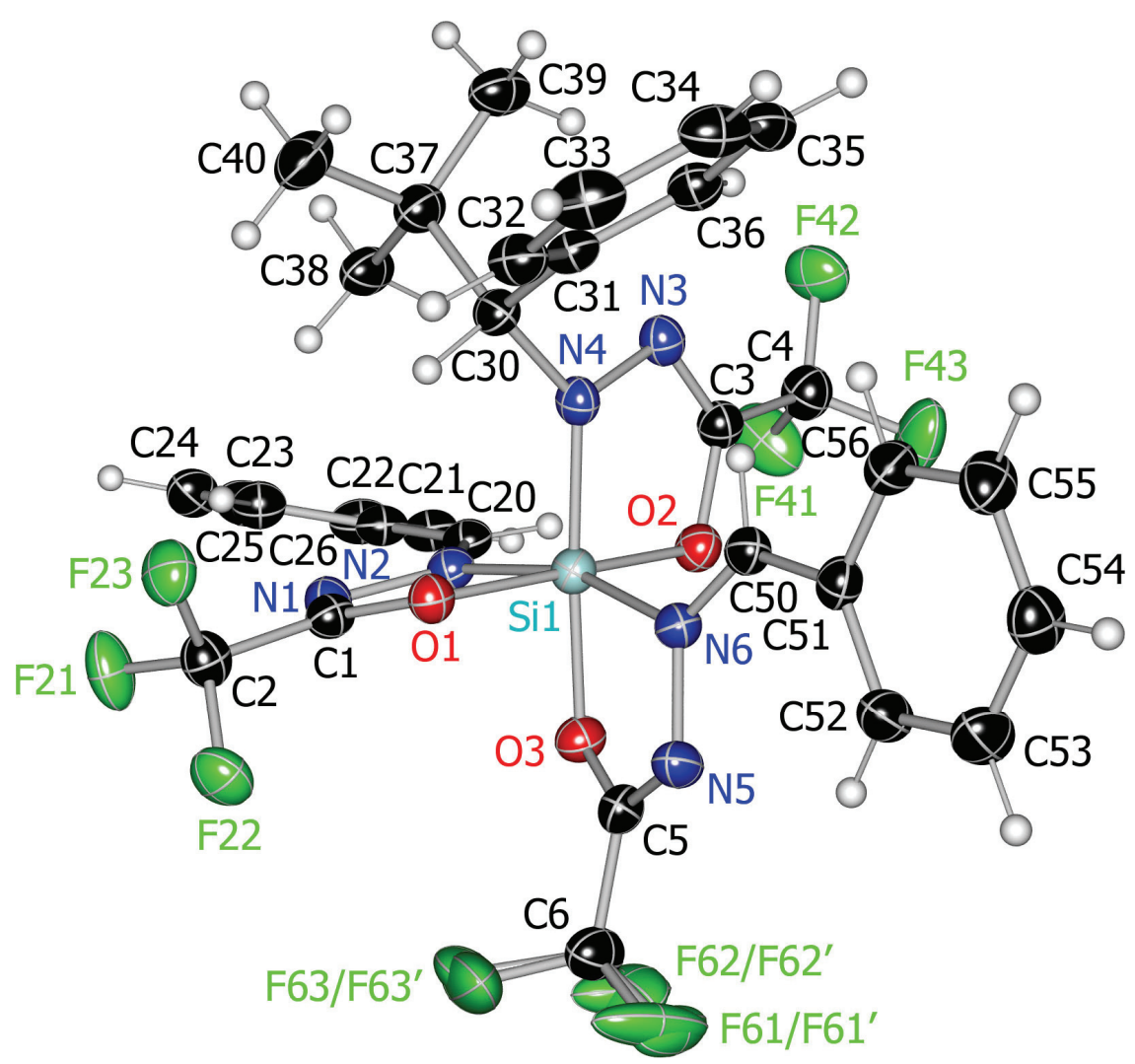

Figure 8-32: ADP representation of the asymmetric unit of $\mathrm{C}_{31} \mathrm{H}_{27} \mathrm{~F}_{9} \mathrm{~N}_{6} \mathrm{O}_{3} \mathrm{Si}$ (Kost59); the ADP's are depicted at the $50 \%$ probability level.

The asymmetric unit of the crystals of $\mathrm{C}_{31} \mathrm{H}_{27} \mathrm{~F}_{9} \mathrm{~N}_{6} \mathrm{O}_{3} \mathrm{Si}$ (Kost59) in the orthorhombic space group Pbca contains a complete molecule.

The $\mathrm{CF}_{3}$ group containing $\mathrm{C} 6$ is disordered over two sites. The sof's refine to 0.53 and 0.47 .

The X-ray experiment for Kost59 has been performed on a Bruker Cu rotating anode $(\lambda=1.54178 \AA)$ equipped with an APEX I CCD detector. Data processing, data reduction and structure refinement were performed as described for the Bruker sealed tube system equipped with an APEX I CCD detector. 


\subsubsection{7 $\mathrm{C}_{22} \mathrm{H}_{27} \mathrm{CIN}_{4} \mathrm{O}_{2} \mathrm{Si}(\mathrm{Kost62})$}

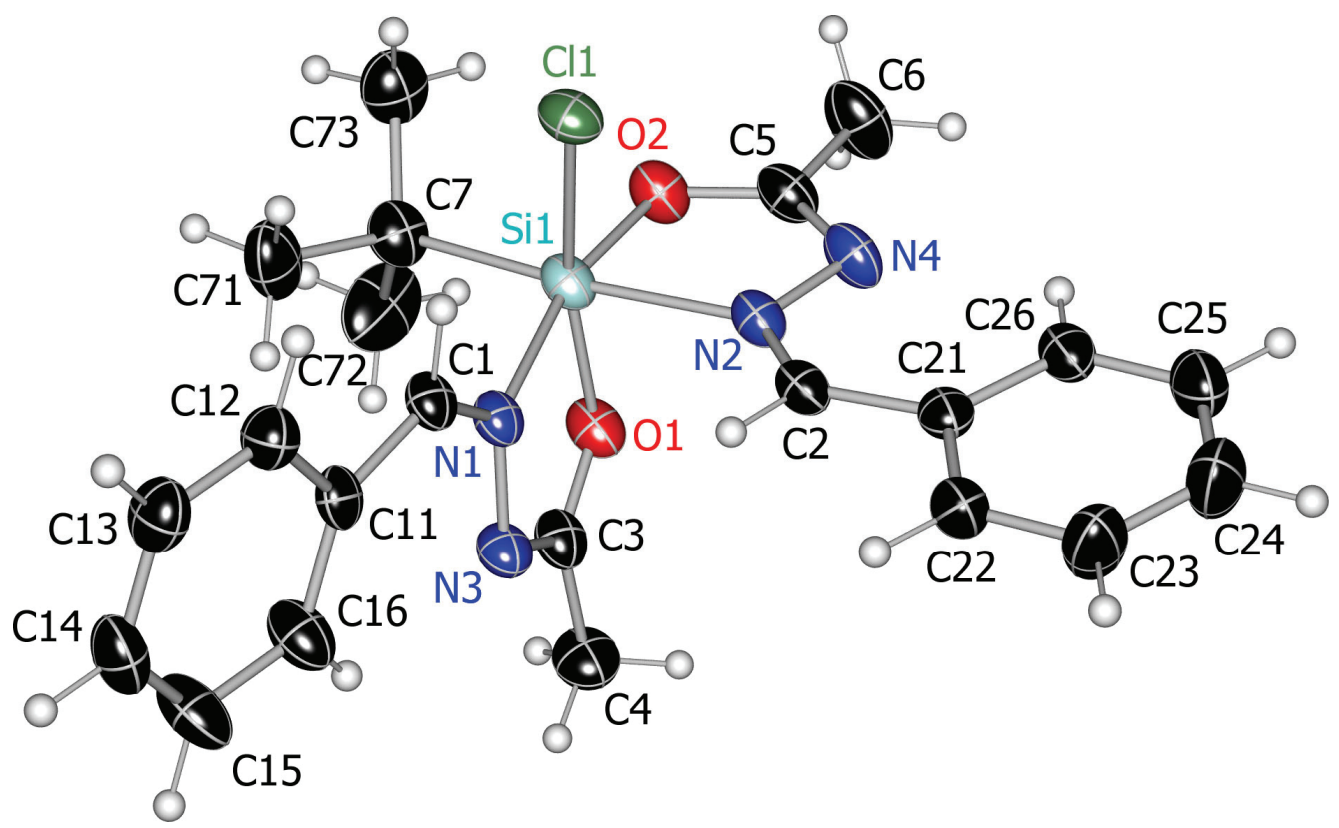

Figure 8-33: ADP representation of the asymmetric unit of $\mathrm{C}_{22} \mathrm{H}_{27} \mathrm{CIN}_{4} \mathrm{O}_{2} \mathrm{Si}$ (Kost62); the ADP's are depicted at the $50 \%$ probability level.

$\mathrm{C}_{22} \mathrm{H}_{27} \mathrm{ClN}_{4} \mathrm{O}_{2} \mathrm{Si}$ (Kost62) crystallizes in the monoclinic space group $\mathrm{P} 2 / 1 / \mathrm{n}$. The asymmetric unit contains a complete molecule, which is reproduced three times by the symmetry operators of the space group. 


\subsubsection{Crystallographic Tables for the Structures from Cooperations}

Table 8-4: Crystal data and structure refinement for the compounds Breuning1, Christl1, and Christl3.

\begin{tabular}{|c|c|c|c|}
\hline compound & Breuning1 & Christl1 & Christl3 \\
\hline identification code & Sparta & Christl1 & Christl3 \\
\hline formula hill & $\mathrm{C}_{15} \mathrm{H}_{27} \mathrm{~B}_{2} \mathrm{~N}_{2}$ & $\mathrm{C}_{19} \mathrm{H}_{22} \mathrm{O}$ & $\mathrm{C}_{20} \mathrm{H}_{27} \mathrm{~N}_{3}$ \\
\hline molecular mass $[\mathrm{g} / \mathrm{mol}]$ & 315.30 & 266.37 & 309.45 \\
\hline crystal size $[\mathrm{mm}]$ & $0.4 \times 0.4 \times 0.25$ & $0.2 \times 0.2 \times 0.2$ & $0.25 \times 0.05 \times 0.05$ \\
\hline temperature $[\mathrm{K}]$ & $100(2)$ & $173(2)$ & $173(2)$ \\
\hline crystal system & monoclinic & monoclinic & monoclinic \\
\hline space group & $\mathrm{P} 2_{1}$ & $\mathrm{P} 2_{1}$ & $\mathrm{P} 2{ }_{1} / \mathrm{c}$ \\
\hline$a[\AA]$ & $8.1605(6)$ & $7.3979(7)$ & $17.140(3)$ \\
\hline $\mathrm{b}[\AA]]$ & $10.6443(8)$ & $9.4054(8)$ & $7.2711(12)$ \\
\hline$c[\AA]$ & $8.4004(7)$ & $10.9015(10)$ & $16.105(3)$ \\
\hline$\alpha\left[^{\circ}\right]$ & 90.00 & 90.00 & 90.00 \\
\hline$\beta\left[^{\circ}\right]$ & $100.1710(10)$ & $98.5930(10)$ & $116.156(4)$ \\
\hline$Y\left[^{\circ}\right]$ & 90.00 & 90.00 & 90.00 \\
\hline$V\left[\AA^{3}\right]$ & $718.22(10)$ & $750.01(12)$ & $1801.7(5)$ \\
\hline Z & 2 & 2 & 4 \\
\hline$\rho_{\text {calc }}\left[\mathrm{Mg} / \mathrm{m}^{3}\right]$ & 1.458 & 1.179 & 1.141 \\
\hline$\mu\left[\mathrm{mm}^{-1}\right]$ & 2.848 & 0.071 & 0.068 \\
\hline$F(000)$ & 332 & 288 & 672 \\
\hline$\theta$ range $\left[{ }^{\circ}\right]$ & $2.46-26.38$ & $2.78-26.37$ & $2.53-25.07$ \\
\hline reflections collected & 15324 & 16114 & 19171 \\
\hline unique reflections & 2930 & 3058 & 3202 \\
\hline min./max. transmission & $0.771 / 0.98$ & $0.89 / 0.98$ & $0.748 / 0.98$ \\
\hline$R_{\text {int }}$ & 0.0169 & 0.0186 & 0.0427 \\
\hline data/restraints/parameters & 2930/1/167 & $3058 / 1 / 269$ & $3202 / 0 / 219$ \\
\hline$g 1 / g 2$ & $0.0389 / 0.2142$ & $0.0545 / 0.0934$ & $0.0347 / 1.2697$ \\
\hline$R 1$ (all data) & 0.0196 & 0.0335 & 0.0802 \\
\hline$R 1(I>2 \sigma(I))$ & 0.0195 & 0.0329 & 0.0727 \\
\hline$w R 2$ (all data) & 0.0524 & 0.0863 & 0.1407 \\
\hline$w R 2(1>2 \sigma(I))$ & 0.0523 & 0.0857 & 0.1371 \\
\hline GoF & 1.039 & 1.072 & 1.237 \\
\hline largest diff. peak/hole [e/Å3] & $0.473 /-0.178$ & $0.230 /-0.176$ & $0.214 /-0.191$ \\
\hline
\end{tabular}


Table 8-5: Crystal data and structure refinement for the compounds Christl5, Christl6, and Christl7.

\begin{tabular}{|c|c|c|c|}
\hline compound & Christ15 & Christl6 & Christl7 \\
\hline identification code & Christl5 & Christl6 & Christl7 \\
\hline formula hill & $\mathrm{C}_{18} \mathrm{H}_{22} \mathrm{~N}_{4} \mathrm{O}_{2}$ & $\mathrm{C}_{19} \mathrm{H}_{16}$ & $\mathrm{C}_{36} \mathrm{H}_{36}$ \\
\hline molecular mass $[\mathrm{g} / \mathrm{mol}]$ & 326.40 & 244.32 & 468.65 \\
\hline crystal size $[\mathrm{mm}]$ & $0.4 \times 0.3 \times 0.2$ & $0.4 \times 0.2 \times .0 .1$ & $0.25 \times 0.2 \times 0.2$ \\
\hline temperature $[\mathrm{K}]$ & $100(2)$ & $133(2)$ & $100(2)$ \\
\hline crystal system & orthorhombic & monoclinic & monoclinic \\
\hline space group & Pbca & $\mathrm{P} 2{ }_{1} / \mathrm{n}$ & $\mathrm{P} 2{ }_{1} / \mathrm{n}$ \\
\hline $\mathrm{a}[\AA]$ & $15.3012(10)$ & $11.023(2)$ & $16.6541(8)$ \\
\hline $\mathrm{b}[\AA]]$ & $14.4327(9)$ & $5.3089(11)$ & $9.7116(5)$ \\
\hline$c[\AA]$ & $15.4683(10)$ & $22.274(5)$ & $17.2645(8)$ \\
\hline$\alpha\left[^{\circ}\right]$ & 90.00 & 90.00 & 90.00 \\
\hline$\beta\left[^{\circ}\right]$ & 90.00 & $97.05(3)$ & $113.6120(10)$ \\
\hline Y [ $\left.{ }^{\circ}\right]$ & 90.00 & 90.00 & 90.00 \\
\hline $\operatorname{V}\left[\AA^{3}\right]$ & $3416.0(4)$ & $1293.6(5)$ & $2558.5(2)$ \\
\hline Z & 8 & 4 & 4 \\
\hline$\rho_{\text {calc }}\left[\mathrm{Mg} / \mathrm{m}^{3}\right]$ & 1.269 & 1.254 & 1.217 \\
\hline$\mu\left[\mathrm{mm}^{-1}\right]$ & 0.085 & 0.071 & 0.068 \\
\hline$F(000)$ & 1392 & 520 & 1008 \\
\hline$\theta$ range $\left[^{\circ}\right]$ & $2.34-26.38$ & $1.84-24.71$ & $1.44-28.28$ \\
\hline reflections collected & 36910 & 7461 & 20782 \\
\hline unique reflections & 3496 & 2452 & 6004 \\
\hline min./max. transmission & $0.892 / 0.98$ & - & $0.88 / 0.97$ \\
\hline$R_{\text {int }}$ & 0.0319 & 0.0335 & 0.0364 \\
\hline data/restraints/parameters & $3496 / 0 / 223$ & $2452 / 0 / 184$ & $6004 / 12 / 335$ \\
\hline$g 1 / g 2$ & $0.0607 / 1.2596$ & $0.0462 / 0.3146$ & $0.0959 / 0.3554$ \\
\hline$R 1$ (all data) & 0.0463 & 0.0417 & 0.0556 \\
\hline$R 1(/>2 \sigma(I))$ & 0.0404 & 0.0338 & 0.0465 \\
\hline$w R 2$ (all data) & 0.1092 & 0.0867 & 0.1516 \\
\hline$w R 2(1>2 \sigma(I))$ & 0.1047 & 0.0833 & 0.1366 \\
\hline GoF & 1.032 & 1.039 & 1.124 \\
\hline largest diff. peak/hole [e/Å3] & $0.351 /-0.177$ & $0.160 /-0.135$ & $0.468 /-0.389$ \\
\hline
\end{tabular}


Table 8-6: Crystal data and structure refinement for the compounds Klingebiel277, Klingebiel282, and Klingebiel3140.

\begin{tabular}{|c|c|c|c|}
\hline compound & Klingebiel277 & Klingebiel282 & Klingebiel3140 \\
\hline identification code & uwe277 & uwe282 & Matthes3140 \\
\hline formula hill & $\mathrm{C}_{16} \mathrm{H}_{20} \mathrm{Cl}_{2} \mathrm{~N}_{2} \mathrm{Li}_{2}$ & $\mathrm{C}_{24} \mathrm{H}_{54} \mathrm{~B}_{2} \mathrm{~N}_{4} \mathrm{Si}_{2}$ & $\mathrm{C}_{36} \mathrm{H}_{88} \mathrm{~B}_{2} \mathrm{~F}_{2} \mathrm{~N}_{6} \mathrm{Si}_{6}$ \\
\hline molecular mass $[\mathrm{g} / \mathrm{mol}]$ & 339.33 & 476.51 & 833.28 \\
\hline crystal size $[\mathrm{mm}]$ & $0.25 \times 0.20 \times 0.10$ & $0.1 \times 0.05 \times 0.05$ & $0.35 \times 0.3 \times 0.2$ \\
\hline temperature $[\mathrm{K}]$ & $100(2)$ & $100(2)$ & $100(2)$ \\
\hline crystal system & monoclinic & orthorhombic & triclinic \\
\hline space group & $\mathrm{C} 2 / \mathrm{c}$ & Pbca & $P \overline{1}$ \\
\hline $\mathrm{a}[\AA]$ & $14.1823(10)$ & $13.0767(5)$ & $9.2195(9)$ \\
\hline $\mathrm{b}[\AA]$ & $8.8223(6)$ & $11.0568(4)$ & $14.4881(13)$ \\
\hline$c[\AA]$ & $13.4525(12)$ & 19.9994(8) & $18.6091(17)$ \\
\hline$\alpha\left[^{\circ}\right]$ & 90.00 & 90.00 & $83.5690(10)$ \\
\hline$\beta\left[^{\circ}\right]$ & 90.08 & 90.00 & $87.3050(10)$ \\
\hline$Y\left[^{\circ}\right]$ & 90.00 & 90.00 & $89.4840(10)$ \\
\hline $\mathrm{V}\left[\AA^{3}\right]$ & $1683.2(2)$ & $2891.64(19)$ & $2467.3(4)$ \\
\hline Z & 4 & 4 & 2 \\
\hline$\rho_{\text {calc }}\left[\mathrm{Mg} / \mathrm{m}^{3}\right]$ & 1.339 & 1.095 & 1.122 \\
\hline$\mu\left[\mathrm{mm}^{-1}\right]$ & 0.452 & 0.141 & 0.208 \\
\hline$F(000)$ & 712 & 1056 & 916 \\
\hline$\theta$ range $\left[{ }^{\circ}\right]$ & $2.72-26.40$ & $2.56-26.09$ & $1.41-28.26$ \\
\hline reflections collected & 31803 & 46203 & 54941 \\
\hline unique reflections & 1726 & 3264 & 11491 \\
\hline min./max. transmission & $0.8954 / 0.9562$ & $0.9293 / 0.9965$ & $0.87 / 0.98$ \\
\hline$R_{\text {int }}$ & 0.0147 & 0.0324 & 0.0199 \\
\hline data/restraints/parameters & $1726 / 0 / 98$ & $2872 / 0 / 152$ & $11491 / 0 / 493$ \\
\hline$g 1 / g 2$ & $0.0337 / 2.0433$ & $0.0450 / 1.4579$ & $0.0581 / 1.2030$ \\
\hline$R 1$ (all data) & 0.0254 & 0.0387 & 0.0411 \\
\hline$R 1(I>2 \sigma(I))$ & 0.0248 & 0.0341 & 0.0365 \\
\hline$w R 2$ (all data) & 0.0676 & 0.0897 & 0.1145 \\
\hline$w R 2(I>2 \sigma(I))$ & 0.0672 & 0.0868 & 0.1044 \\
\hline GoF & 1.058 & 1.061 & 1.162 \\
\hline largest diff. peak/hole [e/Å3] & $0.363 /-0.220$ & $0.359 /-0.251$ & $0.570 /-0.401$ \\
\hline
\end{tabular}


Table 8-7: Crystal data and structure refinement for the compounds Klingebiel3161, Klingebiel4524, and Klingebiel7065.

\begin{tabular}{|c|c|c|c|}
\hline compound & Klingebiel3161 & Klingebiel4524 & Klingebiel7065 \\
\hline identification code & Matthes3161 & Matthes4524 & Matthes7065 \\
\hline formula hill & $\mathrm{C}_{26} \mathrm{H}_{70} \mathrm{~F}_{4} \mathrm{~N}_{4} \mathrm{Si}_{8}$ & $\mathrm{C}_{24} \mathrm{H}_{34} \mathrm{BFN}_{2} \mathrm{Si}_{3}$ & $\mathrm{C}_{16} \mathrm{H}_{40} \mathrm{Al}_{2} \mathrm{Cl}_{8} \mathrm{~N}_{2} \mathrm{Si}_{2}$ \\
\hline molecular mass $[\mathrm{g} / \mathrm{mol}]$ & 739.58 & 464.61 & 654.24 \\
\hline crystal size $[\mathrm{mm}]$ & $0.2 \times 0.2 \times 0.04$ & $0.25 \times 0.2 \times 0.15$ & $0.35 \times 0.25 \times 0.25$ \\
\hline temperature $[\mathrm{K}]$ & $100(2)$ & $100(2)$ & $100(2)$ \\
\hline crystal system & triclinic & monoclinic & tetragonal \\
\hline space group & $P \overline{1}$ & $\mathrm{P} 2{ }_{1} / \mathrm{n}$ & $\mathrm{P} 4_{2} / \mathrm{n}$ \\
\hline $\mathrm{a}[\AA]$ & $9.3365(6)$ & $10.5639(5)$ & $17.9634(4)$ \\
\hline $\mathrm{b}[\AA]$ & $12.3719(8)$ & $11.5388(6)$ & $17.9634(4)$ \\
\hline$c[\AA]$ & $18.8689(12)$ & $22.1079(11)$ & $9.8153(5)$ \\
\hline$\alpha\left[^{\circ}\right]$ & $93.7290(10)$ & 90.00 & 90.00 \\
\hline$\beta\left[^{\circ}\right]$ & $96.0120(10)$ & $93.3450(10)$ & 90.00 \\
\hline$Y\left[^{\circ}\right]$ & $99.5830(10)$ & 90.00 & 90.00 \\
\hline $\mathrm{V}\left[\AA^{3}\right]$ & $2129.7(2)$ & $2690.2(2)$ & $3167.24(19)$ \\
\hline Z & 2 & 4 & 4 \\
\hline$\rho_{\text {calc }}\left[\mathrm{Mg} / \mathrm{m}^{3}\right]$ & 1.153 & 1.147 & 1.372 \\
\hline$\mu\left[\mathrm{mm}^{-1}\right]$ & 0.292 & 0.197 & 0.852 \\
\hline$F(000)$ & 804 & 992 & 1360 \\
\hline$\theta$ range $\left[{ }^{\circ}\right]$ & $1.68-27.14$ & $1.85-27.12$ & $1.60-26.40$ \\
\hline reflections collected & 46383 & 34247 & 33442 \\
\hline unique reflections & 9338 & 5920 & 3259 \\
\hline min./max. transmission & $0.87 / 0.97$ & $0.90 / 0.98$ & $0.86 / 0.98$ \\
\hline$R_{\text {int }}$ & 0.0249 & 0.0210 & 0.0193 \\
\hline data/restraints/parameters & $9338 / 0 / 402$ & $5920 / 0 / 290$ & $3259 / 0 / 150$ \\
\hline$g 1 / g 2$ & $0.0560 / 0.4744$ & $0.0509 / 1.0112$ & $0.0556 / 0.7222$ \\
\hline$R 1$ (all data) & 0.0361 & 0.0343 & 0.0265 \\
\hline$R 1(I>2 \sigma(I))$ & 0.0288 & 0.0310 & 0.0228 \\
\hline$w R 2$ (all data) & 0.1005 & 0.0952 & 0.0942 \\
\hline$w R 2(1>2 \sigma(I))$ & 0.0828 & 0.0870 & 0.0723 \\
\hline GoF & 1.193 & 1.099 & 1.281 \\
\hline largest diff. peak/hole [e/Å3] & $0.478 /-0.319$ & $0.441 /-0.273$ & $0.495 /-0.439$ \\
\hline
\end{tabular}


Table 8-8: Crystal data and structure refinement for the compounds Kost50, Kost51, and Kost52.

\begin{tabular}{|c|c|c|c|}
\hline compound & Kost50 & Kost51 & Kost52 \\
\hline identification code & Kost50 & Kost51 & Kost52 \\
\hline formula hill & $\mathrm{C}_{28} \mathrm{H}_{31} \mathrm{CIN}_{4} \mathrm{O}_{2} \mathrm{Si}$ & $\mathrm{C}_{27} \mathrm{H}_{36} \mathrm{Cl}_{2} \mathrm{~N}_{4} \mathrm{O}_{2} \mathrm{Si}$ & $\mathrm{C}_{28} \mathrm{H}_{34} \mathrm{Cl}_{2} \mathrm{~N}_{4} \mathrm{O}_{2} \mathrm{Si}$ \\
\hline molecular mass $[\mathrm{g} / \mathrm{mol}]$ & 519.11 & 547.59 & 557.58 \\
\hline crystal size $[\mathrm{mm}]$ & $0.2 \times 0.1 \times 0.05$ & $0.4 \times 0.4 \times 0.2$ & $0.2 \times 0.2 \times 0.2$ \\
\hline temperature $[\mathrm{K}]$ & $100(2)$ & $100(2)$ & $173(2)$ \\
\hline crystal system & monoclinic & triclinic & triclinic \\
\hline space group & $\mathrm{P} 2_{1} / \mathrm{n}$ & $P \overline{1}$ & $P \overline{1}$ \\
\hline$a[\AA]]$ & $9.6949(7)$ & $11.1794(6)$ & $7.4846(6)$ \\
\hline $\mathrm{b}[\AA]$ & $14.7650(11)$ & $11.5641(7)$ & $10.1144(8)$ \\
\hline$c[\AA]$ & $18.4193(14)$ & $11.8102(7)$ & $10.1670(8)$ \\
\hline$\alpha\left[^{\circ}\right]$ & 90.00 & $74.1920(10)$ & $66.2930(10)$ \\
\hline$\beta\left[^{\circ}\right]$ & $93.1530(10)$ & $73.6120(10)$ & $83.6630(10)$ \\
\hline$Y\left[^{\circ}\right]$ & 90.00 & $88.2410(10)$ & $74.6210(10)$ \\
\hline$V\left[\AA^{3}\right]$ & $2632.6(3)$ & $1407.63(14)$ & $679.48(9)$ \\
\hline Z & 4 & 2 & 1 \\
\hline$\rho_{\text {calc }}\left[\mathrm{Mg} / \mathrm{m}^{3}\right]$ & 1.310 & 1.292 & 1.363 \\
\hline$\mu\left[\mathrm{mm}^{-1}\right]$ & 0.224 & 0.12 & 0.317 \\
\hline$F(000)$ & 1096 & 580 & 294 \\
\hline$\theta$ range $\left[{ }^{\circ}\right]$ & $1.77-26.40$ & $1.87-26.34$ & $2.19-26.39$ \\
\hline reflections collected & 37282 & 33120 & 8857 \\
\hline unique reflections & 5391 & 5725 & 2778 \\
\hline min./max. transmission & $0.81 / 0.98$ & $0.86 / 0.98$ & $0.9081 / 0.98$ \\
\hline$R_{\text {int }}$ & 0.0353 & 0.0176 & 0.0174 \\
\hline data/restraints/parameters & $5391 / 0 / 333$ & $5725 / 1 / 339$ & $2778 / 0 / 169$ \\
\hline$g 1 / g 2$ & $0.0498 / 2.4623$ & $0.0391 / 0.9126$ & $0.0420 / 0.2744$ \\
\hline$R 1$ (all data) & 0.0487 & 0.0336 & 0.0334 \\
\hline$R 1(\mid>2 \sigma(I))$ & 0.0422 & 0.0327 & 0.0311 \\
\hline$w R 2$ (all data) & 0.1034 & 0.0830 & 0.0820 \\
\hline$w R 2(I>2 \sigma(I))$ & 0.0998 & 0.0823 & 0.0803 \\
\hline GoF & 1.007 & 1.041 & 1.053 \\
\hline largest diff. peak/hole [e/Å3] & $0.430 /-0.265$ & $0.729 /-0.690$ & $0.312 /-0.176$ \\
\hline
\end{tabular}


Table 8-9: Crystal data and structure refinement for the compounds Kost59 and Kost62.

\begin{tabular}{|c|c|c|}
\hline compound & Kost59 & Kost62 \\
\hline identification code & Kost59 & Kost62 \\
\hline formula hill & $\mathrm{C}_{31} \mathrm{H}_{27} \mathrm{~F}_{9} \mathrm{~N}_{6} \mathrm{O}_{3} \mathrm{Si}$ & $\mathrm{C}_{22} \mathrm{H}_{27} \mathrm{ClN}_{4} \mathrm{O}_{2} \mathrm{Si}$ \\
\hline molecular mass $[\mathrm{g} / \mathrm{mol}]$ & 730.68 & 443.02 \\
\hline crystal size $[\mathrm{mm}]$ & $0.15 \times 0.1 \times 0.1$ & $0.4 \times 0.3 \times 0.3$ \\
\hline temperature $[\mathrm{K}]$ & $100(2)$ & $133(2)$ \\
\hline crystal system & orthorhombic & monoclinic \\
\hline space group & Pbca & $\mathrm{P} 2{ }_{1} / \mathrm{n}$ \\
\hline $\mathrm{a}[\AA]$ & $18.3403(11)$ & $9.1022(18)$ \\
\hline $\mathrm{b}[\AA]$ & $18.1997(11)$ & $19.821(4)$ \\
\hline$c[\AA]$ & $19.3869(11)$ & $12.996(3)$ \\
\hline$\alpha\left[^{\circ}\right]$ & 90.00 & 90.00 \\
\hline$\beta\left[^{\circ}\right]$ & 90.00 & $97.21(3)$ \\
\hline$Y\left[^{\circ}\right]$ & 90.00 & 90.00 \\
\hline $\mathrm{V}\left[\AA^{3}\right]$ & $6471.1(7)$ & $2326.2(8)$ \\
\hline Z & 8 & 4 \\
\hline$\rho_{\text {calc }}\left[\mathrm{Mg} / \mathrm{m}^{3}\right]$ & 1.500 & 1.265 \\
\hline$\mu\left[\mathrm{mm}^{-1}\right]$ & 1.509 & 0.241 \\
\hline$F(000)$ & 2992 & 936 \\
\hline$\theta$ range $\left[{ }^{\circ}\right]$ & $2.06-24.58$ & $1.88-24.64$ \\
\hline reflections collected & 57450 & 15409 \\
\hline unique reflections & 4666 & 3899 \\
\hline min./max. transmission & $0.5077 / 0.7511$ & $0.9098 / 0.9312$ \\
\hline$R_{\text {int }}$ & 0.0506 & 0.0765 \\
\hline data/restraints/parameters & $4666 / 12 / 481$ & $3899 / 0 / 276$ \\
\hline$g 1 / g 2$ & $0.0400 / 2.6932$ & $0.0552 / 0.1780$ \\
\hline$R 1$ (all data) & 0.0395 & 0.0654 \\
\hline$R 1(I>2 \sigma(I))$ & 0.0303 & 0.0428 \\
\hline$w R 2$ (all data) & 0.0799 & 0.1059 \\
\hline$w R 2(1>2 \sigma(I))$ & 0.0749 & 0.0972 \\
\hline GoF & 1.042 & 1.030 \\
\hline largest diff. peak/hole [e/Å3] & $0.197 /-0.276$ & $0.307 /-0.221$ \\
\hline
\end{tabular}




\section{REFERENCES}

[1] H. Binder, Lexikon der chemischen Elemente - Das Periodensystem in Fakten, Zahlen und Daten, S. Hirzel, Stuttgart, 1999.

[2] Homer, Odyssey, Book XXII, Greece, 750-650 BC.

[3] A. Pope, The Odyssey of Homer, Book XXII, Kessinger Publishing, Whitefish, 2004.

[4] Compendium of Chemical Terminology, IUPAC Recommendations, Blackwell Scienctific, Oxford, 1997.

[5] R. Steudel, O. Schumann, J. Buschmann, P. Luger, Angew. Chem. 1998, 110, 2502-2504; Angew. Chem. Int. Ed. 1998, 37, 2377-2378.

[6] M. Porter, Vulcanization of Rubber in Organic Chemistry of Sulfur (Ed.: S. Oae), Plenum Press, New York, 1977.

[7] M. Porter, The Reactivity of Allylic Sulphides and Its Relevances to the Vulcanization of Rubber in Perspectives in the Organic Chemistry of Sulfur (Eds.: B. Zwanenburg, A. J. H. Klunder), Elsevier, Amsterdam, 1987.

[8] S. Oae, J. Mol. Struct. 1989, 186, 321-345.

[9] Z. Yunming, Isis 1986, 77, 487-552.

[10] M. M. Labes, P. Love, P. J. Nichols, Chem. Rev. 1979, 79, 1-15.

[11] F. P. Burt, Chem. Soc. Trans. 1910, 97, 1171-1174.

[12] W. Traube, Ber. Dtsch. Chem. Ges. 1892, 25, 2470-2472.

[13] M. Goehring, G. Weis, Angew. Chem. 1956, 68, 678.

[14] C. R. Johnson, Compr. Org. Chem. 1979, 3, 233-235.

[15] S. Bleisch, R. Mayer, Wiss. Z. Tech. Univ. Dresden 1980, 29, 89-99.

[16] R. Bussas, G. Kresze, H. Muensterer, A. Schwoebel, Sulfur Rep. 1982, 2, 215-377.

[17] D. H. Clemens, A. J. Bell, J. L. O'Brien, Tetrahedron Lett. 1965, 6, 1487-1489.

[18] O. Glemser, S. P. von Halasz, U. Biermann, Inorg. Nucl. Chem. Lett. 1968, 4, 591-596.

[19] H. C. Buchholt, A. Senning, P. Kelly, Acta Chem. Scand. 1969, 23, 1279-1287.

[20] R. Mayer, U. Pleiß, Int. J. Sulfur Chem. 1973, 8, 285.

[21] O. J. Scherer, G. Wolmershäuser, Z. Anorg. Allg. Chem. 1977, 432, 173-176.

[22] R. Cramer, J. Org. Chem. 1961, 26, 3476-3478.

[23] B. Cohen, A. G. MacDiarmid, Angew. Chem. 1963, 75, 207; Angew. Chem. Int. Ed. Engl. 1963, 2, 151.

[24] J. Kuyper, K. Vrieze, J. Organomet. Chem. 1974, 74, 289-305.

[25] R. Appel, J. Kohnke, Chem. Ber. 1970, 103, 2152-2156.

[26] R. Appel, J. Kohnke, Chem. Ber. 1971, 104, 2648-2649.

[27] O. J. Scherer, R. Wies, Z. Naturforsch. 1970, 25b, 1486-1487.

[28] I. Ruppert, V. Bastian, R. Appel, Chem. Ber. 1975, 108, 2329-2339.

[29] W. Haubold, H. G. Fehlinger, G. Frey, Z. Naturforsch. 1981, B36, 157-160.

[30] Y. X. Ding, W. P. Weber, J. Org. Chem. 1987, 52, 4625-4626. 
[31] C. P. Warrens, J. D. Woollins, Inorg. Synth. 1989, 25, 43-47.

[32] O. Glemser, J. Wegener, Angew. Chem. 1970, 82, 324; Angew. Chem. Int. Ed. Engl. 1970, 9, 309.

[33] O. Glemser, S. Pohl, F.-M. Tesky, R. Mews, Angew. Chem. 1977, 89, 829-830; Angew. Chem. Int. Ed. Engl. 1977, 16, 789.

[34] W. Lidy, W. Sundermeyer, W. Verbeek, Z. Anorg. Allg. Chem. 1974, 406, 228-234.

[35] R. Fleischer, S. Freitag, F. Pauer, D. Stalke, Angew. Chem. 1996, 108, 208-211; Angew. Chem. Int. Ed. Engl. 1996, 35, 204.

[36] R. Fleischer, A. Rothenberger, D. Stalke, Angew. Chem. 1997, 109, 1141-1143; Angew. Chem. Int. Ed. Engl. 1997, 36, 1105.

[37] I. Langmuir, J. Am. Chem. Soc. 1919, 41, 868-934.

[38] I. Langmuir, J. Am. Chem. Soc. 1919, 41, 1543-1559.

[39] M. A. Beswick, D. S. Wright, Coord. Chem. Rev. 1998, 176, 373-406.

[40] R. Fleischer, D. Stalke, Coord. Chem. Rev. 1998, 176, 431-450.

[41] D. Stalke, Proc. Ind. Acad. Sci. 2000, 112, 155-170.

[42] J. K. Brask, T. Chivers, Angew. Chem. 2001, 113, 4082-4098; Angew. Chem. Int. Ed. 2001, 40, 3960.

[43] G. M. Aspinall, M. C. Copsey, A. P. Leedham, C. R. Russell, Coord. Chem. Rev. 2002, 227, 217-232.

[44] R. Mews, P. G. Watson, E. Lork, Coord. Chem. Rev. 1997, 158, 233-273.

[45] R. Meij, D. J. Stufkens, K. Vrieze, J. Organomet. Chem. 1979, 164, 353-370.

[46] J. L. Morris, C. W. Rees, Chem. Soc. Rev. 1986, 15, 1-15.

[47] K. B. Sharpless, T. Hori, J. Org. Chem. 1976, 41, 176-177.

[48] R. Bussas, G. Kresze, H. Münsterer, A. Schwöbel, Sulfur Rep. 1983, 2, 215-377.

[49] I. Dyong, H. Friege, T. zu Höne, Chem. Ber. 1982, 115, 256-260.

[50] G. Kresze, H. Münsterer, J. Org. Chem. 1983, 48, 5361-5364.

[51] Sulfur Nitrogen Compounds in Gmelin Handbook of Chemistry, Vol. 2, Springer, Berlin, 1985.

[52] F. Pauer, D. Stalke, J. Organomet. Chem. 1991, 418, 127-128.

[53] F. Pauer, J. Rocha, D. Stalke, J. Chem. Soc., Chem. Commun. 1991, 20, 1477-1479.

[54] F. T. Edelmann, F. Knösel, F. Pauer, D. Stalke, W. Bauer, J. Organomet. Chem. 1992, 438, 110.

[55] S. Freitag, W. Kolodziejski, F. Pauer, D. Stalke, J. Chem. Soc., Dalton Trans. 1993, 3479-3488.

[56] R. Fleischer, B. Walfort, A. Gbureck, P. Scholz, W. Kiefer, D. Stalke, Chem. Eur. J. 1998, 4, 2266-2279.

[57] J. Kuyper, K. Vrieze, J. Chem. Soc., Chem. Commun. 1976, 64-65.

[58] U. Wannagat, H. Kuckertz, Angew. Chem. 1962, 74, 117-118; Angew. Chem. Int. Ed. Engl. $1962,1,113$.

[59] O. J. Scherer, R. Schmitt, J. Organomet. Chem. 1969, 16, P11-P13.

[60] J. Kuyper, P. C. Keijzer, K. Vrieze, J. Organomet. Chem. 1976, 116, 1-13. 
[61] D. Hänssgen, H. Hupfer, M. Nieger, M. Pfendtner, R. Steffens, Z. Anorg. Allg. Chem. 2001, 627, $17-22$.

[62] B. Walfort, R. Bertermann, D. Stalke, Chem. Eur. J. 2001, 7, 1424-1430.

[63] C. Selinka, D. Stalke, Z. Naturforsch. 2003, 58b, 291-298.

[64] T. Schulz, Diploma Thesis, Würzburg (Germany), 2006.

[65] B. Walfort, D. Stalke, Angew. Chem. 2001, 113, 3965-3969; Angew. Chem. Int. Ed. 2001, 40, 3846.

[66] S. Deuerlein, Diploma Thesis, Würzburg (Germany), 2003.

[67] E. J. Corey, M. Chaykovsky, J. Am. Chem. Soc. 1962, 84, 3782-3783.

[68] E. J. Corey, M. Chaykovsky, J. Am. Chem. Soc. 1965, 87, 1353-1364.

[69] P. Reuter, Dr. Thesis, Bonn (Germany), 1986.

[70] H. Helten, Research Report, Würzburg (Germany), 2002.

[71] R. Fleischer, D. Stalke, Chem. Commun. 1998, 343-345.

[72] F. A. Carey, R. J. Sundberg, Advanced Organic Chemistry, Part A, Plenum Press, New York, 1984.

[73] J. March, Advanced Organic Chemistry, Wiley-Interscience, New York, 1992.

[74] K. P. C. Vollhardt, N. E. Schore, Organic Chemistry, W. H. Freeman \& Co Ltd., San Francisco, 1994.

[75] P. M. Mitrasinovic, Chem. Phys. 2003, 286, 1-13.

[76] Y.-L. Zeng, S.-J. Zheng, L.-P. Meng, Huaxue Xuebao 2002, 60, 1564-1570.

[77] S. Oae, Historical Development of Sulfur Bonding in Organic Sulfur Chemistry, Vol. 5 (Eds.: F. Bernardi, I. G. Csizmadia, A. Mangini), Elsevier, Amsterdam, 1985.

[78] V. Kral, Z. Arnold, Z. Havlas, Collect. Czech. Chem. Commun. 1981, 46, 883-891.

[79] C. C. Price, S. Oae, Sulfur Bonding, Plenum Press, New York, 1962.

[80] D. Leusser, B. Walfort, D. Stalke, Angew. Chem. 2002, 114, 2183-2186; Angew. Chem. Int. Ed. 2002, 41, 2079-2082.

[81] D. Leusser, J. Henn, N. Kocher, B. Engels, D. Stalke, J. Am. Chem. Soc. 2004, 126, 17811793.

[82] J. Henn, D. Ilge, D. Leusser, D. Stalke, B. Engels, J. Phys. Chem. 2004, A108, 9442-9452.

[83] T. Stey, D. Stalke, Lead Structures in Lithium Organic Chemistry in The Chemistry of Organolithium Compounds (Eds.: Z. Rappoport, I. Marek), John Wiley \& Sons, Chichester, 2004, pp. 47-120.

[84] R. G. Pearson, J. Am. Chem. Soc. 1963, 85, 3533-3539.

[85] R. G. Parr, R. G. Pearson, J. Am. Chem. Soc. 1983, 105, 7512-7516.

[86] R. G. Pearson, J. Am. Chem. Soc. 1985, 107, 6801-6806.

[87] T. S. Stevens, E. M. Creighton, A. B. Gordon, M. MacNicol, J. Chem. Soc. 1928, 3193-3197.

[88] G. Wittig, G. Felletschin, Liebigs Ann. Chem. 1944, 555, 133-145.

[89] G. Wittig, H. Fritz, Justus Liebigs Ann. Chem. 1952, 577, 39-46.

[90] V. K. Aggarwal, J. Richardson, Chem. Commun. 2003, 21, 2644-2651. 
[91] V. K. Aggarwal, C. L. Winn, Acc. Chem. Res. 2004, 37, 611-620.

[92] R. Appel, J. Kohnke, Chem. Ber. 1971, 104, 3875-3883.

[93] S. Brandt, P. Helquist, J. Am. Chem. Soc. 1979, 101, 6473-6475.

[94] K. A. M. Kremer, P. Helquist, R. C. Kerber, J. Am. Chem. Soc. 1981, 103, 1862-1864.

[95] E. J. O'Connor, P. Helquist, J. Am. Chem. Soc. 1982, 104, 1869-1874.

[96] L. Weber, Angew. Chem. 1983, 95, 539-551; Angew. Chem. Int. Ed. Engl. 1983, 22, 516.

[97] M. Mikolajczyk, J. Organomet. Chem. 2005, 690, 2488-2496.

[98] V. Franzen, H.-E. Driesen, Chem. Ber. 1963, 96, 1881-1890.

[99] R. S. Tewari, A. K. Awasthi, A. Awasthi, Synthesis 1983, 4, 330-331.

[100] E. Vedejs, J. Org. Chem. 2004, 69, 5159-5167.

[101] B. Walfort, A. P. Leedham, C. R. Russell, D. Stalke, Inorg. Chem. 2001, 40, 5668-5674.

[102] R. Fleischer, D. Stalke, Organometallics 1998, 17, 832-838.

[103] N. Kocher, PhD thesis, Wuerzburg (Germany), 2003.

[104] N. Kocher, C. Selinka, D. Leusser, D. Kost, I. Kahlikhman, D. Stalke, Z. Anorg. Allg. Chem. 2004, 630, 1777-1793.

[105] N. Kocher, D. Leusser, A. Murso, D. Stalke, Chem. Eur. J. 2004, 10, 3622-3631.

[106] N. Kocher, J. Henn, B. Gostevskii, D. Kost, I. Kalikhman, B. Engels, D. Stalke, J. Am. Chem. Soc. 2004, 136, 5563-5568.

[107] D. Leusser, Dr. Thesis, Würzburg (Germany), 2002.

[108] K. Iwata, S. Yoneda, Z.-I. Yoshida, J. Am. Chem. Soc. 1971, 93, 6745-6750.

[109] T. Kottke, D. Stalke, Angew. Chem. 1993, 105, 619-621; Angew. Chem. Int. Ed. Engl. 1993, 32, 580.

[110] E. Matito, J. Poater, F. M. Bickelhaupt, M. Solà, J. Phys. Chem. 2006, B110, 7189-7198.

[111] A. Streitwieser, Jr., J. E. Williams, Jr., S. Alexandratos, J. M. McKelvey, J. Am. Chem. Soc. 1976, 98, 4778-4784.

[112] A. Streitwieser, J. Organomet. Chem. 1978, 156, 1-3.

[113] H. Schiffer, R. Ahlrichs, Chem. Phys. Lett. 1986, 124, 172-179.

[114] W. Bauer, W. R. Winchester, P. v. R. Schleyer, Organometallics 1987, 33, 2371-2379.

[115] J. P. Ritchie, S. M. Bachrach, J. Am. Chem. Soc. 1987, 109, 5909-5916.

[116] R. J. Bushby, H. L. Steel, J. Organomet. Chem. 1987, 336, C25-C32.

[117] E. Kaufmann, K. Raghavachari, A. E. Reed, P. v. R. Schleyer, Organometallics 1988, 7, 15971607.

[118] P. C. Hiberty, D. L. Cooper, J. Mol. Struct. 1988, 169, 437-446.

[119] J. Cioslowski, J. Am. Chem. Soc. 1989, 111, 8333-8336.

[120] K. B. Wiberg, C. M. Breneman, J. Am. Chem. Soc. 1990, 112, 8765-8775.

[121] R. J. Bushby, H. L. Steel, J. Chem. Soc., Perkin Trans. 2 1990, 1143-1153.

[122] C. Lambert, M. Kaupp, P. v. R. Schleyer, Organometallics 1993, 12, 853-859.

[123] C. Lambert, P. v. R. Schleyer, Angew. Chem. 1994, 106, 1187-1199; Angew. Chem. Int. Ed. Engl. 1994, 33, 1129. 
[124] A. M. El-Nahas, P. v. R. Schleyer, Angew. Chem. 1994, 15, 596-626.

[125] D. L. Cooper, J. Gerratt, P. B. Karadakov, M. Raimondi, J. Chem. Soc., Faraday Trans. 1995, 91, 3363-3365.

[126] S. C. Tyerman, G. K. Corlett, A. M. Ellis, T. A. Claxton, J. Mol. Struct. 1996, 364, 107-119.

[127] T. Kremer, S. Harder, M. Junge, P. v. R. Schleyer, Organometallics 1996, 15, 585-595.

[128] F. M. Bickelhaupt, N. J. R. van Eikema Hommes, C. F. Guerra, E. J. Baerends, Organometallics 1996, 15, 2923-2931.

[129] C. Fressigné, J. Maddaluno, C. Giessner-Prettre, J. Chem. Soc., Perkin Trans. 2 1999, 10, 2197-2201,.

[130] G. Scalamani, J. L. Brédas, V. Barone, J. Chem. Phys. 2001, 112, 1178-1191.

[131] O. Kwon, F. Sevin, M. L. McKee, J. Phys. Chem. 2001, 105, 913-922.

[132] R. Ponec, J. Roithova, X. Girone's, L. Lain, A. Torre, R. Bochicchio, J. Phys. Chem. 2002, A106, 1019-1026.

[133] F. M. Bickelhaupt, M. Solà, C. F. Guerra, J. Chem. Theo. Comput. 2006, 2, 965-980.

[134] L. M. Seitz, T. M. Brown, J. Am. Chem. Soc. 1966, 88, 2174-2178.

[135] L. M. Seitz, T. M. Brown, J. Am. Chem. Soc. 1966, 88, 4140-4147.

[136] K. C. Williams, T. M. Brown, J. Am. Chem. Soc. 1966, 88, 4134-4140.

[137] L. Andrews, J. Chem. Phys. 1967, 47, 4834-4842.

[138] L. D. McKeever, R. Waack, M. A. Doran, E. B. Baker, J. Am. Chem. Soc. 1969, 91, $1057-1061$.

[139] E. Weiss, G. Hencken, J. Organomet. Chem. 1970, 21, 265-268.

[140] F. J. Landro, J. A. Gurak, J. W. Chinn, Jr., R. J. Lagow, J. Organomet. Chem. 1983, $249,1-9$.

[141] J. W. Chinn, Jr., R. J. Lagow, Organometallics 1984, 3, 75-77.

[142] E. Weiss, T. Lambertsena, B. Schubert, J. K. Cockcroft, A. Wiedenmann, Chem. Ber. 1990, 123, 79-81.

[143] D. B. Grotjahn, T. C. Pesch, J. Xin, L. M. Ziurys, J. Am. Chem. Soc. 1997, 119, 12368-12369.

[144] D. B. Grotjahn, A. J. Apponi, M. A. Brewster, J. Xin, L. M. Ziurys, Angew. Chem. 1998, 110, 2824-2827; Angew. Chem. Int. Ed. 1998, 37, 2678.

[145] D. B. Grotjahn, T. C. Pesch, M. A. Brewster, L. M. Ziurys, J. Am. Chem. Soc. 2000, 122, 47354741.

[146] J. C. Stowell, Carbanions in Organic Synthesis, Wiley, New York, 1979.

[147] S. W. Staley, C. K. Dustman, Reactive Intermediates, Vol. 2 (Eds.: M. Jones, Jr., R. A. Moss), Wiley, New York, 1981.

[148] R. B. Bates, Comprehensive Carbanion Chemistry Part A - Structure and Reactivity in Studies in Organic Chemistry (Eds.: E. Buncel, T. Durst), Elsevier, Amsterdam, 1987.

[149] J. P. Collman, L. S. Hegedus, J. R. Norton, R. G. Finke, Principles and Applications of Organotransition Metal Chemistry, University Science Books, Mill Valley, 1987.

[150] C. Elschenbroich, A. Salzer, Organometallics - A Concise Introduction, VCH, Weinheim, 1992.

[151] E. Mitscherlich, Abhandlungen der Preußischen Akademie der Wissenschaften 1822.

[152] J. Bernstein, Progress in Clinical and Biological Research 1989, 289, 203-215. 
[153] G. R. Desiraju, Nature Materials 2002, 1, 77-79.

[154] G. R. Desiraju, Science 1997, 278, 404-405.

[155] J. P. Jog, Materials Science and Technology 2006, 22, 797-806.

[156] D. Braga, F. Grepioni, Chem. Soc. Rev. 2000, 29, 229-238.

[157] G. M. Sheldrick, XPREP in SHELXTL v6.12, Bruker AXS Inst. Inc., Madison (WI, USA), 2000.

[158] D. Hänssgen, R. Steffens, J. Organomet. Chem. 1982, 236, 53-60.

[159] D. Hänssgen, R. Steffens, Z. Naturforsch. 1985, 40b, 919-922.

[160] B. K. Vainshtein, V. L. Indenbom, V. M. Fridkin, Structure of Crystals in Modern Crystallography, Vol. 2 (Eds.: B. K. Vainshtein), Springer, Berlin, 2000.

[161] Accurate Molecular Structure (Eds.: A. Domenicano, I. Hargittai), Oxford University Press, Oxford, 1992.

[162] P. Coppens, X-Ray Charge Densities and Chemical Bonding, Oxford University Press, Oxford, 1997.

[163] A. Volkov, Y. A. Abramov, P. Coppens, C. Gatti, Acta Crystallogr. 2000, A56, 332-339.

[164] T. Kottke, D. Stalke, J. Appl. Crystallogr. 1993, 26, 615-619.

[165] W. Kabsch, J. Appl. Crystallogr. 1988, 21, 916-924.

[166] W. Kabsch, XDS - X-ray Detector Software v2006-12-06, Heidelberg (Germany), 2006.

[167] H. Hope, Acta Crystallogr. 1988, B44, 22-26.

[168] D. Stalke, Chem. Soc. Rev. 1998, 27, 171-178.

[169] Bruker APEX v2.1-0, Bruker AXS Inst. Inc., Madison (WI, USA), 2007.

[170] SAINT v7.34A in Bruker APEX v2.1-0, Bruker AXS Inst. Inc., Madison (WI, USA), 2005.

[171] G. M. Sheldrick, SADABS 2006/4, Göttingen, 2006.

[172] A. Volkov, P. Macchi, L. J. Farrugia, C. Gatti, P. R. Mallinson, T. Richter, T. Koritsanszky, XD2006, A Computer Program Package for Multipole Refinement, Topological Analysis of Charge Densities and Evaluation of Intermolecular Energies from Experimental or Theoretical Structure Factors, 2006.

[173] W. Friedrich, P. Knipping, M. Laue, Sitzungsbericht der kaiserlich Akademischen Wissenschaften München 1912, 303-322.

[174] M. Born, Z. Phys. 1926, A38, 803-827.

[175] P. P. Ewald, Physica 1925, 5, 363-369.

[176] W. H. Zachariasen, Acta Crystallogr. 1967, A23, 558-564.

[177] R. F. Stewart, D. Feil, Acta Crystallogr. 1980, A36, 503-509.

[178] C. A. Coulson, M. W. Thomas, Acta Crystallogr. 1971, B27, 1354-1359.

[179] International Tables for X-Ray Crystallography, Vol. 4 (Eds.: C. K. Johnson, H. A. Levy), Kynoch Press, Birmingham, 1974.

[180] P. Coppens, Neutron Diffraction in Topics in Current Physics, Vol. 6 (Eds.: H. Dachs), Springer Verlag, Berlin, 1978.

[181] F. H. Allen, Acta Crystallogr. 1968, B42, 515-522.

[182] G. A. Jeffrey, D. W. J. Cruickshank, Quart. Rev. Chem. Soc. London 1953, 7, 335-376. 
[183] P. Coppens, M. S. Lehmann, Acta Crystallogr. 1976, B32, 1777-1784.

[184] M. S. Lehmann, P. Coppens, Acta Chem. Scand. 1977, A31, 530-535.

[185] N. K. Hansen, P. Coppens, Acta Crystallogr. 1978, A34, 909-921.

[186] G. M. Sheldrick, SHELXS in SHELXTL v6.12, Bruker AXS Inst. Inc., Madison (WI, USA), 2000.

[187] G. M. Sheldrick, SHELXL in SHELXTL v6.12, Bruker AXS Inst. Inc., Madison (WI, USA), 2000.

[188] R. F. Stewart, J. Chem. Phys. 1968, 48, 4882-4889.

[189] R. F. Stewart, J. Chem. Phys. 1969, 51, 4569-4577.

[190] R. F. Stewart, J. Chem. Phys. 1973, 58, 1668-1676.

[191] R. F. Stewart, J. Chem. Phys. Letters 1979, 65, 5335.

[192] E. Clementi, D. L. Raimondi, J. Chem. Phys. 1963, 38, 2686-2689.

[193] E. Clementi, C. Roetti, Atom. Data Nucl. Data Tab. 1974, 14, 177-478.

[194] F. L. Hirshfeld, Acta Crystallogr. 1976, A32, 239-244.

[195] Z. Su, P. Coppens, Acta Crystallogr. 1998, A54, 646-652.

[196] P. Macchi, P. Coppens, Acta Crystallogr. 2001, A57, 656-662.

[197] W. J. Hehre, R. Ditchfield, R. F. Stewart, J. A. Pople, J. Chem. Phys. 1970, 52, 2769-2773.

[198] G. R. Moss, M. Souhassou, R. H. Blessing, Acta Crystallogr. 1995, B51, 650-660.

[199] E. Espinosa, E. Molins, C. Lecomte, Phys. Rev. 1997, B56, 1820-1833.

[200] S. Dahaoui, V. Pichon-Pesme, J. A. K. Howard, C. Lecomte, J. Phys. Chem. 1999, A103, 62406250.

[201] P. M. Dominiak, P. Coppens, Acta Crystallogr. 2006, A62, 224-227.

[202] A. Volkov, Y. A. Abramov, P. Coppens, Acta Crystallogr. 2001, A57, 272-282.

[203] R. F. W. Bader, Atoms in Molecules - A Quantum Theory, Oxford University Press, New York, 1990.

[204] R. F. W. Bader, P. M. Beddall, J. Chem. Phys. 1972, 56, 3320-3329.

[205] D. Cremer, E. Kraka, Angew. Chem. 1984, 96, 612-614; Angew. Chem. Int. Ed. Engl. 1984, 23, 627.

[206] R. G. A. Bone, R. F. W. Bader, J. Phys. Chem. 1996, 100, 10892-10911.

[207] R. F. W. Bader, J. Phys. Chem. 1998, A102, 7314-7323.

[208] T.-H. Tang, R. F. W. Bader, P. J. MacDougall, Inorg. Chem. 1985, 24, 2047-2053.

[209] R. J. Gillespie, Molecular Geometry, Reinhold Van Nostrand, London, 1972.

[210] R. J. Gillespie, I. Hargittai, The VSEPR Model of Molecula Geometry, Allyn and Bacon, Boston, 1991.

[211] I. Bytheway, R. J. Gillespie, T.-H. Tang, R. F. W. Bader, Inorg. Chem. 1995, 34, 2407-2414.

[212] R. J. Gillespie, E. A. Robinson, Angew. Chem. 1996, 108, 539-560; Angew. Chem. Int. Ed. Engl. 1996, 35, 477.

[213] P. J. MacDougall, M. B. Hall, R. F. W. Bader, J. R. Cheeseman, Can. J. Chem. 1989, 67, 18421846.

[214] R. F. W. Bader, R. J. Gillespie, P. J. MacDougall, Mol. Struct. Energ. 1989, 11, 1-51. 
[215] R. F. W. Bader, S. Johnson, T.-H. Tang, P. L. A. Popelier, J. Phys. Chem. 1996, 100, 1539815415.

[216] Chemical Bonding and Molecular Geometry (Eds.: R. J. Gillespie, P. L. A. Popelier), Oxford University Press, New York, 2001.

[217] R. F. W. Bader, R. J. Gillespie, P. J. MacDougall, J. Am. Chem. Soc. 1988, 110, 7329-7336.

[218] H. Hopf, Math. Ann. 1927, 96, 209-224.

[219] K. Collard, G. G. Hall, Int. J. Quantum Chem. 1977, 12, 623-637.

[220] A. Haaland, D. J. Shorokhov, N. V. Tverdova, Chem. Eur. J. 2003, 10, 4416-4421.

[221] C. F. Matta, J. Hernández-Trujillo, T.-H. Tang, R. F. W. Bader, Chem. Eur. J. 2003, 9, 19401951.

[222] J. Henn, D. Leusser, D. Stalke, J. Comput. Chem. 2007, 28, 2317-2324.

[223] G. T. Smith, P. R. Mallinson, C. S. Frampton, J. A. K. Howard, J. Chem. Soc., Perkin Trans. 2 $1997,7,1329-1333$.

[224] D. S. Yufit, J. A. K. Howard, M. G. Davidson, J. Chem. Soc., Perkin Trans. 2 2000, 2, 249-253.

[225] G. N. Lewis, J. Am. Chem. Soc. 1916, 38, 762-785.

[226] CRC Handbook of Chemistry and Physics (Ed.: D. R. Lide), Taylor \& Francis, Boca Raton, 2006.

[227] Kaye \& Laby - Tables of Physical and Chemical Constants (Eds.: J. G. Noyes, J. Asher, O. C. Jones, G. F. Philipps), NPL, Hampshire, 1995.

[228] S. Pillet, M. Souhassou, Y. Pontillon, A. Caneschi, D. Gatteschi, C. Lecomte, New J. Chem. 2001, 25, 131-143.

[229] I. Vidal, S. Melchor, J. A. Dobado, J. Phys. Chem. 2005, A109, 7500-7508.

[230] Cambridge Structural Database, v5.28 (November 2006), Cambridge Crystallographic Data Centre, Cambridge, 2006.

[231] R. Fleischer, S. Freitag, D. Stalke, J. Chem. Soc., Dalton Trans. 1998, 193-197.

[232] X. Shijing, Q. Minxiw, Z. Naijue, T. Youqi, Sci. Sin., Ser. B 1986, 1030-1033.

[233] V. Di Noto, S. Bresadola, R. Zannetti, M. Viviani, G. Valle, G. Bandoli, Z. Kristallogr. 1992, 201, 161-170.

[234] V. Di Noto, G. Bandoli, A. Dolmella, B. Zarli, M. Viviani, M. Vidali, J. Chem. Crystallogr. 1995, 25, 375-378.

[235] F. A. Cotton, S. C. Haefner, J. H. Matonic, X. Wang, C. A. Murillo, Polyhedron 1997, 16, $541-$ 550.

[236] D. E. Hibbs, C. Jones, A. F. Richards, J. Chem. Soc., Dalton Trans. 1999, 3531-3532.

[237] R. Fleischer, D. Stalke, J. Organomet. Chem. 1998, 550, 173-182.

[238] P. Rademacher, Strukturen organischer Moleküle, VCH, New York, 1987.

[239] D. Ilge, D. S. Wright, D. Stalke, Chem. Eur. J. 1998, 4, 2275-2279.

[240] B. Walfort, T. Auth, B. Degel, H. Helten, D. Stalke, Organometallics 2002, 21, 2208-2214.

[241] B. Walfort, S. K. Pandey, D. Stalke, Chem. Commun. 2001, 1640-1641. 
[242] A. G. M. Barrett, A. A. Gray, M. S. Hill, P. B. Hitchcock, P. A. Procopiou, A. J. P. White, Inorg. Chem. 2006, 45, 3352-3358.

[243] J. K. Brask, T. Chivers, M. Parvez, G. P. A. Yap, Inorg. Chem. 1999, 38, 3594-3595.

[244] J. K. Brask, T. Chivers, M. Parvez, Angew. Chem. 2000, 112, 988-990; Angew. Chem. Int. Ed. 2000, 39, 958.

[245] D. Steinborn, T. Rüffer, C. Bruhn, F. W. Heinemann, Polyhedron 1998, 17, 3275-3280.

[246] C. Strohmann, B. C. Abele, D. Schildbach, K. Strohfeldt, Chem. Commun. 2000, 10, 865-866.

[247] T. Rüffer, C. Bruhn, D. Steinborn, Z. Anorg. Allg. Chem. 2001, 627, 2408-2412.

[248] R. Meij, J. Kuyper, D. J. Stufkens, K. Vrieze, J. Organomet. Chem. 1976, 110, 219-233.

[249] R. Meij, T. A. M. Kaandrop, K. Vrieze, J. Organomet. Chem. 1977, 128, 203-211.

[250] I.-P. Lorenz, M. Limmert, K. Polborn, H. Nöth, Z. Anorg. Allg. Chem. 2000, 626, 2313-2317.

[251] A. J. Souers, T. D. Owens, A. G. Oliver, F. J. Hollander, J. A. Ellman, Inorg. Chem. 2001, 40, 5299-5301.

[252] M. Pfeiffer, T. Stey, H. Jehle, B. Klüpfel, W. Malisch, D. Stalke, V. Chandrasekhar, Chem. Commun. 2001, 4, 337-338.

[253] J. J. Schneider, Nachrichten aus der Chemie 2000, 48, 614-620.

[254] A. Bader, E. Lindner, Coord. Chem. Rev. 1991, 108, 27-110.

[255] C. S. Slone, D. A. Weinberger, C. A. Mirkin, Progress in Inorganic Chemistry 1999, 48, 233350.

[256] P. Braunstein, F. Naud, Angew. Chem. 2001, 113, 702-722; Angew. Chem. Int. Ed. 2001, 40, 680.

[257] U. Schubert, J. Pfeiffer, F. Stöhr, D. Sturmayr, S. Thompson, J. Organomet. Chem. 2002, 646, 53-58.

[258] A. Fukuoka, M. Ichikawa, J. A. Hriljac, D. F. Shriver, Inorg. Chem. 1987, 26, 3643-3645.

[259] S. Velmathi, S. Swarnalakshmi, S. Narasimhan, Tetrahedron: Asymmetry 2003, 14, 113-117.

[260] N. Yamagiwa, S. Matsunaga, M. Shibasaki, J. Am. Chem. Soc. 2003, 125, 16178-16179.

[261] D. Prim, B. Andrioletti, F. R.-M. Rose-Munch, E. Rose, F. Couty, Tetrahedron 2004, 60, 33253347.

[262] S. W. Ragsdale, M. Kumar, Chem. Rev. 1996, 96, 2515-2540.

[263] T. I. Doukov, T. M. Iverson, J. Seravalli, S. W. Ragsdale, C. L. Drennan, Science 2002, 298, 567-572.

[264] C. Darnault, A. Volbeda, E. J. Kim, P. Legrand, X. Vernede, P. A. Lindahl, J. C. FontecillaCamps, Nature Struct. Biol. 2003, 10, 271-279.

[265] N. Sträter, T. Klabunde, P. Tucker, H. Witzel, B. Krebs, Science 1995, 268, 1489-1492.

[266] J. A. Tainer, E. D. Getzoff, J. S. Richardson, D. C. Richardson, Nature 1983, 306, 284-286.

[267] L. Wang, E. Hauptman, L. K. Johson, E. F. McCord, Y. Wang, S. D. Ittel, Catalysts for Olefin Polymerization, E.I. Du Pont De Nemours and Company, WO/2001/092342, 2001.

[268] P. Braunstein, M. D. Fryzuk, F. Naud, S. J. Rettig, J. Chem. Soc., Dalton Trans. 1999, 589-594.

[269] P. Braunstein, F. Naud, C. Graiff, A. Tiripicchio, Chem. Commun. 2000, 897-898. 
[270] K. S. Coleman, M. L. H. Green, S. I. Pascu, N. H. Rees, A. H. Cowley, L. H. Rees, J. Chem. Soc., Dalton Trans. 2001, 3384-3395.

[271] Z. Guan, W. J. Marshall, Organometallics 2002, 21, 3580-3586.

[272] W. T. Robinson, C. J. Wilkins, Z. Zeying, J. Chem. Soc., Dalton Trans. 1990, 1, 219-227.

[273] Y. S. Ng, G. R. Rodley, W. T. Robinson, Acta Crystallogr. 1977, B33, 931-934.

[274] L. M. Engelhardt, C. L. Raston, C. R. Whitaker, A. H. White, Aust. J. Chem. 1986, 39, 21512154.

[275] D. G. Gilheany, Chem. Rev. 1994, 94, 1339-1374.

[276] W. Wolfsberger, H. Schmidbaur, Synth. React. Inorg. Met.-Org. Chem. 1974, 4, 149-156.

[277] H. Karsch, H. Schmidbaur, Z. Naturforsch. 1977, 32b, 762-767.

[278] H.-P. Abicht, K. Issleib, Z. Chem. 1981, 10, 341-349.

[279] R. A. Benkeser, T. E. Johnston, J. Am. Chem. Soc. 1966, 88, 2200-2225.

[280] G. M. Sheldrick, SMART-NT V5.6, Bruker AXS Inst. Inc., Madison (WI, USA), 2000.

[281] G. M. Sheldrick, SAINT-NT in SAINTPLUS v6/6.0, Bruker AXS Inst. Inc., Madison (WI, USA), 2000.

[282] G. M. Sheldrick, SADABS 2.0 in SAINTPLUS v6/6.0, Bruker AXS Inst. Inc., Madison (WI, USA), 2000.

[283] G. M. Sheldrick, SADABS 2004/1, Göttingen, 2004.

[284] X-AREA, Stoe \& Cie GmbH, Darmstadt, 2002.

[285] M. N. Burnett, C. K. Johnson, ORTEP-III: Oak Ridge Thermal Ellipsoid Plot Program for Crystal Structure Illustrations, Oak Ridge National Laboratory Report ORNL-6895, Oak Ridge, 1996.

[286] C. Cason, POV-Ray - Persistence of Vision Ray Tracer v3.6, Persistence of Vision Raytracer Pty. Ltd., Williamstown, 2005.

[287] G. M. Sheldrick, CELL_NOW in Bruker APEX v2.1-0, Bruker AXS Inst. Inc., Madison (WI, USA), 2005.

[288] G. M. Sheldrick, TWINABS v1.05 in Bruker APEX v2.1-0, Bruker AXS Inst. Inc., Madison (WI, USA), 2005.

[289] M. Christl, M. Braun, H. Fischer, S. Groetsch, G. Müller, D. Leusser, S. Deuerlein, D. Stalke, M. Arnone, B. Engels, Eur. J. Org. Chem. 2006, 5045-5058.

[290] M. Christl, S. Lesch, S. Deuerlein, D. Stalke, Helv. Chim. Acta 2005, 88, 1421-1431.

[291] B. Gostevskii, G. Silbert, K. Adear, A. Sivaramakrishna, D. Stalke, S. Deuerlein, N. Kocher, M. G. Voronkov, I. Kalikhman, D. Kost, Organometallics 2005, 24, 2913-2920.

[292] B. Gostevskii, V. Pestunovich, I. Kalikhman, A. Sivaramakrishna, N. Kocher, S. Deuerlein, D. Leusser, D. Stalke, D. Kost, Organometallics 2004, 23, 4346-4348.

[293] I. Kalikhman, B. Gostevskii, E. Kertsnus, M. Botoshansky, C. A. Tessier, W. J. Youngs, S. Deuerlein, D. Stalke, D. Kost, Organometallics 2007, 26, 2652-2658. 


\section{Publications}

[1] A. Aharoni, A. P. Giri, S. Deuerlein, F. Griepink, W.-J. de Kogel, F. W. A. Verstappen, H. A. Verhoeven, M. A. Jongsma, W. Schwab, H. J. Bouwmeester, "Terpenoid Metabolism in WildType and Transgenic Arabidopsis Plants" Plant Cell 2003, 15, 2866-2884.

[2] C. Selinka, S. Deuerlein, T. Häuser, D. Stalke, "Heteroaromatic substituted diimidosulfinates", Inorg. Chim. Acta 2004, 357, 1873-1880.

[3] B. Gostevskii, V. Pestunovich, I. Kalikhman, A. Sivaramakrishna, N. Kocher, S. Deuerlein, D. Leusser, D. Stalke, D. Kost, "Donor-Stabilized Silyl Cations. 8. Carbon-Carbon Bond Formation through a Novel Interchelate Molecular Rearrangement in Pentacoordinate Siliconium-lon Salts", Organometallics 2004, 23, 4346-4348.

[4] L. Lameyer, O. A. Salah, S. Deuerlein, T. Stey, D. Stalke, "Structural Variances in the Homologous Series of Alkaline Earth Metallated Octamethylcyclotetrasilazandiides" Z. Anorg. Allg. Chem. 2004, 630, 1801-1806.

[5] R. von Bülow, S. Deuerlein, Th. Stey, R. Herbst-Irmer, H. Gornitzka, D. Stalke, "N-Aryl Anions: Half Way between Amides and Carbanions" Z. Naturforsch. 2004, 59b, 1471-1479.

[6] M. Christl, S. Lesch, S. Deuerlein, D. Stalke, "The Thermolysis of the Cycloadducts between Aryl Azides and Hexamethyl-Dewar-Benzene Revisited" Helv. Chim. Acta 2005, 88, 1421-1431.

[7] B. Gostevskii, G. Silbert, K. Adear, A. Sivaramakrishna, D. Stalke, S. Deuerlein, N. Kocher, M. G. Voronkov, I. Kalikhman, D. Kost, "Donor-Stabilized Silyl Cations. 9. Two Dissociation Patterns of Hexacoordinate Silicon Complexes: A Model Nucleophilic Substitution at Pentacoordinate Silicon", Organometallics 2005, 24, 2913-2920.

[8] M. Christl, M. Braun, H. Fischer, S. Groetsch, G. Müller, D. Leusser, S. Deuerlein, D. Stalke, M. Arnone, B. Engels, "The Stereochemical Course of the Generation and Interception of a SixMembered Cyclic Allene: $3 \delta^{2}-1 \mathrm{H}-$ Naphthalene (2,3-Didehydro-1,2-dihydronaphthalene)" Eur. J. Org. Chem. 2006, 5045-5058.

[9] I. Kalikhman, B. Gostevskii, E. Kertsnus, M. Botoshansky, C. A. Tessier, W. J. Youngs, S. Deuerlein, D. Stalke, D. Kost, "Competitive Molecular Rearrangements in Hexacoordinate Cyano-Silicon Dichelates" Organometallics 2007, 26, 2652-2658.

[10] C. Matthes, U. Klingebiel, S. Deuerlein, H. Ott, D. Stalke, B. Heisen, A. Ringe, J. Magull, "Bis(1,3-disila-2-amino-) and Bis(1,3-disila-2-amino(-2-amido)ethylene-diamines, Cyclisation to Sila- and Boracyclononanes" Z. Anorg. Allg. Chem., 2007, submitted.

[11] S. Deuerlein, D. Leusser, U. Flierler, H. Ott, D. Stalke, "[(thf) $\left.L_{2}\left\{\mathrm{H}_{2} C S\left(N^{t} B u\right)_{2}\right\}\right]_{2}$ : Synthesis, Polymorphism, and Experimental Charge Density to Elucidate the Bonding Properties of a Lithium Sulfur Ylide" J. Am. Chem. Soc. 2007, submitted. 


\section{Poster Presentations}

[1] S. Deuerlein, D. Leusser, T. Schulz, D. Stalke, "Crystallisation of a Suitable Polymorph for Charge Density Studies", $4^{\text {th }}$ European Charge Density Meeting, 2006, Brandenburg/Havel, Germany.

[2] T. Schulz, S. Deuerlein, D. Stalke, "Heterobimetallische Komplexe als mögliche Katalysatoren für die Ziegler-Natta-Olefinpolymerisation", Wissenschaftsforum Chemie 2007 - GDChJahrestagung, 2007, Ulm, Germany.

\section{INVITED TALKS}

[1] S. Deuerlein, "Structure and Electron Density Determination of Novel Polyimido Sulfur Compounds", Kekulé-Institut für Organische Chemie und Biochemie within the Collaborative Research Center (Sonderforschungsbereich) 624 of the DFG (German Research Association), 2007, University of Bonn, Germany.

\section{BOOK CONTRIBUTIONS}

[1] S. Deuerlein, D. Stalke, in Elfenbeinturm der Wissenschaft, Vol. 3, (Eds.: E. M. Neher), Wallstein, Göttingen, 2007. 


\section{CURRICULUM VITAE}

\section{Persönliche Daten}

$\begin{array}{ll}\text { Name: } & \text { Stephan Michael Deuerlein } \\ \text { Adresse: } & \text { Nürnberger Str. 8, 91710 Gunzenhausen } \\ \text { Telefon: } & +49-9831-3388 \\ \text { E-mail: } & \text { Stephan.Deuerlein@gmx.de } \\ \text { Titel: } & \text { Dipl.-Chem. Univ. } \\ \text { Geburtsdatum/-ort: } & \text { 05. April 1979, Gunzenhausen } \\ \text { Staatsangehörigkeit: } & \text { deutsch } \\ \text { Familienstand: } & \text { ledig, keine Kinder }\end{array}$

\section{Schulische Ausbildung}

09/1985 - 07/1989

$09 / 1989-06 / 1998$

06/1998
Besuch der Stephanie-Grundschule in Gunzenhausen Besuch des Simon-Marius-Gymnasiums in Gunzenhausen

Abschluss der Gymnasiallaufbahn mit dem Abitur (Note: 1,5) (Facharbeit in Chemie über Harnstoff in Wasser) mit Auszeichnung durch die Christian-Hauff-Stiftung

\section{Wehrdienst}

07/1998-04/1999

Grundwehrdienst beim Panzerbataillon 304 in Heidenheim am Hahnenkamm als Funktioner (Computeradministration, Aktenverwaltung und Zeichnen) im S3-Stab (Ausbildungs- und Einsatzplanung)

\section{Universitäre Ausbildung}

$04 / 1999-12 / 2003$

$04 / 2001$

$03 / 2003$

$12 / 2003$

$01 / 2004-03 / 2005$

$04 / 2005-$
Studium der Chemie (Diplom) an der Bayerischen JuliusMaximilians-Universität in Würzburg

Mündliche Diplom-Vorprüfung (Note: gut) Mündliche Diplomprüfung (Note: sehr gut)

Abschluss des Studiums mit Abgabe der Diplomarbeit über Schwefel-Ylide in der Metallkoordination (Betreuer: Prof. Dr. D. Stalke, Note: sehr gut)

Promotion an der Bayerischen Julius-Maximilians-Universität Würzburg über "Syntheses and Electron Density Determination of Novel Polyimido Sulfur Ylides" (Betreuer: Prof. Dr. D. Stalke)

Fortführung der Promotion an der Georg-August-Universität in Göttingen begründet durch den Umzug des Arbeitskreises von Prof. Dr. D. Stalke

\section{Angestrebter Abschluss}

$11 / 2007$

Dr. rer. nat (in Chemie) 


\section{Beruflicher Werdegang/Praktika}

$08 / 1997$

$09 / 2000-03 / 2001$

$05 / 2001-08 / 2001$

$09 / 2001-10 / 2001$

$03 / 2002-04 / 2002$
Dreiwöchige Ferienarbeit bei den Glaswerken Arnold $\mathrm{GmbH}$ \& Co. in Merkendorf

Wissenschaftliche Hilfskraft am Fraunhofer Institut für Silicatforschung in Würzburg im Bereich Suspensionen und elektro-/magneto-rheologische Flüssigkeiten

Sechswöchiges Forschungspraktikum mit Fortführung der Tätigkeit am Fraunhofer Institut für Silicatforschung in Würzburg

Sechswöchiges Forschungspraktikum am Institut für Lebensmittelchemie der Bayerischen Julius-MaximiliansUniversität Würzburg im Bereich der Untersuchung genmanipulierter Pflanzen

\section{Universitäre Tätigkeiten}

- Röntgenschutzbeauftragter des Arbeitskreises (Fach- und Sachkunde im Strahlenschutz nach StISchV und RöV)

- Röntgenkristallographische Servicemessungen für die Arbeitskreise von Prof. Dr. M. Christl (Würzburg), Prof. Dr. D. Kost (Negev, Israel), Prof. Dr. U. Klingebiel (Göttingen)

- Messung an Großforschungseinrichtungen (Synchrotron DESY/HASYLAB, Hamburg und Neutronenreaktor RESI/FRMII, Garching)

- Systemadministrator (Microsoft Server 2003-gesteuerte Domäne mit 20 Workstations, Linux-Cluster mit 14 CPUs)

- Leitender Assistent im Anorg.-Chem. Praktikum I und II für Lehramtskandidaten

- Assistent im Anorg.-Chem. Praktikum II für Chemiker nach dem Vordiplom

- Betreuung von zehn Forschungspraktikanten (je 6 bzw. 4 Wochen)

- Vortrag auf Einladung am Kekulé-Institut für Organische Chemie und Biochemie der Universität Bonn über Structure and Electron Density Determination of Novel Polyimido Sulfur Compounds im Rahmen des Sonderforschungsbereichs 624

- Sachkunde im Umgang mit Gefahrstoffen

- Schwerpunktpraktikum in Kristallographie

- Schwerpunktpraktikum in Technischer und Makromolekularer Chemie

\section{Fremdsprachenkenntnisse/Engagements}

- Sehr gutes Englisch in Wort und Schrift durch Zusatzkurz Englisch-Konversation und Schüleraustausch mit West Chicago, IL, USA während der Schulzeit

- Tutor (Betreuung von Fünft- und Sechstklässlern) und Mitglied der Schülermitverwaltung am Simon-Marius-Gymnasium in Gunzenhausen

- Leiter diverser Pfadfindergruppen der Deutschen Pfadfinderschaft Sankt Georg in Gunzenhausen (Mädchen und Jungen von $6-21$ Jahren in verschiedenen Altersstufen) 1996 - 2007

- Ortsvorsitzender der Jungen Union in Gunzenhausen von 2000 - 2006

- Tanzlehrer für Gesellschaftstanzen am Insitut für Sportwissenschaften der Bayerischen Julius-Maximilians-Universität Würzburg 2002 - 2004 

